\title{
Podzols and podzolization in temperate regions
}


ISM Monograph 1 
ISM Monograph 1

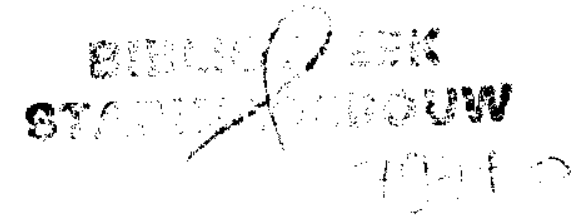

\section{Podzols and podzolization in temperate regions}

D.L. Mokma ${ }^{1}$ and P. Buurman ${ }^{2}$

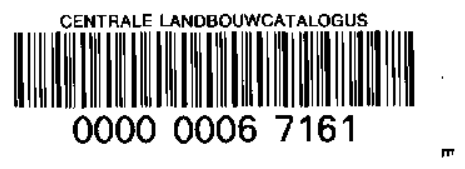

${ }^{1}$ Department of Crop and Soil Sciences, Michigan State University, East Lansing, Michigan

${ }^{2}$ Department of Soil Science and Geology, Agricultural University, Wageningen, The Netherlands

International Soil Museum - Wageningen - The Netherlands 466.34 
CIP-gegevens

Mokma, D.L.

Podzols and podzolization in temperate regions/ D.L. Mokma and P. Buurman.

Wageningen: International Soil Museum. - I11. - (ISM monograph; 1)

Met lit. opg.

ISBN 90-6672-011-5

SISO 631.2 UDC 631.4

Trefw. : Bodemkunde.

Correct citation:

Mokma, D.L. and P. Buurman (1982).

Podzols and podzolization in temperate regions.

ISM monograph 1, Int. Soil Museum, Wageningen, $126 \mathrm{pp}$.

ISBN $90-6672-011-5$ 


\section{Foreword}

This is the first of an envisaged series of ISM Monographs to be published by the International Soil Museum in addition to the series appearing under the name 'Soil Monolith Papers'. While a soil Monolith Paper deals specifically with a soil unit of the FAO-Unesco Soil Legend, based on one representative example in the ISM soil monolith collection, the new series is open for a wider range of subjects in soil science. In particular it may describe the results of studies in soil genesis and classification, soil analysis and land evaluation of a major group of soils. The general aim is to strengthen the state of knowledge on the world's soil resources, for application in the field of land management and agro-technology transfer.

The present paper is the result of a comparative study on the characteristics, genesis and analysis of a major group of similar soils, the podzols, with the aim to define classification criteria of universal validity. This study has been conducted in the framework of the ISM soil correlation programme by a visiting scientist from Michigan State University (USA) and a staff member of the Agricultural University of Wageningen.

ISM appreciates any comment on its publications and any suggestion for research needs. Individual soil scientists are welcome to join ISM as guest researcher, to prepare either a Soil Monograph or a Soil Monolith Paper.

Wageningen, July 1982

W.G. Sombroek

Director 


\section{Contents}

\section{Foreword}

1 Introduction 1

2 Podzol and spodosol concepts 1

3 Environmental setting of podzols 3

4 The podzolization process 4

5 Extractions of $C, F e$ and $A l$ relative to the podzolization process 8 5.1 Organic carbon $\quad 8$

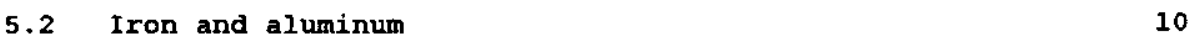

6 Present criteria for spodic or podzol B horizons $\quad 12$

6.1 USSR $\quad 12$

6.2 Federal Republic of Germany 12

6.3 Netherlands $\quad 13$

6.4 England and Wales 14

6.5 Canada 16

6.6 France 17

6.7 Australia 19

6.8 New Zealand 19

6.9 United States 19

6.10 FAO-Unesco $\quad 22$

7 Methods $\quad 23$

8 Materials $\quad 25$

8.1 USSR podzol monoliths $\quad 25$

9 Results and discussion 28

9.1 Particle size distribution $\quad 28$

9.2 Carbon and sesquioxides $\quad 28$

9.2.1 Carbon/aluminum ratios $\quad 29$

9.2.2 Carbon/iron ratios 34

9.2 .3 Carbon/sesquioxide ratios 35

9.2.4 Discussion carbon/metal ratios 40

9.3 CEC-organic carbon relations $\quad \mathbf{4 4}$

9.4 Imogolite $\quad 46$

9.5 Iron content and color after ignition $\quad 47$

9.6 Spodic horizon criteria $\quad 50$

10 Conclusions $\quad 57$

11 Acknowledgements $\quad 58$

12 References $\quad 59$ 
Table 1 soil profiles in this study and the methods used for their CEC and organic C determination

Table 2 Mean and standard deviation of $\mathrm{Al}$, Fe and $\mathrm{C}$ extractions from the reference sample (Becket soil series B21ir)

Table 3 classification of the soils investigated

Table 4 Carbon/aluminum atomic ratios for separating eluvial and illuvial horizons in Orthic/Humic and Gleyic Podzols

Table 5 Linear regression and correlation between $c_{t}$ and $c_{p}$ ' and $c_{t}$ and $c_{h}$

Table 6 Linear regression and correlation between $\mathrm{CEC}_{8.2}$ and carbon contents

Table 7 Numerical values assigned to Munsell color codes

Table 8 Selected properties and classification of Dutch, Belgian and Swiss soils

Table 9 Selected properties and classification of soils in the monolith collection of the International soil Museum

Table 10 selected properties and classification of soils described in literature

List of text figures

Figure 1. C/Al ratios of orthic and Humic Podzols

Figure 2. C/Al ratios of Gleyic Podzols

Figure 3. $c_{h} / A l$ ratios of Orthic and Humic Podzols

Figure 4. $C_{h} / A l$ ratios of Gleyic Podzols 
Figure 8. Depth functions of $\mathrm{CEC}_{\text {soil }}$ and $\mathrm{CEC}_{8.2}$

Figure 9. Regression of $\mathrm{CEC}_{8.2}$ with $\mathrm{C}_{\mathrm{p}}$ for all samples

Figure 10. Color after ignition and Fe content of Orthic/Humic and Gleyic Podzols

Appendix 1. Descriptions of the profiles from the Netherlands, Belgium and USA

Appendix 3. Particle size distribution of all profiles and moist color profiles

Appendix 4. Selected chemical properties and carbon/sesquioxide atomic ratios

4A. Profiles from the Netherlands, Belgium and Switzerland

4B. Profiles in the ISM collection

Appendix 5. Selected chemical data from literature and carbon/ sesquioxide atomic ratios calculated from the data

Appendix 6. Determination of carbon in soils and soil extracts (by A.J.M. van Oostrum and D.L. Mokma)

Appendix 7. Note on the plate "Podzols and related soils"

Separate plate: Podzols and related soils 


\section{Introduction}

The term 'podzol' which originated in Russia has been adopted in several soil classification systems and is now defined in various ways. The concept varies from country to country and with time in a single country.

Several processes play a role in the formation of podzols. Insight into the processes involved has changed with time, depending on the kind of information gathered. Variation in the information collected has depended, at least partially, on changes in the podzol concept.

The most important feature of Podzols or spodosols is the presence of a horizon with an accumulation of amorphous organic matter and aluminum, with or without iron. Therefore, criteria for a podzol B horizon or spodic horizon have been based, at least partially, on the amounts of organic carbon, Al and Fe extracted by specific solutions from these horizons.

The objectives of this study were to 1 . review the literature on the Podzols and spodosols, the criteria for classifying Podzols and spodosols, and the processes involved in podzolization; 2. study the processes of podzolization in profiles collected for this purpose in the Netherlands and Belgium and on other profiles existing in the International soil Museum collection and 3 . develop new chemical criteria for classifying Podzols and spodosols and compare these with existing criteria.

\section{Podzol and spodosol concepts}

The term 'podzol' was first applied by Russian workers solely to the bleached horizon that occurred at or near the surface of soils (Muir, 1961). It has been generally assumed that 'podzol' was derived from the Russian terms 'pod' meaning under or beneath and 'zol' or 'zola' meaning ashes. According to Muir (1961), the Russian term 'pod' should have the same meaning as the German term 'Boden', the Greek term 'pedon', and the Latin term 'peda'; therefore the term podzol means ashy soil (in fact, the latin word is pes, pl. pedes). Ponomareva (1964) assumed that the term 'pod' originated from the fact that the gray or ashy layer of soil is usually found under some other layer or layers of soil materials. For a summary of the historical development of the podzol concept the reader is referred to Muir (1961).

Differences in the concept of a podzol have persisted between soil scientists from Russia and Western Europe. Podzols in Western Europe were

* Throughout this report, when referring to literature, original horizon designations and classification terms are maintained; otherwise, horizon designations and classification terms of FAO (1974; 1977) will be used. 
restricted to sandy soils while Russian podzols included clayey soils with clay illuviation. Early western European soil scientists considered the translocation of materials from the eluvial horizon to the illuvial horizon to occur in solution. These scientists were reluctant to accept the mechanical translocation of clay as part of the podzolization process. The Western European concept of podzols is reflected in the soil classification systems of the various countries. This concept was carried to the United States by Marbut (Muir, 1961). According to Byers et al. (1938) podzols had an illuvial horizon with an accumulation of humus, iron and aluminum and occurred only on coarser textured parent materials. This concept reflects the Western European concept, a reddish-brown horizon beneath a bleached horizon, rather than the Russian concept, only a bleached horizon.

The order spodosol and diagnostic spodic horizon in the new soil classification system, Soil Taxonomy (Soil Survey staff, 1975), also originated in the Western European concept of podzols. In the 7th Approximation (Soil Survey staff, 1960) and in soil Taxonomy, spodosols were identified by the spodic horizon and not the albic horizon. The spodic horizon was defined as an illuvial accumulation of sesquioxides and organic matter. Later the spodic horizon was defined as one in which active amorphous materials, composed of organic matter and aluminum with or without iron, have precipitated (Soil Survey staff, 1975). The term 'active' described material that had high cation exchange capacity, large surface area and high water retention.

In virgin areas the spodic horizon usually lies below an albic horizon (whitish or grayish eluvial horizon). Emphasis is not placed on the albic horizon for two reasons (Smith, 1965). First, the albic horizon may be thin and incorporated into the A horizon by plowing, pasturing or by earthworms. second, it is related to an absence of free iron oxide coatings. This may result from soil genesis or from unique parent materials. In Florida white quartz sand dunes are forming over older brown sands and they could be considered Spodosols if emphasis is placed too strongly on the albic horizon. Spodosols include most of the Podzols, Brown Podzolic soils and Ground-water Podzols of the 1938 U.S. soil classification system (Baldwin et al., 1938). The podzolic $B$ horizon of England and Canada is similar to the podzol $B$ horizon. In the soil classification system of England and wales (Avery, 1980), the podzolic $B$ horizon is one in which organic matter and aluminum and/or iron have accumulated in amorphous forms. It usually underlies a bleached E horizon. Podzolic soils have a podzolic B horizon. Podzolic soils and Spodosols have similar concepts (Avery et al., 1977; Avery, 1980).

In the Canadian system of soil classification, soils in the Podzolic order have podzolic $B$ horizons in which the dominant illuvial material is amorphous material composed mainly of organic matter with varying amounts of iron and aluminum (Canada soil survey Committee, 1978). The podzolic B 
horizon usually, but not always, underlies a light-colored eluvial horizon.

In the FAo-Unesco system (Food and Agriculture organization, 1974) Podzol is used for soils with a spodic B horizon which has an illuvial accumulation of iron or organic matter, or both, but without clay skins on ped faces or in pores. A continuous albic horizon is not required above the spodic $B$ horizon.

Except for the Russian concept, there appears to be much agreement among the definition of Podzols or spodosols. The most important characteristic of Podzols is the translocation and accumulation of humus and/or sesquioxides. A grayish or whitish eluvial horizon is usually, but not always, present above the illuvial horizon. The translocation of humus and sesquioxides is not related to the translocation of silicate clays.

\section{Environmental setting of podzols}

Podzols (Spodosols) are only found in humid regions where precipitation exceeds evapotranspiration (Soil survey staff, 1960). They are not found in arid environments. However, they are found in Mediterranean climates which have long dry summers (Soil survey staff, 1975).

There appears to be no relationship between soil temperature and occurrence of podzols. They are found in cool to hot climates (soil survey staff, 1975). Earlier American soil scientists (Baldwin et al., 1938) thought podzols were typically found in cool climates and that those which occur outside these climates result from special local conditions, e.g. siliceous parent materials.

In cold climates podzols tend to be shallow while in warmer climates they tend to be thicker. The eluvial horizon of podzols in tropical areas tend to be thick (Barshad and Rojas-Cruz, 1950; Bleackley and Khan, 1963; Klinge, 1965; Andriesse, 1969) while those in cold climates tend to be thin (Chandler, 1942; Kubota and Whittig, 1960; Stevens, 1963; Ponomareva, 1964 ).

Podzols have been described in many areas of the world. They are found in almost all countries in Europe, in all provinces of Canada (NCSS, NSSC and FAO, 1975), and in many states in the U.S.A. from Alaska to Florida (Soil Survey staff, 1975). Podzols have been reported in the Amazon Basin (Klinge, 1965), British Guiana (Bleackley and Khan, 1963), Columbia, South America (Barshad and Rojas-Cruz, 1950), East Malaysia (Andriesse, 1969, 1970), Indonesia (Tan et al., 1970), and Zambia (Brammer, 1973).

outside the cold climates podzols form, for the most part, in siliceous parent materials (Byers et al., 1938;Racz, 1968; stace et al., 1968; Andriesse, 1969; Soil Survey Staff, 1975; Canada Soil survey Committee, 1978, De Bakker, 1979). They are low in weatherable minerals. Some may have more than $95 \%$ 
quartz, zircon, tourmaline, rutile, or other relatively insoluble crystalline minerals that do not weather to produce iron or aluminum. In the humid environments most of the bases are leached and therefore podzols have a low base saturation and $\mathrm{pH}$.

In cool climates podzols have had a heath (Erica and Calluna) or a forest vegetation. Most have had a coniferous or oak forest. In forested areas podzols are more strongly developed under some species, such as hemlock (Tsuga canadensis) and kauri (Agathis australis), than under others. In warmer climates podzols occur under savannah, palms, and mixed forests. Podzols in Zambia developed under similar savannah forest as oxisols but on different parent materials (Brammer, 1973).

Podzols form both in well drained solls and in soils with a shallow, fluctuating watertable. If the water level is within the podzol $B$ horizon for long periods, the B horizon may contain little or no iron. Podzols do not appear to form in soils that are permanently saturated with water and have strong reducing conditions.

\section{The podzolization process}

The podzolization process comprises the reactions and processes involved in the formation of a podzol $B$ or a spodic horizon and the removal of sesquioxides and organic carbon from overlying layers. It involves the translocation of organic compounds, aluminum and iron. The mechanisms of podzolization must explain the release, mobilization, migration and immobilization of these materials.

Many studies have been conducted to obtain information on the mechanisms involved in the podzolization process. No attempt will be made to review each of these studies. Several authors have reviewed the literature concerning the major processes (Stobbe and wright, 1959; Bloomfleld, 1963; Wright and Schnitzer, 1963; Ponomareva, 1964; McKeague and St Arnaud, 1969; Petersen, 1976; Mckeague et al., 1978; De Coninck, 1980; Flach et al., 1980 ). A summary of the conditions for and the processes of podzolization follows.:

Processes of podzolization may be grouped as follows: accumulation of organic matter in and on the topsoil; leaching and acidification; weathering; translocation of organic compounds, aluminum and iron; 1mmobilization of organo-metallic complexes; formation of humus pellets, and cementation.

The accumulation of organic matter in the 0 and $A$ horizon results from the deposition of litter on the soll and the incorporation of its decay products into the mineral soil by fauna. Roots also contribute to organic matter in the Ah horizons. The major portion of the organic matter in solls consists of humic substances, of which the main components are humic and fulvic acids (Schnitzer and Kodama, 1977). Both humic and fulvic acids, Iike other organic acids, form complexes with bi- en trivalent cations. These complexes may be 
soluble in water when unsaturated with cations and insoluble when saturated. The leachate collected between the $A e$ and Bhf horizons of a Humic Podzol was primarily (87\%) fulvic acid (Schnitzer and Desjardins, 1969). These acids are also active in mineral degradation (Ponomareva, 1964; Ponomareva and Ragim-Zade, 1969; Kodama and Schnitzer, 1972; Baker, 1973; Schnitzer and Kodama, 1976).

The order of stability of some fulvic acid-metal complexes at low $\mathrm{pH}$ (<3.5) was: $\mathrm{Fe}^{3+}>\mathrm{Al}^{3+}>\mathrm{Ca}^{2+}>\mathrm{Mg}^{2+}$ (Khanna and stevenson, 1962; Khan, 1969; Schnitzer, 1969; Schnitzer and Hansen, 1970). The greater affinity of fulvic acid for $\mathrm{Fe}^{3+}$ than $\mathrm{Al}^{3+}$ may explain the greater dissolution of $\mathrm{Fe}-$ rich chlorites and micas than the Fe-poor minerals (Kodama and schnitzer, 1972; Schnitzer and Kodama, 1976). According to Van Dijk (1971) at pH 5.0 there was no large difference in bond strength for humic acid-metal complexes involving $\mathrm{Ca}^{2+}, \mathrm{Mg}^{2+}$ and $\mathrm{Fe}^{2+}$. $\mathrm{Fe}^{3+}$ was more firmly bound while $\mathrm{Al}^{3+}$ formed a hydroxide. The above sequences differ from that based on bond stability: $\mathrm{Al}^{3+}>\mathrm{Fe}^{3+}>\mathrm{Mg}^{2+}>\mathrm{Ca}^{2+}$ (De Coninck, 1980). Thus, the preferences of the organic 1igands for $\mathrm{Al}^{3+}$ and $\mathrm{Fe}^{3+}$ may change with $\mathrm{pH}$.

The complexation properties of organic matter imply that before appreciable amounts of humus, aluminum and iron can be translocated, soluble salts, such as calcium carbonate, and most exchangeable bases, especially calcium, must be removed from the upper horizons. The calcium and other bases will form insoluble compounds with the water-soluble organic materials. Soils with a high clay content are likely to have low amounts of water-soluble organic compounds, because these soils will have readily available aluminum and iron in clay lattices, which can completely neutralize the negative charges. The soils which are most likely to become podzolized are sandy soils which contain small amounts of bases, aluminum and iron and which easily become acid. In these soils the water-soluble organic compounds take up small amounts of aluminum and iron in the A horizons where they are released during the weathering of primary minerals.

As the organo-metallic complexes migrate downward, they will take up more aluminum and iron. Immobilization may occur either when sufficient amounts of aluminum and iron are adsorbed to form large immobile, polymerized organo-metallic compounds, or through desiccation, or when a horizon with a different ionic concentration or acidity (hydrolysis is encountered. Finally, precipitation of sesquioxides may result from oxidation of the organic component of the complex.

Most of the organic matter of a podzol Bh horizon (Schnitzer, 1969) and an ironpan of a Humic Podzol (McKeague et al., 1967) was soluble in dilute alkali and acid, indicating it was predominantly fulvic acid (FA). In solutions of purified fulvic acid and $\mathrm{AlCl}_{3}$ and $\mathrm{FeCl}_{3}$ at $\mathrm{pH} 4.0, \mathrm{Fe}^{3+}-\mathrm{fulvic}$ acid and $\mathrm{Al}^{3+}$-fulvic acid complexes were water soluble when the metal/FA molar ratio was one but insoluble when the ratio was six (Schnitzer and skinner, 1963). The molecular weight of fulvic acid was taken as 670 (Schnitzer 
and Desjardins, 1962). In the ironpan of a Humic Podzol the $\mathrm{Fe}^{3+} / \mathrm{FA} \mathrm{molar}$ ratio was about six (McKeague et al., 1967). The B horizons of several Canadian podzols had ratios of pyrophosphate extractable iron plus aluminum to fulvic acid between six and nine while the Ae horizons had ratios of 3.5 and 5.0 (McKeague, 1968).

Molar ratios expressed as metal/fulvic acid or metal/humic acid are rather inaccurate because of the difficulties in determining the molecular weight of organic matter fractions. Various authors, therefore, chose to use atomic ratios with respect to elemental carbon.

In laboratory experiments, aluminum- and iron-fulvic acid complexes were soluble up to an Fe/C atomic ratio of 0.2 and $A l / C$ atomic ratio of slightly greater than 0.2 (McKeague et al., 1971). In dilute HCI extracts of the B horizons of a Canadian podzol, the (Al+Fe)/C atomic ratio was 0.2 (Schnitzer and Skinner, 1964). Similar results were obtained for a Russian podzol: ( $\mathrm{Al}+\mathrm{Fe}$ )/C ratios for the $\mathrm{A} 2$ and the two $\mathrm{B}$ horizons were $0.26,0.12$ and 0.15 , respectively (Kononova and Bel'chikova, 1970). In other investigations, ratios of pyrophosphate extractable sesquioxides to total carbon were higher. B horizons of Canadian podzols had (Al+Fe) ${ }_{p} / C_{t}$ atomic ratios of 0.28 to 0.92 , while ratios of sodium hydroxide-tetraborate extractable sesquioxides to total $C,(\mathrm{~A} 1+\mathrm{Fe})_{\mathrm{ht}} / \mathrm{C}_{t^{\prime}}$, varied between 0.05 and 0.17 (McKeague and Sheldrick, 1977). A similar range of ratios were obtained for $B$ horizons of Belgian podzols: $(\mathrm{A} 1+\mathrm{Fe})_{\mathrm{p}} / \mathrm{C}_{\mathrm{t}}$ ratios between 0.03 and 0.42 and $(\mathrm{Al}+\mathrm{Fe}){ }_{\mathrm{ht}} / \mathrm{C}_{\mathrm{t}}$ ratios between 0.03 and 0.11 (Higashi et al., 1981). In these Belgian soils, the range of $(\mathrm{Al}+\mathrm{Fe}){ }_{\mathrm{p}} / \mathrm{C}_{\mathrm{p}}$ ratios was 0.05 to 0.60 and that of $(\mathrm{Al}+\mathrm{Fe})_{\mathrm{ht}} / \mathrm{C}_{\mathrm{ht}}$ atomic ratios was 0.04 to 0.27 .

In a study of Danish podzols, Petersen (1976) used $\mathrm{C} / \mathrm{Al}, \mathrm{C} / \mathrm{B}_{2} \mathrm{Fe}$ and $\mathrm{C} /\left(\mathrm{Al}+\frac{1}{2} \mathrm{Fe}\right)$ weight ratios. Sesquioxides were extracted with sodium dithioniteEDTA. C/( $\left.\mathrm{Al}+\frac{1}{2} \mathrm{Fe}\right)$ ratios in B horizons varied from 0.7 to 17 ; in $\mathrm{A} 2$ horizons from 11 to 120. Petersen also carried out several titration experiments where extracts of Ah horizon organic matter were titrated with solutions of $\mathrm{AlCl}_{3}$ and $\mathrm{FeCl}_{3}$. Fifty percent of the dissolved organic matter was precipitated at a $\mathrm{C} / \mathrm{Al}$ weight ratio of 7.5 and $\mathrm{C} / \mathrm{M} / \mathrm{Fe}$ ratio of 5.0 . These are equivalent to $\mathrm{Al} / \mathrm{C}$ and $\mathrm{Fe} / \mathrm{C}$ atomic ratios of 0.06 and 0.09 , respectively.

Also Ponomareva (1964) found that precipitation of iron required less organic matter (fulvic acid) than that of aluminum. other authors also found that fulvic acid has a greater affinity for $\mathrm{Fe}^{3+}$ than for $\mathrm{Al}^{3+}$ (Kodama and Schnitzer, 1972; Schnitzer and Kodama, 1976), although $\mathrm{Al}^{3+}$ more readily precipitates the acids. Such differences might be instrumental in the differentiation of iron and aluminum maxima in podzol B horizons. This affinity may also explain the Fe and $A l$ distributions in some Welsh soils (Adams et al., 1980). Iron exhibited the typical pattern of eluviation and illuviation but Al rarely accumulated in B horizons enriched in Fe.

Although the metal-carbon ratios for precipitation of organic matter, obtained by various authors, vary considerably, they suggest that the dis- 
tribution of organic matter in eluvial and illuvial horizons of podzols is regulated by the amount of sesquioxides bound to organic matter, that saturation of organic matter with sesquioxides leads to mutual precipitation and that the transport of sesquioxides is regulated by this process.

This is contrary to the theory recently proposed by Farmer et al. (1980) that the transport of aluminum in podzols is by means of proto-imogolite. Imogolite and/or proto-imogolite have been found in podzol B horizons (Tait et al., 1978; Ross and Kodama, 1979; Farmex et al., 1980; Ross, 1980a; 1980b; McKeague and Kodama, 1981). This mineral has not been observed in eluvial horizons and in the upper part of illuvial horizons (Tait et al., 1978; Farmer et al., 1980). According to these authors large amounts of humic substances may inhibit the formation of imogolite in $\mathrm{Bh}$ horizons.

When immobilization occurs, the organo-metallic compounds are still surrounded by water of hydration (De Coninck, 1980). Water molecules and cations are trapped inside voids during the formation of large particles. A gel state results rather than a solid state. Dehydration occurs gradually under the influence of different factors: 1) decrease in charge when reacting with cations, 2) increase in concentration of ions inside the voids, and/or 3) desiccation. The gel gradually loses its water and changes into a solid state.

Some podzol B horizons are cemented while others are not. Cemented and uncemented horizons may have similar chemical composition (McKeague and Wang, 1980). The cemented B horizons in some European podzols are dominated by polymorphic pellets and aggregates (De Coninck, 1980). The monomorphic coatings are strongly cracked, indicating the transition from the gel to solid state. Uncemented horizons have many features indicating much biological activity, such as, many roots, thorough mixing of organic matter with silt and clay, and pedotubules (Wang et al., 1978; De Coninck, 1980). In some Canadian podzols cemented and uncemented horizons had similar fabrics (Mckeague and wang, 1980). Ortstein, cracked coatings and dark pellets are morphological requirements for a spodic hoxizon (Soil survey staff, 1975).

Biological activity and translocation of organo-metallic compounds, occur simultaneously. The relative intensities of these two processes determine the kind of podzol B horizon that will form (De Coninck, 1980). If biological activity predominates, the horizon will be loose. If the accumulation of organo-metallic compounds predominates the horizon will gradually become cemented. The dominant cementing material in ortstein horizons from podzols in France (Righi and De Coninck, 1977) and Canada (Miles et al., 1979; McKeague and Wang, 1980) was Al-organic matter complex.

In early stages of podzolization sufficient aluminum and iron is present in the surface layer and immobilization will occur near the soil surface. The soil will have a shallow B horizon. With time the B horizon will move to greater depths. The aluminum and iron contents of the A horizons will become lower and lower. The soluble organic compounds will have smaller and 
smaller amounts of aluminum and iron when they reach the B horizon. These compounds will then remove from the upper portion of the B horizon some of the aluminum and iron from the organo-metallic compounds which were immobilized earlier. This will mobilize some of the organic matter which had originally precipitated. This organic matter will migrate downward and may be immobilized at greater depths. This process may repeat itself many times. This could explain the thin lamellae with humus coatings found in podzols in the Netherlands (Van den Broek, 1965; De Bakker, 1979) and Belgium (Higashi et al., 1981).

This review indicates that the major controversies as well as research needs are in the carbon/sesquioxide ratios, the extraction methods, the presence and role of imogolite, and the differentiation of material in the podzol-B horizon. This study will therefore further evaluate the use of carbon/sesquioxide atomic ratios for describing podzols and the podzolization process; check the presence and discuss the role of imogolite, and evaluate the significance of complexation behavior of organic matter relative to differentiation in the podzol B horizon.

If carbon/sesquioxide ratios can be used describing the podzolization process, they may also provide a better separation between iron-less Gleyic Podzols and well-drained orthic and Humic Podzols that are low in iron.

Because the choice of extraction method for iron and aluminum is of utmost importance, four widely used methods will be discussed in the next chapter.

\section{Extractions of $\mathrm{C}, \mathrm{Fe}$ and $\mathrm{Al}$ relative to the podzolization process}

\subsection{ORGANIC CARBON}

Extraction of organic $\mathrm{c}$ has been done with several kinds of solutions: water, aqueous solutions of neutral salts, organic solvents, acid solutions, alkaline solutions, and complexing agents (Petersen, 1976). Water usually dissolves small amounts of organic compounds. Water extracted larger amounts of organic carbon from the $\mathrm{AO}-\mathrm{Al}$ and $\mathrm{Bl}(\mathrm{Bh})$ than from $\mathrm{Bs}$ and $\mathrm{C}$ horizons of Danish podzols (Petersen, 1976).

Aqueous solutions of neutral salts extracted only small amounts of organic carbon from the $A 1$ and B21 horizons of a Canadian podzol (Schnitzer et al., 1958).

In general, organic solvents such as alcohols, ethers and benzene are not effective extractants for organic compounds found in soil (Petersen, 1976).

Various organic and inorganic acids have been used to extract organic carbon from soils. The kind and concentration of the acid and the conditions of extraction determine the amount of organic carbon extracted. The kind of 
horizon also influences the amount extracted. Relatively large amounts of organic carbon were extracted from a Canadian podzol B2l horizon but only small amounts were extracted from the Ao horizon by $0.5 \% \mathrm{HCl}$ and $0.5 \% \mathrm{HF}$ (Schnitzer et al., 1958).

Alkaline solutions can extract a portion of the organic carbon from soils. The amount of organic carbon extracted depends on the concentration and kind of base and the kind of soil horizon. Of the various alkaline solutions ( $\mathrm{NaOH}, \mathrm{KOH}, \mathrm{NH}_{4} \mathrm{OH}, \mathrm{Na}_{2} \mathrm{CO}_{3}$ ), sodium hydroxide is the most frequently used (Hayes and Swift, 1978). From a podzol, schnitzer et al. (1958) extracted $24.8 \%$ of the total organic carbon from the Ao horizon and $96.3 \%$ from the B21 horizon using $0.5 \mathrm{~N} \mathrm{NaOH}$. Only small differences in composition and properties of organic matter were found in $0.5 \mathrm{~N} \mathrm{NaOH}$ extracts from a podzol Ao and $B h$ horizon under air and nitrogen (wright and schnitzer, 1959). No significant differences were found in the elemental composition and content of functional groups of organic matter extracted by $0.5 \mathrm{~N}$ NaOH and $0.1 \mathrm{~N} \mathrm{HCl}$ from a podzol B horizon (Schnitzer and skinner, 1968). According to Hayes et al. (1975), sodium hydroxide was the best reagent for extracting humic materials from a wide range of soil materials.

Several organic and inorganic compounds can form complexes with metal ions thereby making the organic matter soluble. Sodium pyrophosphate, sodium fluoride, and EDTA extracted similar amounts (in excess of $80 \%$ ) of organic carbon as did sodium hydroxide from a podzol B21 horizon but not from the podzol Ao horizon (Schnitzer et al., 1958). From the Ao horizon less than $10 \%$ was extracted by the complexing compounds where as about $25 \%$ was extracted by sodium hydroxide.

Based on their solubility in alkali and acid, humic substances can be divided into three fractions: humic acid, fulvic acid, and humin. Humic acid is soluble in dilute alkali but is precipitated by acidification of the alkaline extract. Fulvic acid is soluble in dilute alkali and remains soluble when the alkaline extract is acidified. Humin is not soluble in dilute alkali and acid.

structurally the three humic fractions are similar, but they differ in molecular weight, analytical characteristics, and functional group composition (Schnitzer and Kodama, 1977). Fulvic acid has a lower molecular weight than humic acid and humin. Elemental and functional group analyses of humic acid and humin are similar but they differ from those of fulvic acid. Humic acid and humin contain more $C, H, N$ and $S$ but less oxygen than fulvic acid. Fulvic acid has more oxygen-containing functional groups ( $\mathrm{COOH}, \mathrm{OH}, \mathrm{C}=0$ ) per unit weight than humic acid and humin. The COOH content of fulvic acid is about two times greater than that of the other two fractions. The ratio of $\mathrm{COOH}$ to phenolic oH groups in fulvic acid is about 3 and that in humic acid and humin is about 2. For a more detailed discussion of the chemical composition and physical properties of humic substances, the reader is directed to articles by schnitzer and khan (1972), Flaig et al, (1975), schnitzer and Kodama (1977), Hayes and Swift (1978), and Schnitzer (1978). 
The differing carbon content of fulvic and humic acids has repercussions as to the method of carbon determination that is suitable for the present investigation.

\subsection{IRON AND ALUMINUM}

Many methods have been employed to determine amorphous iron and/or aluminum in soils with the objective of relating them to soil forming processes and soil classification. Acids and complexing agents extract both Fe and Al, reducing agents extract primarily $\mathrm{Fe}$ compounds, and alkaline solutions extract primarily Al compounds from soils.

\section{Dithionite}

Sodium dithionite was used as a reducing agent to dissolve iron oxides from soils (Deb, 1950). Some silicate minerals, such as montmorillonite were attacked. Kilmer (1960) modified this method to permit extraction at room temperature. Mitchell and MacKenzie (1954) recommended using $0.05 \mathrm{~N} \mathrm{HCl}$ and dithionite to prevent the precipitation of ferrous sulfide in the dithionite extracts. Aguilera and Jackson (1953) modified Deb's dithionite method by adding sodium citrate as a complexing agent. Mehra and Jackson (1969) modified the dithionite-citrate method by adding sodium bicarbonate to buffer the mixture at pH 7.3. This method completely dissolved crystalline iron oxides. Coffin (1963) replaced the sodium bicarbonate buffer with a citrate buffer of pH 4.75. Coffin's method did not extract all crystalline iron oxides but did attack nontronite. Holmgren (1967) extracted icon oxides using dithionite and a large excess of sodium citrate at room temperature.

Dithionite-citrate-bicarbonate is considered to extract the crystalline, amorphous and organically bound Fe from soils (Schwertmann, 1964; Mckeague and Day, 1966; Blume and schwertmann, 1969). It also extracts Al from organic complexes and non-crystalline hydrous oxides (Wada and Greenland, 1970; Tokashiki and Wada, 1975).

Oxalate

An oxalate buffer, $\mathrm{pH}$ 3.2-3.3, was used to extract 'colloidal' Fe and Al (Tamm, 1922), but silicate minerals were partially destroyed by this extractant (Tamm, 1932). The amount of Fe extracted increased when the extraction was done in sunlight (Schofield, 1949; Deb, 1950). Schwertmann (1959, 1964) found ammonium oxalate extracted only amorphous oxides when the extraction was done in darkness. Ammonium oxalate dissolves some crystalline iron oxides (Baril and Britton, 1967; Mckeague et al., 1971; Schwertmann, 1973; Borggaard, 1976).

Ammonium oxalate extracts most of the Fe and Al from amorphous materials but not much from crystalline oxides (Schwertmann, 1964; Mckeague and Day, 
1966; Blume and Schwertmann, 1969). It also extracts aluminum and silica from allophane-like materials and to a lesser extent from imogolite.

The ratio of oxalate extractable Fe ( $\mathrm{Fe}_{0}$ ) to dithionite extractable $\mathrm{Fe}$ ( $\mathrm{Fe}_{\mathrm{d}}$ ), also called the 'activity ratio', has been used as a relative measure of the crystallinity and mobility of free iron oxides and to separate Bhir horizons from B2t horizons in some German soils (Blume and Schwertmann, 1969). The Bhir horizons had higher values than B2t horizons. The $\mathrm{Fe}_{\mathrm{o}} / \mathrm{Fe}_{\mathrm{d}}$ ratio distinguished brown podzolic soils from podzols in England and wales (Loveland and Bullock, 1976).

Pyrophosphate

A $0.1 M$ sodium pyrophosphate solution was used to extract Fe and Al from soils (Aleksandrova, 1960). The dissolution is due to direct complexation of the Fe and Al (McKeague, 1967). Franzmeier, et al. (1965) used a pyrophosphate-dithionite reagent ( $\mathrm{pH} \mathrm{7.3)} \mathrm{to} \mathrm{extract} \mathrm{Fe}, \mathrm{Al}$ and $\mathrm{C}$ from soils, especially spodic horizons. McKeague (1967) found that pyrophosphate-dithionite extracted not only the amorphous Fe but also some crystalline Fe. A 0.1M potassium pyrophosphate solution ( $\mathrm{pH}$ 10) extracted very little Fe from crystalline Fe oxides but successfully extracted amorphous organic complexes of Fe and Al (Bascomb, 1968). Organic C was also determined in the potassium pyrophosphate extract.

Pyrophosphate extracts all organic-complexed $\mathrm{Fe}$ and $\mathrm{Al}$, and minor amounts of the non-crystalline hydrous oxides (McKeague, 1967; Bascomb, 1968). Ball and Beaumont (1972) regarded the Fe extracted by pyrophosphate ( $\mathrm{Fe}_{\mathrm{p}}$ ) as the mobile fraction and the $F e_{\circ}$ as the mobile plus stable amorphous fraction. The stable amorphous fraction represented the aged amorphous hydrous oxides accumulated in situ.

\section{Tetraborate}

Sodium hydroxide-tetraborate has been introduced (Nguyen Kha and Bruckert, 1972) to extract organic-complexed Fe from soils. The only function of the tetraborate is to buffer the solution at $\mathrm{pH} 9.5$. This solution extracted less Al and Fe from some podzol B horizons than did pyrophosphate (Mckeague and Sheldrick, 1977; Higashi et al., 1981). Bruckert and souchier (1975) and Higashi et al. (1981) concluded tetraborate removed only the organicbound $A l$ and Fe and pyrophosphate also removed some $A l$ and Fe not bound by organic matter. On the other hand, McKeague and sheldrick (1977) found tetraborate did not remove all of the $A$ l and Fe from synthetic Al- and Fe-fulvic acid complexes but pyrophosphate did and therefore concluded tetraborate was not suitable for extracting organically bound Fe and Al from spodic horizons. Higashi and shinagawa (1981) concluded pyrophosphate was more effective extractant of $\mathrm{Al}-$ and Fe-humus complexes in A1 horizons of Dystrandepts than was tetraborate. 


\section{Present criteria for spodic or podzol B horizons}

The criteria used to define the podzol B horizon or spodic horizon vary considerably. In some countries only morphological criteria are used, while in others both morphological and chemical criteria are used.

\subsection{USSR}

When Dokuchaiev first applied the term 'podzol', it referred to a group of soils with a bleached horizon (Muir, 1961). Later, Zakharov in 1906 advocated the recognition of an illuvial horizon as part of the podzolic profile. In the USSR podzols are subdivided based on the degree of podzolization (Ivanova and Rozov, 1960). Weakly, moderately, and strongly developed podzols are defined on the basis of the ratio of the thickness of the Al horizon to that of the A2 horizon. If the ratio is greater than 1, the podzol is weakly developed, if equal to 1 it is moderately developed, and if less than 1 it is strongly developed (Tavernier, 1963).

\subsection{FEDERAL REPUBLIC OF GERMANY}

Early German workers recognized the bleached horizon and the "Ortstein"; senft described such a podzol in 1862 (Muir, 1961). This concept of a bleached, eluvial horizon and an illuvial horizon, "Ortstein" or "Orterde", continues today. In the present German classification system (Arbeitsgemeinschaft Bodenkunde, 1971) a podzol is a soil with an O-Ah-Ae-B-C profile. Podzols are differentiated only on morphological properties, including:

1 Texture and parent material

2 Depth to lower boundary of $B$ horizon

$\begin{array}{lrl}\text { Solum } & 5 \mathrm{~cm} & \text { very shallow (Micropodzol) } \\ \text { Solum } 5-20 \mathrm{~cm} & \text { shallow (Shallow Podzol) } \\ \text { Solum } 20-40 \mathrm{~cm} & \text { medium (Medium Podzol) } \\ \text { Solum }>40 \mathrm{~cm} & \text { deep (Deep Podzol) }\end{array}$

3 Cementation of the $B$ horizon

Weakly cemented or no cementation (Orterde)

Medium cemented ("firm" orterde)

strongly cemented (Ortstein)

4 Thickness of the $B$ horizon

5 Thickness and kind of raw humus layer (O horizon)

6 Thickness of the Ae horizon

7 Thickness and humus content of Ah horizon

8 Degree of erosion: Podzol with truncated profile. 
Subdivisions:

\begin{tabular}{lll} 
Type & Subtype & Profile \\
\hline Podzol & Iron-humus Podzol & O-Ah-Ae-Bhs-C \\
(Normaler Podsol = Eisenhumuspodsol) & \\
& Iron Podzol (Eisenpodsol) & O-A-Ae-Bs-C \\
& Humus Fodzol (Humuspodsol) & O-Ah-Ae-Bh-C \\
& Ironpan Podzol (Bändchenpodsol) & \\
& Brown Earth Podzol (Braunerde-Podsol) & O-Ah-Ae-Bhs-Bv-C \\
& (Gray Wooded) Podzol & O-Ah-Ae-Bhs-Al-Bt-C \\
& (Parabraunerde-Podsol) & \\
& Pseudogley Podzol (Pseudogley-Podsol) & O-Ah-Ae-Bhs-S \\
& Gley-Podzol (Gley-Podsol) & O-Ah-Ae-Bhs-G \\
& Peat-Podzol (Hochnoor-Podsol) & Bh-Ah-Ae-Bsh-Bv-C
\end{tabular}

\subsection{NETHERLANDS}

In the Netherlands the podzol $B$ horizon is an illuvial horizon in which amorphous humus with or without sesquioxides have accumulated or sesquioxides with non-amorphous humus have accumulated (De Bakker and Schelling, 1966). The prominent podzol $B$ horizon has the following characteristics below $20 \mathrm{~cm}$ depth:

1 a B2h horizon of at least $3 \mathrm{~cm}$ thickness with a color value of 2 or less and a chroma of 1.5 or less; and/or

2 a B2 horizon with color value differences between the B2 and the $C$ horizon as follows:

thickness of the B2

$$
\begin{array}{r}
0-5 \mathrm{~cm} \\
5-20 \mathrm{~cm} \\
20-30 \mathrm{~cm}
\end{array}
$$$$
>30 \mathrm{~cm}
$$

\section{value difference}

$>3$

$>2$

$>1.5$

$>1$;or:

3 a B horizon, which continues to a depth of $120 \mathrm{~cm}$, with a color value of 5.5 or less; or:

4 a reworked B horizon with lumps of B2 differing more than 1.5 value from the $\mathrm{c}$ horizon.

A prominent humuspodzol B horizon is a prominent podzol B horizon with below $20 \mathrm{~cm}$ depth (1) a B2h horizon or (2) amorphous organic matter in at least the upper part of the $B$ horizon. This horizon may or may not contain iron. A prominent moderpodzol $B$ horizon is a prominent podzol B horizon with below $20 \mathrm{~cm}$ depth (1) no B2h horizon and (2) non-amorphous organic matter, usually 
moder, in the B horizon. This horizon must contain iron (De Bakker and Schelling, 1966).

\section{Subdivisions}

Order suborder

Podzol Moderpodzol

Organic $\mathrm{C}$ and $\mathrm{Fe}$, not amorphous

Hydropodzol

Organic $C$ with little or no $F e$ and hydromorphic characteristics

Xeropodzol

Organic $\mathrm{C}$ with little or no $\mathrm{Fe}$

\subsection{ENGLAND AND WALES}

In England and wales the podzolic $B$ horizon was defined by the following characteristics (Avery, 1973; Avery et al., 1977):

1 usually underlies a bleached $E$ horizon or a dark Ah, $H$ or $O$ horizon in which the mineral grains are uncoated;

2 begins within $1.5 \mathrm{~m}$ of the soil surface;

3 extends to at least $15 \mathrm{~cm}$ depth, excluding surface litter (L, F);

4 the following horizons can form all or part of a podzolic $B$ horizon:

Bh at least $2.5 \mathrm{~cm}$ thick;

contains translocated organic matter and $\mathrm{Al}$, or $\mathrm{Fe}$ and $\mathrm{Al}$;

it is darker and has more organic C ( 0.6 percent) than an overlying $E$ horizon, if present;

contains more $\mathrm{Al}_{\mathrm{p}}$ * and $\mathrm{Fe}_{\mathrm{p}}$ than an overlying $\mathrm{E}$ or $\mathrm{A}$ horizon;

if the $\mathrm{Fe}_{\mathrm{d}}$ content exceeds 0.3 percent, both value and chroma are 3 or less.

Bs at least $5 \mathrm{~cm}$ thick;

contains Fe and Al with organic matter;

has organo-ferruginous coatings on mineral grains and/or sand or silt

size, pelletlike, peds;

value and/or chroma are more than 3 ;

$\mathrm{Fe}_{p}$ plus $\mathrm{Al}$ p exceed 0.3 percent;

$\mathrm{Fe}_{\mathrm{p}}$ plus $\mathrm{Al}_{\mathrm{p}}$ divided by percent clay is greater than 0.05 .

Bf less than $5 \mathrm{~mm}$ thick;

black to dark brown;

brittle or cemented;

enriched in $\mathrm{Fe}_{\mathrm{p}}$ and $\mathrm{c}_{\mathrm{p}}$.

* ${ }^{A l_{p}}, F e_{p}$ and $C_{p}$ are pyrophosphate extractable $A l, F e$ and $C_{;} A I_{d}$ and $F e_{d}$ are dithionite-citrate extractable $\mathrm{Al}$ and $\mathrm{Fe} ; \mathrm{Al}_{0}$ and $\mathrm{Fe} \mathrm{o}_{0}$ are ammonium oxalate extractable Al and Fe. 
Ragg et al. (1978) proposed a ratio of $\mathrm{Fe}_{\mathrm{p}}$ to $\mathrm{Fe}_{\mathrm{d}}$ of greater than 0.36 for $B$ horizons of podzols. This ratio was more effective in separating podzols from non-podzols in scotland than $\left(\mathrm{Fe}_{\mathrm{p}}+\mathrm{Al}_{\mathrm{p}}\right) \div \mathrm{clay} \geq 0.05$.

Recently the podzolic $B$ horizon has been redefined as a $B$ horizon in which amorphous materials containing $\mathrm{C}$ and $\mathrm{Al}$, Fe, or both have accumulated, either by illuviation or by weathering in situ (Avery, 1980). the B horizon has the following requirements:

1 qualifies as a Bh, Bs or Bf, or comprises some combinations of these horizons.

$\mathrm{Bh}$ - contains translocated organic matter with $\mathrm{Al}$, or $\mathrm{Al}$ and $\mathrm{Fe}$ in coatings on sand and silt particles or in sand or silt-size aggregates;

- is darker and has more organic matter than an overlying eluvial horizon;

- contains more $\mathrm{Al}_{\mathrm{p}}+\mathrm{Fe}_{\mathrm{p}}$ than an overlying $\mathrm{E}$ or $\mathrm{A}$ horizon; may be cemented;

- has organic $\mathrm{C} \geq 0.6 \%$ and may or may not contain significant amounts of $\mathrm{Fe}$;

- have value and chroma of 3 or less if $\mathrm{Fe}_{\mathrm{d}}>0.3 \%$.

Bs - has moist value and/or chroma of 4 or more;

- contains $\mathrm{Al}_{\mathrm{p}}+\mathrm{Fe}_{\mathrm{p}}>0.3 \%$;

- has (Alp $\left.+\mathrm{Fe}_{\mathrm{p}}\right) \div \mathrm{clay} \geq 0.05$;

- reacts positively to the NaF test for reactive hydroxy-Al;

- contains sand or silt-size pellet-like aggregates, sesquioxidic coatings on mineral grains, or both.

Bf - is black to reddish brown;

- is brittle or cemented (ironpan);

- is < $10 \mathrm{~mm}$ thick;

- is enriched in $\mathrm{Fe}_{\mathrm{p}}$ and $\mathrm{C}_{\mathrm{p}}$.

2 Moist chroma is greater than 3 , or the value is 3 or less.

3 Begins within $120 \mathrm{~cm}$ depth;

underlies an $\mathrm{E}, \mathrm{A}, \mathrm{H}$, or $\mathrm{O}$ horizon;

extends below $15 \mathrm{~cm}$ depth, excluded fresh or partially decomposed litter.

4 At least $10 \mathrm{~cm}$ thick if there is no overlying $E$ horizon and it is composed only of a Bs horizon; or

at least $2.5 \mathrm{~cm}$ thick if it consists only of a Bh horizon lying below an E horizon.

In addition podzolic $B$ horizons usually have the following associated properties:

a high pH dependent CEC; the difference between CEC (pH 8) and CEC (soil $\mathrm{pH}) \geq 8 \mathrm{meq} / 100 \mathrm{~g}$ soil.

b large water holding capacity relative to particle size distribution, when not cemented. 
$c c_{p} \div c_{t} \geq 0.3$ (>0.5 in well-expressed horizons)

$\mathrm{Fe}_{\mathrm{p}} \div \mathrm{Fe}_{\mathrm{d}}>0.3$ (>0.5 in well-expressed horizons).

d high $P$ retention capacity.

e high fluoride reactivity.

\section{Subdivisions}

Major group Group

Podzolic Brown podzolic soils Bs horizon, no E horizon

soils

$\begin{array}{ll}\text { Humic cryptopodzols } & \text { thick, humose Bh horizon } \\ \text { Podzols } & \text { E horizon and distinct Bh horizon } \\ \text { Gley-podzols } & \text { E and Bh with gleying below B horizon } \\ \text { Stagnopodzols } & \text { gleyed E over Bs horizon, or thin } \\ & \text { iron pan below peaty topsoil, E or } \\ & \text { Bh horizon }\end{array}$

\subsection{CANADA}

The definition of the podzolic $B$ horizon in Canada has been modified several times. In 1963 the National soil survey Committee of Canada defined a Bf horizon as a horizon enriched with Fe and having a chroma of 3 or more and redder than the horizon above or below (McKeague and Day, 1966) In 1966 McKeague and Day proposed Bf horizons be required to have $\Delta(\mathrm{Fe}+\mathrm{Al})$ * greater than 0.8 percent or have at least 1 percent more Fe $\mathrm{d}$ than the $\mathrm{C}$ horizon.

Clark et al. (1966) proposed to use pH-dependent CEC as an additional means of defining podzolic B (spodic) horizons. A pH-dependent portion of the CEC of $8 \mathrm{meq} / 100 \mathrm{~g}$ soil was suggested as the lower limit for podzolic B horizons. The horizons were also required to meet the appropriate organic matter and free oxide limits: Bf must contain 0.5 to $5 \%$ organic matter and have $\Delta(\mathrm{Fe}+\mathrm{Al})>0.8 \%$.

In 1974 the Canada Soil survey Committee (1974) defined Podzolic Soils as soils with Podzolic B horizons (Bh, Bhf, Bfh or Bf horizons). The Bf, Bfh and Bhf horizons were required to have $\Delta(\mathrm{Fe}+\mathrm{Al})>0.8 \%$. The Bh horizons usually had $\Delta(\mathrm{Fe}+\mathrm{Al})<0.8 \%$. The organic matter content of the $\mathrm{Bf}$ is $<5 \%$, of the Bfh is $5-10 \%$ and of the Bhf is $>10 \%$. The $\mathrm{Bh}$ has $>2 \%$ organic matter and a ratio of organic matter to $\mathrm{Fe}_{\circ}$ of 20 or more. The $\mathrm{Bh}$ has a color value and chroma of 3 or less when moist. Mckeague (1967) found that horizons which had $\Delta(\mathrm{Fe}+\mathrm{Al})$ greater than $0.8 \%$ also had $\mathrm{Fe}_{\mathrm{p}}$ plus ${ }^{\mathrm{Al}} \mathrm{p}$ greater than $0.65 \%$

* $\Delta(\mathrm{Fe}+\mathrm{Al})=$ percentage oxalate-extractable Fe plus Al in a BF horizon minus percentage oxalate-extractable Fe plus Al in the $C$ horizon. 
A limit of $0.6 \% \mathrm{Al}_{0}$ gave good separation of podzolic $\mathrm{B}$ horizons from other horizons (McKeague and Day, 1969). Baril and Tran (1977) found $\mathrm{Fe}_{\mathrm{p}}$ plus $A_{p}$ and its ratio over clay were useful to classify podzols. The limits proposed were $\mathrm{Fe}_{p}+\mathrm{Al}_{\mathrm{p}} \geq 0.6 \%$ and $\left(\mathrm{Fe}_{\mathrm{p}}+\mathrm{Al}_{\mathrm{p}}\right) \div \mathrm{clay} \geq 0.05$. Podzolic horizons appeared to be separated from non-podzolic horizons using a value of $6 \mathrm{meq} / 100 \mathrm{~g}$ for the organic pH-dependent CEC (Clark and Nichol, 1968).

The Canada soil survey Committee (1978) defined a podzolic B horizon as having the following morphological and chemical properties:

\section{Morphological:}

1 at least $10 \mathrm{~cm}$ thick;

2 moist color is black or the hue is 7.5YR or redder or loYR near the upper boundary and becomes yellower with depth. The chroma is greater than 3 or the value is 3 or less;

3 accumulation of amorphous material is indicated by brown to black coatings on some mineral grains or brown to black micro-aggregates. The material feels silty when rubbed wet, unless it is cemented;

4 texture is coarser than clay.

\section{Chemical :}

1 if it is a Bh subhorizon very low in $\mathrm{Fe}$, it must be at least $10 \mathrm{~cm}$ thick and have organic $\mathrm{C}>1 \%, \mathrm{Fe}_{\mathrm{p}}<0.3 \%$, and organic $\mathrm{C} / \mathrm{Fe}_{\mathrm{p}} \geq 20$;

2 if it is a Bf or Bhf subhorizon with appreciable Fe and Al, it must be at least $10 \mathrm{~cm}$ thick and have organic $\mathrm{C}>0.5 \%$,

$\mathrm{Al}_{\mathrm{p}}+\mathrm{Fe}_{\mathrm{p}}>0.6 \%$ if finer than sand, $\mathrm{Al} \mathrm{l}_{\mathrm{p}}+\mathrm{Fe}_{\mathrm{p}} \geq 0.4 \%$ if sand, $\left(\mathrm{Al} p+\mathrm{Fe}_{\mathrm{p}}\right) / \mathrm{Clay}>0.05$, and $\mathrm{Fe} \geq 0.3 \%$ and/or organic $\mathrm{C} / \mathrm{Fe}_{\mathrm{p}}<20$. Several ortstein horizons in Canadian podzols did not have the required organic $\mathrm{C}$ or extractable $\mathrm{Al}$ and $\mathrm{Fe}$ contents of the podzolic $\mathrm{B}$ horizon (Wang et al., 1978; Miles et al., 1979; McKeague and Wang, 1980).

\section{Subdivisions}

Order

Podzolic

6.6 FRANCE

\section{Great Groups}

Humic Podzol

Ferro-Humic Podzol

Humo-Ferric Podzol
High organic $\mathrm{C}$ relative to $\mathrm{Fe}$, usually associated with wetness High organic $C$ with $\mathrm{Fe}$ and $\mathrm{Al}$ Low organic $\mathrm{C}$ with $\mathrm{Fe}$ and $\mathrm{Al}$

While soil classification in France is not based on diagnostic horizons, the general criteria used for the distinction of the B horizon of 'sols pod- 
zolisés' are virtually identical to those in other countries, i.e. (CPCS, 1967):

- a high content of 'free' sesquioxides with respect to the parent material

- a high content of organic matter ( $>0.5 \%$ ) with a $\mathrm{C} / \mathrm{N}$ ratio $>14$, and a higher content of organic matter than the $A_{2}$ horizon.

- presence of coatings of iron and organic matter on mineral grains

- presence of silt size iron oxide and organic matter pellets.

The degree of development of the 'sols podzolisés' is related to the intensity of the ashy color of the $A_{2}$ horizon (Tavernier, 1963), but the subdivisions of the classification are based on climate and hydrology (CPCS, 1967). Bruckert (1979) proposed using the Fe/Al ratio from buffered tetraborate extracts ( $\mathrm{pH} 9.5$ ) to classify brown soils (sols bruns) and podzolized soils (sols podzolisés). Podzolized soils had a ratio greater than 1 and brown solls a ratio less than 1 .

\section{Subdivisions}

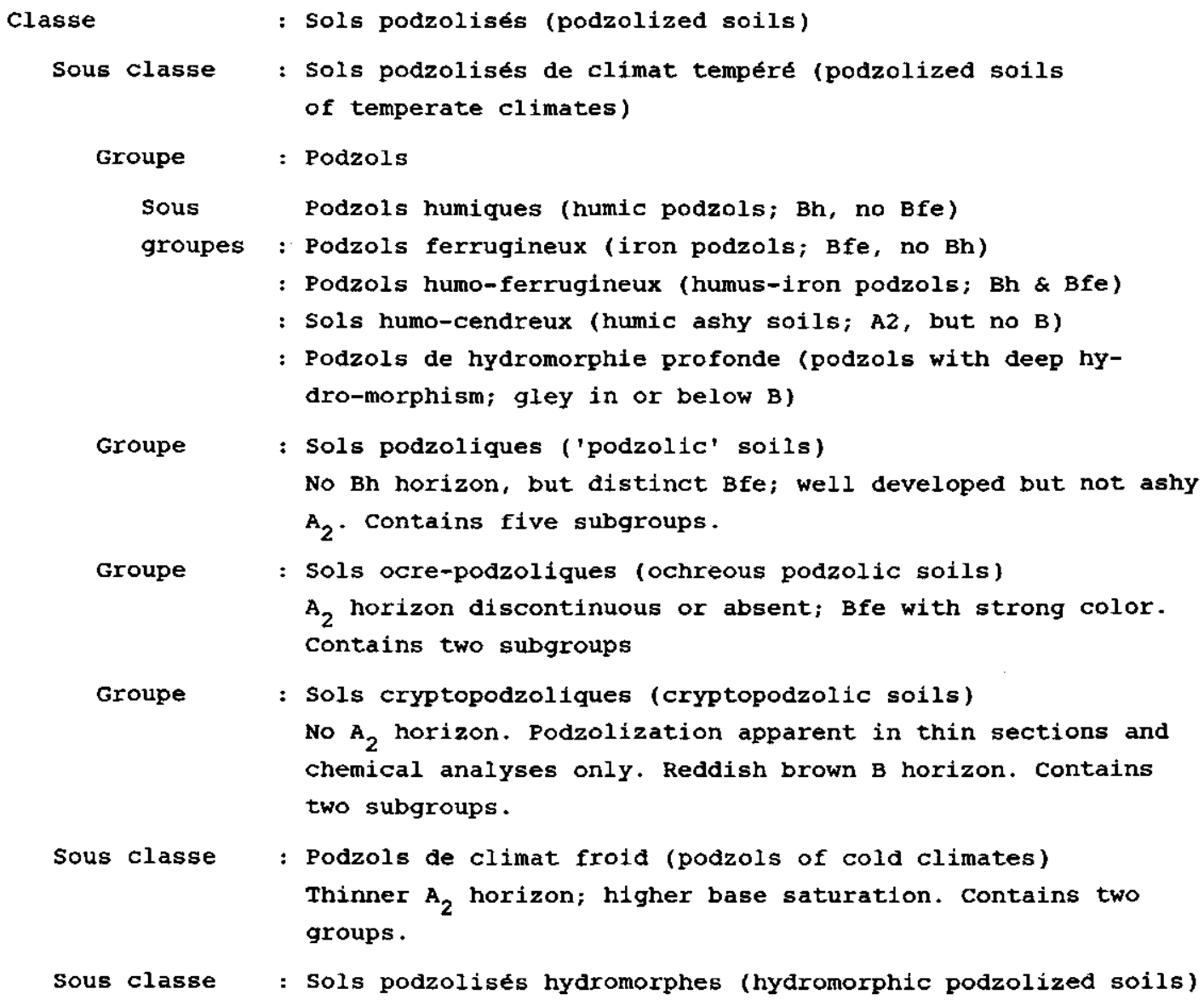




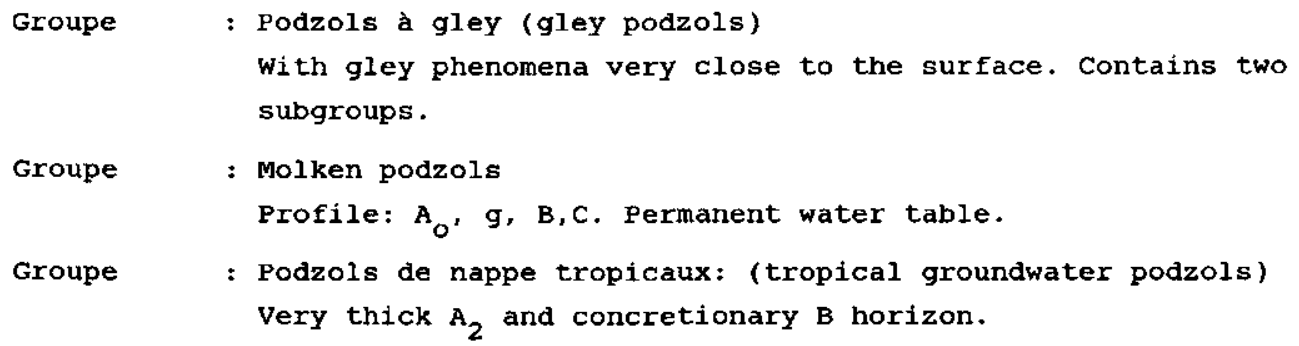

\subsection{AUSTRALIA}

In Australia podzols are defined as acid, sandy soils with a gray Al horizon, a thick whitish sand A2 and $a$ B horizon with an accumulation of organic matter and/or sesquioxides (stace et al., 1968). Australian podzols seldom have a continuous o horizon.

\subsection{NEW ZEALAND}

In New Zealand Podzol soils are called Podiform soils and have a prominent $O$ hortzon; an ash-gray, structureless, silica-rich A2 horizon; and usually, but not always, a humus and iron enriched illuvial horizon (Taylor and Pohlen, 1968). The A2 horizon is the main differentiating characteristic.

\subsection{UNITED STATES}

In the 1938 soll classification system (Byers et al., 1938) the B2 horizon of Podzols was defined as having an accumulation of humus, iron and aluminum and a clay content that was not unusually high. The spodic horizon is basically the same concept as the original concept of the podzol $B$ horizon (Soil survey staff, 1960). A spodic horizon had the following properties:

1 amorphous coatings of humus and allophane or of humus, allophane, and free sesquioxides on particles of sand or silt; or rounded to subangular pellets of humus or of humus and sesquioxides between 20 and $50 \mu \mathrm{m}$ in diameter; or both.

2 more than $0.29 \%$ organic $c$ or $1 \%$ free sesquioxides in some part.

3 no clay skins; under crossed polarizers coatings in thin sections show slight or no birefringence and no extinction on rotation, which indicates substance forming the coatings are not both crystalline and oriented.

4 no structure; or structure other than blocklike; or blocklike structure only if the grade of structure is weak.

$5 \mathrm{C} / \mathrm{N}$ ratio of more than 14 , if profile is virgin.

$6 \mathrm{SiO}_{2} / \mathrm{R}_{2} \mathrm{O}_{3}$ ratio in clay fraction less than that in clay fraction of overlying A2 or albic horizon and less than that in clay fraction of parent material. 
Horizons are not considered to be spodic if they are so thin, are so near the surface, and are so weakly expressed that the cutting of a forest and plowing a few times to a depth of 6 to 7 in. obliterates all traces.

Franzmeier et al. (1965) proposed the following criteria for the spodic horizon:

$1 \quad \mathrm{CEC}_{\text {moist }}-\mathrm{CEC}_{240^{\circ} \mathrm{C}} \times 100>30$

CEC moist

$2(\mathrm{C}+\mathrm{Fe}+\mathrm{Al}) * \div \mathrm{clay}>0.15$

In the 1967 supplement (Soil Survey Staff, 1967) to the 7th Approximation the spodic horizon criteria were revised:

1 If an $\mathrm{O}, \mathrm{A}, \mathrm{Al}$, or albic horizon overlies the spodic horizon, the spodic horizon has:

a a 15-bar water content of less than $20 \%$;

b less than $60 \%$ volcanic ash, pumice and other pyroclastic materials in the 20-200 $\mathrm{mm}$ fraction;

$c$ enough amorphous material that $\frac{(\mathrm{C}+\mathrm{Fe}+\mathrm{Al})^{*}}{\mathrm{Clay}} \geq 0.15$;

d a thickness of $1 \mathrm{~cm}$ or more, either as a continuous horizon or as a sum of lamallae;

e moist colors of 7.5YR or redder and moist values of 3 or less in some continuous part of the horizon or in any one subhorizon that is at least $1 \mathrm{~cm}$ thick and hues as red or redder than the underlying horizon, or $(\mathrm{C}+\mathrm{Fe}+\mathrm{Al}) *=1 \%$;

$f$ enough depth that the horizon is not obliterated by plowing to $18 \mathrm{~cm}$ or enough degree of expression that the horizon after mixing to $18 \mathrm{~cm}$ meets criteria under 2 .

2 If an Ap is present and is not underlain by a diagnostic subsurface horizon other than a fragipan, with or without an albic horizon, the Ap is considered a spodic horizon if it has the following properties:

a contains more than $3 \%$ organic matter ( $1.7 \%$ organic $C$ );

b $(\mathrm{C}+\mathrm{Fe}+\mathrm{Al}) * \div \mathrm{clay} \geq 0.20$;

$c$ fragments of amorphous coatings or pellets can be clearly identified;

d the hue is redder than 1OYR and the moist color value less than 3 , or the chroma is 3 or more in hues of lOYR or redder;

e a 15-bar water content of < 20\%;

$f$ less than $60 \%$ volcanic ash, pumice, or other pyroclastic material in the 20-200 $\mu \mathrm{m}$ fraction.

When Soil Taxonomy (Soil Survey staff, 1975) was published, the criteria for the spodic horizon had been revised again. A spodic horizon is normally a subsurface horizon that underlies an O, A1, Ap or A2 horizon. It may, however, meet the definition of an ochric or umbric epipedon. A spodic horizon

* Pyrophosphate-dithionite extractable. 
has the morphological or the chemical and physical characteristics that are listed below, and its hue and chroma remain constant with increasing depth or the subhorizon that has the reddest hue or the highest chroma is near the top of the horizon. The color changes within $50 \mathrm{~cm}$ from the top of the horizon. A thin black horizon that has a color value of 2 or less may overlie this horizon. If the soil temperature regime is frigid or warmer, some part of the spodic horizon must meet one or more of the following requirements below a depth of $12.5 \mathrm{~cm}$ or below any Ap horizon that is present. If the soil temperature regime is cryic or pergelic, there is no requirement for depth. In addition, the spodic horizon must meet one or more of the following requirements :

1 Have a subhorizon $2.5 \mathrm{~cm}$ thick that is continuously cemented by some combination of organic matter with iron or aluminum or both;

2 have a particle-size class that is sandy or coarse loamy, and sand grains are covered with cracked coatings or there are distinct pellets of coarsesilt size, or both; or

3 have one or more subhorizons in which,

a If there is $0.1 \%$ or more extractable $F e$, $\% \mathrm{Fe}_{\mathrm{p}}+\mathrm{Al}_{\mathrm{p}}$ at $\mathrm{pH} 10$ $\%$ clay

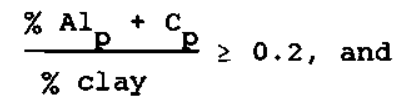

b $\frac{\% \mathrm{Fe}_{\mathrm{p}}+\mathrm{Al}_{\mathrm{p}}}{2 \mathrm{Fe}}=0.5$, and

c The combined index of accumulation of amorphous material must be 65 or more. The index for each subhorizon is calculated by subtracting half of the clay percentage from CEC at pH 8.2 and multiplying the remainder by the thickness of the subhorizon in centimeters. The results for all subhorizons are then added and the total must be 65 or more.

\section{Subdivisions}

$\begin{array}{lll}\text { Order } & \text { Suborder } & \text { Criteria } \\ \text { Spodosol } & \text { Aquods } & \text { Wet } \\ & \text { Ferrods } & \text { High percentage of Fe relative to } \\ & \text { organic } \mathrm{C} \\ \text { Humods } & \text { High percentage of organic } \mathrm{C} \text { rela- } \\ & \text { tive to Fe } \\ & \text { Arthods } & \text { About equal amounts of Fe and } \mathrm{C}\end{array}$




\subsection{FAO-UNESCO}

The FAO-Unesco system (Food and Agriculture Organization, 1974), defines the spodic B horizon similar to that in Soil Taxonomy. A spodic B horizon must have one or more of the requirements $(1,2$ or 3 above) below a depth of $12.5 \mathrm{~cm}$, or, when present, below an Ap horizon.

Subdivision

$\begin{array}{lll}\text { Unit } & \text { Subunit } & \\ \text { Podzols } & \text { Placic Podzols } & \text { thin ironpan in or over B horizon } \\ \text { Gleyic Podzols } & \text { hydromorphic properties within } 50 \mathrm{~cm} \\ \text { Humic Podzols } & \text { contains hums, little or no Fe } \\ \text { Ferric Podzols } & \text { \% free Fe/\% organic C } \geq 6 \\ \text { Leptic Podzols } & \text { thin or no E horizon, no B horizon } \\ & \text { enriched with carbon } \\ & \text { orthic Podzols } & \text { other Podzols }\end{array}$

The soil classification systems of Canada, England and Wales, FAo-Unesco and United states all use the ratio of $\left(\mathrm{Al}_{\mathrm{p}}+\mathrm{Fe}_{\mathrm{p}}\right) \div$ clay, but the limiting value varies. Both the Canadian and English systems use 0.05 as the critical value while the FAO-Unesco and U.S. systems use 0,20. Several researchers (De Kimpe and Martel, 1976; Baril and Tran, 1977; Avery et al., 1977; Singer et al., 1978; Knuteson and Harpstead, 1980; Stanley and ciolkosz, 1980) have found soils which morphologically appear to be spodosols or Podzols but do not have $\left(\mathrm{Al}_{\mathrm{p}}+\mathrm{Fe}_{\mathrm{p}}\right) \div \mathrm{clay} \geq 0.20$. Avery et al. (1977) and Adams et al. (1980) found some soils which did not appear morphologically to be spodosols or Podzols did have $\left(\mathrm{Al}_{\mathrm{p}}+\mathrm{Fe}_{\mathrm{p}}\right) \div \mathrm{clay} \geq 0.05$. De Kimpe and Martel (1976) proposed a critical value of 0.10 be used to define the spodic horizon or podzol B horizon.

All values have an empirical rather than a theoretical background. The differences are due to the populations of podzols that occur within a given country.

However, values of chemical characteristics that are derived from processes that play a role in podzolization might be more generally applicable. This thought is pursued in the present investigation. 


\section{Methods}

Soil samples were air dried and crushed to pass through a $2 \mathrm{~mm}$ sieve. After removal of organic matter with $\mathrm{H}_{2} \mathrm{O}_{2}$ and washing free of salts, particle size distribution was determined by sieving the greater than $50 \mu \mathrm{m}$ fraction and by pipette method for the less than $50 \mu \mathrm{m}$ fraction (Kilmer and Alexander, 1949). Soil $\mathrm{pH}$ was determined using a $1: 2.5$ soil:water ratio and using a $1: 2.5$ soil:1 $\mathrm{N} \mathrm{KCl}$ ratio.

For some profiles (Table 1) CEC was determined at pH of the soil and $\mathrm{pH} 8.2$ by saturating with $\mathrm{BaCl}_{2}$, exchanging with $\mathrm{Mg}$ and titrating excess $\mathrm{Mg}$ (Bascomb, 1964). For the other profiles CEC was determined at pH 7.0 by leaching with $\mathrm{NaOAC}$ and $\mathrm{NH}_{4} \mathrm{OAC}$ (modified from USDA, 1972). Air-dried soil was saturated with $\mathrm{Na}$ by leaching the samples with $1 \mathrm{~N}$ NaOAC (pH 7.0). Excess $\mathrm{Na}$ was removed by washing with $95 \%$ ethanol. Adsorbed Na was replaced by leaching with $1 \mathrm{~N} \mathrm{NH}_{4} \mathrm{OAC}(\mathrm{pH} 7.0)$. Na in the leachate was determined by atomic absorption spectrophotometry.

Total organic carbon ( $C t$ ) was determined using wet combustion. Organic carbon was estimated for some profiles (Table 1) using rapid titration (Walkley and Black, 1934). For the other profiles total organic carbon was measured by potentiometry (Van Oostrum and Mokma, this volume). Organic carbon was also measured in $0.5 \mathrm{~N}$ NaOH using a $1: 10$ soil:solution ratio (Ch) (Schnitzer et al., 1958; Schnitzer and skinner, 1968; chen et al., 1978). Organic carbon in the supernatant was determined potentiometrically (Van oostrum and Mokma, this volume).

$\mathrm{Al}$ and Fe were determined in sodium dithionite-citrate, ammonium oxalate and sodium pyrophosphate extracts ( $\mathrm{Al} d$ and $\mathrm{Fe}_{\mathrm{d}} ; \mathrm{Al}_{\mathrm{o}}$ an $\mathrm{Fe} e_{0} \mathrm{Al}_{\mathrm{p}}$ and $\mathrm{Fe} \mathrm{p}$ respectively) (USDA, 1972). All three extracts of the same soil sample were made during the same $24 \mathrm{hr}$ period. A reference sample was extracted with each batch. Al and Fe were determined by atomic absorption spectrophotometry (Perkin Elmer model 460) on the same day as the extracts were made. $C$ was determined using a carbon auto analyzer (Beckman model 915B) on the same day as the extracts were made. Standard deviations and means of the analyses on the reference sample are reported in Table 2 .

To examine for the presence of imogolite with an electron microscope, the air-dry, < $2 \mathrm{~mm}$ material was treated with $\mathrm{H}_{2} \mathrm{O}_{2}$ to remove organic matter and then was adjusted to $\mathrm{pH} 4$. The $<2 \mu \mathrm{m}$ fraction was separated by sedimentation and the < $0.2 \mu \mathrm{m}$ fraction was separated by centrifugation. Electron microscope examination was made with a Philips EM 400 transmission electron microscope on specimens prepared by allowing a drop of dilute clay suspension to dry at room temperature on a carbon-coated, copper grid. 
Table 1 Soil profiles in this study and the methods used for their CEC and organic $C$ determinations

\begin{tabular}{|c|c|c|c|}
\hline \multicolumn{2}{|c|}{ CEC } & \multicolumn{2}{|c|}{ Organic C } \\
\hline $\mathrm{BaCl}_{2}$ & $\mathrm{NH}_{4} \mathrm{OAC}$ & Potentiometry & Rapid Titration \\
\hline$N L-101$ & CDN-13 & NL- 101 & CDN- 13 \\
\hline NL- 102 & CDN- 14 & NL- 102 & $\mathrm{CDN}-24$ \\
\hline NL- 103 & CDN-24 & $N L-103$ & $D-11$ \\
\hline $\mathrm{NI}-104$ & $D-11$ & NL- 104 & F-2 \\
\hline NL- 105 & $F-2$ & NL-105 & IRL-9 \\
\hline NL-106 & $F-10$ & NL- 106 & $N-1$ \\
\hline NL- 107 & IRL-1 & NL- 107 & $\mathrm{~N}-2$ \\
\hline$N L-108$ & IRL-9 & $N L-108$ & $N L-2$ \\
\hline NL- 109 & $\mathrm{~N}-1$ & NL-109 & $s-2$ \\
\hline$N L-110$ & $\mathrm{~N}-2$ & NL- 110 & S-9 \\
\hline B-101 & NL-2 & B-101 & $s-10$ \\
\hline B- 102 & $s-2$ & B- 102 & $S-14$ \\
\hline B-103 & $s-9$ & B-103 & $S-15$ \\
\hline B- 104 & $s-10$ & B-104 & $S-16$ \\
\hline B- 105 & $S-14$ & B- 105 & $S F-4$ \\
\hline \multirow[t]{13}{*}{ B- 106} & $S-15$ & B-106 & SK-3 \\
\hline & $S-16$ & USA-1 & $S K-4$ \\
\hline & $s-17$ & GMC- 4 & \\
\hline & SF-4 & GMC-6 & \\
\hline & SK-2 & GMC-7 & \\
\hline & SK-3 & GMC-8 & \\
\hline & SK-4 & GMC- 13 & \\
\hline & GMC-4 & CDN-14 & \\
\hline & GMC- 6 & $F-10$ & \\
\hline & GMC-7 & IRL-1 & \\
\hline & GMC- 8 & $s-17$ & \\
\hline & GMC-13 & SK-2 & \\
\hline & USA-1 & & \\
\hline
\end{tabular}

Table 2 Mean and standard deviation of $\mathrm{Al}, \mathrm{Fe}$ and $\mathrm{C}$ extractions from the reference sample, a B21ir horizon of Becket soil series.

\begin{tabular}{lllll}
\hline Extractant & Element & Mean $(\%)$ & $\begin{array}{l}\text { Standard } \\
\text { deviation }\end{array}$ & $\begin{array}{l}\text { Number of } \\
\text { determination }\end{array}$ \\
\hline Dithionite-citrate & Al & 0.48 & 0.05 & 26 \\
Oxalate & Fe & 0.77 & 0.05 & 27 \\
& Al & 1.03 & 0.07 & 28 \\
Pyrophosphate & Fe & 0.38 & 0.03 & 30 \\
Hydroxide & Fe & 0.38 & 0.02 & 27 \\
Total C & $\mathrm{C}$ & 0.17 & 0.01 & 27 \\
\hline
\end{tabular}




\section{Materials}

For this study soil samples were obtained from three sources:

1) ten soil profiles in the Netherlands; six soil profiles in Belgium and one soil profile in Michigan, U.S.A. described and collected by the authors;

2) 23 soil monoliths in the International Soil Museum collection and

3) five soil monoliths collected by Russian soil scientists for the First International Congress of Soil science held in 1927 (section 8.1).

Soil profiles were described according to FAO Guidelines (FAO, 1977). Detailed profile descriptions of the Dutch, Belgian and Michigan profiles collected by the authors as well as of the Russian profiles are given in Appendices 1 and 2. Descriptions of the profiles from the museum collection can be obtained from ISM. A large number of the profiles used in this study have been selected for photographic representation on the colour plate "Podzols and related soils", which is issued as a separate sheet.

\subsection{USSR PODZOL MONOLITHS}

Russian soil scientists prepared many soil monoliths for display at the First International Congress of soil science held in washington D.C. in 1927. The monoliths did not arrive in time for display at the Congress (Truog, 1928 ). The U.S. Departinent of Agriculture received custody of them and placed them in storage (Bailey, 1980). In 1954 or 1955 Roy w. Simonson and C.C. Nikiforoff placed many of the monoliths on display at the Beltsville Agricultural Research Centre. In an attempt to preserve the collection, the monoliths were treated with poured vinyl resin (laminac thinned with styrene). They were on display until 1961 and then returned to storage. In 1979 the monolith collection was donated to the International soil Museum and is now known as the "Glinka Memorial Collection". Soil samples from some of the monoliths were removed and stored with the U.S. National Soil survey Laboratory. A tentative placement in the U.S. soil taxonomic system was also made. After the monoliths arrived at the International soil Museum in 1980, those monoliths which had been tentatively classified as Spodosols were selected for study (Monolith numbers $4,6,7,8$ and 13 assigned by C.C. Nikiforoff and numbers 24,26 , 27, 28 and 33 assigned by Russian soil scientists for the congress).

Brief descriptions of the five monoliths as they were given in the original publication (Anonymous, 1927) follow.

Monolith 24 - Peaty - podzolized - gley soil on sandy loam. Pine-forest with an undergrowth of Vaccinium myrtillus and moss-cover. Leningrad - okhta forestry.

Monolith 26 - Podzolized soil with ortstein on heavy loam. Forest meadows. plain south of Pskov gvt. Velikiye Luki district. 
Monolith 27 - Podzolized soil without ortstein on boulder loam. skirt of deciduous forest. Leningrad gvt. Leningrad district.

Monolith 28 - Sandy-loamy podzol. Meadow over the terrace of slavianka River. Leningrad gvt. Trotsk district.

Monolith 33 - Sandy-loamy podzol. Fir-forests with moss-cover, over a slope towards a swamp. Tver gvt. Rzhev district.

Brief descriptions of the five monoliths as prepared by c.c. Nikiforoff (Bailey, 1980) follow (number in parenthesis are those assigned in the original publication).

Monolith GMC* 4 (24) - Podzolized peaty-gley soil with a distinct bleached $G$ horizon. Developed under poorly drained, predominantly coniferous forest (spruce, pine, with birch). okhta forest, near Leningrad (about $60^{\circ} \mathrm{N}, 30^{\circ} \mathrm{E}$ ).

Monolith GMC 6 (26) - Podzolic soil with ortstein from Velikiye Luki region (about $56^{\circ} \mathrm{N}, 30^{\circ} \mathrm{E}$ ).

Monolith GMC 7 (27) - Podzolic soil without ortstein developed from glacial drift (boulder loam). Sablino, near Leningrad (about $60^{\circ} \mathrm{N}, 30^{\circ} \mathrm{E}$ ).

Monolith GMC 8 (28) - Sandy podzol on the terrace of slavianka River, Gatchina district, near Leningrad.

Monolith GMC 13 (33) - Sandy podzol under spruce forest with hypnum moss. Nearly flat area near the sphagnum peat-bog in the Rzher district of Kalinin oblast.

* (GMC denotes Glinka Memorial collection)

Because vinyl resin had been poured on the front of the monoliths, soil samples for chemical and physical analyses could not be taken from the front side. To obtain samples which were not affected by the vinyl resin, it was decided to remove material from the back of the monoliths. To obtain the samples, $2.5 \mathrm{~cm}$ thick styrofoam was cut to $\mathrm{fit}$ inside the monolith box and placed on the front of the monolith. The front of the box was replaced and the back of the box was removed. The styrofoam expanded and pushed the monolith out the back of the box 1 to $1.5 \mathrm{~cm}$. The horizons were identified and described. Because some of the vinyl resin may have run along the sides of the box when it was poured on the front of the monolith, about $1 \mathrm{~cm}$ thickness of the soil which extended beyond the sides of the box was removed and discarded. The remaining soil which extended beyond the box was then removed for laboratory analysis.

Classification of the soils studied according to the FAO-Unesco system (FAO, 1974) and soil Taxonomy (Soil survey staff, 1975) is given in Table 3. 
Table 3 Classification of the soils investigated.

\begin{tabular}{|c|c|c|c|}
\hline $\begin{array}{l}\text { Profile } \\
\text { Number }\end{array}$ & Country & FAO-Unesco & Soil Taxonomy \\
\hline NL-101 & Netherlands & Orthic Podzol & Typic Haplohumod \\
\hline NL-102 & Netherlands & Gleyic Podzol & Aeric Haplaquod \\
\hline NL- 103 & Netherlands & Gleyic Podzol & Aeric Haplaquod \\
\hline NL-104 & Netherlands & Orthic Podzol & Typic Haplohumod \\
\hline NL-105 & Netherlands & Orthic Podzol & Typic Haplorthod/Haplohumod \\
\hline$N L-106$ & Netherlands & Cambic Arenosol & spodic Udipsamment \\
\hline NL-107 & Netherlands & Orthic Podzol & Plaggeptic Haplohumod \\
\hline NL-108 & Netherlands & Humic Podzol & Typic Haplohumod \\
\hline NL-109 & Netherlands & Orthic Podzol & Aquic Haplorthod \\
\hline NL-110 & Netherlands & Humic Podzol & Typic Haplohumod \\
\hline$B-101$ & Belgium & Orthic Podzol & Typic Haplorthod \\
\hline B-102 & Belgium & Gleyic Podzol & Aeric Haplaquod \\
\hline$B-103$ & Belgium & Gleyic Podzol & Aeric Haplaquod \\
\hline B-104 & Belgium & Gleyic Podzol & Typic Haplaquod \\
\hline B-105 & Belgium & Gleyic Podzol & Aeric Haplaquod \\
\hline$B-106$ & Belgium & Gleyic Podzol & Typic Haplaquod \\
\hline SER-3 & Switzerland & Ranker & Lithic Cryumbrept \\
\hline SER-10 & Switzerland & Dystric Cambisol & Typic Dystrochrept \\
\hline CDN-13 & Canada & Dystric Cambisol & Typic Fragiochrept \\
\hline CDN-14 & Canada & Gleyic Podzol & Typic Haplaquod \\
\hline CDN-24 & Canada & Dystric Cambisol & Dystric Cryochrept \\
\hline$D-11$ & Germany & Dystric Cambisol & Typic Dystrochrept \\
\hline F-2 & France & Dystric Cambisol & Typic Dystrochrept \\
\hline$F-10$ & France & Cambic Arenosol & Spodic Udipsamment \\
\hline IRL-1 & Ireland & Cambic Arenosol & Spodic Udipsamment \\
\hline IRL-9 & Ireland & Placic Podzol & Typic Placohumod \\
\hline $\mathrm{N}-1$ & Norway & Calcaric Regosol & Typic Cryorthent \\
\hline $\mathrm{N}-2$ & Norway & Gleyic Podzol & Placic Haplaquod \\
\hline $\mathrm{NL}-2$ & Netherlands & Cambic Arenosol & Typic Udipsamment \\
\hline$s-2$ & Sweden & Dystric Cambisol & Typic Dystrochrept \\
\hline$s-9$ & Sweden & Orthic Podzol & Tupic Cryorthod \\
\hline$s-10$ & Sweden & Orthic Podzol & Typic Cryohumod \\
\hline s-14 & Sweden & Cambic Arenosol & Typic Cryopsamment \\
\hline$s-15$ & Sweden & Humic Podzol & Typic Cryohumod \\
\hline$s-16$ & Sweden & Dystric Cambisol & Dystric Cryochrept \\
\hline s-17 & Sweden & Orthic Podzol & Typic Cryorthod \\
\hline SF-4 & Finland & $\begin{array}{l}\text { Cambic Arenosol/ } \\
\text { orthic Podzol }\end{array}$ & $\begin{array}{l}\text { Spodic Udipsamment/ } \\
\text { Typic cryorthod }\end{array}$ \\
\hline SK-2 & Sarawak (Mal.) & Humic Podzol & Tropohumod \\
\hline SK-3 & Sarawak (Mal.) & Cambic Arenosol & Typic Tropopsamment \\
\hline SK-4 & Sarawak (Mal.) & Cambic Arenosol & Typic Tropopsamment \\
\hline GMC-4 & Soviet Union & Gleyic Podzol & Typic Cryaquod \\
\hline GMC-6 & Soviet Union & Orthic Luvisol & Typic Glossoboralf \\
\hline GMC-7 & Soviet Union & Orthic Luvisol & Aquic Cryoboralf \\
\hline GMC-8 & Soviet Union & Orthic Podzol & Typic Haplorthod \\
\hline GMC-13 & Soviet Union & Gleyic Acrisol & Aquic Hapludalf \\
\hline USA-1 & United States & Orthic Podzol & Typic Haplor thod \\
\hline
\end{tabular}




\section{Results and discussion}

\subsection{PARTICLE SIZE DISTRIBUTION}

The particle size distribution of the soils is given in Appendix 3 . The moist color of the horizons of the profiles not described previously are included in Appendix 3. The soils from the Netherlands and Belgium were all sandy or the profile was developed in the sandy portion.

In the soviet Union profiles, podzols developed in sandy materials and argillic horizons developed in finer materials. Spodic horizons tended to develop in coarser textured material, while non-spodic horizons tended to develop in finer textured material.

\subsection{CARBON AND SESQUIOXIDES}

Selected chemical properties of the soils studied are given in Appendix 4.

with the exception of the Sarawak soils, dithionite-citrate extracted the most iron and pyrophosphate extracted the least from a given sample. This agrees with the general theory that dithionite-citrate extracts crystalline and amorphous forms of iron, oxalate extracts some crystalline and all amorphous iron and pyrophosphate extracts the iron which is organically bound. The three extractants, pyrophosphate excepted, are not as specific for aluminum.

In most of the soils there is little difference between the $\mathrm{Al}_{0}$ and Alp contents. This indicates that in these there is little amorphous Al which is not organically bound. In the Dutch and Belgian soils the $\mathrm{Al}_{\mathrm{d}^{\prime}} \mathrm{Al}_{\mathrm{O}}$ and $\mathrm{Al}_{\mathrm{p}}$ contents are similar. In several of the other soils $\mathrm{Al}_{\mathrm{d}}$ contents are significantly lower than $A_{0}$ o contents. This is not surprising since Al is not affected by reducing agents.

In $A$ horizons and some $E$ horizons pyrophosphate did not extract all of the organic $\mathrm{C}$. Roots present in these horizons are not extracted by pyrophosphate. In most $B$ horizons of podzols the $c_{t}$ and $c_{p}$ contents were similar indicating there is relatively little contribution of organic $\mathrm{C}$ from roots.

Carbon/aluminum, carbon/iron and carbon/sesquioxides atomic ratios have been calculated using total carbon, sodium hydroxide-extractable carbon, pyrophosphate-extractable carbon and sesquioxides extracted by dithionite, oxalate and pyrophosphate (Appendix 4 and Figures 1 to 8 ).

The $\mathrm{C} / \mathrm{Al}, \mathrm{C} / \mathrm{Fe}$ and $\mathrm{C} / \mathrm{Ses}$ atomic ratios are combined in graphs that show both variation with depth and within horizons. C/Al graphs are given in detail because the $\mathrm{C} / \mathrm{Al}$ ratios proved most useful for distinction between eluvial and illuvial horizons. In case of ratios with respect to pyrophosphateextractable matter, B horizons are split up in detail, while for the other extractants $\mathrm{B}$ horizons have been grouped into one bar for the $\mathrm{Bh}$ and one 
for the Bs horizon. $\mathrm{C} / \mathrm{Fe}$ and $\mathrm{C} / \mathrm{ses}$ graphs have been condensed in this way, and $c_{h} / F e$ and $c_{h} /$ ses ratios are not shown in the graphs. Orthic/humic and Gleyic Podzols are treated separately for $\mathrm{C} / \mathrm{Al}$ and $\mathrm{C} / \mathrm{Ses}$ ratios, while they have been combined in the $\mathrm{C} / \mathrm{Fe}$ graphs in order to allow distinction between these groups on the basis of $\mathrm{C} / \mathrm{Fe}$ ratio. Some atomic ratios are less accurate than others because the values for $A l$ or Fe are near the detection limit. For example, ratios for $B$ horizons tend to be more accurate than those for $E$ horizons. In the figures the ratios obtained with sesquioxide contents of $0.02 \%$ and lower have been underlined.

\subsubsection{Carbon/aluminum ratios}

The $C / A l$ atomic ratios for the three organic carbon fractions $\left(c_{t}\right.$, $c_{h}$ ' $C_{p}$ ) and the three aluminum extractions ( $A l_{d}, A l_{0}, A l_{p}$ ) all decrease with depth, i.e. from Ah to $C$ horizons (figures 1 to 4 ). This trend holds for all podzols in this study.

\section{Pyrophosphate aluminum}

In the Humic and orthic Podzols from the Netherlands and Belgium, a $c_{t} / A_{p}$ ratio of about 45 gives an almost perfect separation between eluvial and illuvial horizons. An and $E$ horizons have ratios higher than 45 , while all $B$ horizons have ratios below 45 . There is only one E horizon sample with a value less than 45 that overlaps with those of the B horizons. This horizon is from profile $\mathrm{NL}-108$ and may have had some $\mathrm{B}$ horizon material mixed in it.

$C_{h} / A l_{p}$ ratios do not give as good a separation between eluvial and illuvial horizons; the ratios of $\mathrm{E}$ and $\mathrm{B}$ horizons overlap between the values 18 and 35. All $B$ horizons have $C_{h} / A l p$ ratios less than 35 but four $E$ horizons also have values less than 35. Two of these $E$ horizons are from profile NL-108 and a third has less than $0.02 \% \mathrm{Al}$.

$C_{p} / A_{p}$ ratios give good separation between eluvial and illuvial horizons. The ratios for $B$ horizons were all less than 40 but three $E$ horizons also had ratios less than 40 . Two of these $E$ horizons were from profile NL-108 and the other has only $0.01 \% \mathrm{Al}$.

In the Dutch and Belgian Gleyic Podzols, the $C_{t} / A_{p}$ ratio also gives good separation of eluvial and illuvial horizons, at a ratio of approximately 40. Only the $A h$ and $E$ horizons of profile NL-103 have ratios less than 40, but these horizons have been covered by more recent wind-blown sand and may have received some illuvial sesquioxides from this sand cover, where podzolization is also active.

The $C_{h} / A l_{p}$ ratio does not give a good separation in the Gleyic Podzol profiles. Many $A h$ and $E$ horizons have ratios in the same range as the $B$ horizons. 


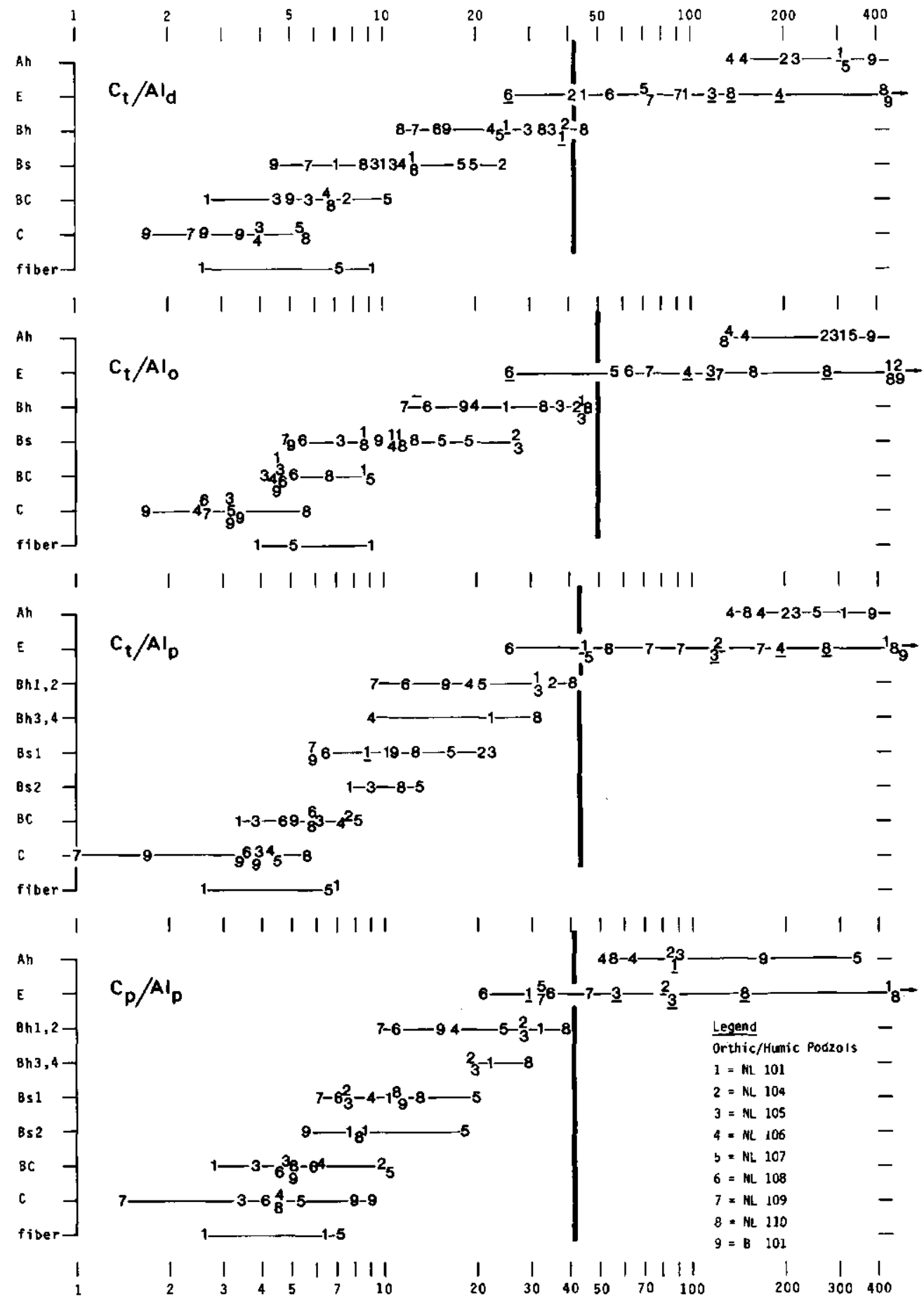

Figure 1. C/Al ratios of Orthic and Humic Podzols 


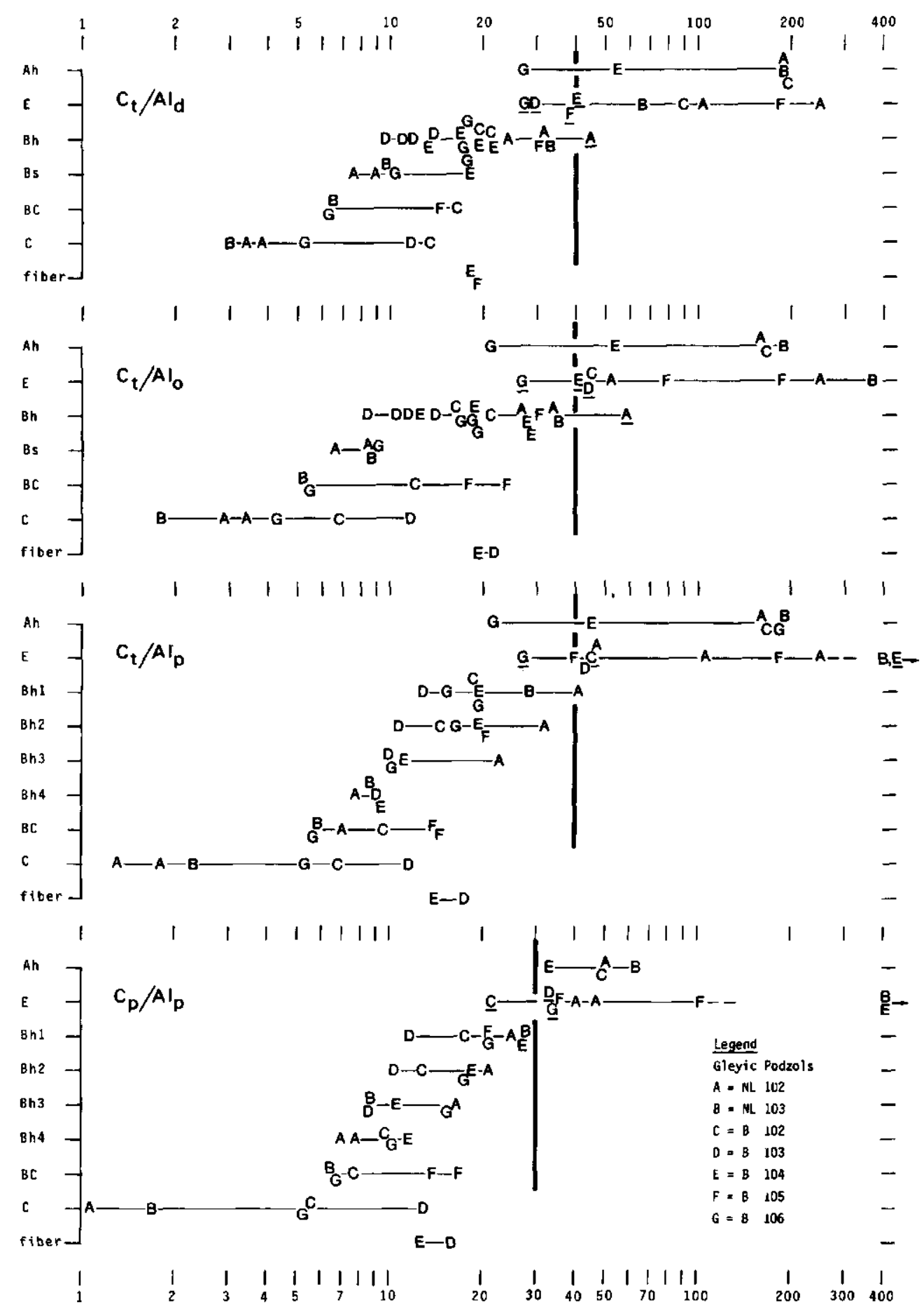

Figure 2. C/Al ratios of Gleyic Podzols 


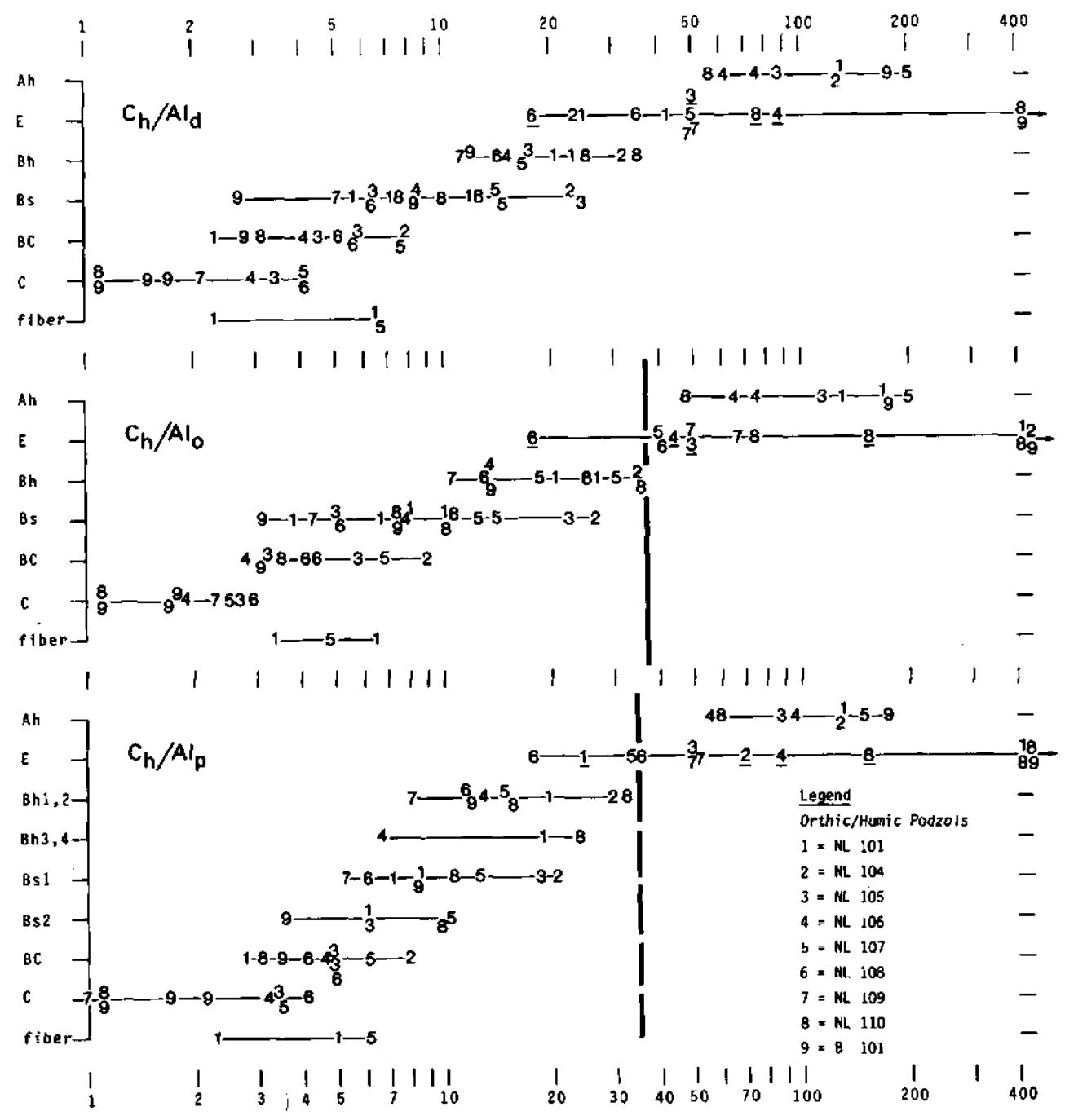

Figure 3. $c_{h} / A 1$ ratios of Orthic and Humic Podzols 


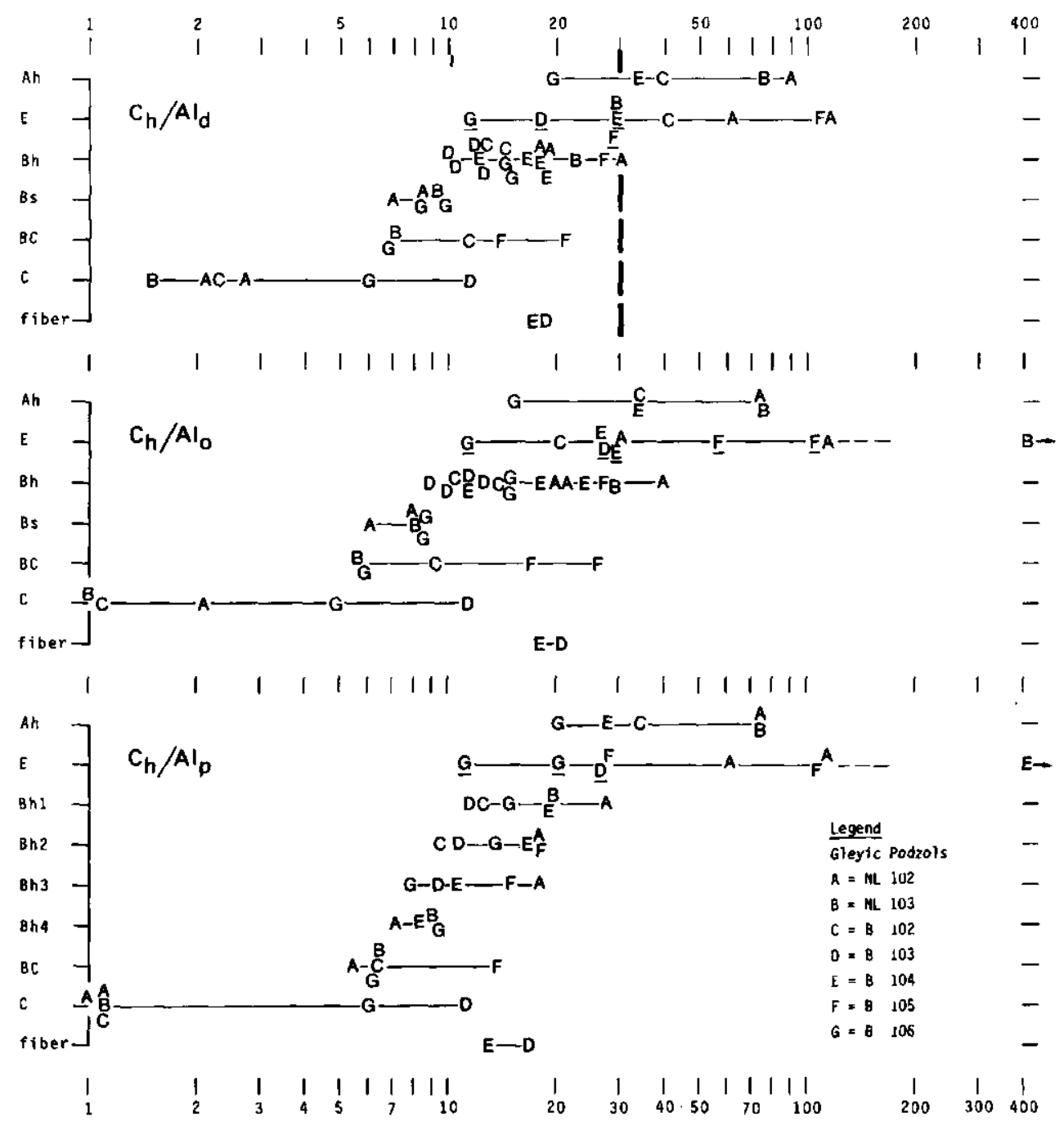

Figure 4. $C_{h} / A I$ ratios of Gleyic Podzols 
The $\mathrm{C}_{\mathrm{p}} / \mathrm{Al}$ p ratios, however, give good separation with only one overlapping value but in this $E$ horizon the $\mathrm{Al}_{\mathrm{p}}$ content was $0.02 \%$. The ratio for separating $\mathbf{E}$ and $\mathrm{B}$ horizons is about 30 .

Dithionite aluminum

In Humic and Orthic Podzols from The Netherlands and Belgium, $\mathrm{C}_{\mathrm{t}^{/ \mathrm{Al}} \mathrm{d}}$ ratios give a fairly accurate separation between $E$ and $B$ horizons. The break is at a ratio of about 40-45. The $C_{h} / A l_{d}$ ratio, however, gives a broad overlap between illuvial and eluvial horizons.

In Gleyic Podzols, the separation is not as good as in the dryer profiles. Only after elimination of less accurate $C_{t} / A l_{d}$ ratios, is a separation value of about 40 obtained. The same holds true for the $C_{h} / A l_{d}$ ratios. After elimination of less accurate ratios, the separation value can be set at the highest ratio found in the $B$ horizons, 30 .

Oxalate aluminum

In the Dutch and Belgian Humic and Orthic Podzols, $C_{t} / A l o g i v e s$ a good separation between $\mathrm{E}$ and $\mathrm{B}$ horizons at values between 45 and 55 . As mentioned earlier, the only overlapping $\mathbf{E}$ horizon sample probably has admixtures of $B$ horizon material. The $C_{h} / A l_{0}$ ratios also give a good separation, at values 35-40.

The oxalate aluminum in Gleyic Podzol profiles shows the same problems as with dithionite aluminum. $\mathrm{C}_{t} / \mathrm{Al}$ o give a fairly good separation at values between 30-35, which is improved after elimination of less accurate ratios. The $C_{h} / A l_{0}$ ratios on the other hand do not give very good results. The highest accurate value in the $B$ horizon is 40 but there are many $A h$ and $E$ horizons with values lower than this.

The $C_{t} / A l$ ratios are slightly higher than $C_{h} / A l$ and $C_{p} / A l$ ratios. The $C_{t} / A I_{p}$ ratio gives good separation in both Humic/Orthic Podzols and Gleyic Podzols. Moreover, the separation values are similar for both groups studied. The $C_{p} / A l_{p}$ ratio also gives fair to good separation but the separation value is 40 for the Humic/Orthic Podzols and 30 for the Gleyic Podzols.

\subsubsection{Carbon/iron ratios}

The $\mathrm{C} / \mathrm{Fe}$ atomic ratios for the three organic $\mathrm{C}$ fractions and the three iron extractions all tend to decrease with depth, i.e. from the Ah to the $C$ horizons for the Humic, Orthic and Placic Podzols but not the Gleyic Podzols (Appendix 4 and Figure 5). None of the $\mathrm{C} / \mathrm{Fe}$ ratios gives a good separation between eluvial and illuvial horizons in the Dutch and Belgian soils. The ratios behave erratically, but in some soils there is clear separation between $E$ and Bs horizons. 
The Gleyic Podzols without gley mottles have higher $\mathrm{C} / \mathrm{Fe}$ ratios than the Humic and orthic Podzols. Therefore, these ratios may be used to distinguish between those Gleyic Podzols that have no mottles of iron compounds below the $B$ horizons and have very low iron contents, and Humods and orthods which lack a distinct Bs horizon. The $C_{p} / F e_{p}$ ratios of $B$ horizons give the best separation between these two groups of Podzols. A $\mathrm{C}_{\mathrm{p}} / \mathrm{Fe}$ patio of 150 can be used to distinguish between the Gleyic Podzols (higher ratios) and the fumic and Orthic Podzols (lower ratios). There are ratios from only three profiles which overlap, two are Gleyic Podzols and the other is a Humic Podzol. The samples from two of the profiles have low iron contents, $0.03 \%$ or less. The third profile is a Gleyic Podzol which is intergrading to Humic Podzol.

All Gleyic Podzols in the ISM monolith collection had $C_{p} / F e_{p}$ atomic ratios of $B$ horizons greater than 150. Only one of the Humic and orthic Podzols had a $\mathrm{C}_{\mathrm{p}} / \mathrm{Fe}_{\mathrm{p}}$ ratio of $\mathrm{B}$ horizon greater than 150 . The ratio of the Bhl horizon was 159 but that of the Bh2 was only 24.6. Consequently, Gleyic Podzols without gley mottles might be defined as having ratios higher than 150 in all subhorizons of the B, while orthic and Humic Podzols have a ratio lower than 150 in at least one subhorizon.

The other $\mathrm{C} / \mathrm{Fe}$ ratios give separation between Gleyic Podzols and Humic and orthic Podzols at values of 110 to 150. There is some overlap, especially in the Bh horizons.

\subsubsection{Carbon/sesquioxide ratios}

The $\mathrm{c} / \mathrm{ses}$ atomic ratios for the three organic $\mathrm{c}$ fractions and the three aluminum and iron extractions all decrease with depth, i.e. from the Ah to the $C$ horizons (Appendix $4 \mathrm{a}, 4 \mathrm{~b}$ and Figures 6-8). This trend holds for all Podzols included in this study. $c_{h} /$ Ses $_{d, o}$ ratios have not been included in the figures. For values, the reader is referred to Appendix 4.

\section{Pyrophosphate sesquioxides}

None of the $\mathrm{c} / \mathrm{Ses}_{\mathrm{p}}$ atomic ratios gives a good separation between eluvial and illuvial horizons in the Dutch and Belgian soils. In the Humic and orthic Podzols the $c_{t} /$ ses $_{p}$ ratio gives separation between the eluvial and illuvial horizons at values of 25-35. The highest ratio in the $B$ horizon is 35 and the lowest in the $E$ horizon is 25 . The $c_{h} /$ ses $p$ ratio shows an overlap of values for $E$ and $B$ horizons. Also the $C_{p} /$ Ses $p$ ratios show some overlap of values for $A h$ and $E$ horizons with $B$ horizons.

In the Gleyic Podzols $C_{t} /$ Ses ratios give fair separation at a value of 35. The overlapping values from the $E$ horizons are for samples with very low, less than $0.02 \%, \mathrm{Al}$ and Fe contents. The overlapping values for $\mathrm{Ah}$ horizons are from profiles NL-103 and B-103, which have sand covers and the Ah horizons 

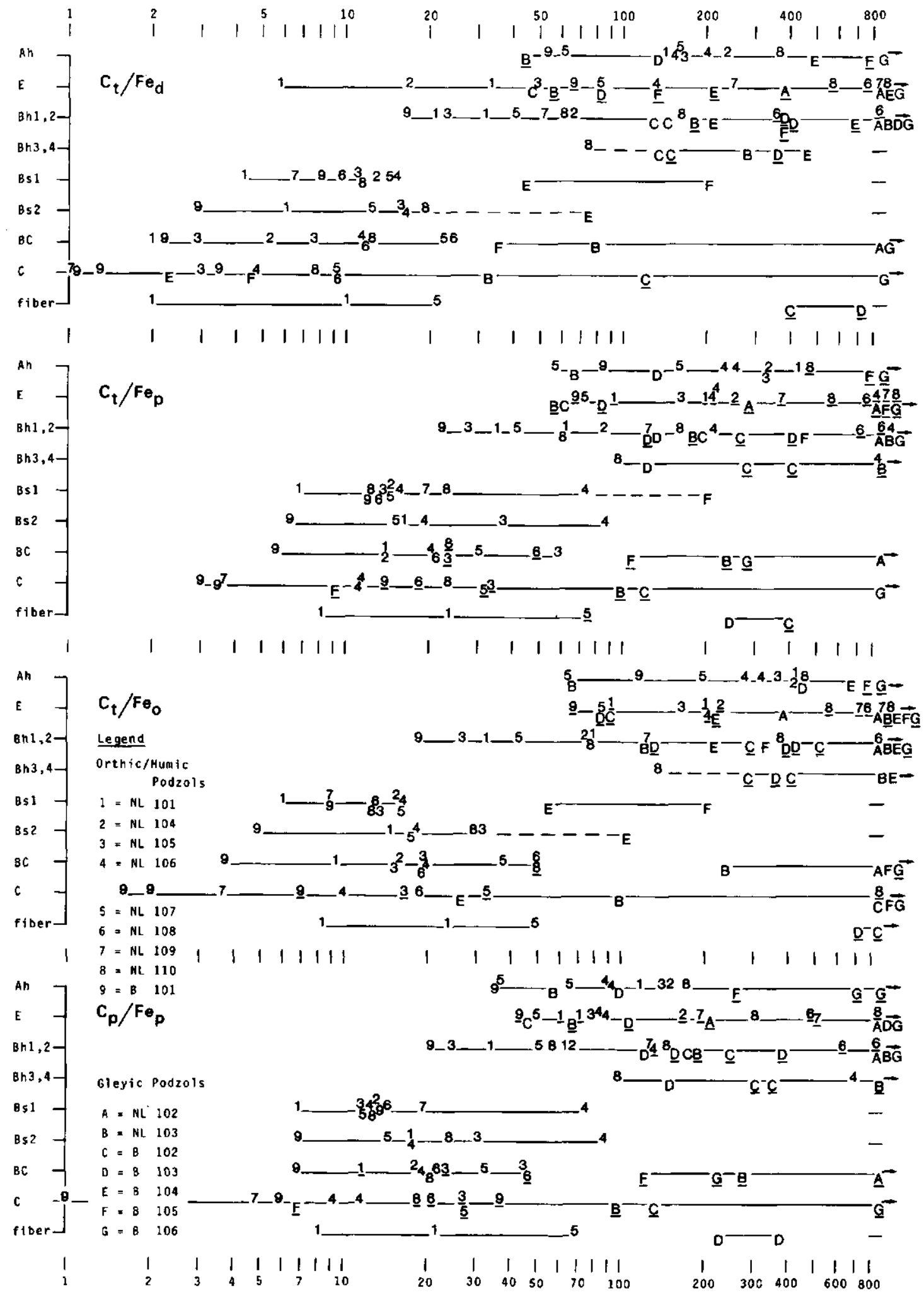

Figure 5. C/Fe ratios of Orthic/Humic and Gleyic Podzols 

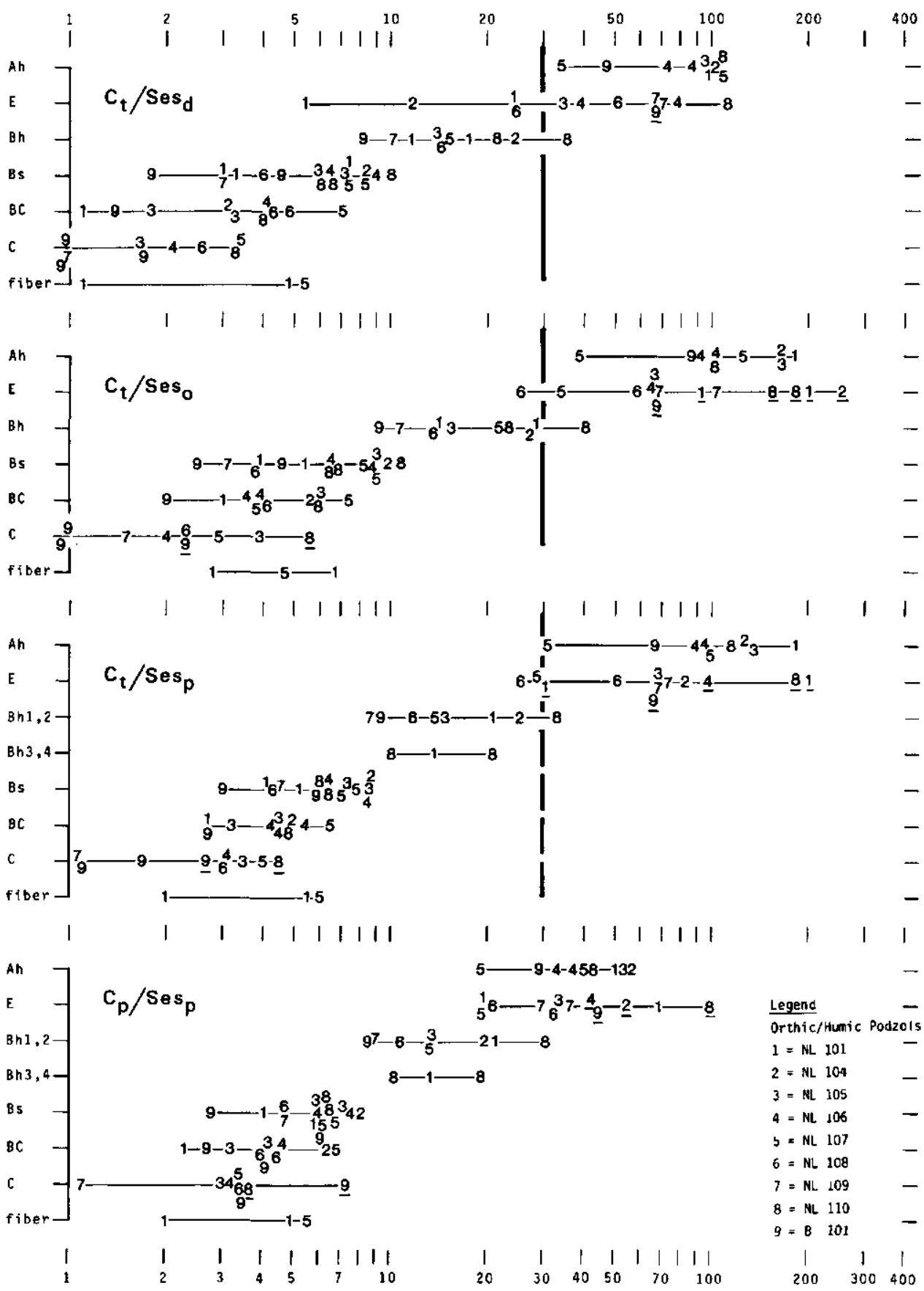

Figure 6. C/ses ratios of orthic and Humic Podzols 


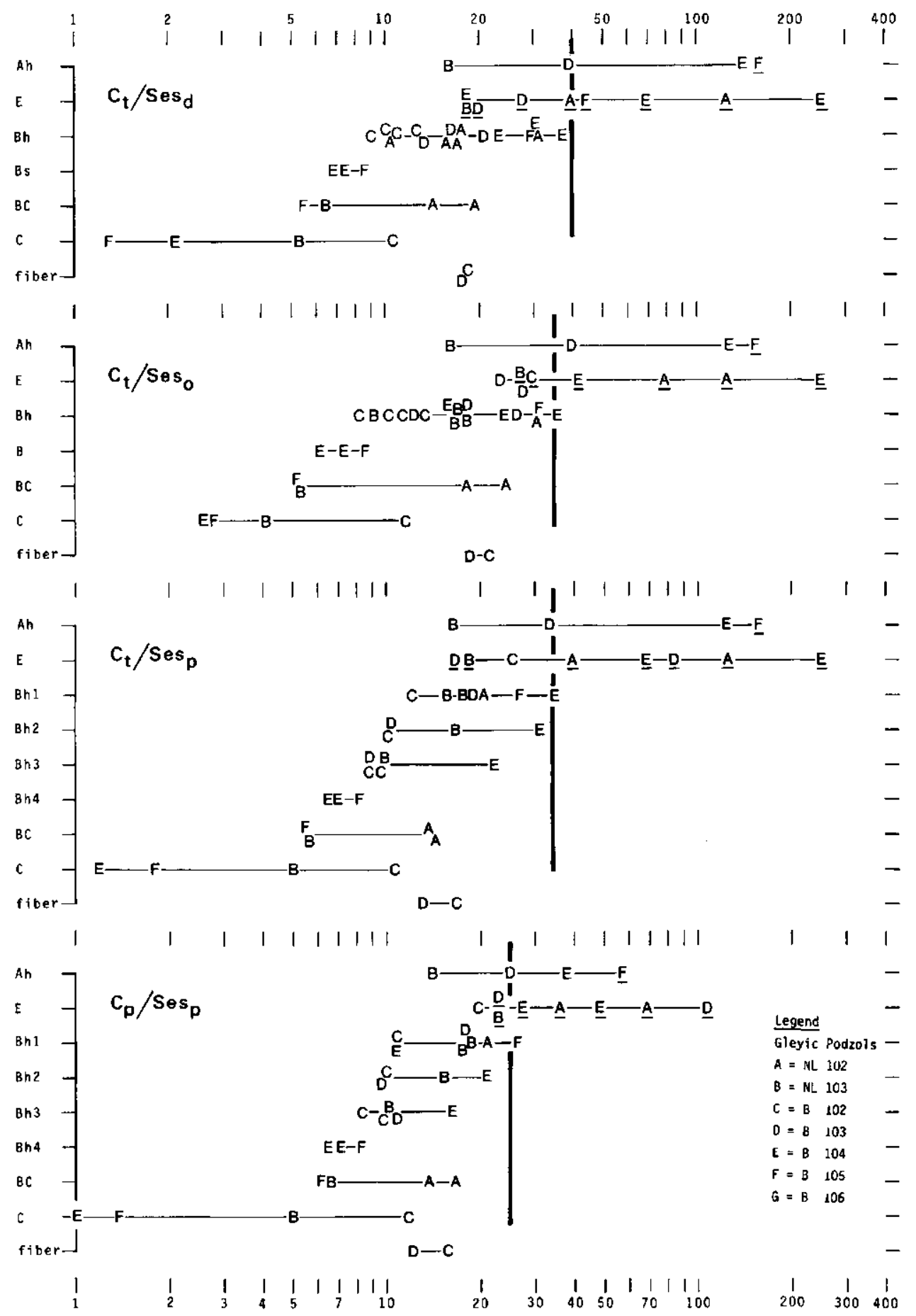

Figure 7. C/Ses ratios of Gleyic Podzols 


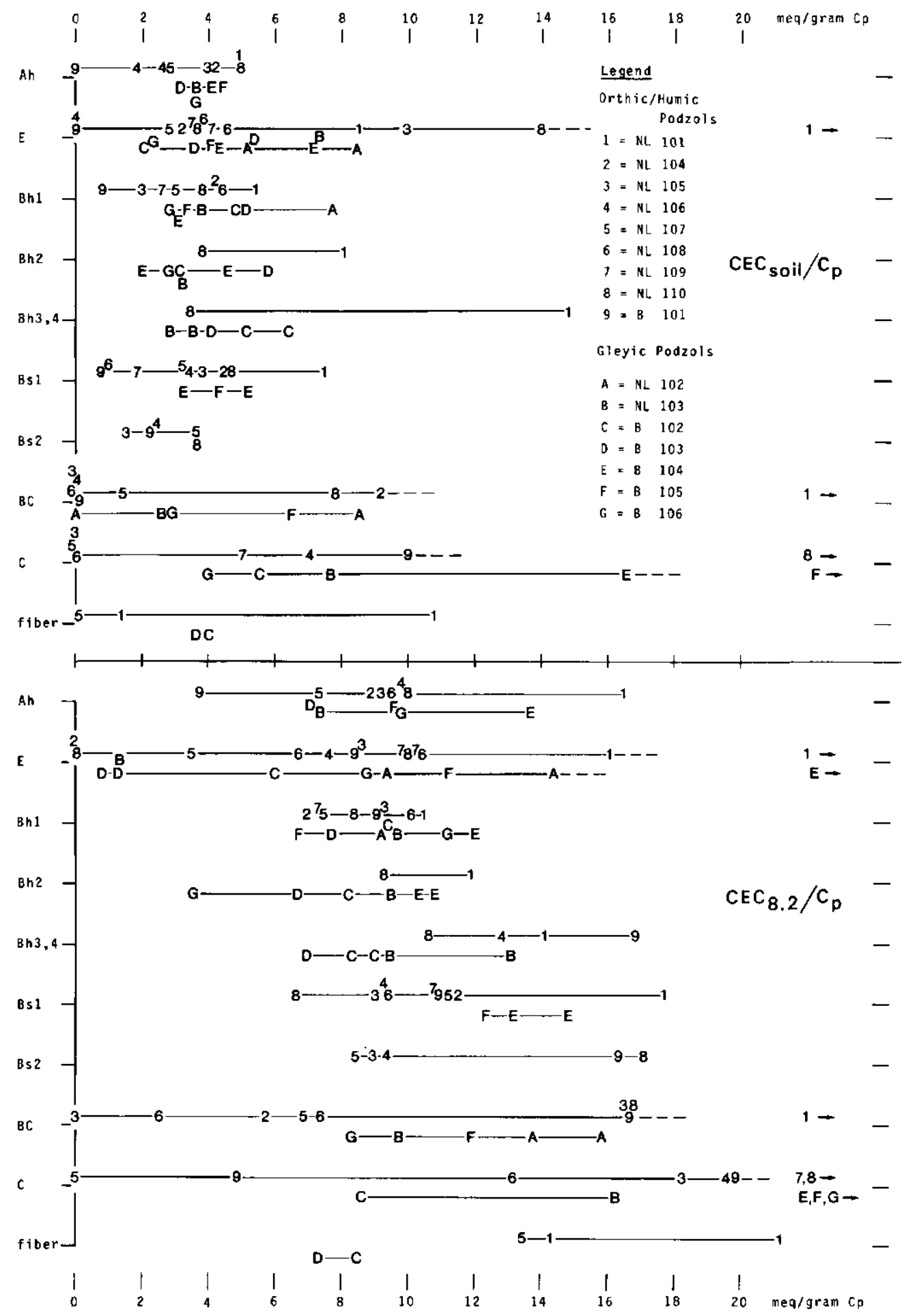

Figure 8. Depth functions of $\mathrm{CEC}_{\text {soil }}$ and $\mathrm{CEC}_{8.2}$ 
may have received some illuvial sesquioxides from this material. The $\mathrm{C}_{\mathrm{h}} / \mathrm{Ses}_{\mathrm{p}}$ ratio gives separation at a value of 25 after eliminating less accurate values. The $\mathrm{C}_{\mathrm{p}} / \mathrm{Ses}_{\mathrm{p}}$ ratio gives separation at approximately the same value after eliminating the less accurate values.

Dithionite sesquioxides

There is considerable overlap of C/Ses $\mathrm{d}$ ratios between the $\mathrm{Ah}, \mathrm{E}$ and $\mathrm{B}$ horizons. In the Humic and orthic Podzols the $c_{t} /$ ses $d$ and $c_{h} /$ Ses $_{d}$ ratios give poor separation at values of 25-30. With both ratios there is considerable overlap of values in the $\mathrm{E}$ and $\mathrm{B}$ horizons.

In the Gleyic Podzols similar results were obtained. Both the $\mathrm{C}_{t} /$ ses $_{d}$ ratio and the $c_{h} /$ Ses $d$ ratio give poor separation.

Oxalate sesquioxides

In the Humic and Orthic Podzols the $c_{t} /$ Ses ${ }_{o}$ ratio gives fair separation at values of \pm 30 . The overlap of values from Ah and $E$ horizons with those from B horizons occurs in two profiles: NL-107 and NL-108. Profile NL-107 has a plaggen epipedon and some sesquioxides may have eluviated from above and accumulated in the $E$ horizon. The $E$ horizon of profile NL-108 may have had some admixture of $B$ horizon material. The $C_{h} /$ ses 0 ratio gives fair separation at values of 25-30. Most of the overlapping values from the $A h$ and $E$ horizons are less accurate.

In the Gleyic Podzols the $c_{t}$ /Ses o ratios give fair separation of eluvial and illuvial horizons at values of about 35. The $E$ horizons with values which overlap the $B$ horizon range have either low aluminum and iron contents or have a sand cover. The Ah horizon with a ratio which overlaps with the $B$ horizon range also has a sand cover. The $c_{h} /$ ses, ratios give poor separation. Most of the overlapping values are from profiles with low aluminum and iron contents in the $\mathrm{E}$ horizon or with a sand cover.

\subsubsection{Discussion carbon/metal ratios}

The separation values for all carbon fractions and all sesquioxide extractions found in Dutch and Belgian soils also hold true for most of the podzols in the ISM monolith collection (Appendix 4b) and for several reported in literature (Appendix 5). For the soils that do not fit the above separation, the $\mathrm{C} / \mathrm{Al}$ ratios in the $\mathrm{B}$ horizons do not exceed the separation values, but the $\mathrm{C} / \mathrm{Al}$ ratios of the $\mathrm{E}$ horizons are lower than these values. Profile F-10 is the only profile where C/Al ratios of the $B$ horizon exceed the separation value. Roots in the $B$ horizon may have caused the high $C_{t} / A 1$ ratio.

It is likely that the highest atomic ratios in the B horizon, or the separation values, indicate the minimum amount of sesquioxides necessary 
for the precipitation of the complex. In the Humic and orthic Podzols the C/Al separation values are about 45 for $C_{t} / A l$, about 35 for $C_{h} / A l$ and about 40 for $C_{p} / A l$. In the Gleyic Podzois the $C / A 1$ separation values are about 40 for $C_{t} / A l, 30$ for $C_{h} / A l$ and about 30 for $C_{p} / A l$.

$\mathrm{C} / \mathrm{Al}$ and $\mathrm{C} / \mathrm{Ses}$ ratios in $\mathrm{E}$ and $\mathrm{B}$ horizons tend to increase with podzol development. For the $\mathrm{E}$ horizons it indicates a net removal of sesquioxides; for the $B$ horizons it is accompanied by a clearer separation of Bh and Bs horizons. Because not all sesquioxides in the Bs horizon are bound to organic matter (compare dithionite and pyrophosphate extractions) this implies that the $\mathrm{C} / \mathrm{Al}$ and $\mathrm{C} /$ Ses ratios in the upper $\mathrm{Bh}$ horizons of well-developed profiles are more characteristic for the minimum amount of sesquioxides required to precipitate organic matter than ratios obtained from $B$ horizons of less strongly differentiated profiles. Consequently, the highest ratios in the B-horizon should be used to set it off against the $E$ horizon.

The lowest $\mathrm{c}_{\mathrm{p}} /$ Ses $_{\mathrm{p}}$ atomic ratios in the $\mathrm{B}$ horizon should indicate the maximum amount of sesquioxides that organic matter can bind, provided that pyrophosphate does not extract sesquioxides that are inorganically bound, such as $\mathrm{Fe}$ in oxyhydrates and $\mathrm{Al}$ in allophanic compounds. In the Gleyic Podzols from the Netherlands and Belgium all B horizons had ratios greater than 6.0. In the Humic and orthic Podzols only four Bh, Bhs and Bs horizons had $c_{p} /$ Ses $_{p}$ ratios below 5.8 (Appendix $4 a, b$ ). Most of the $B$ horizons of the non-podzols reported in literature (Appendix 5) had $c_{p} /$ ses $p$ ratios below 5.8. This would indicate that a $\mathrm{C}_{\mathrm{p}} / \mathrm{ses}$ p ratio of 5.8 reflects about the maximum amount of sesquioxides that organic matter in podzol $B$ horizons can bind.

Two profiles with fibers (NL-101 and NL-107) have low $C_{p} /$ Ses $p$ ratios in the Bs horizons (Figure 6). In profile NL-101 the ratios for the Bs and BC horizons are below 5.8 and in profile NL-107 both the Bhs and the BC horizon have a ratio of 6.8 .

Higashi et al. (1981), however, assumed that it is impossible for organic matter to bind metallic ions in metal/c atomic ratios higher than 0.12 , which is equivalent to a $\mathrm{C} /$ Ses ratio of about 8.5 . However, these authors did not prove that a value of 0.12 is more accurate than the value of 0.16 (or $\mathrm{C} / \mathrm{ses}=6$ ) they arrived at after provisional calculations. The latter value is in accordance with the assumptions made in this paper.

$\mathrm{C} / \mathrm{Al}$ ratios behave regularly and provide a good separation between eluvial and illuvial horizons; $\mathrm{C} / \mathrm{Fe}$ ratios behave erratically, and $\mathrm{C} / \mathrm{ses}$ ratios behave regularly but separation is not as good as with C/Al ratios. This, and the near absence of iron in Gleyic podzols supports the earlier assumption that aluminum rather than iron regulates the precipitation of organic matter.

In podzols, the B horizon moves downward with time and the $\mathrm{E}$ horizon becomes thicker (De Coninck, 1980). One of the mechanisms used to explain this process is the oxidation of organic matter from the complexes that have 
precipitated and further transport of the sesquioxides by fresh organic matter from above. This theory does not explain why one chelate would be more resistant to oxidation than another, nor does it explain that in many podzols the maxima of organic matter, aluminum and iron do not coincide.

If one accepts the theory that organic matter is immobilized by absorption of a certain amount of sesquioxides, it is also possible that a once precipitated chelate can be remobilized by the addition of fresh, undersaturated organic ligands from above or from decomposition of roots in the $B$ horizon. This redissolution process, together with a pH-dependent preferent Ee to Al complexation (Schnitzer and skinner, 1963) may be the key to the diverging iron and aluminum maxima.

In early stages of podzolization, sufficient iron and aluminum is present in the surface layer, and immobilization will occur near the surface layer. The soil will have a shallow B horizon. Further eluviation results in dissolution of the upper part of the B horizon; the solubilized complexes are redeposited in the lower part of the same horizon. As mentioned previously, fulvic acids preferentially complex $\mathrm{Fe}^{3+}$ at the prevailing $\mathrm{pH}$. This causes a gradual depletion of iron in the upper part of the $B$ horizon, and consequently an enrichment in the lower part while the precipitation of organic matter in the upper part of the B horizon is more dependent on aluminum. Thus, instead of the Bh horizon forming on top of a Bhs horizon, it may form by differentiation of the Bhs horizon.

Differences in $\mathrm{pH}$ or in organic matter composition may cause differences in preferential complexation, so that the places of aluminum and iron maxima are exchanged. In the well-drained podzols of this investigation, however, a $\mathrm{Bh}$ horizon always has less iron than the underlying Bhs.

The formation of lamellae or fibres with humus and sesquioxides below $\mathrm{Bh}$ and $\mathrm{Bs}$ horizons is not explained by the precipitation of humus upon increasing saturation with sesquioxides. Because the $c_{p} /$ ses $p$ ratios of the fibers are lower than those in the $E$ and $B$ horizons (Table 4, Figure 6,7) of the same profiles, it is likely that either a different mechanism is involved in the precipitation of the fibers, or the composition of the organic matter in the fibers is different and has different complexation properties. Possibly, this organic matter is not primarily precipitated by sesquioxides, but immobilized physically. Organic matter may have percolated through the soil with water, and come to a stand still with the water front. When the soil dries out, the soluble substances are precipitated. This would explain the irregular shape of humus fibers in homogeneous sediments, and the tendency to accumulate at textural changes, slips, and other unconformities that hamper percolation of water. 
Tabel 4 Carbon/aluminum atomic ratios for separating eluvial and illuvial horizons in Orthic/Humic and Gleyic Podzols.

\begin{tabular}{|c|c|c|c|c|}
\hline \multirow[t]{2}{*}{ Ratio } & \multicolumn{2}{|c|}{ Orthic/Humic } & \multicolumn{2}{|c|}{ Gleyic } \\
\hline & Separation & Value & Separation & Value \\
\hline$c_{t /} A_{p}$ & good & \pm 45 & good & \pm 40 \\
\hline & fair & \pm 35 & poor & - \\
\hline $\mathrm{C}_{\mathrm{p}} / \mathrm{Al}$ & good & \pm 40 & good & \pm 30 \\
\hline $\mathrm{C}_{\mathrm{t}} / \mathrm{AI} \mathrm{d}$ & fair & $40-45$ & fair & \pm 40 \\
\hline $\mathrm{C}_{\mathrm{t}} / \mathrm{Al} \mathrm{o}_{\mathrm{o}}$ & good & $45-55$ & good & \pm 40 \\
\hline $\mathrm{C}_{\mathrm{h}} / \mathrm{Al}_{\mathrm{d}}$ & poor & - & fair & \pm 30 \\
\hline $\mathrm{C}_{\mathrm{h}} / \mathrm{Al}{ }_{\mathrm{o}}$ & good & $35-40$ & poor & - \\
\hline
\end{tabular}

Table 5 Linear regression and correlation between $C_{t}$ and $C_{p}$ and $C_{t}$ and $C_{h}$.

\begin{tabular}{llll}
\hline & $\mathrm{n}$ & & $\mathrm{r}^{2}$ \\
A) for all A-horizons & 39 & $\mathrm{C}_{\mathrm{p}}=0.35+0.18 \mathrm{C}_{\mathrm{t}}$ & 0.80 \\
and E-horizons & 81 & $\mathrm{C}_{\mathrm{p}}=0.08+0.86 \mathrm{C}_{\mathrm{t}}$ & 0.96 \\
$\begin{array}{l}\text { for all B- and } \\
\mathrm{C}-\text { horizons }\end{array}$ & 39 & $\mathrm{C}_{\mathrm{h}}=0.14+0.42 \mathrm{C}_{\mathrm{t}}$ & 0.81 \\
C) for all A- and \\
$\begin{array}{l}\text { E-horizons } \\
\text { for all B- and } \\
\text { C-horizons }\end{array}$ & 81 & $C_{h}=0.06+0.73 C_{t}$ & 0.93 \\
\hline
\end{tabular}

Table 6 Linear regression and correlation between $\mathrm{CEC}_{8.2}$ and carbon contents.

\begin{tabular}{llll}
\hline & & & $\mathrm{r}^{2}$ \\
A) for all profiles & 120 & $\mathrm{CEC}_{8.2}=0.81+8.80 \mathrm{C}_{\mathrm{p}}$ & 0.86 \\
and all horizons & 120 & $\mathrm{CEC}_{8.2}=2.98+4.76 \mathrm{C}_{\mathrm{t}}$ & 0.61 \\
& 120 & $\mathrm{CEC}_{8.2}=1.50+8.83 \mathrm{C}_{\mathrm{h}}$ & 0.76 \\
B) as for A) less all & 102 & $\mathrm{CEC}_{8.2}=0.64+8.27 \mathrm{C}_{\mathrm{t}}$ & 0.87 \\
$\begin{array}{l}\text { A-horizons } \\
\text { C) for dry podzols only }\end{array}$ & & & \\
and all horizons & 70 & $\mathrm{CEC}_{8.2}=0.89+8.53 \mathrm{C}_{\mathrm{p}}$ & 0.87 \\
\hline
\end{tabular}




\subsection{CEC-ORGANIC CARBON RELATIONS}

Since the podzols investigated are very low in clay content, it is assumed that the CEC in these soils is mainly due to organic matter and sesquioxides. In horizons where ses ${ }_{p}$ equals ses $d^{\prime}$ which is the case in the $E$ and $B$ horizons of Gleyic Podzols, and in some of the $E$ and $B$ horizons of Orthic and Humic Podzols from the Netherlands and Belgium, the CEC can be fully attributed to organic matter alone. Both CEC at soil pH and CEC at $\mathrm{pH} 8.2$ were determined $\left(\mathrm{CEC}_{\text {soil }}\right.$, resp. $\left.\mathrm{CEC}_{8.2}\right)$.

To decide which organic carbon fraction would most likely be highly correlated with CEC, correlations between $\left(c_{t}\right.$ and $\left.c_{p}\right)$ and $\left(C_{t}\right.$ and $\left.c_{h}\right)$ were calculated (Table 5). Any relation between $C_{p}$ and $C_{h}$ was considered to originate from the preceding relations and was therefore not calculated.

All correlations are significant at the $0.01 \%$ probability level. Both in the $c_{p}-c_{t}$ regression correlation and in the $c_{h}-c_{t}$ regression correlation, correlations are better for the $B$ and $C$ horizons than for $A$ and $E$ horizons, which is probably due to a relatively high and variable root content in $A$ and $E$ horizons. In the $B$ and $c$ horizons, the $c_{p}-c_{t}$ correlation is better than the $C_{h}-C_{t}$. Pyrophosphate extracts more organic matter from these horizons than hydroxide.

Regression of cation exchange capacities with $c_{t}, c_{h}$ and $c_{p}$ respectively showed that $C_{\text {soil }}$ had a much lower correlation than $C_{8 C}, 2$ (Table 6, only regressions between $\mathrm{CEC}_{8.2}$ and carbon contents are shown). Intra-profile correlations for $\mathrm{CEC}_{\text {soil }}$ were higher than the correlation over all profiles. The facts that 1) contents of sesquioxides vary more strongly within profiles than between profiles and 2 ) sesquioxides have a higher negative charge at high $\mathrm{pH}$ suggest that sesquioxides are of minor importance for the CEC of the podzols investigated. This is corroborated by an estimate of the maximum contribution of sesquioxides to the $\mathrm{CEC}_{\mathrm{B.2}}$ : maximum amounts of sesquioxides encountered in the $B$ horizons of any profile is about $1 \%$. If no sesquioxides were bound by organic matter they might account for a maximum CEC of about $0.35 \mathrm{me} / 100 \mathrm{~g}$ (Parfitt, 1980). This is negligible compared to the CEC determined in these horizons. The variations in $\mathrm{CEC}_{\text {soil }}$ and its relatively low correlation with organic carbon content should therefore probably be explained by the variation of te charge of organic matter with $\mathrm{pH}$ (the soil-pH varies per sample, viz. $\mathrm{pH}-\mathrm{kCl})$. Of the $\mathrm{CEC}_{8.2}-\mathrm{C}$ regressions, $\mathrm{CEC}_{8.2} \mathrm{C}_{\mathrm{p}}$ gives the best correlation (Table 6 ). The $\mathrm{CEC}_{8.2}-\mathrm{C}_{t}$ correlation is significantly lower but becomes much better when $A$ horizons are excluded. This again points to the inclusion of inactive organic material in the $c_{t}$ determination. As correlation with $c_{p}$ is better than with $c_{h}$ it is concluded that $c_{p}$ more closely represents the active organic fraction than does $c_{h}$.

From the high correlation between $c_{p}$ and $C_{8.2}$ it can be concluded that throughout the podzol profile and between various podzol profiles, the organic matter has a fairly constant $\mathrm{CEC}_{\mathbf{8 . 2}}$ per gram $\mathrm{C}$. Trends with depth 


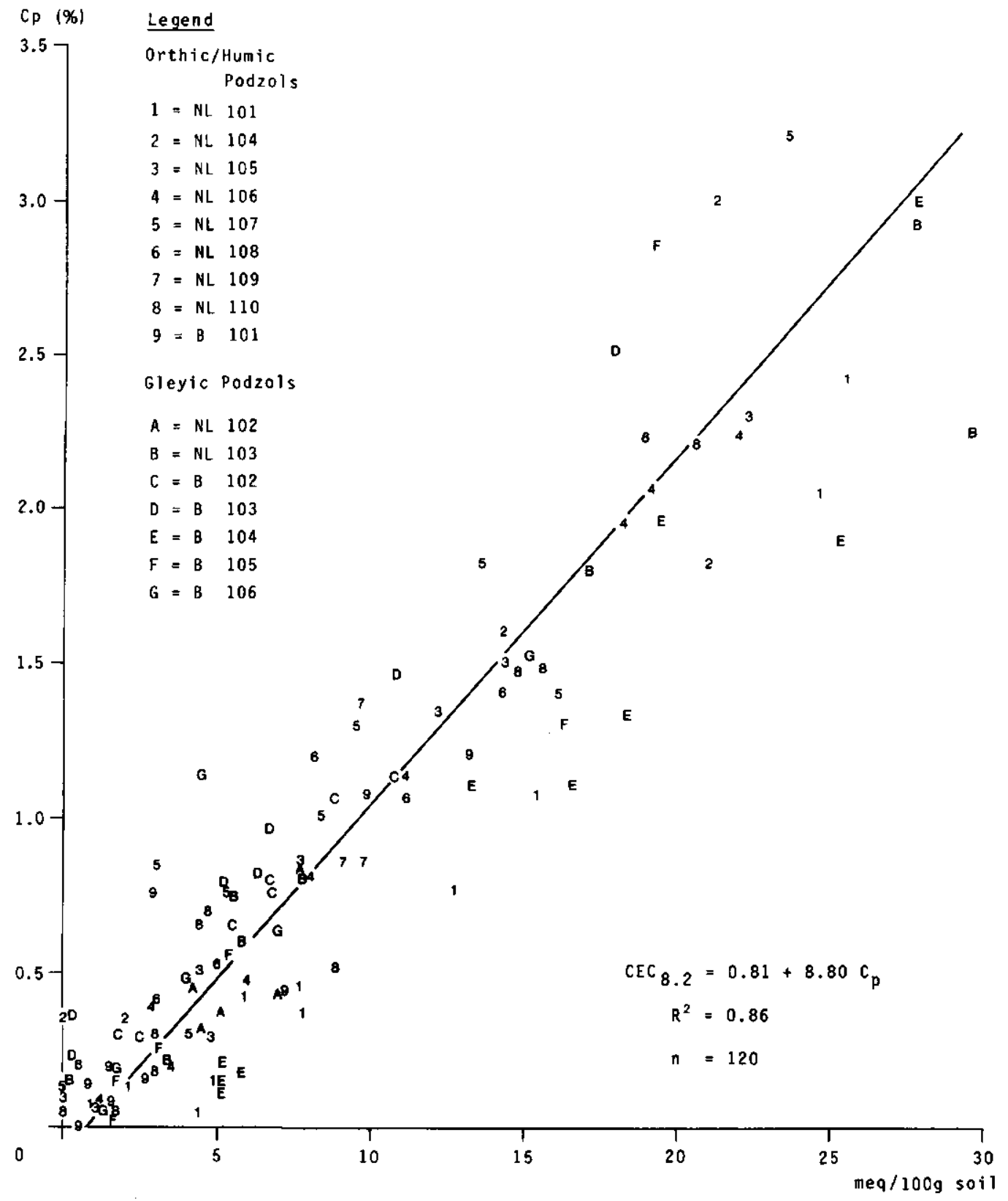

Figure 9. Regression of $\mathrm{CEC}_{8.2}$ with $C_{p}$ for all samples 
are illustrated in Figure 8 for both $\mathrm{CEC}_{\mathrm{soil}}$ and $\mathrm{CEC}_{\mathbf{8 . 2}}$. Mean values are 3-4 meq/g $C_{p}$ at soil $\mathrm{pH}$ and $8-10 \mathrm{me} / \mathrm{g} \mathrm{C}_{\mathrm{p}}$ at $\mathrm{pH} 8.2$. There is no distinct trend of CEC with depth, although fibers tend to have a higher CEC/C than the horizon in which they are found. No differences are found between Bumic and Orthic Podzols on one hand and Gleyic Podzols on the other. Extremely high CEC/C values occur when both CEC and $\mathrm{C}$ figures are low. Such ratios are therefore less reliable. The regression between $\mathrm{CEC}_{8.2}$ and $\mathrm{C}_{\mathrm{p}}$ is illustrated in Figure 9.

\subsection{IMOGOLITE}

Imogolite was not detected in the fine clay and clay fractions of the samples examined. This is in contrast to the imogolite found in spodic horizons in Scotland and Canada (Tait et al., 1978; Ross and Kodama, 1979; Farmer et al., 1980; Ross, 1980; McKeague and Kodama, 1981). Possible explanations for this difference are the occurrence of imogolite in the parent material, the addition of volcanic ash to the soils, and the formation of imogolite after transport of aluminum to the $B$ horizons. In the scottish soils studied by Farmer et al. (1980) imogolite was present in the $C$ horizon or in the deepest horizon samples in the three profiles with imogolite in the B horizons. In the profile without imogolite'in the $\mathrm{C}$ horizon, no imogolite was found in the B horizon. In the Scottish soils studied by rait et al. (1978) one podzol had no imogolite in the $\mathrm{B}$ horizon and no $\mathrm{C}$ horizons were examined. The soils in the Canadian studies were from British columbia and only B horizons were examined (Ross and Kodama, 1979; Ross, 1980; Mckeague and Kodama, 1981). Volcanic ash was detected in the sand fraction of the two soils studied by Ross and Kodama (1979).

Another contrast between the soils of this study and those reported in literature is in the $\mathrm{Al}_{0}$ content. In only six soils was the $\mathrm{Al}_{0}$ content of the B horizons greater than $1 \%$ and in two of these soils the $\mathrm{Al}_{\mathrm{p}}$ content was also relatively high. The $B$ horizons of these six soils also have relatively high organic carbon contents which may inhibit the formation of imogolite (Tait et al., 1978). This indicates that the B horizons of most of these soils do not have much amorphous $A l$ which is not organically bound. In the Canadian and some of the Scottish soils the $\mathrm{Al}$ o contents were high, greater than 1\% (Tait et al., 1978; Ross and Kodama, 1979; Ross, 1980; Mckeague and Kodama, 1981). Farmer et al. (1980) found acetic acid extracted much more Al than did EDTA. This indicates that most of the canadian and scottish soils have large amounts of amorphous $\mathrm{Al}$.

It is possible that the imogolite formed in those B horions after the Al had been deposited and released from the organic matter complex. This would explain the absence of imogolite in any of the eluvial horizons and in the upper B horizons of several of the soils. On the other hand, if volcanic ash or its weathering products allophane and/or imogolite had been 
present in the parent material, these would certainly have been removed from the eluvial horizons by the podzolization process, and thus result in an absence of allophane in the eluvial and a presence in the illuvial and lower horizons. Certainly, in soils containing volcanic ash particles in the sand fraction, an explanation for the presence of imogolite should not be sought in the podzolization process. Furthermore, the present authors feel that the transport of aluminum as a silicate complex would not explain the coprecipitation of aluminum and organic matter. Nor is it likely that the transport mechanism for iron would be different from that for aluminum. The transport of iron would not be explained by the imogolite model.

\subsection{IRON CONTENT AND COLOR AFTER IGNITION}

Both the content of 'free' iron and color after ignition have been used to separate Gleyic Podzols from well-drained Podzols. Most classifications do not state a minimum iron content for well-drained podzols, nor are any definite criteria available for the amount of color change after ignition that should be present to call a sample 'redder'. In order to solve both problems and arrive at suitable criteria for the iron content and color for Gleyic Podzols and well-drained podzols, an effort was made to correlate both properties.

For this purpose it was necessary to attribute numerical values to Munsell color codes. This was done by attributing the value 1 to the color $2.5 Y$ $8 / 1$ (the strongest white color found in ignited samples) and adding 1 for the distance of one unit, both in horizontal (chroma) and vertical direction (value). Numerical values then read $1,2,3,4,6,8$ for $2.5 Y 8 / 1,8 / 2,8 / 3$, $8 / 4,8 / 6$ and $8 / 8$ respectively and for $8 / 1,7 / 1,6 / 1,5 / 1,3 / 1$ and $1 / 1$ respectively. Values within the matrix were obtained by multiplying the respective row and column values, e.g. the numerical value for $2.5 Y 4 / 5$ is $4 \times 4=16$. These values were multiplied by 2 for each redder hue. The resulting matrices are given in Table 7. Each numerical value can be otbained by several colors, e.g. the numerical value 96 stands for $7.5 \mathrm{YR} 6 / 8$ and $5 / 6 ; 5 Y R 7 / 6,6 / 4$ and $5 / 3 ; 2.5 \mathrm{YR} 8 / 6,7 / 3$ and $6 / 2$; and $10 \mathrm{YR} 8 / 3$ and $6 / 1$. Not all colors of the matrices occur in ignited samples. Those colors encountered are printed in italics.

Dithionite-citrate extractable iron plotted against the numerical color value of the ignited sample gives a population that can be divided into two subpopulations (Figure 10). One set of B horizon samples has numerical color values below 100 and free iron contents of less than $0.125 \%$. The second set of samples has color values above 100 and iron contents above $0.135 \%$. The population with the low contents contains $B$ horizons of podzols that have been classified in the field as 'Gleyic Podzols' and Bhl horizons of welldrained profiles. Color values of over 1000 are reached with iron contents as low as $0.5 \%$ in Bhs and Bs horizons. 
Table 7 Numerical values assigned to Munsell color codes.

Hue $2.5 Y$

\begin{tabular}{rrrrrrr}
\hline & $/ 1$ & $/ 2$ & $/ 3$ & $/ 4$ & $/ 6$ & $/ 8$ \\
\hline $8 /$ & 1 & 2 & 3 & 4 & 6 & 8 \\
$7 /$ & 2 & 4 & 6 & 8 & 12 & 16 \\
$6 /$ & 3 & 6 & 9 & 12 & 18 & 24 \\
$5 /$ & 4 & 8 & 12 & 16 & 24 & 32 \\
$4 /$ & 5 & 10 & 15 & 20 & 30 & 40 \\
\hline
\end{tabular}

Hue $7.5 Y R$

$/ 1 \quad / 2 \quad / 3 \quad / 4 \quad / 6 \quad / 8$

\begin{tabular}{rrrrrrr}
\hline $8 /$ & 4 & 8 & 12 & 16 & 24 & 32 \\
$7 /$ & 8 & 16 & 24 & 32 & 48 & 64 \\
$6 /$ & 12 & 24 & 36 & 48 & 72 & 96 \\
$5 /$ & 16 & 32 & 48 & 64 & 96 & 128 \\
$4 /$ & 20 & 40 & 60 & 80 & 120 & 160
\end{tabular}

Hue $2.5 Y R$

\begin{tabular}{rrrrrrr}
\hline & $/ 1$ & $/ 2$ & $/ 3$ & $/ 4$ & $/ 6$ & $/ 8$ \\
\hline $8 /$ & 16 & 32 & 48 & 64 & 96 & 128 \\
$7 /$ & 32 & 64 & 96 & 128 & 192 & 256 \\
$6 /$ & 48 & 96 & 144 & 192 & 288 & 384 \\
$5 /$ & 64 & 128 & 192 & 256 & 384 & 512 \\
$4 /$ & 80 & 160 & 240 & 320 & 480 & 640
\end{tabular}

Hue 10YR

\begin{tabular}{rrrrrrr}
\hline & $/ 1$ & $/ 2$ & $/ 3$ & $/ 4$ & $/ 6$ & $/ 8$ \\
\hline $8 /$ & 2 & 4 & 6 & 8 & 12 & 16 \\
$7 /$ & 4 & 8 & 12 & 16 & 24 & 32 \\
$6 /$ & 6 & 12 & 18 & 24 & 36 & 48 \\
$5 /$ & 8 & 16 & 24 & 32 & 48 & 64 \\
$4 /$ & 10 & 20 & 30 & 40 & 60 & 80 \\
\hline
\end{tabular}

Hue 5YR

$/ 1 \quad / 2 \quad / 3 \quad / 4 \quad / 6 \quad / 8$

\begin{tabular}{rrrrrrr}
\hline $8 /$ & 8 & 16 & 24 & 32 & 48 & 64 \\
$7 /$ & 16 & 32 & 48 & 64 & 96 & 128 \\
$6 /$ & 24 & 48 & 72 & 96 & 144 & 192 \\
$5 /$ & 32 & 64 & 96 & 128 & 192 & 256 \\
$4 /$ & 40 & 80 & 120 & 160 & 240 & 320
\end{tabular}

Hue 10R

\begin{tabular}{|c|c|c|c|c|c|c|}
\hline & $/ 1$ & $/ 2$ & $/ 3$ & 14 & 16 & 18 \\
\hline $8 /$ & 32 & 64 & 96 & 128 & 192 & 256 \\
\hline 71 & 64 & 128 & 192 & 256 & 384 & 512 \\
\hline $6 /$ & 96 & 192 & 288 & 384 & 576 & 768 \\
\hline $5 /$ & 128 & 256 & 384 & 512 & 768 & 1024 \\
\hline $4 /$ & 160 & 320 & 480 & 640 & 960 & 1280 \\
\hline
\end{tabular}




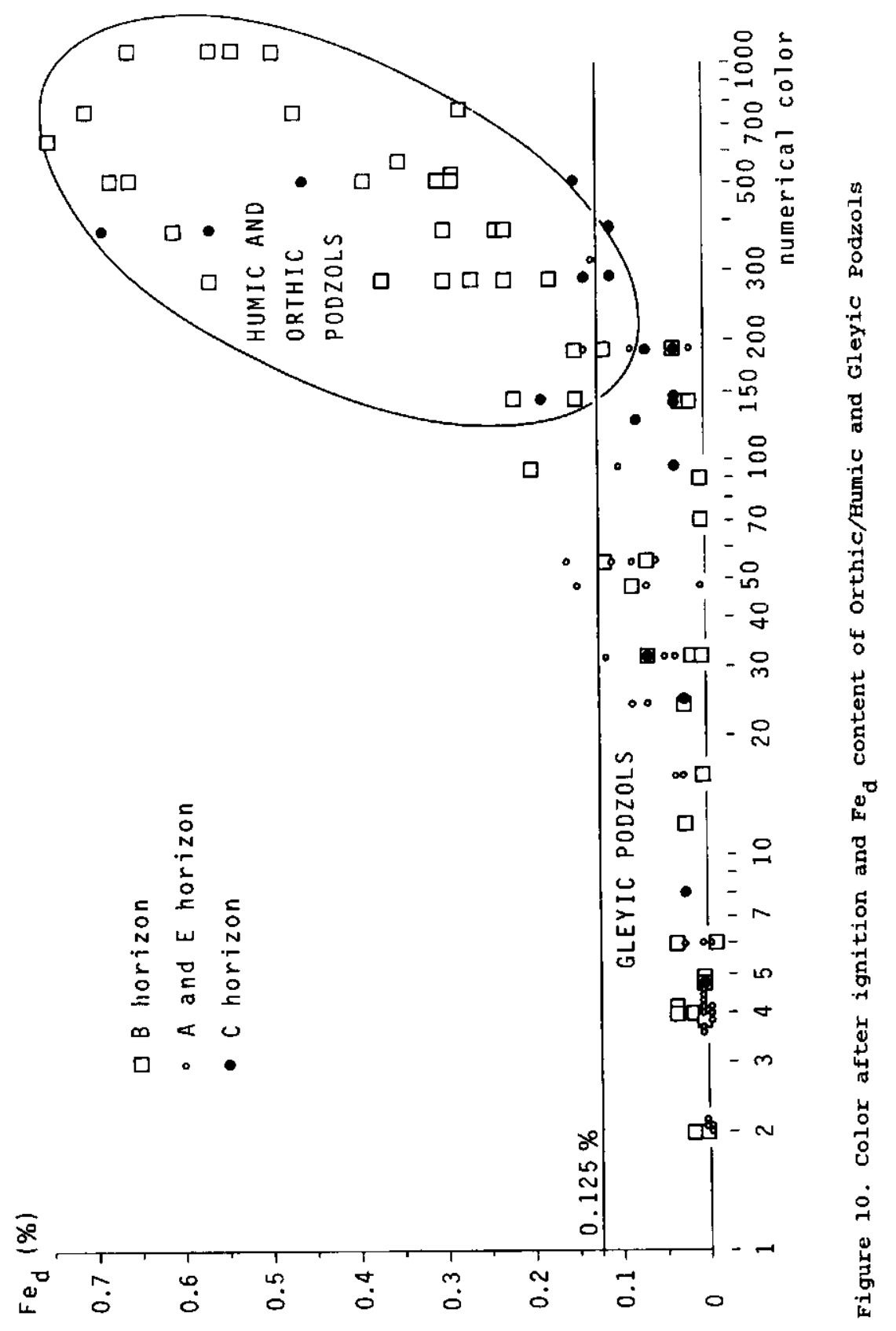


It appears that color after ignition and iron content of the sample are well-correlated and that either a free iron content of $<0.12 \%$ or a numerical color value of less than 150 would serve to define the Gleyic Podzol profiles 'that lack iron coatings'.

\subsection{SPODIC HORIZON CRITERIA}

Tables 8,9 and 10 summerize the data used to classify the soils into the FAO-Unesco system (FAO-Unesco, 1974) and Soil Taxonomy (Soil survey staff, 1975). Most of the soils studied had the morphology of a spodosol or a Podzol; however, several soils did not classify as spodosol or Podzols according to these systems.

Because the spodic horizon is considered as a horizon having an illuvial accumulation of organic matter and aluminum, with or without iron, it was decided to concentrate on these three properties to develop new criteria with which to define the spodic horizon. Pyrophosphate is generally considered to extract $\mathrm{Al}$ and $\mathrm{Fe}$ bound to organic matter. By complexing $\mathrm{Al}$ and Fe pyrophosphate makes the organic matter soluble. Therefore it was concluded that pyrophosphate extractable $C, A l$ and Fe would be the best properties on which to define the spodic horizon.

The chemical criteria for defining the spodic horizon were developed based on the data collected from the soils sampled in the Netherlands, Belgium and switzerland (Table 8). It was assumed that a B horizon with a 7.5YR $4 / 4$ color would morphologically qualify as a spodic horizon, a B horizon with a 1OYR 4/4 color would sometimes qualify as a spodic horizon, a $B$ horizon with a $5 / 4$ color or lighter would not qualify. B horizons with a $7.5 Y R$ $4 / 4$ color had $\mathrm{C}_{\mathrm{p}}+\mathrm{Al}_{\mathrm{p}}+\mathrm{Fe}_{\mathrm{p}} \geq 0.50$ and $\mathrm{B}$ and $\mathrm{C}$ horizons with a 10YR 5/4 color or lighter and no mottles had $C_{p}+\mathrm{Al}_{p}+\mathrm{Fe} p \leq 0.42$. Two $\mathrm{BC}$ horizons with lOYR $4 / 4$ color had $C_{p}+A_{p}+F e_{p}$ of 0.76 and 0.36 .

From this it was concluded the minimal value of $C_{p}+A_{p}+F e$ for a spodic horizon should be 0.50 .

In Gleyic Podzols without mottling, $\mathrm{B}$ horizons have $\mathrm{C}_{\mathrm{p}} / \mathrm{Fe}$ atomic ratios greater than 150 and in Humic and Orthic Podzols B horizons have ratios less than 150. The $\mathrm{C}_{\mathrm{p}} /\left(\mathrm{Al} \mathrm{p}_{\mathrm{p}}+\mathrm{Fe}_{\mathrm{p}}\right)$ atomic ratios of $\mathrm{B}$ horizons in Gleyic Podzols were less than 30.0 and those of $B$ horizons in Humic and orthic Podzols were

less than 26.0 .

The amount and distribution of amorphous material varies greatly in spodic horizons. Some horizons have large amounts in thin horizons and others have small amounts in thick horizons. Therefore a minimum accumulation of amorphous materials must be defined. The minimum $C_{p} /\left(A l_{p}+F_{p}\right)$ atomic ratio was taken as 5.8 , which is the value between the highest $C_{p} /\left(A 1_{p}+\mathrm{Fe}_{p}\right)$ atomic ratios in the two Swiss soils, one having the morphology of a spodosol or Podzol and the other not (Table 8$)$. Also, the minimum $C_{p} /\left(A l_{p}+F_{p}\right.$ ) atomic ratio in most subhorizons of the B horizons was 5.8 . The minimal thickness 


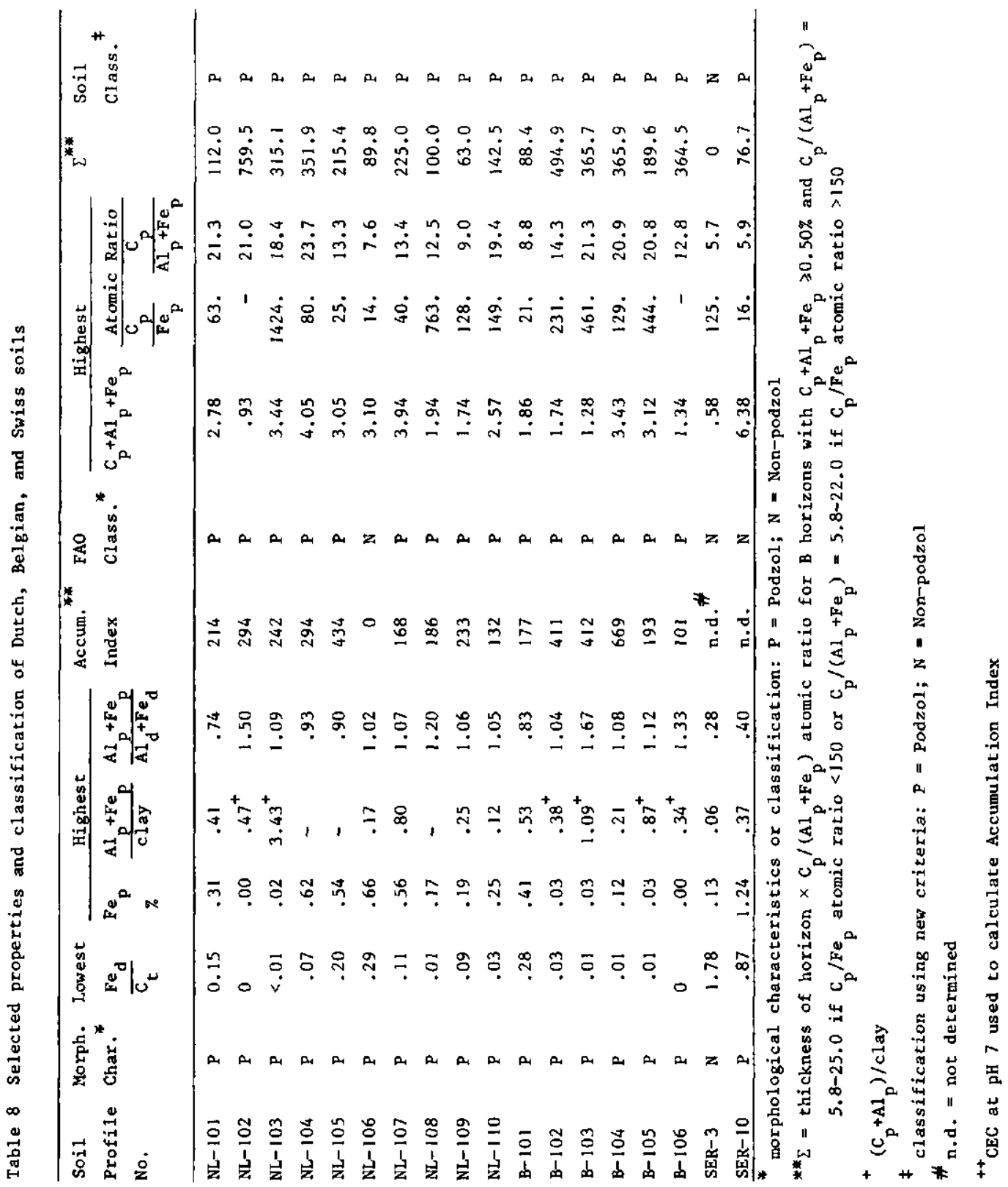




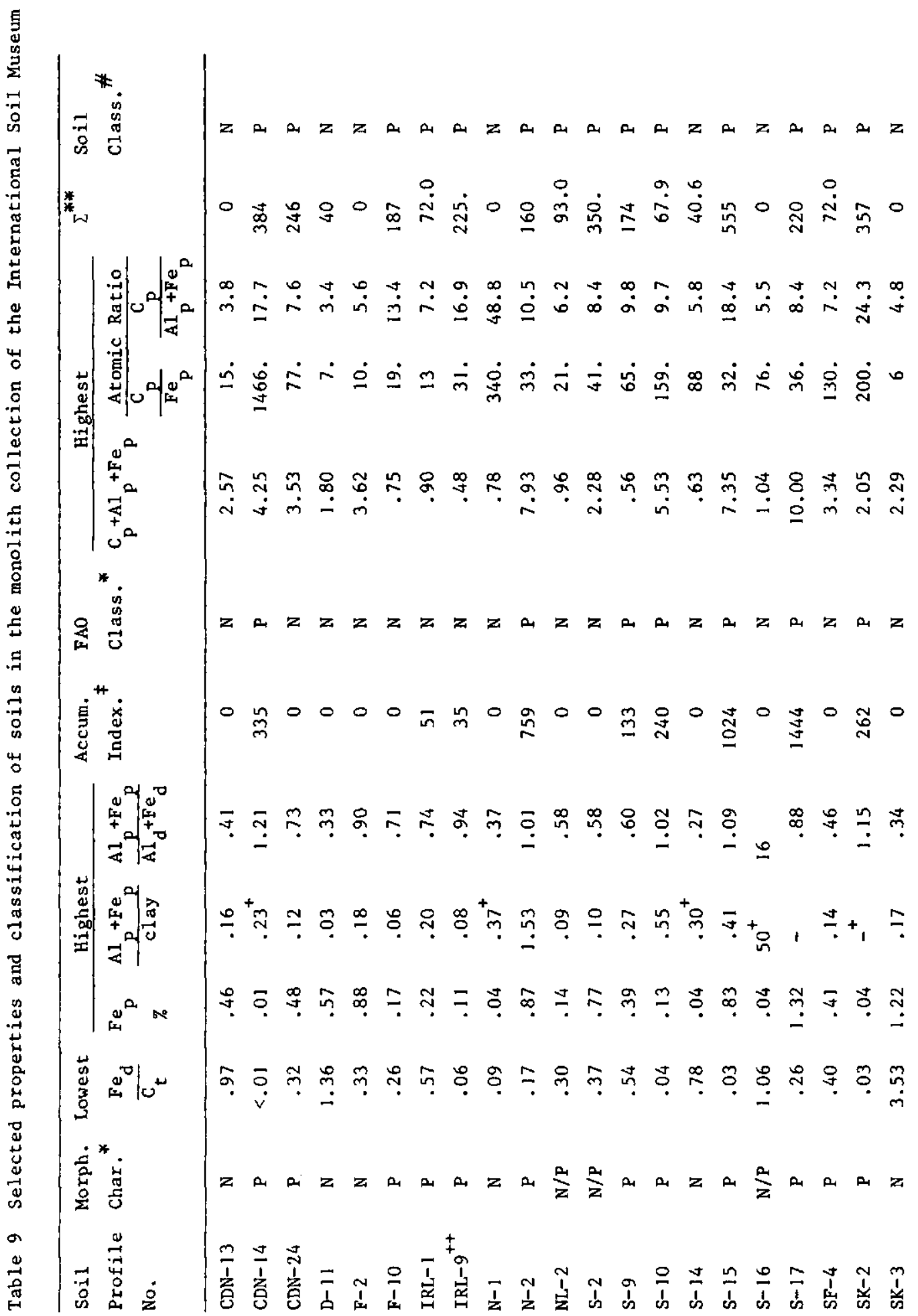




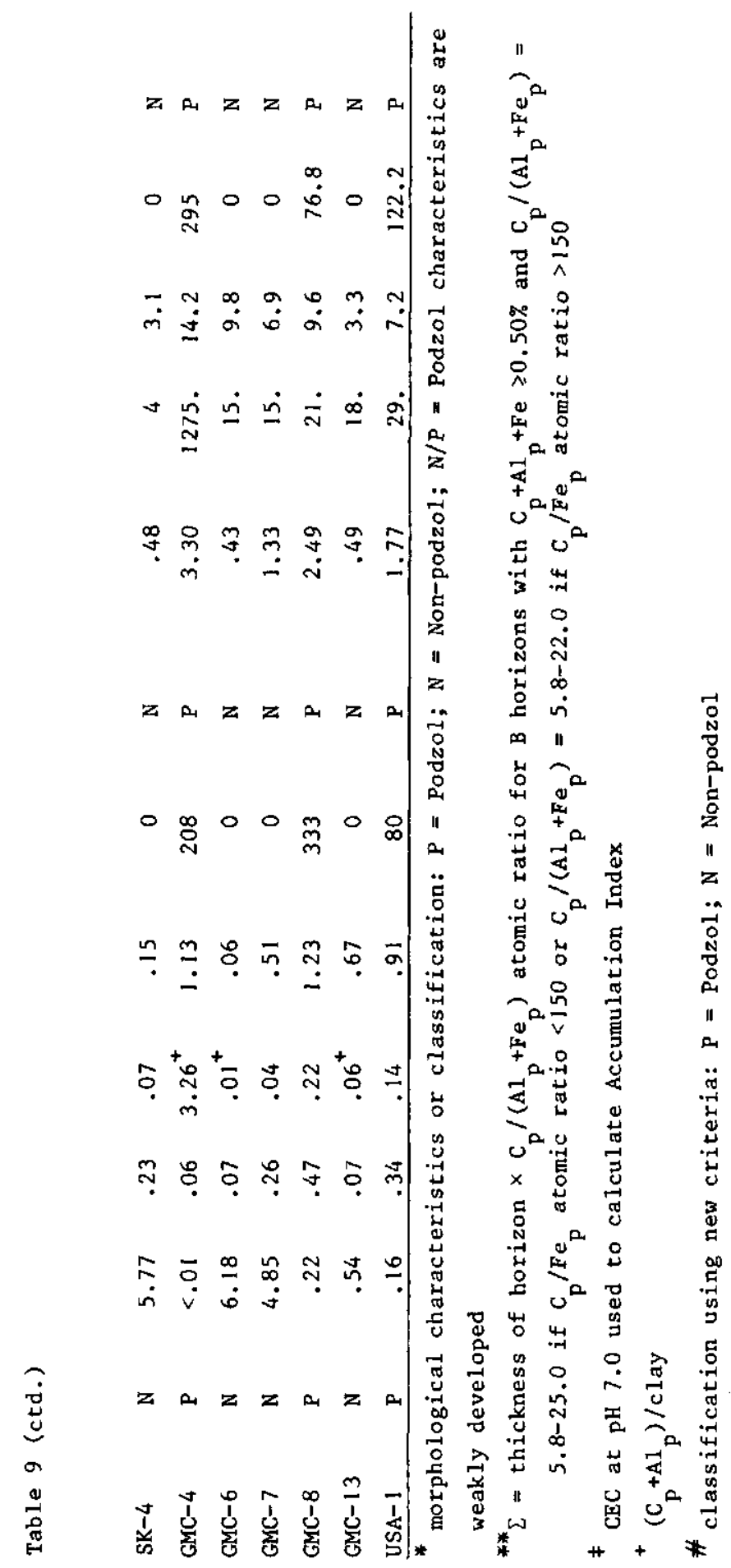




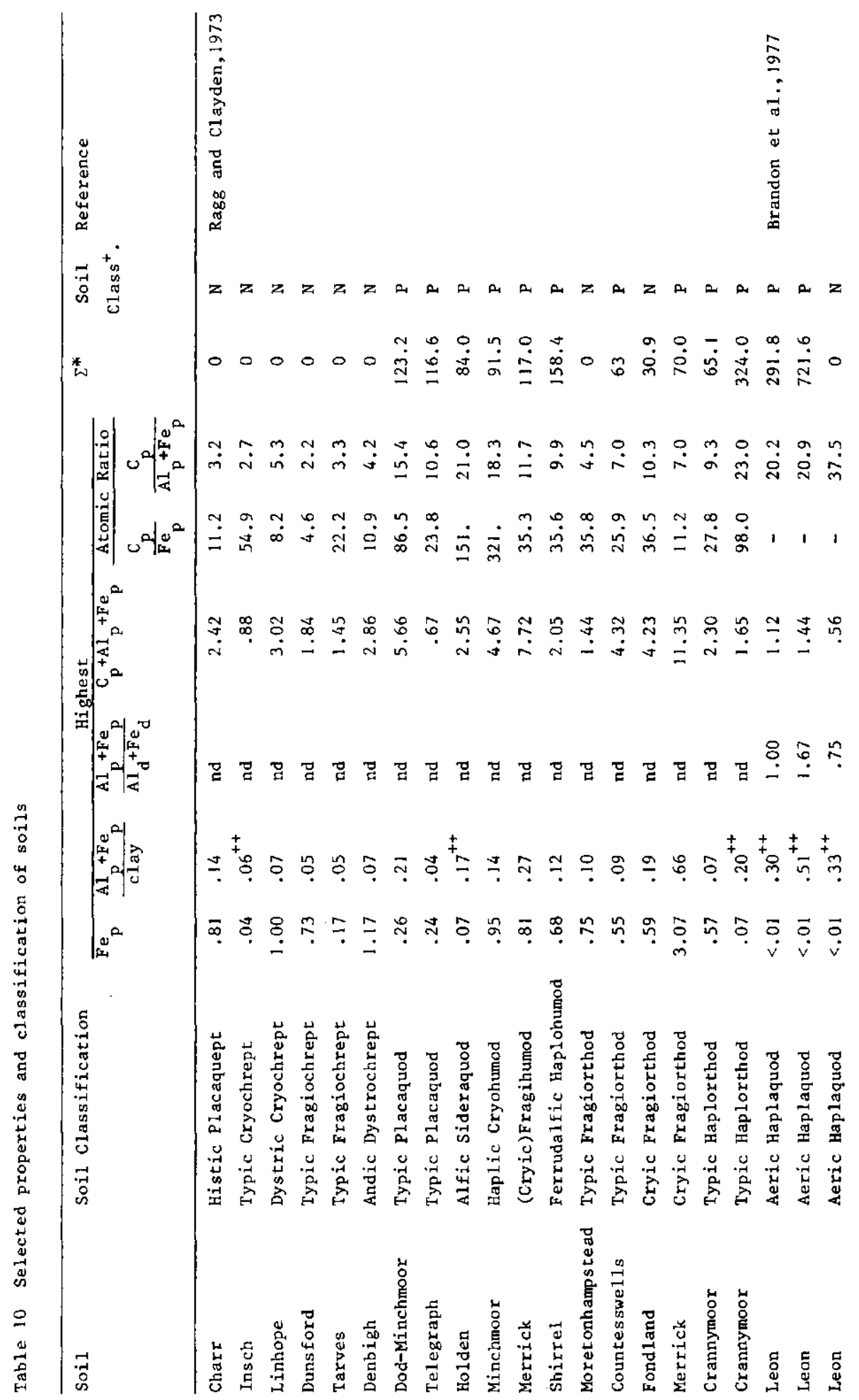




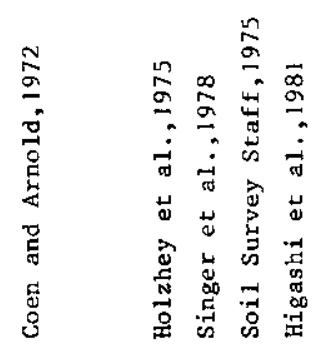

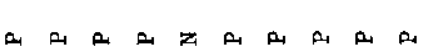

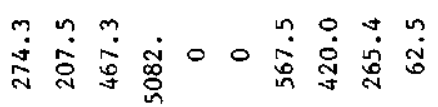

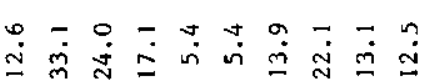

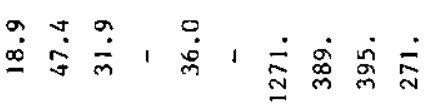

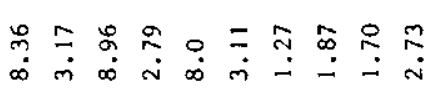

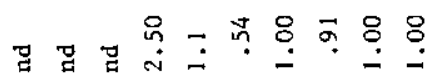

ปี

กี ํํㄹ

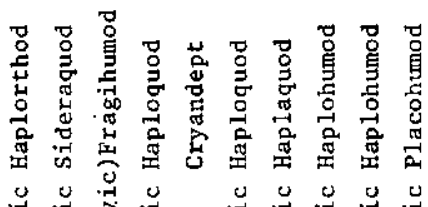

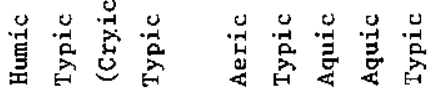

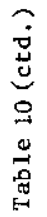
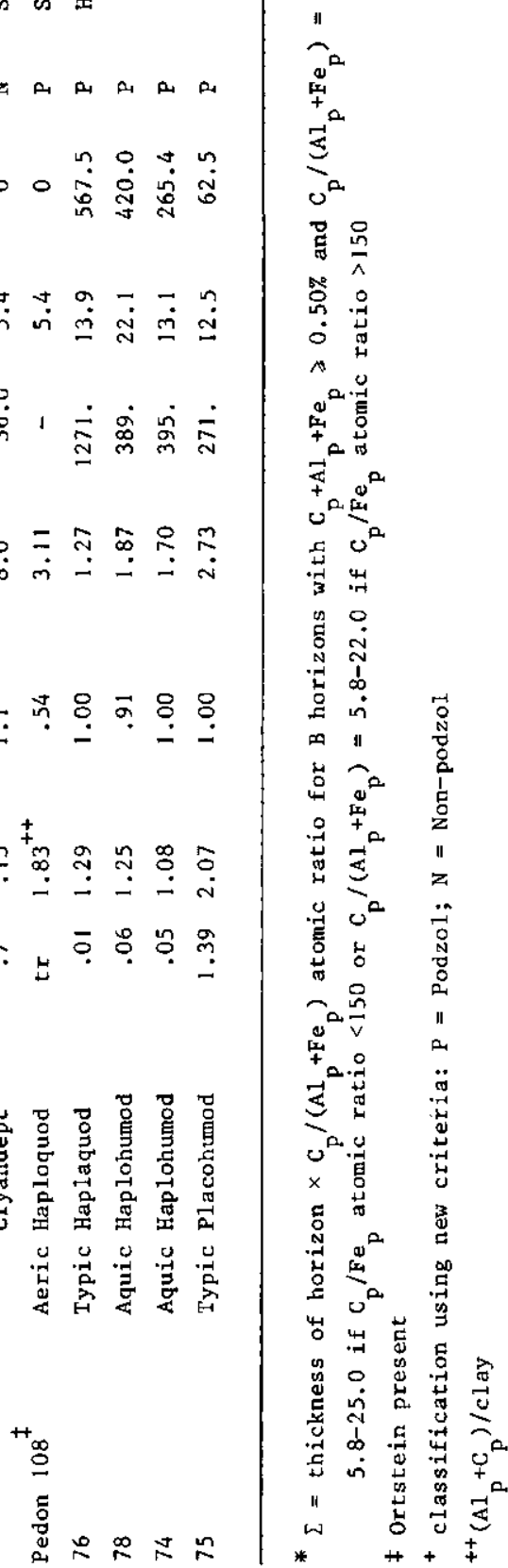
of a spodic horizon was taken to be $10 \mathrm{~cm}$ which is used in the Canadian (Canada soil survey Committee, 1978) and English (Avery, 1980) systems. Therefore the sum of the products $\mathrm{C}_{\mathrm{p}} /\left(\mathrm{Al} \mathrm{p}_{\mathrm{p}}+\mathrm{Fe}_{\mathrm{p}}\right)$ atomic ratio and horizon thickness must exceed 58 .

In summary, the proposed chemical requirements for a spodic horizon are:

1. $\mathrm{C}_{p} /\left(\mathrm{Al} p+\mathrm{Fe}_{\mathrm{p}}\right) \geq 0.50 \%$;

2. $\mathrm{C}_{\mathrm{p}} /\left(\mathrm{Al} \mathrm{p}+\mathrm{Fe}_{\mathrm{p}}\right)$ atomic ratio $=5.8$ to 30.0 if $\mathrm{C}_{\mathrm{p}} / \mathrm{Fe}_{\mathrm{p}}$ atomic ratio $>150$, or

5.8 to 26.0 if $\mathrm{C}_{\mathrm{p}} / \mathrm{Ee}_{\mathrm{p}}$ atomic ratio $<150$

and

3. Sum of horizon thickness $\mathrm{x} \mathrm{C}_{\mathrm{p}} /\left(\mathrm{Al} \mathrm{l}_{\mathrm{p}}+\mathrm{Fe} \mathrm{p}_{\mathrm{p}}\right)$ atomic ratio $\geq 58$, for $\mathrm{B}$ horizons with 1 and 2 above.

All soils in Table 8 with podzol morphology meet these requirements and the one soil without podzol morphology did not meet these requirements.

The criteria were tested by applying them to the soils in the ISM monolith collection (Table 9). All soils with definite podzol morphology meet the requirements and two of the three soils with weak podzol morphology meet the requirements. Soils that did not have a podzol morphology did not meet the requirements.

The criteria were further tested by applying them to soils which have been reported in Iiterature (Table 10). The soils were limited to those which had been classified according to soil Taxonomy and had been analyzed for $\mathrm{C}_{\mathrm{p}}, \mathrm{Al}_{\mathrm{p}}$ and $\mathrm{Fe}_{\mathrm{p}}$. Of the 24 soils classified as spodosols by the authors eight did not have $\left(A l_{p}+F e_{p}\right) / C l a y$ or $\left(C_{p}+A l_{p}\right) / c l a y$ equal to or greater than 0.20 and should not have been classified as spodosols. When using the proposed criteria only four soils fail to meet the chemical criteria for spodic horizon and one of these soils has an ortstein which is sufficient to classify it as a spodosol. None of the Inceptisols, including the Cryandept, meet the proposed criteria for spodic horizon.

Note that the present proposal does not use the ratios of amorphous matter to clay. 


\section{Conclusions}

1. Precipitation of organic matter in the $B$ horizon in both orthic/Humic and in Gleyic Podzols is regulated by aluminum rather than iron.

2. Total carbon is not an appropriate measure for the active organic matter in podzols. Pyrophosphate extractable carbon $\left(C_{p}\right)$ gave better correlations with CEC than either total carbon or sodium hydroxide extractable carbon. Therefore, $c_{p}$ is considered to represent more closely the chemically active fraction.

3. Carbon/metal atomic ratios can be used to separate illuvial and eluvial horizons in podzols. of $\mathrm{C} / \mathrm{Al}, \mathrm{C} / \mathrm{Fe}$ and $\mathrm{C} /$ Sesquioxide atomic ratios, the $\mathrm{C} / \mathrm{Al}$ ratios and, more specifically, the $\mathrm{C}_{\mathrm{p}} / \mathrm{Al}_{\mathrm{p}}$ (pyrophosphate extractable carbon to pyrophosphate extractable aluminum) and $\mathrm{C}_{t} / \mathrm{Al}_{\mathrm{p}}$ (total carbon to $C_{p}$ ) atomic ratios are most suitable for this separation. The presence of roots in the $B$ horizon appears not to influence these ratios. Pelletal humus formed from decaying roots in the $B$ horizon appears to have the same chemical characteristics as organic matter in organans.

4. Organic matter in podzols is mobile at $\mathrm{C}_{p} / \mathrm{Al} p$ atomic ratios above 30 (Gleyic Podzols) or 40 (Orthic/Humic Podzols), and immobilized at lower ratios.

5. $\mathrm{C} / \mathrm{Fe}$ atomic ratios do not provide a good separation between illuvial and eluvial horizons in either orthic/Humic or Gleyic Podzols. Humic/ orthic podzols can be separated from Gleyic podzols that are poor in iron (no mottles) by a $\mathrm{C}_{\mathrm{p}} / \mathrm{Fe}_{\mathrm{p}}$ atomic ratio of 150 . In Gleyic Podzols all subhorizons in the $B$ horizons have ratios above 150; in Humic/Orthic Podzols, at least some subhorizon of the $B$ has a ratio lower than 150 .

An iron content of more than $0.12 \%$ (dithionite extractable) was found to suffice for the sample to turn redder upon ignition.

6. Although $\mathrm{C} /$ Sesquioxide ratios are less suitable for separating illuvial and eluvial horizons than are $\mathrm{C} / \mathrm{Al}$ ratios, the $\mathrm{C}_{\mathrm{p}} / \mathrm{ses}_{\mathrm{p}}$ ratio is useful for identifying a spodic horizon. A minimum $c_{p} /$ Ses $p$ ratio of 5.8 in the B horizon, which represents an estimate of the maximum amount of metal bound per unit $C$, can be used to define an accumulation index. The proposed criteria for a spodic horizon are as follows:

a. $\mathrm{C}_{p}+\mathrm{Al}_{\mathrm{p}}+\mathrm{Fe}_{\mathrm{p}}: \geq 0.50 \%$

b. $\mathrm{Cp} / \mathrm{Sesp}$ atomic ratio is higher than 5.8 but lower than 40 in at least one subhorizon of the $B$ (spodic horizon)

c. The accumulation index should exceed 58 . The accumulation index is defined as thickness $(\mathrm{cm}) \times \mathrm{c}_{\mathrm{p}} /$ Ses $_{\mathrm{p}}$ atomic ratio. 
7. The gradual deepening of the podzol profile and the differentiation of the $B$ horizon into $B h$ and $B s$ can be explained by redissolution of the upper part of the B horizon by added unsaturated organic compounds, and a preference of these compounds for Fe, while precipitation is regulated by $A 1$. The $B h$ and $B s$ horizons thus form by differentiation within the $B$ horizon and not because the Bh precipitated on top of the Bs horizon.

8. Fibers below the B horizon are not precipitated at the same $\mathrm{C} / \mathrm{metal}$ ratios as the organic matter in the $B$ horizon and saturation with metals may not play a crucial role in the precipitation of amorphous matter in fibers.

9. Imogolite does not play an essential part in the podzolization process. Although imogolite might be formed in B horizons, it is not instrumental in the transport of aluminum.

\section{Acknowledgements}

The authors thank the staff at the International Soil Museum for their co-operation and assistance in the laboratory work and the realization of this paper. We also thank Mr. Peter Oomens, Department of soil science and Geology, Agricultural university, for his help. D.L. Mokma thanks the International Agriculture Centre and the Department of soil science and Geology, Agriculture University for financial support during his stay in wageningen. 


\section{References}

Adams, W.A., M.A. Raza and L.J. Evans. 1980. Relationships between net redistribution of $\mathrm{Al}$ and $\mathrm{Fe}$ extractable levels in podzolic scils derived from Lower Palaeozoic sedimentary rocks. J. Soil Sci. 31:533-545.

Aguilera, N.H. and M.L. Jackson. 1953. Iron oxide removal from soils and clays. Soil Sci. Soc. Amer. Proc. 17:359-364.

Aleksandrova, L.N. 1960. The use of sodium pyrophosphate for isolating free humic substances and their organic-mineral compounds from soil. Soviet Soil Sci. no. 2, p. 190-197.

Andriesse, J.P. 1969. A study of the environment and characteristics of tropical podzols in Sarawak (East-Malaysia). Geoderma 2:201-227.

Andriesse, J.P. 1970. The development of the podzol morphology in the tropical lowlands of Sarawak (Malaysia). Geoderma 3:261-279.

Anonymous. 1927. Soil science of USSR: collection of soils exposed in Washington in the year 1927. Leningrad. $31 \mathrm{pp}$.

Arbeitsgemeinschaft Bodenkunde. 1971. Kartieranleitung. Anleitung und Richtlinien zur Herstellung der Bodenkarte 1:25.000. 2nd ed. Bundesanstalt für Bodenforschung und Geologischen Landesämtern der Bundesrepublik Deutschland. Hanover, Germany. 169 pp.

Avery, B.W. 1973. Soil classification in the soil survey of England and Wales. J. Soil Sci. 24:324-338.

Avery, B.W. 1980. Soil classification for England and Wales (higher categories). Soil Surv. Tech. Monogr. No. 14. Harpenden, England. 67 pp.

Avery, B.W., B. Clayden, and J.M. Ragg. 1977. Identification of podzolic soils (Spodosols) in Upland Britain. Soil Sci. 123:306-318.

Bailey, G.D. 1980. A brief history of the Russian monoliths. Personal communication.

Baker, W.E. 1973. The role of humic acids from Tasmanian podzolic soils in mineral degradation and metal mobilization. Geochem. Cosmochim. Acta 37:269-281.

Baldwin, M., C.E. Kellogg and J. Thorp. 1938. Soil Classification. In: Yearbook Agr. U.S.D.A. Soils and Men. U.S. Govt. Printg. Off. Washington, D.C. p. 979-1001.

Ball, D.F. and P. Beaumont. 1972. Vertical distribution of extractable iron and aluminum in soil profiles from a Brown Earth-Peaty Podzol association. J. Soil Sci. 23:298-308.

Baril, R. and G. Britton. 1967. Anomalous values of free iron in some Quebec soils containing magnetite. Can. J. Soil Sci. 47:261.

Baril, R.W. and T.S. Tran. 1977. Etude sur la valeur des critères chimiques proposés par la commission pédologique du Canada pour la classification taxonomique des sols du Québec. Can. J. Soil Sci. 57:233-247.

Barshad, I. and L.A. Rojas-Cruz. 1950. A pedologic study of a podzol profile from the equatorial region of Colombia, South America. Soil Sci. 70:221-236.

Bascomb, C.L. 1964. Rapid method for the determination of cation-exchange capacity of calcareous and non-calcareous soils. J. Sci. Fd. Agric. 15:821-823.

Bascomb, C.L. 1968. Distribution of pyrophosphate-extractable iron and organic carbon in soils of various groups. J. Soil Sci. 19:251-268.

Bleackley, D. and E.J.A. Khan. 1963. Observations on the white-sand areas of the Berbice Formation, British Guiana. J. Soil Sci. 14:44-51. 
Bloonfield, C. 1963. Mobilization phenomena in soils. Rep. Rothamsted Exp. Sta. pp 226-239.

Blume, H.P. and U. Schwertmann. 1969. Genetic evaluation of profile distribution of aluminum, iron and manganese oxides. Soil Sci. Soc. Amer. Proc. 33:438-444.

Borggaard, O.K. 1976. Selective extraction of amoxphous iron oxide by EDTA from a mixture of amorphous iron oxide, goethite, and hematite. J. Soil Sci. $27: 478-486$.

Brammer, H, 1973. Podzols in Zambia. Geoderma 10:249-250.

Brandon, C.E., S.W. Buol, E.E. Gamble and R.A. Pope. 1977. Spodic horizon brittleness in Leon (Aeric Haplaquod) soils. Soil Sci. Soc. Amer. J. 41:951-954.

Bruckert, S. 1979. Classification des sols bruns ocreux et cryptopodzoliques par analyse des extraits tetraborates tamponnés à pH 9.5. Geoderma 22:205-212.

Bruckert, S. and Souchier. 1975. Mise au point d'un test de différenciation chimique des horizons cambiques et spodiques. C.R. Acad. Sci. Paris, Sér. D., 280:1361-1364.

Buurman, P., L. van der Plas and S. Slager. 1976. A toposequence of alpine soils on calcareous micaschists, northern Adula region, Switzerland. J. Soil Sci. $27: 395-410$.

Byers, H.G., C.E. Kellogg, M.S. Anderson and J. Thorpe. 1938. Formation of soil. In: Yearbook Agr. USDA. Soils and Men. U.S. Govt. Printg. Off. Washington D.C., p. 948-978.

Canada Soil Survey Committee. 1974. The system of soil classification for Canada. Can. Dept. Agric. Publ. 1455. Information Canada, Ottawa, Ont. 255 pp.

Canada Soil Survey Committee. 1978. The Canadian system of soil classification. Can. Dep. Agric. Publ. 1646. Supply and Services Canada, Ottawa, Ont. 164 pp.

Chandler, R.F., Jr. 1942. The time required for podzol profile formation as evidenced by the Mendenhall glacial deposits near Juneau, Alaska. Soil Sci. Soc. Amer. Proc. 7:454-459.

Chen, Y., N. Senesi and M. Schnitzer. 1978. Chemical and physical characteristics of humic and fulvic acids extracted from soils of the Mediterranean Region. Geoderma 20:87-104.

Clark, J.S., J.A. McKeague and W.E. Nichol. 1966. The use of pH-dependent cationexchange capacity for characterizing the B horizons of Brunisolic and Podzolic soils. Can. J. Soil Sci. 46:161-166.

Clark, J.S. and W.E. Nichol. 1968. Estimation of the inorganic and organic pH-dependent cation exchange capacity of the $B$ horizons of Podzolic and Brunisolic soils. Can. J. Soil Sci. 48:53-63.

Coen, G.M. and R.W. Arnold. 1972. Clay mineral genesis of some New York Spodosols. Soil Sci. Soc. Amer. Proc. 36:342-351.

Coffin, D.E. 1963. A method for the determination of free iron in soils and clays . Can. J. Soil Sci. 43:7-17.

Commission de Pédologie et de Cartographie des Sols-CPCS. 1967. Classification des sols. ENSA, Grignon, France. $87 \mathrm{pp}$.

Deb, B.D. 1950. the estimation of free iron oxides in soils and clays and their removal. J. Soil Sci. 1:212-220.

De Bakker, H. 1979. Major soils and soil regions in the Netherlands. Pudoc, Wageningen, $203 \mathrm{pp}$.

De Bakker, H. and J. Schelling, 1966. Systeem van bodemclassificatie voor Nederland. De hogere niveaus. Pudoc, Wageningen. $217 \mathrm{pp}$. 
De Coninck, F. 1980. Major mechanisms in formation of spodic horizons. Geoderma 24:101-128.

De Kimpe, C.R. and Y.A. Martel. 1976. Effects of vegetation on the distribution of carbon, iron, and aluminum and the B horizons of Northern Appalachian Spodosols. Soil Sci. Soc. Amer. J. 40:77-80.

Duchaufour, P. 1976. Atlas écologique des sols de monde. Masson, Paris. 178 pp.

Farmer, V.C., J.D. Russell and M.L. Berrow. 1980. Imogolite and proto-imogolite allophane in spodic borizons: evidence for a mobile aluminum silicate complex in podzol formation. J. Soil Sci. 31:673-684.

Flach, K.W., C.S. Holzhey, F. De Coninck and R.J. Bartlett. 1980. Genesis and classification of Andepts and Spodosols. In: B.K.G. Theng (ed.), Soils with variable charge. N.Z. Soc. Soil Sci., p. 411-426.

Flaig, W., H. Beutelspacher and E. Rietz. 1975. Chemical composition and physical properties of humic substances. In: J.E. Gieseking (ed.), Soil Components. Vol. 1. Organic Components. Springer-Verlag, Berlin, p. 1-211.

Food and Agriculture Organization. 1974. Soil Map of the World. Volume I. Legend. Unesco, Paris, 59 pp.

Food and Agriculture Organization. 1977. Guidelines for soil profile description (second edition). FAO, Rome. 66 pp.

Franzmeier, D.P., B.F. Hajek and C.H. Simonson. 1965. Use of amorphous material to identify spodic horizons. Soil Sci. Soc. Amer. Proc. 29:737-743.

Hayes, M.H.B. and R.S. Swift. 1978. The chemistry of soil organic colloids. In: D.J. Greenland and M.H.B. Hayes (eds.), The chemistry of soil constituents. John Wiley and Sons, New York. p. 179-320.

Hayes, M.H.B., R.S. Swift, R.E. Wardle and J.K. Brown. 1975. Humic materials from an organic soil: a comparison of extractants and of properties of extracts. Geoderma 13:231-245.

Higashi, T., F. De Coninck and F. Gelaude. 1981. Characterization of some spodic horizons of the Campine (Belgium) with dithionite-citrate, pyrophosphate and sodium hydroxide-tetraborate. Geoderma 25:131-142.

Higashi, T. and A. Shinagawa. 1981. Comparison of sodium hydroxide-tetraborate and sodium pyrophosphate as extractants of Al/Fe-humus "complexes" in Dystrandepts, Japan. Geoderma 25:285-292.

Holmgren, G.G.S. 1967. A rapid citrate-dithionite extractable iron procedure. Soil Sci. Soc. Amer. Proc. 31:210-211.

Holzhey, C.S., R.B. Daniels and E.E. Gamble. 1975. Thick Bh horizons in the North Carolina Coastal Plain: II Physical and chemical properties and rates of organic additions from surface sources. Soil Sci. Soc. Amer. J. 39:1182-1187.

Hubert, G. and A. Gonzalez. 1970. Extraction et repartition du fer et de l'aluminum liés à la matiere organique dans quatre Podzols du Quebec. Can. J. Soil Sci. 50:281-290.

Ivanova, E.N. and N.N. Rozo. 1960. Classification of soils and the soil map of the USSR. 7th Intern. Cong. Soil Sci., Madison, Wis. IV:77-87.

Khan, S.U. 1969. Interaction between the humic acid fraction of soils and certain metallic cations. Soil Sci. Soc. Amer. Proc. 33:851-854.

Khanna, S.S. and F.J. Stevenson. 1962. Metallo-organic complexes in soil: I. Potentiometric titration of some organic matter isolates in the presence of transitional metals. Soil Sci. 93:298-305. 
Kilmer, J. 1960. The estimation of free iron oxides in soils. Soil Sci. Soc. Amer. Proc. 24:420-421.

Kilmer, V.J. and L.T. Alexander. 1949. Methods of making mechanical analyses of soils. Soil Sci, 68:15-24.

KIinge, H. 1965. Podzol soils in the Amazon Basin. J. Soil Sci. 16:95-103.

Knuteson, J.A. and M.I. Harpstead. 1980. Variation of spodic characteristics in North Central Wisconsin. Agronomy Abstracts. 72nd Annual Meeting, Amer. Soc. Agron., Madison, Wisconsin. p. 182.

Kononova, M.M. and N.P. Bel'chikova. 1970. Use of Na-pyrophosphate for extracting and characterizing organic compounds of iron and aluminum in soil. Pochvovedenie No. 6:61-75:

Kodama, H. and M. Schnitzer. 1972. Dissolution of chlorite minerals by fulvic acid. Can. J. Soil Sci. 53:240-243.

Kubota, J. and L.D. Whittig. 1960. Podzols in the vicinity of the Nelchina and Tazlina Glaciers, Alaska. Soil Sci. Soc. Amer. Proc. 24:133-136.

Loveland, P.J. and P. Bullock. 1975. Crystalline and amorphous components of the clay fractions in Brown Podzolic soils. Clay Minerals 10:451-469.

Loveland, P.J. and P. Bullock. 1976. Chemical and mineralogical properties of Brown Podzolic soils in comparison with soils of other groups. J. Soil Sci. $27: 523-540$.

McKeague, J.A. 1967. An evaluation of 0.1 M pyrophosphate and pyrophosphate-dithionite in comparison with oxalate as extractants of the accumulation products in Podzols and some other soils. Can. J. Soil Sci. 47:95-99.

McKeague, J.A. 1968. Humic-fulvic acid ratio, Al, Fe, and C in pyrophosphate extracts as criteria of $A$ and B horizons. Can. J. Soil Sci. 48:27-35.

McKeague, J.A., J.E. Brydon and N.M. Miles. 1971. Differentiation of forms of extractable iron and aluminum in soils. Soil Sci. Soc. Amer. Proc. 35:33-38.

McKeague, J.A. and J.K. Day. 1966. Dithionite- and oxalate-extractable Fe and $A l$ as aids in differentiating various classes of soils. Can. J. Soil Sci. 46:13-22.

McKeague, J.A. and J.H. Day. 1969. Oxalate-extractable Al as a criterion for identifying podzol B horizons. Can. J. Soil Sci. 49:161-163.

McKeague, J.A. and H. Kodama. 1981. Imogolite in cemented horizons of some British Columbia soils. Geoderma 25:189-197.

McKeague, J.A., G.J. Ross and D.S. Gamble. 1978. Properties, criteria of classification, and concepts of genesis of Podzolic soils in Canada. In: W.C. Mahaney (ed.), Quaternary Soils. Geo Abstracts, Norwich, England p. 27-60.

McKeague, J.A., M. Schnitzer and P.K. Heringa. 1967. Properties of an Ironpan Humic Podzol from Newfoundland. Can. J. Soil Sci, 47:23-32.

McKeague, J.A. and B.H. Sheldrick. 1977. Sodium hydroxide-tetraborate in comparison with sodium pyrophosphate as an extractant of "complexes" characteristics of spodic horizons. Geoderma 19:97-104.

McKeague, J.A. and R.J. St. Arnaud. 1969. Pedotranslocation: Eluviation - illuviation in soils during the Quarternary. Soil Sci. 107:428-434.

McKeague, J.A. and C. Wang. 1980. Micromorphology and energy dispersive analysis of ortstein horizons of podzolic soils from New Brunswick and Nova Scotia, Canada. Can. J. Soil Sci. 60:9-21.

Mehra, O.P. and M.L. Jackson. 1960. Iron oxide removal from soils and clays by a dithionite-citrate system buffered with sodium bicarbonate. Clay and Minerals $7: 317-327$. 
Miles, N.M., C. Wang and J.A. McKeague. 1979. Chemical and clay mineralogical properties of ortstein soils from the Maritime Provinces. Can. J. Soil Sci. $59: 287-299$.

Mitchell, B.D. and R.C. Mackenzie. 1954. Removal of free iron oxide from clays. Soil Sci. 77:173-184.

Muir, A. 1961. The podzol and podzolic soils. Adv. Agron. 13:1-56.

NCSS, NSSC and FAO. National Co-operative Soil Survey of United States of America, National Soil Survey Committee of Canada and Food and Agriculture Organization of United Nations. 1975. Soil Map of the World, Volume II. North America, Unesco, Paris, 210 pp.

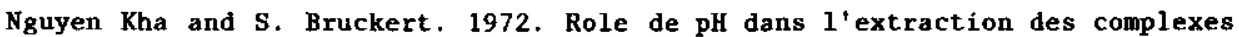
organo-ferriques par l'hydroxide ou le pyrophosphate de sodium. C.R. Acad. Sci. Paris, Sér. D., 274:667-670.

Parfitt, R.L. 1980. Chemical properties of variable charge soils. In: B.K.G. Theng (ed.): Soils with variable charge. p. 167-194. New Zealand Soc. Soil Sci.

Petersen, L. 1976. Podzols and podzolization. Diss. Royal Veterinary and Agricultural University, Copenhagen. 293 pp.

Ponomareva, V.V. 1964. Theory of podzolization. "Nauka", Moskva-Leningrad, Israel Progran for Scientific Translations, Jerusalem, 1969. 309 pp.

Ponomareva, V.V. and A.I. Ragim-Zade. 1969. Comparative study of fulvic and humic acids as agents of silicate mineral decomposition. Sov. Soil Sci. 2:157-166.

Racz, Z, 1968. Podzols on the territory of Croatia (Yugoslavia) and their micromorphological properties. Geoderma 2:41-55.

Ragg, J.M., J.M. Bracewell, J. Logan and L. Robertson. 1978. Some characteristics of the Brown Forest soils of Scotland. J. Soil Sci. 29:228-242.

Ragg, J.M. and B. Clayden. 1973. The classificaton of some British soils according to the Comprehensive System of the United States. Soil Surv. Tech. Monogr. No. 3. Harpenden. $227 \mathrm{pp}$.

Righi, D. and F. De Coninck. 1977. Mineralogic evolution in hydromorphic sandy soils and podzols in "Landes du Médoc", France. Geoderma 19:339-359.

Ross, G.J. 1980a. Mineralogical, physical and chemical characteristics of amorphous constituents in some Podzolic soils from British Columbia. Can. J. Soil Sci. 60:31-43.

Ross, G.J. 1980b. The mineralogy of spodosols. In: B.K.G. Theng (ed.), Soil with variable charge. N.Z. Soc. Soil Sci., p. 127-143.

Ross, G.J. and H. Kodama. 1979. Evidence for imogolite in Canadian soils. Clays Clay Min. 27:297-300.

Schnitzer, M. 1969. Reactions between fulvic acid, a soil humic compound and inorganic soil constituents. Soil Sci. Soc. Amer. Proc. 33:75-81.

Schnitzer, M. 1978. Humic substances: chemistry and reactions. In: M. Schnitzer and S.U. Khan (eds.), Soil Organic Matter. Elsevier, Amsterdam. p. 1-64.

Schnitzer, M. and J.G. Desjardins. 1962. Molecular and equivalent weights 'of the organic matter of a podzol. Soil Sci. Soc. Amer. Proc. 26:362-365.

Schnitzer, M. and J.G. Desjardins, 1969. Chemical characteristics of a natural soil leachate from a humic podzol. Can. J. Soil Sci. 49:151-158.

Schnitzer, M. and E.H. Hansen. 1970. Organo-metallic interactions in soils: 8 . An evaluation of methods for the determination of stability constants of metalfulvic acid complexes. Soil Sci. 109:333-340. 
Schnitzer, M. and S.U. Khan. 1972. Humic substances in the environment. Marcel Dekker, New York. 327 pp.

Schnitzer, M. and H. Kodama. 1976. The dissolution of micas by fulvic acid. Geoderma $15: 381-391$.

Schnitzer, M. and H. Kodama. 1977. Reactions of minerals with soil humic substances. In: J.B. Dixon and S.B. Weed (eds.), Minerals in Soil Environments. Soil Sci. Soc. Amer., Madison, Wis., p. 741-770.

Schnitzer, M. and S.I.M. Skinner. 1963. Organo-metallic interactions in soils: 1. Reactions between a number of metal ions and the organic matter of a podzol Bh horizon. Soil Sci. 96:86-94.

Schnitzer, M. and S.I.M. Skinner. 1964. Organo-metallic interactions in soils:3. Properties of iron and aluminium-organic matter complexes, prepared in the laboratory and extracted from soil. Soil Sci.98:197-203.

Schnitzer, M. and S.I.M. Skinner. 1968. Alkali versus acid extraction of soil organic matter. Soil Sci. 105:392-396.

Schnitzer, M., J.R. Wright and J.G. Desjardins. 1958. A comparison of the effectiveness of various extractants for organic matter from two horizons of a Podzol profile. Can. J. Soil Sci. 38:49-53.

Schofield, R.K. 1949. Effect of pH on electric charges carried by clay particles. J. Soil Sci. 1:1-8.

Schwertmann, U, 1959. Die fractionierte Extraktion der freien Eisenoxide in Böden, ihre mineralogischen Formen und ihre Entstehungsweisen. Z. Pflanzenernähr. Düng. Bodenkunde, 84:194-204.

Schwertmann, U. 1964. Differenzierung der Eisenoxide des Bodens durch Extraktion mit Ammoniumoxalat-lösung. 2. Pflanzenernähr. Düng. Bodenkunde 105:194-202.

Schwertmann, U. 1973. Use of oxalate for Fe extraction from soils. Can. J. Soil Sci. 53:244-246.

Singer, M., F.C. Ugolini and J. Zachara. 1978. In situ study of podzolization on tephra and bedrock. Soil Sci. Soc. Amer. J. 42:105-111.

Smith, G.D. 1965. Lectures on soil classification. Pédologie. Special Issue No. 4. Belgian Soil Sci. Soc. Ghent. 134 pp.

Soil Survey Staff. 1960. Soil classification, a comprehensive system, 7 th approximation. U.S. Gov't. Prtg. Off., Washington, D.C. 265 pp.

Soil Survey Staff. 1967. Supplement to Soil Classification System (7th Approximation). U.S. Gov't. Prtg. Off. Washington, D.C. 207 pp.

Soil Survey Staff. 1975. Soil Taxonomy. A basic system of soil classification for making and interpreting soil surveys. Agric. Handbk. No. 436. U.S. Gov't. Prtg. Off., Washington, D.C. 20402. 754 pp.

Stace, H.C.T., G.D. Hubble, R. Brewer, K.H. Northcote, J.R. Sleeman, M.J. Mulcahy and E.G. Hallsworth. 1968. A handbook of Australian soils. Rellim Technical Publications, Glenside, South Australia. 435 pp.

Stanley, S.R. and E.J. Ciolkosz. 1980. Classification and genesis of spodosols of the Central Appalachians. Agron. Abstr. 72nd Annual Meeting, Amer. Soc. Agron., Madison, Wisconsin, p. 187.

Stevens, M.E. 1963. Podzol development on a moraine near Juneau, Alaska. Soil Sci. Soc. Amer. Proc. 27:357-358.

Stobbe, P.C. and J.R. Wright. 1959. Modern concepts of the genesis of Podzols. Soil Sci. Soc. Amer. Proc. 23:161-164. 
Tait, J.M., N. Yoshinaga and B.D. Mitchell, 1978. The occurrence of imogolite in some Scottish soils. Soil Sci. Plant Nutr. 24:145-151.

Tamm, 0.1922 . Om bestämning av de oorganiska componenterna i markens gelkomplex. Medd. Stat. Skogsförsöksanst. 19:385-404.

Tamm, 0. 1932. Über die Oxalatmethode in der Chemischen Bodenanalyse. Medd. Stat. Skogsförsöksanst. 27:1-20.

Tan, K.H., H.F. Perkins and R.A. McCreery. 1970. The characteristics, classification and genesis of some tropical spodosols. Soil Sci. Soc. Amer. Proc. $34: 775-779$.

Tavernier, R. 1963. The 7th approximation: its application in western Europe. Soil Sci. 96:35-39.

Taylor, N.H. and I.J. Pohlen. 1968. Classification of New Zealand soils. Soils of New Zealand. Part I. N.2. Soil Bur. Bull. 26(1). 142 pp.

Tokashiki, $Y$. and $K$. Wada. 1975. Weathering implications of the mineralogy of clay fractions of two Ando soils, Kyushu, Geoderma 14:47-62.

Truog, E. 1928. General exhibits. Soil Sci. 25:89-95.

U.S. Department of Agriculture, SCs. 1972. Soil survey laboratory methods and procedures for collecting soil samples. Soil Survey Investigations Report. No. 1. Washington, D.C. 63 pp.

Van den Broek, J.M.M. 1965. Podzolen in Tertiaire zanden in Zuid-Limburg. Boor en Spade 14:184-195.

Van Dijk, H. 1971. Cation binding of humic acids. Geoderma 5:53-67.

Van Dostrum, A.J.M. and D.L. Mokma. 1981. Determination of carbon in soils and soil extracts. See Appendix of this report.

Wada, K. and D.J. Greenland. 1970. Selective dissolution and differential infrared spectroscopy for characterization of "amorphous" constituents in soil clays. Clay Miner. 8:241-254.

Walkley, A. and I.A. Black. 1934. An examination of the Degtjareff method for determining soil organic matter and a proposed modification of the chromic acid titration method. Soil Sci. 37:29-38.

Wang, C., G.J. Beke and J.A. McKeague. 1978. Site characteristics, morphology and physical properties of selected ortstein soils from the Maritime Provinces. Can. J. Soil Sci. 58:405-420.

Wright, J.R. and M. Schnitzer. 1959. Oxygen-containing functional groups in the organic matter of a podzol soil. Nature 184:1462-1463.

Wright, J.R. and M. Schnitzer. 1963. Metallo-organic interactions associated with podzolization. Soil Sci. Soc. Amer. Proc. 27:171-176. 
APPENDIX 1. DESCRIPTION OF THE DUTCH AND BELGIAN PROFILES

PROEILE NO.: NL-101 (Plate)

Location : Galgenberg, Province of Limburg, Netherlands $51^{\circ} 31^{\prime} 13^{\prime \prime} \mathrm{N} ; 6^{\circ} 07^{\prime} 52^{\prime \prime} \mathrm{E}$

\section{Profile description}

$0 \quad 3-0 \mathrm{~cm}$

Very dark gray (lOYR 3/1) decomposed needle litter;

very friable; abrupt wavy boundary.

Ah $\quad 0-5 \mathrm{~cm}$

Very dark gray (lOYR $3 / 1$ ) and light brownish gray (1OYR 6/2) sand; weak medium granular structure; very friable; abrupt wavy boundary; $\mathrm{pH} 4.0$.

E1 $5-24 \mathrm{~cm}$

Dark brown (7.5YR 4/2) sand with common coarse distinct pinkish gray (7.5YR 6/2) mottles; single grained; loose; abrupt wavy boundary; pH 4.2

E2 $24-41 \mathrm{~cm}$

Dark brown (7.5YR 4/2) sand with many coarse distinct pinkish gray (7.5YR 6/2) mottles; single grained; loose; abrupt wavy boundary; pH 4.2 .

Bh1 41 - $45 \mathrm{~cm}$ Black (7.5YR 2/0) sand; weak medium subangular blocky to massive structure; friable; abrupt wavy boundary; pH 3.8 .

Bh2 $45-47 \mathrm{~cm}$ Black (5YR 2.5/1) sand; weak medium subangular blocky to massive structure; very friable; abrupt wavy boundary; $\mathrm{pH} 3.8$.

Bsl $47-53 \mathrm{~cm}$ strong brown (7.5YR 5/8) sand; single grained; 100se; clear wavy boundary; pH 4.1 .

Bs2 $53-82 \mathrm{~cm}$ Dark brown (7.5YR 3/2) sand; single grained; loose; clear wavy boundary; $\mathrm{pH} 4.4$; contains tongues of $\mathrm{Bh}$ and Bs materials.

C/B $\quad 82-150 \mathrm{~cm}$ Yellowish brown (lOYR 5/4) sand, single grained, loose, C part; dark brown (7.5YR $3 / 2)$ sand, massive, very friable, $B$ part as thin regularly spaced humus lamellae; pH 4.6. 


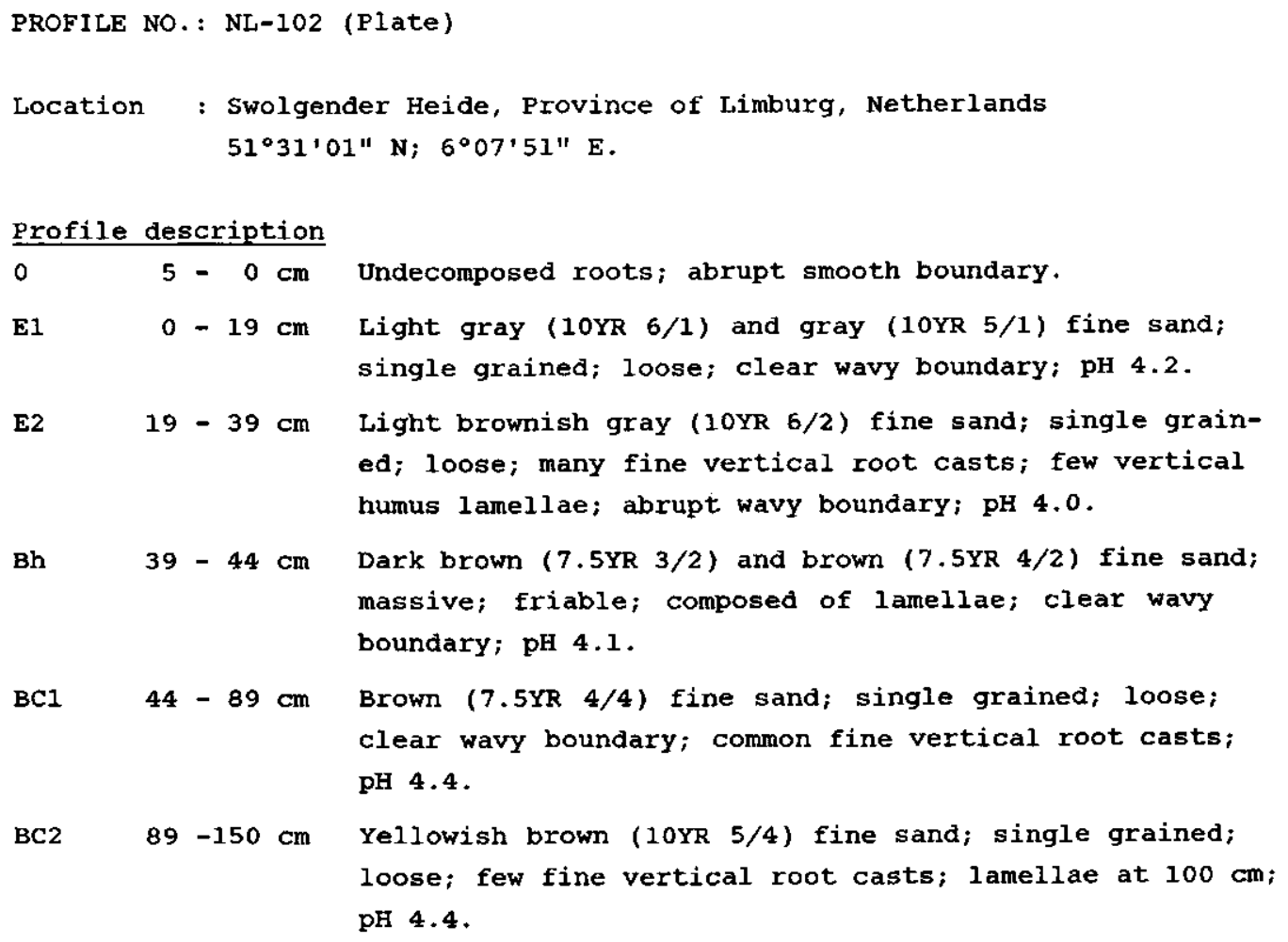




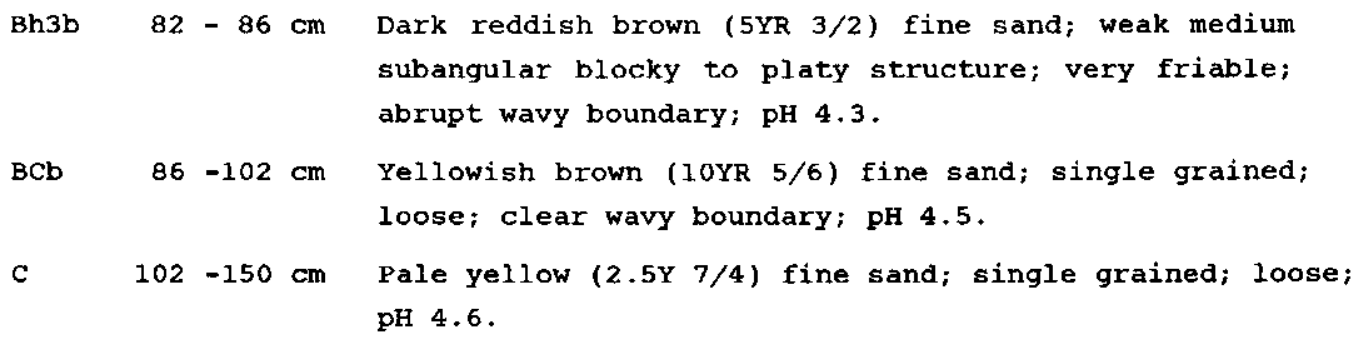

\section{Profile description}

$0 \quad 7-0 \mathrm{~cm}$

Decomposed needle litter and roots; very friable; abrupt smooth boundary.
Ah $\quad 0-18 \mathrm{~cm}$
very dark gray (IOYR $3 / 1$ ) sand; weak medium granular structure; very friable; clear wavy boundary; $\mathrm{pH} 3.7$.
$\mathbf{E}$
$18-38 \mathrm{~cm}$
Dark gray (lOYR $4 / 1$ ) sand; few fine gravels; single graines; loose; abrupt wavy boundary; $\mathrm{pH} \mathrm{4.2}$. structure; very firm; strongly cemented; clear wavy boundary; pH 3.8 .
Bhm $38-47 \mathrm{~cm}$ Black (7.5YR 2/0) sand; weak medium subangular blocky
Bhs $\quad 47-61 \mathrm{~cm}$ Very dark gray (5YR 3/1) sand; weak medium subangular blocky structure; very friable; abrupt wavy boundary; $\mathrm{pH} 3.8$.
BC $\quad 61-120 \mathrm{~cm}$ Brown (10YR 4/3) sand; single grained; loose; pH 4.2.

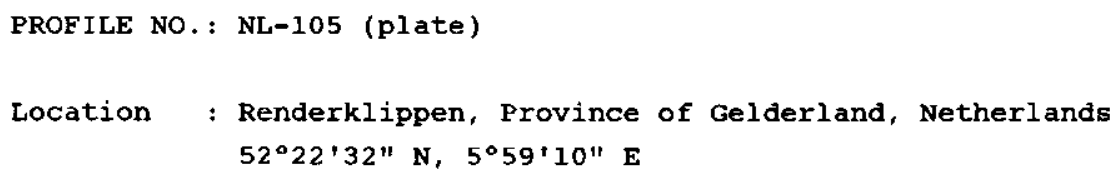

\section{Profile description}

$0 \quad 3$ - $0 \mathrm{~cm}$ Decomposed leaf an needle litter; very friable; abrupt smooth boundary.

Ah 0 - $7 \mathrm{~cm}$ Black (7.5YR 2/0) sand; weak medium granular structure; very friable; abrupt smooth boundary; $\mathrm{pH} 3.8$. 
E

Bh $\quad 16-22 \mathrm{~cm}$

BhsI $22-30 \mathrm{~cm}$

Bhs2 $30-43 \mathrm{~cm}$

$\mathrm{BCl} \quad 43-61 \mathrm{~cm}$

$\mathrm{BC} 2 \quad 61-88 \mathrm{~cm}$

C

$88-150 \mathrm{~cm}$

Brown (7.5YR $5 / 2$ ) fine sand; single grained; loose; abrupt wavy boundary; pH 4.0 .

Black (7.5YR 2/0) sand; weak medium subangular blocky structure; very friable; abrupt wavy boundary; pH 3.9.

Dark reddish brown (5YR $2.5 / 2)$ sand with many coarse distinct strong brown ( $7.5 Y R 4 / 6$ ) mottles; single grained; loose; clear wavy boundary; $\mathrm{pH} 4.0$.

Dark brown (7.5YR 3/4) sand with many coarse distinct yellowish brown (10YR 5/6) mottles; single grained; loose; clear wavy boundary; $\mathrm{pH} 4.6$.

Yellowish brown (1OYR 5/6) gravelly sand; single grained; loose; clear wavy boundary; pH 4.7.

Brownish yellow (10YR 6/6) gravelly sand; single grained; loose; clear wavy boundary; pH 4.7.

Light yellowish brown (10YR 6/4) fine sand; single grained; cryoturbate with streaks of iron accumulation and bleaching; $\mathrm{pH} 5.0$.

PROFILE NO.: NL-106 (Plate)

Location : Havelterberg, Province of Drente, Netherlands. $52^{\circ} 47^{\prime} 19^{\prime \prime} \mathrm{N}, 6^{\circ} 13^{\prime} 05^{\prime \prime} \mathrm{E}$.

\section{Profile description}

$0 \quad 5-0 \mathrm{~cm}$

Decomposed leaf litter; very friable; abrupt smooth boundary.

Ahl $0-6 \mathrm{~cm}$

Very dark gray (10YR 3/1) loamy fine sand; weak medium granular structure; very friable; abrupt wavy boundary; pH 4.0 .

Ah2 $6-11 \mathrm{~cm}$

Black (5YR 2.5/1) loamy fine sand; weak medium granular structure; very friable; abrupt wavy boundary; pH 4.0.

E $\quad 11-22 \mathrm{~cm}$

Pinkish gray (7.5YR $6 / 2$ and $7.5 Y R$ 5/2) loamy fine sand; massive; very friable; abrupt irregular boundary; $\mathrm{pH}$ 4.4 .

Bhs1 $22-29 \mathrm{~cm}$

Dark reddish brown (5YR 2.5/2) loamy fine sand; weak medium subangular blocky structure; very friable; abrupt wavy boundary; pH 4.3.

Bhs2 $29-35 \mathrm{~cm}$

Dark brown (7.5YR 4/4) loamy fine sand; weak medium subangular blocky structure; very friable; clear wavy boundary; pH 4.4 . 


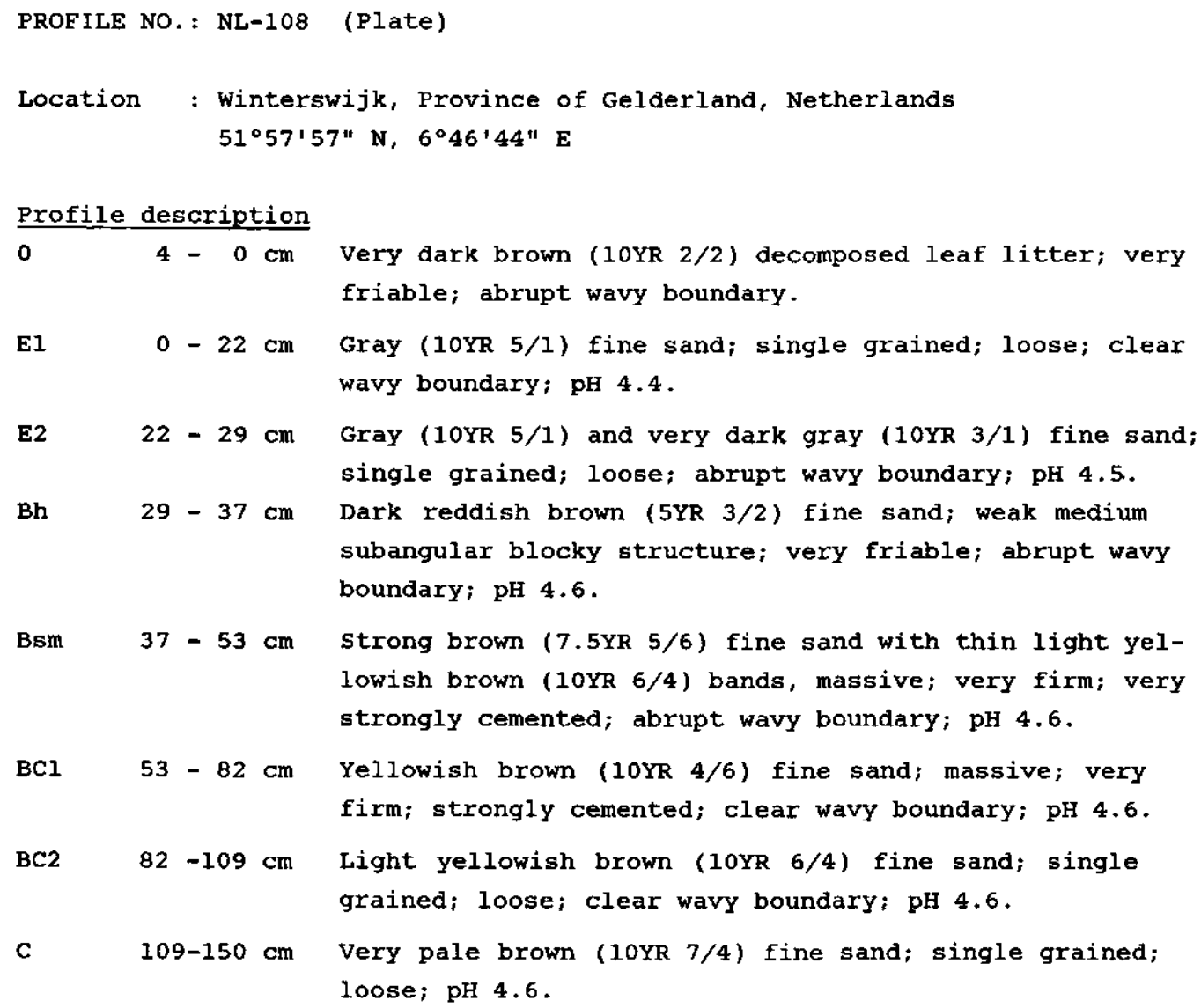




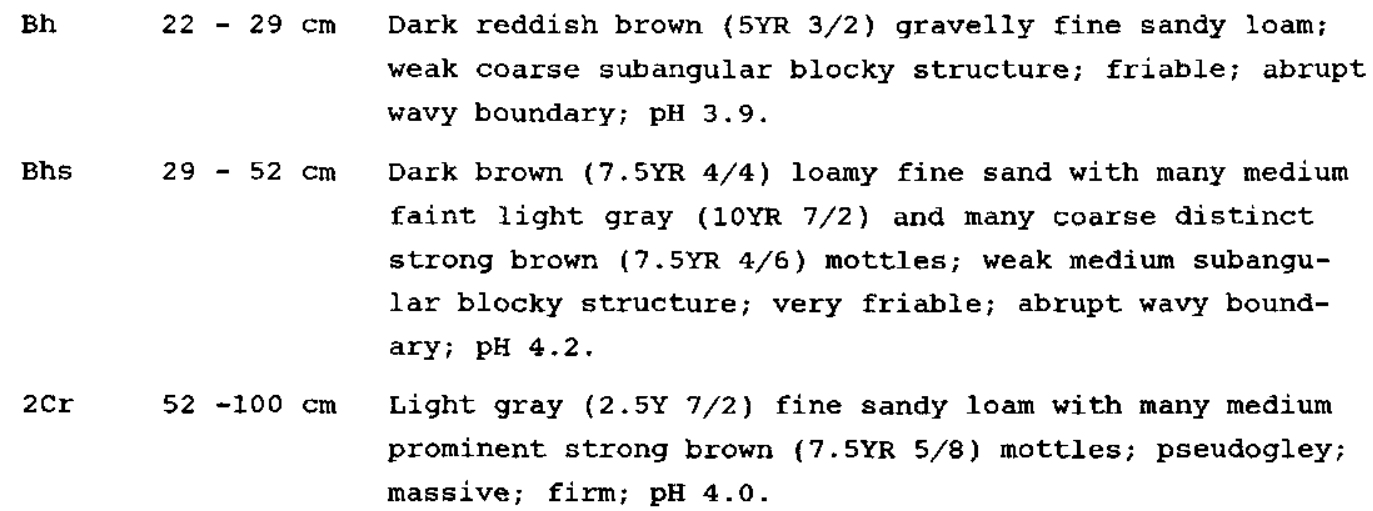




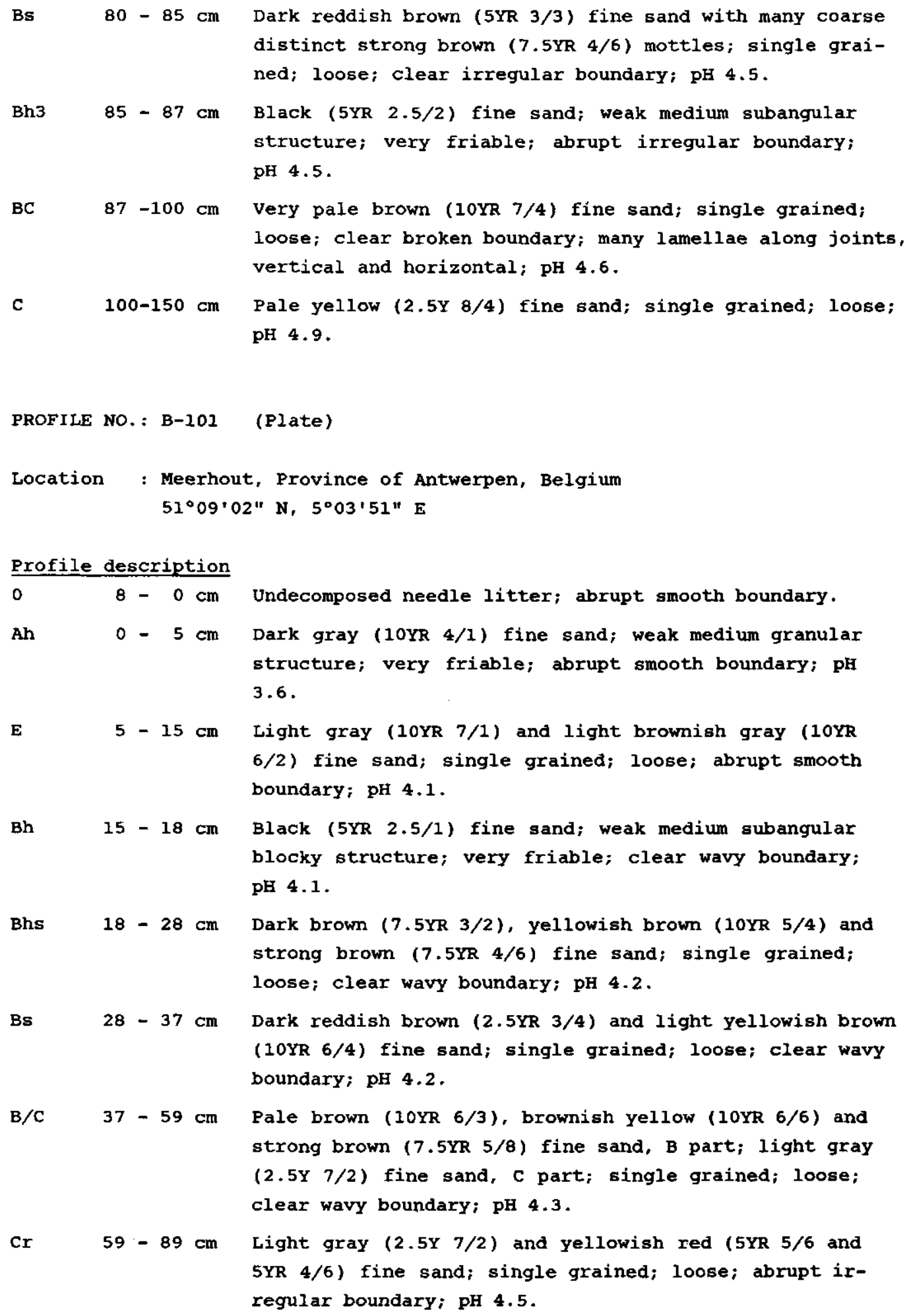




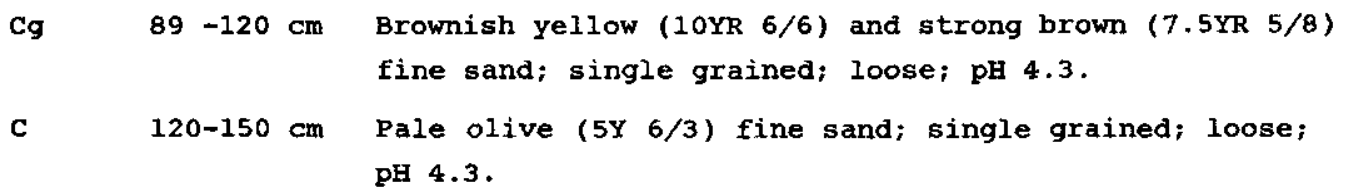


Profile description

$0-23 \mathrm{~cm}$ wind blown sand.

\begin{tabular}{|c|c|c|c|c|}
\hline Ahb & 23 & -30 & $\mathrm{~cm}$ & $\begin{array}{l}\text { Very dark gray (10YR } 3 / 1) \text { fine sand; weak medium granu- } \\
\text { lar structure; very friable; abrupt smooth boundary; } \\
\text { pH } 4.3 \text {. }\end{array}$ \\
\hline $\mathrm{ab}$ & 30 & -58 & $\mathrm{~cm}$ & $\begin{array}{l}\text { Light gray (10YR } 7 / 1 \text { ) fine sand; single grained; loose; } \\
\text { abrupt wavy boundary; pH } 4.7 \text {. }\end{array}$ \\
\hline $\mathrm{Bb}$ & 58 & -85 & $\mathrm{~cm}$ & $\begin{array}{l}\text { Grayish brown (10YR } 5 / 2) \text { fine sand; single grained; } \\
\text { loose; clear wavy boundary; pH } 4.6 \text {. }\end{array}$ \\
\hline hlb & 85 & -103 & $\mathrm{~cm}$ & $\begin{array}{l}\text { Dark reddish brown ( } 5 \mathrm{YR} 3 / 3) \text { fine sand; weak medium } \\
\text { subangular blocky structure; very friable; clear wavy } \\
\text { boundary; pH } 4.6 \text {. }\end{array}$ \\
\hline$h 2 b$ & 103 & -125 & $\mathrm{~cm}$ & $\begin{array}{l}\text { Dark reddish brown }(5 \mathrm{YR} 3 / 3) \text { fine sand; weak medium } \\
\text { subangular blocky structure; very friable; clear wavy } \\
\text { boundary; pH } 4.5 \text {. }\end{array}$ \\
\hline Bh3b & 125 & -155 & $\mathrm{~cm}$ & $\begin{array}{l}\text { Dark reddish brown ( } 5 \text { YR } 3 / 4) \text { fine sand; single grained; } \\
\text { loose; abrupt wavy boundary; pH } 4.5 \text {. }\end{array}$ \\
\hline $\mathrm{amb}$ & 155 & -1 & $\mathrm{~cm}$ & $\begin{array}{l}\text { Black ( } 5 Y \mathrm{R} 2.5 / 1) \text { fine sand; weak coarse subangular } \\
\text { blocky structure to massive; strongly cemented; very }\end{array}$ \\
\hline
\end{tabular}

PROFILE NO.: B-104 (Plate)

Location : Opgrimbie, Province of Limburg, Belgium $50^{\circ} 57^{\prime} 10^{\prime \prime} \mathrm{N}, 5^{\circ} 38^{\prime} 03^{\prime \prime} \mathrm{E}$

\section{Profile description}

012 - $1 \mathrm{~cm}$ Undecomposed needle litter; abrupt smooth boundary.

021 - $0 \mathrm{~cm}$ Black (7.5YR 2/0) well decomposed needle litter; very friable; abrupt smooth boundary.

Ah $0-5 \mathrm{~cm}$ Very dark gray (10YR 3/1) loamy fine sand; weak medium granular structure; very friable; abrupt wavy boundary; pH 3.8 .

E1 $5-18 \mathrm{~cm}$ Grayish brown (10YR 5/2) gravelly fine sand; weak medium subangular blocky structure; very friable; clear wavy boundary; $\mathrm{pH} 4.1$.

E2 $18-33 \mathrm{~cm}$

Brown (7.5YR 5/2) gravelly fine sand; weak medium subangular blocky structure; very friable; abrupt wavy boundary; $\mathrm{pH} 4.1$. 


\begin{abstract}
Bhl $33-36 \mathrm{~cm}$ Black (l0YR 2/l) slightly gravelly loamy fine sand; weak medium subangular blocky structure; very friable; abrupt wavy boundary; pH 3.9.

Bh2 $36-40 \mathrm{~cm}$

Black (5YR 2.5/1) gravelly loamy fine sand; weak medium subangular blocky to platy structure; very friable; abrupt wavy boundary; pH 3.9 .

Bh3 $40-42 \mathrm{~cm}$ Dark reddish brown (5YR 2.5/1) gravelly fine sand; weak medium subangular blocky to platy structure; very friable; wavy boundary; pH 4.1 .

Bhsl 42 - $53 \mathrm{~cm}$ Dark reddish brown (5YR 3/3) gravelly fine sand; weak medium subangular blocky to platy structure; very friable clear wavy boundary; $\mathrm{pH} 4.3$.

Bhs2 $53-70 \mathrm{~cm}$ Dark brown (7.5YR 4/4) gravelly fine sand; weak medium subangular blocky structure; very friable; clear wavy boundary; pH 4.4 .

$2 \mathrm{Cg} \quad 70-100 \mathrm{~cm}$ Light reddish brown (5YR 6/3) with many coarse prominent strong brown (7.5YR 5/6) mottles and yellowish brown (10YR 5/6) with many coarse prominent dark brown (7.5YR 4/4) mottles; loamy fine sand; massive; friable; pH 4.3 .
\end{abstract}

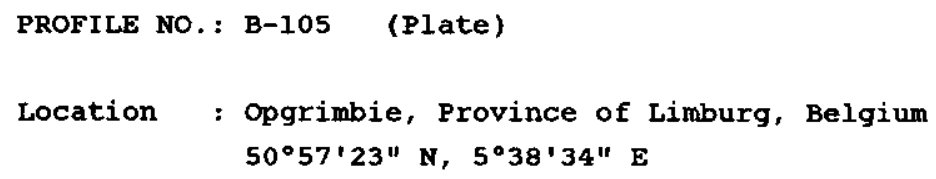

\title{
Profile description
}

\begin{tabular}{|c|c|c|c|c|}
\hline 0 & 2 & -0 & $\mathrm{~cm}$ & $\begin{array}{l}\text { Decomposed needle litter; very friable; abrupt smooth } \\
\text { boundary. }\end{array}$ \\
\hline $\mathrm{Ah}$ & 0 & - & $\mathrm{cm}$ & $\begin{array}{l}\text { Very dark gray (10YR } 3 / 1 \text { ) fine sand; weak medium granu- } \\
\text { lar blocky structure; very friable; abrupt smooth } \\
\text { boundary; pH } 4.3 \text {. }\end{array}$ \\
\hline $\mathbf{E}$ & 8 & -23 & $\mathrm{~cm}$ & $\begin{array}{l}\text { Light gray (10YR } 6 / 1 \text { ) fine sand; single grained; loose; } \\
\text { abrupt wavy boundary; pH } 4.6 \text {. }\end{array}$ \\
\hline Bh & 23 & -30 & $\mathrm{~cm}$ & $\begin{array}{l}\text { Very dark gray (1OYR } 3 / 1 \text { ) fine sand; weak medium suban- } \\
\text { gular blocky structure; very friable; clear wavy bound- } \\
\text { ary; pH } 3.9 \text {. }\end{array}$ \\
\hline Bhs & 30 & -35 & $\mathrm{~cm}$ & $\begin{array}{l}\text { Dark reddish brown ( } 5 \text { YR } 2.5 / 2) \text { fine sand; weak medium } \\
\text { subangular blocky structure; very friable; clear wavy } \\
\text { boundary: pH } 4.1 \text {. }\end{array}$ \\
\hline
\end{tabular}




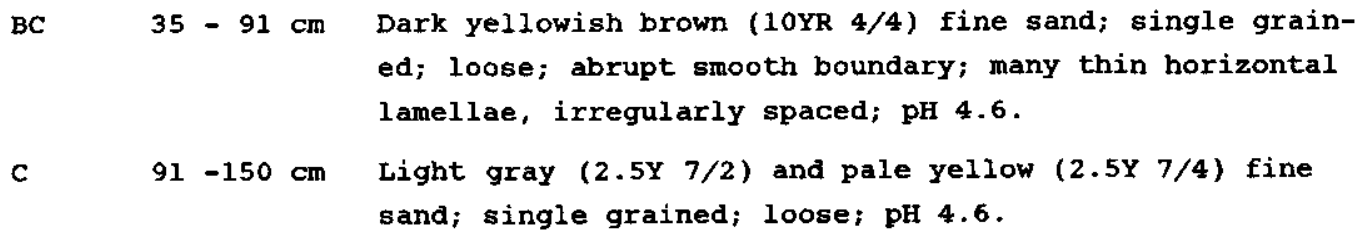




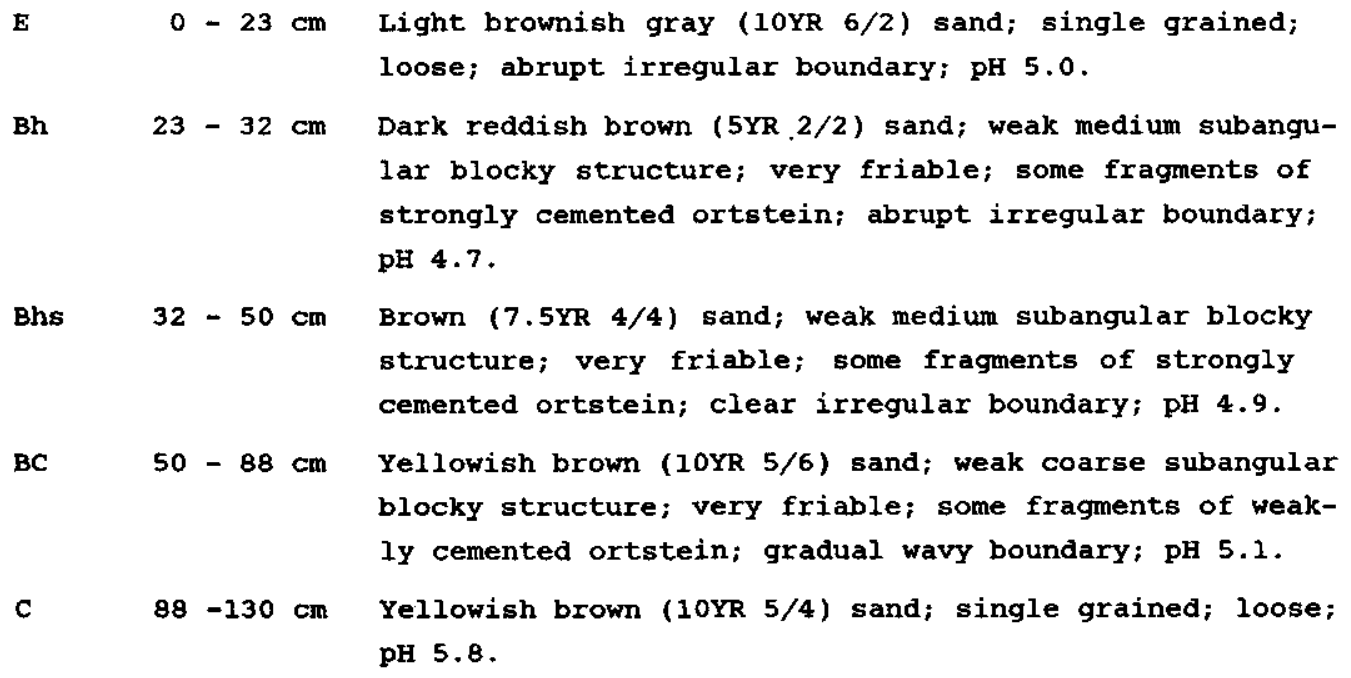

APPENDIX 2. DESCRIPTIONS OF THE RUSSIAN PROFILES

ISM PROFILE NO.: GMC-4 (Plate)

Location : Near Leningrad, soviet Union

About $60^{\circ} \mathrm{N}, 30^{\circ} \mathrm{E}$

\section{Profile description}

\begin{tabular}{|c|c|c|c|c|}
\hline 0 & 5 & 0 & $\mathrm{~cm}$ & Black (10YR 2/1) decomposed leaf litter; weak medium \\
\hline E1 & 0 & -12 & $\mathrm{~cm}$ & $\begin{array}{l}\text { Pinkish gray }(7.5 Y R \text { 6/2) loamy very fine sand; single } \\
\text { grained; loose; clear wavy boundary; } \mathrm{pH} 3.7 \text {. }\end{array}$ \\
\hline E2 & 12 & -19 & $\mathrm{~cm}$ & $\begin{array}{l}\text { Light brownish gray (10YR } 6 / 2 \text { ) loamy very fine sand; } \\
\text { single grained; loose; abrupt wavy boundary; pH } 4.1 \text {. }\end{array}$ \\
\hline BE & 19 & -23 & $\mathrm{~cm}$ & $\begin{array}{l}\text { Dark brown ( } 7.5 Y R 4 / 2) \text { very fine sand; weak fine suban- } \\
\text { gular blocky structure; very friable; clear wavy bound- } \\
\text { ary; pH } 4.3 \text {. }\end{array}$ \\
\hline Bh & 23 & -30 & $\mathrm{~cm}$ & $\begin{array}{l}\text { Dark reddish brown ( } 5 \mathrm{YR} 3 / 4 \text { ) loamy very fine sand; weak } \\
\text { fine subangular blocky structure; friable; abrupt smooth } \\
\text { boundary; pH } 4.2 \text {. }\end{array}$ \\
\hline Bhs & 30 & -36 & $\mathrm{~cm}$ & $\begin{array}{l}\text { Dark brown ( } 7.5 Y R 3 / 4 \text { ) very fine sand; weak medium sub- } \\
\text { angular blocky structure; very friable; clear wavy } \\
\text { boundary; pH } 4.3 \text {. }\end{array}$ \\
\hline Bs & 36 & -42 & $\mathrm{~cm}$ & $\begin{array}{l}\text { Dark yellowish brown (10YR 4/4) loamy very fine sand; } \\
\text { weak fine subangular blocky structure; very friable; }\end{array}$ \\
\hline
\end{tabular}




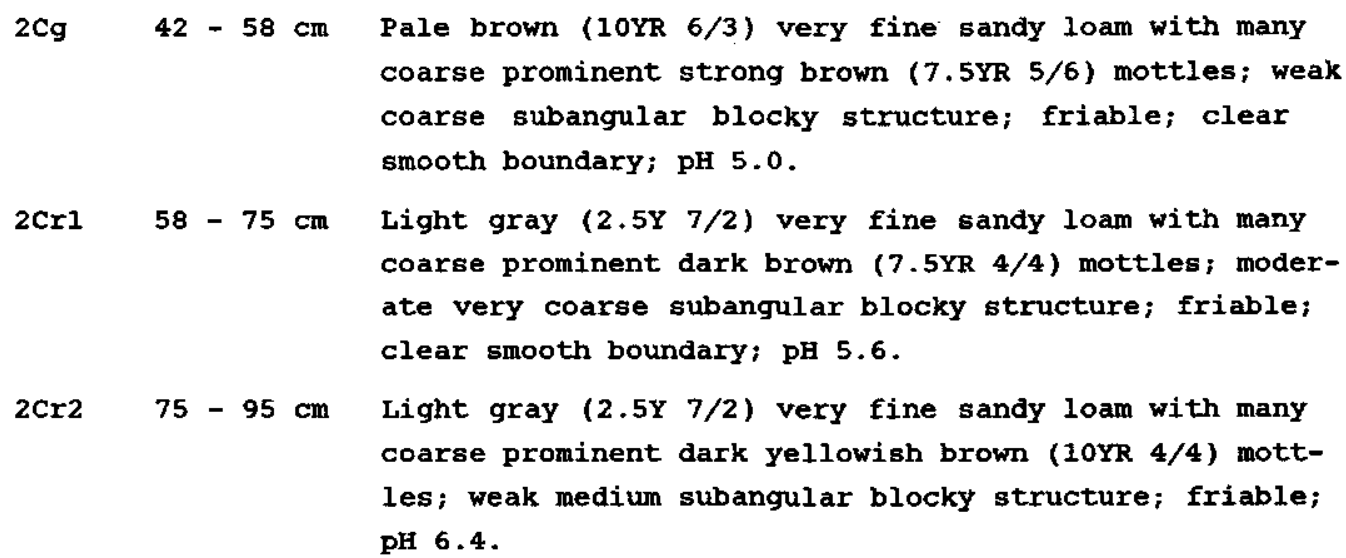

ISM PROFILE NO.: GMC-6

Location : Velikiye Luki Region, soviet Union About $56^{\circ} \mathrm{N}, 30^{\circ} \mathrm{E}$

\section{Profile description}

Ap $0-12 \mathrm{~cm}$

Dark grayish brown (10YR 4/2) clay loam; weak medium subangular blocky structure; firm; abrupt smooth boundary; $\mathrm{pH} 6.5$.

$\mathrm{E} / \mathrm{B} \quad 12-21 \mathrm{~cm}$

Pale brown (10YR 6/3) A part; dark brown (7.5YR 4/4) B part; silty clay loam; weak medium subangular blocky structure; firm; clear wavy boundary; $\mathrm{pH} 5.4$.

B/E $\quad 21-30 \mathrm{~cm}$ Reddish brown (5YR 4/4) B part; light yellowish brown (10YR 6/4) A part; silty clay; weak fine subangular blocky structure; very firm; clear wavy boundary; pH 5.1.

Bt $\quad 30-57 \mathrm{~cm}$ Reddish brown (5YR 4/4) silty clay; moderate very fine angular blocky structure; very firm; abrupt wavy boundary; $\mathrm{pH}$ 5.0.

$2 \mathrm{Cr} \quad 57-66 \mathrm{~cm}$

Gray (10YR 6/1) clay with common medium prominent strong brown (7.5YR 4/6) mottles; weak fine angular blocky structure, very firm; abrupt wavy boundary; pH 4.9 .

$2 \mathrm{C1} \quad 66-73 \mathrm{~cm}$ Dark brown (7.5YR 4/4) clay with common fine distinct yellowish brown (10YR 5/6) and gray (5Y 6/1) mottles; weak medium subangular blocky structure; very firm; abrupt wavy boundary; $\mathrm{pH} .5 .0$. 


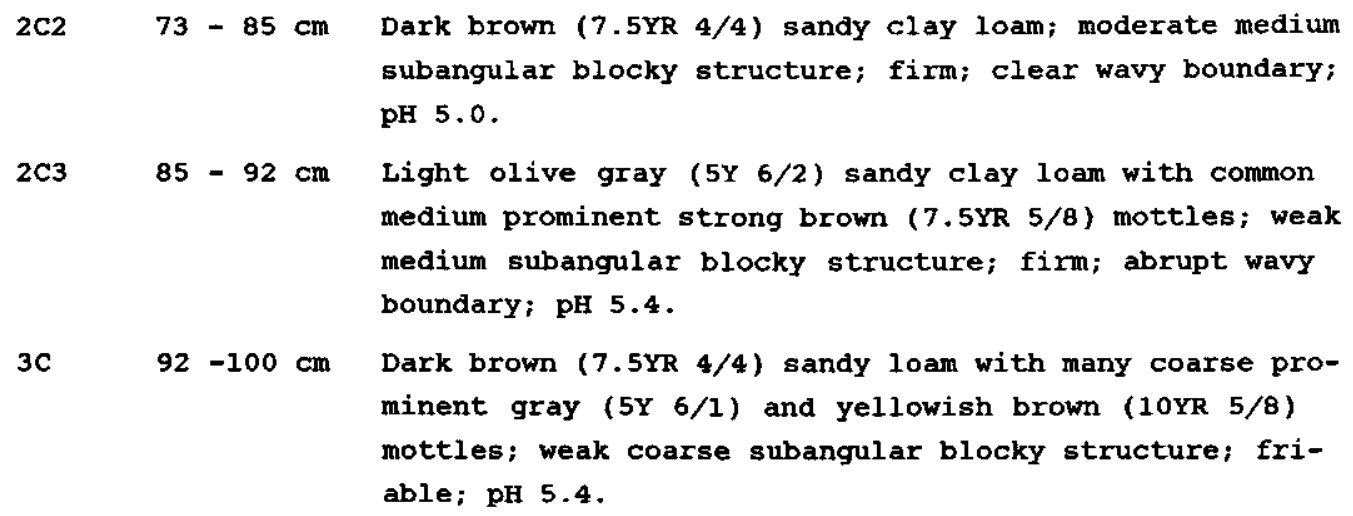

ISM PROFILE NO.: GMC-7

Location : Near Leningrad, Soviet Union About $60^{\circ} \mathrm{N}, 30^{\circ} \mathrm{E}$

\section{Profile description}

\begin{tabular}{|c|c|c|c|c|}
\hline Ah & 0 & $5 c$ & $\mathrm{~cm}$ & $\begin{array}{l}\text { Very dark grayish brown (10YR } 3 / 2 \text { ) loam; weak medium } \\
\text { granular structure; friable; clear smooth boundary. }\end{array}$ \\
\hline Bs & 5 & $-13 c$ & $\mathrm{~cm}$ & $\begin{array}{l}\text { Yellowish brown (10YR 5/4) loam; weak medium subangular } \\
\text { blocky structure; friable; clear smooth boundary; } \\
\text { pH } 4.8 \text {. }\end{array}$ \\
\hline $\mathbf{E}$ & 13 & $-25 c$ & $\mathrm{~cm}$ & $\begin{array}{l}\text { Light brownish gray }(2.5 Y 6 / 2) \text { loam; very weak fine } \\
\text { subangular blocky structure; friable; abrupt irregular } \\
\text { boundary; pH } 4.9 \text {. }\end{array}$ \\
\hline t. & 25 & -54 & $\mathrm{crn}$ & $\begin{array}{l}\text { Dark yellowish brown (10YR } 4 / 4 \text { ) loam; weak medium sub- } \\
\text { angular blocky structure; friable; clear wavy boundary; } \\
\text { pH } 5.1 \text {. }\end{array}$ \\
\hline t.2 & 54 & $-69 c$ & $\mathrm{~cm}$ & $\begin{array}{l}\text { Yellowish brown (10YR 5/4) loam with coarse medium dis- } \\
\text { tinct strong brown ( } 7.5 \mathrm{YR} 5 / 6) \text { mottles; weak medium } \\
\text { subangular blocky structure; friable; clear smooth } \\
\text { boundary; pH } 5.8 \text {. }\end{array}$ \\
\hline $\mathrm{Cr}$ & 69 & -85 & $\mathrm{~cm}$ & $\begin{array}{l}\text { Grayish brown }(2.5 Y 5 / 2) \text { loam with coarse medium promi- } \\
\text { nent yellowish brown (loYR } 5 / 6) \text { mottles; weak coarse } \\
\text { platy to weak fine subangular blocky structure; friable; } \\
\text { clear smooth boundary; pH } 5.8 \text {. }\end{array}$ \\
\hline & 85 & -100 & $\mathrm{~cm}$ & $\begin{array}{l}\text { Light olive brown }(2.5 Y 5 / 4) \text { loam with many coarse dis- } \\
\text { tinct olive gray }(5 y 5 / 2) \text { mottles; weak coarse platy } \\
\text { to weak medium subangular blocky structure; friable; } \\
\text { pH } 5.3 \text {. }\end{array}$ \\
\hline
\end{tabular}




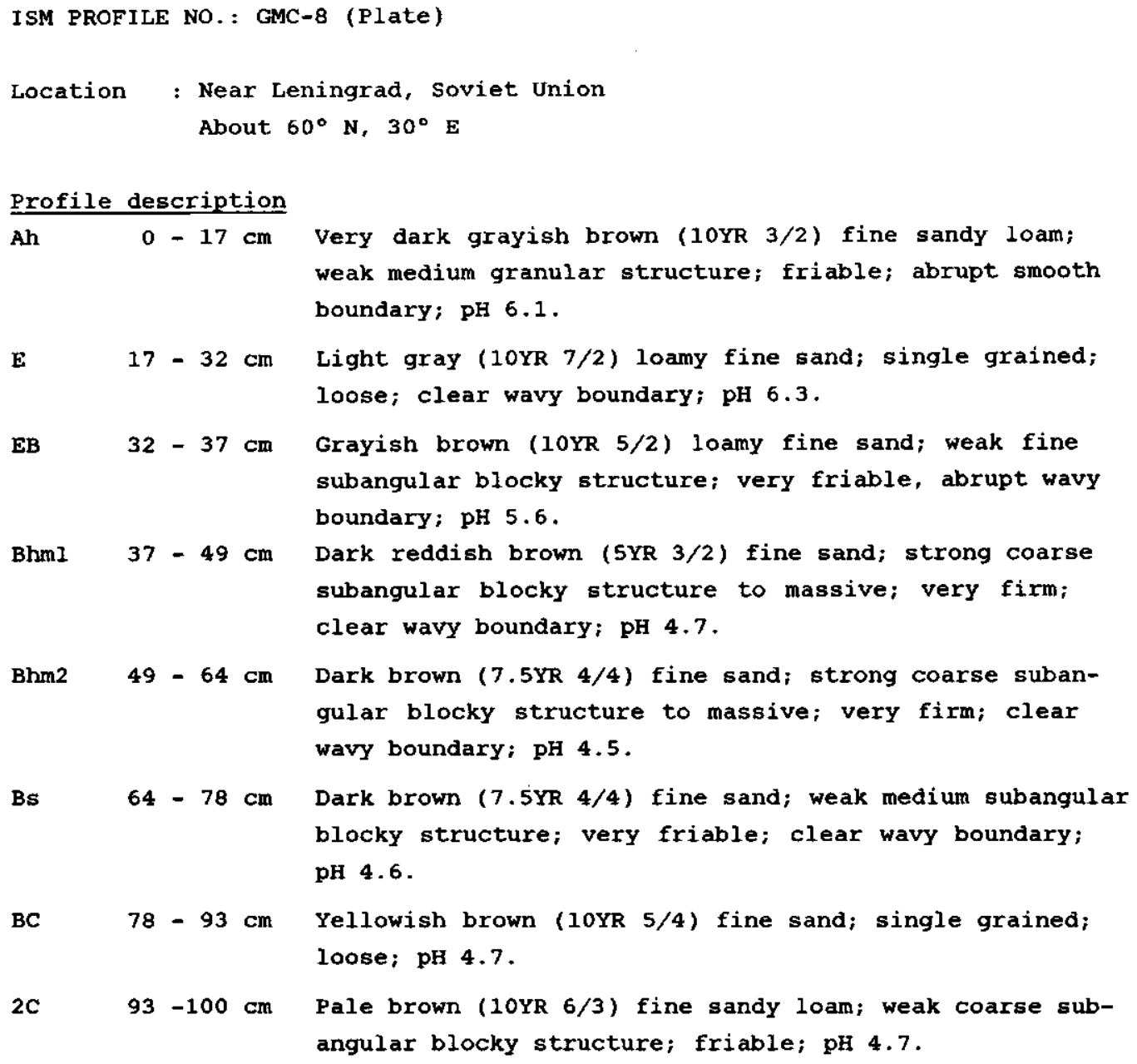

ISM PROFILE NO.: GMC-13

Location : Rzhev District of Kaolin Oblast, Soviet Union About $56^{\circ} \mathrm{N}, 35^{\circ} \mathrm{E}$

\section{Profile description}

$04-0 \mathrm{~cm}$

Black (10YR 2/1) charred twigs; abrupt smooth boundary.

Ah 0 - $10 \mathrm{~cm}$ Grayish brown (10YR 5/2) sandy loam; weak medium subangular blocky structure; friable; clear wavy boundary; pH 4.0.

E1 $\quad 10-19 \mathrm{~cm}$ Light gray (10YR 7/2) sandy loam, weak medium subangular blocky structure; friable; abrupt smooth boundary; pH 4.8 . 
Bs

E2

2Bt2
$32-46 \mathrm{~cm}$

$19-32 \mathrm{~cm}$

$46-68 \mathrm{~cm}$

$68-96 \mathrm{~cm}$
2Btl

Yellowish brown (10YR 5/4) sandy loam; weak medium subangular blocky structure; friable; clear wavy boundary; pH 5.2 .

Light yellowish brown (10YR 6/4) sandy loam; weak medium subangular blocky structure; friable; abrupt wavy boundary; $\mathrm{pH} 5.7$.

Light yellowish brown (10YR 6/4) loam with common coarse distinct strong brown $(7.5 Y R 5 / 6)$, dark brown (7.5YR 4/4) and pale brown (10YR 6/3) mottles; weak medium subangular blocky structure; friable; abrupt smooth boundary; pH 4.5.

Brown (7.5YR 5/4) sandy loam with common medium distinct reddish brown (5YR 5/4) and light brown (7.5YR $6 / 4)$ mottles; moderate medium subangular blocky structure; friable; pH 4.6. 

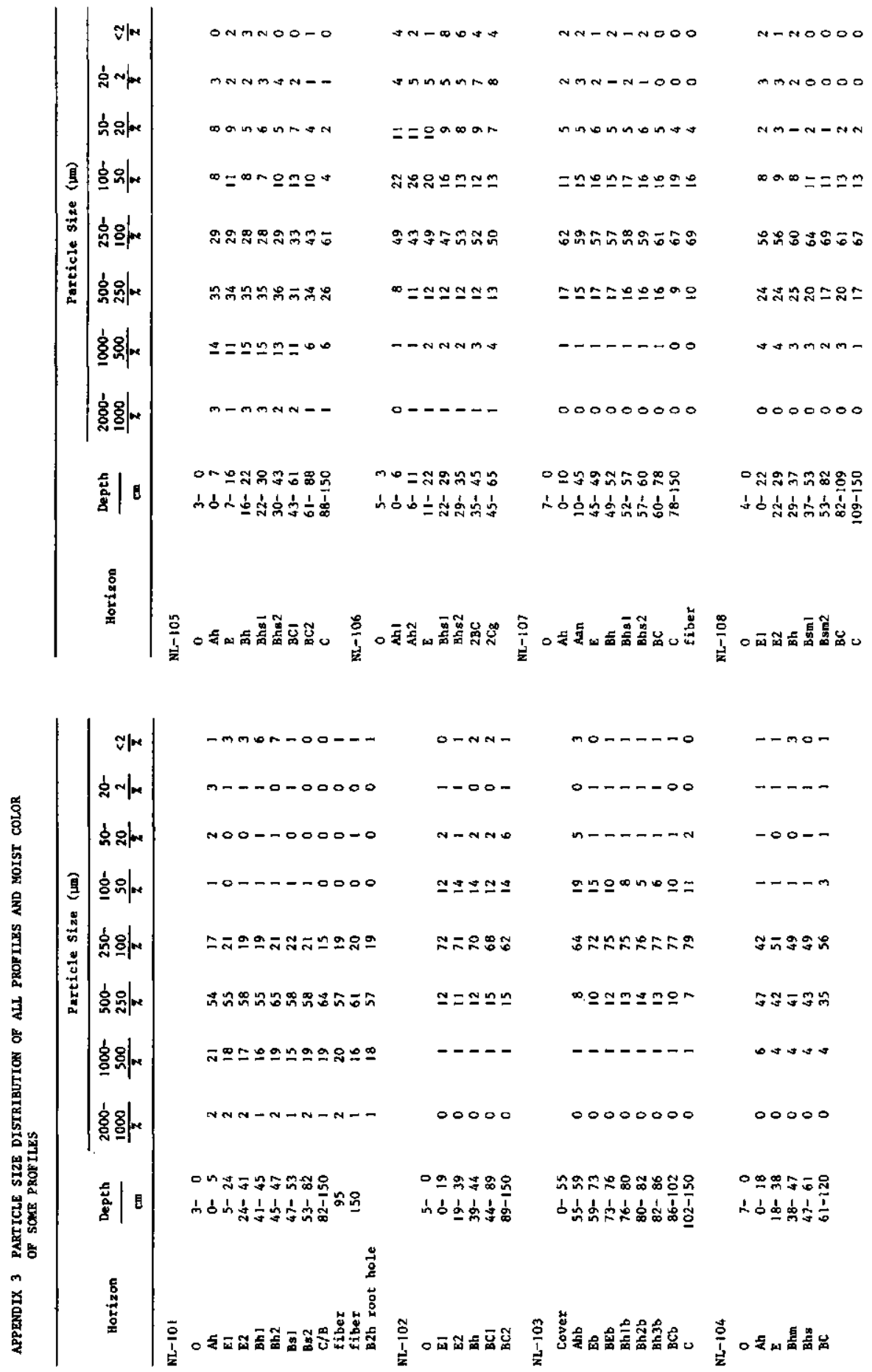

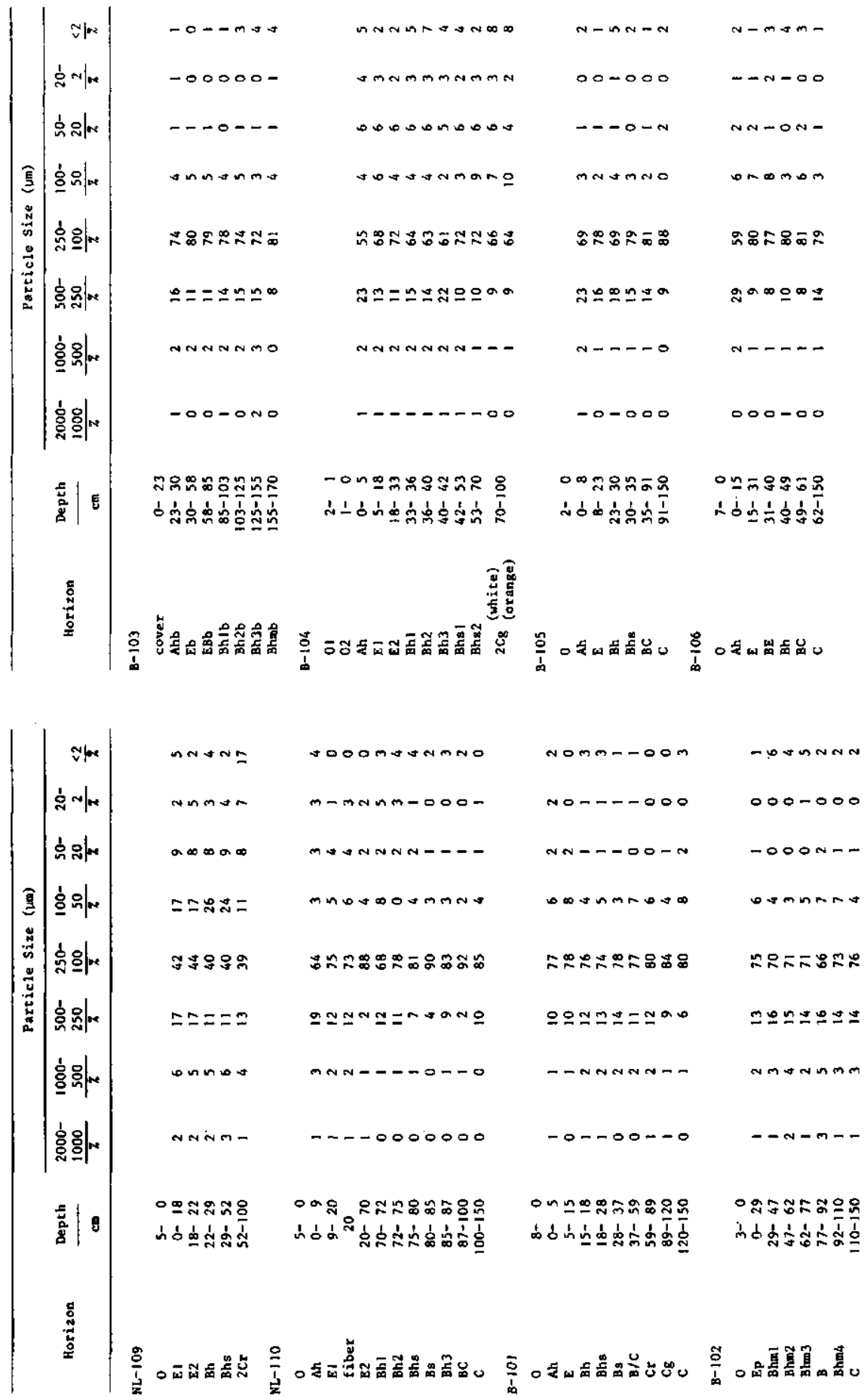

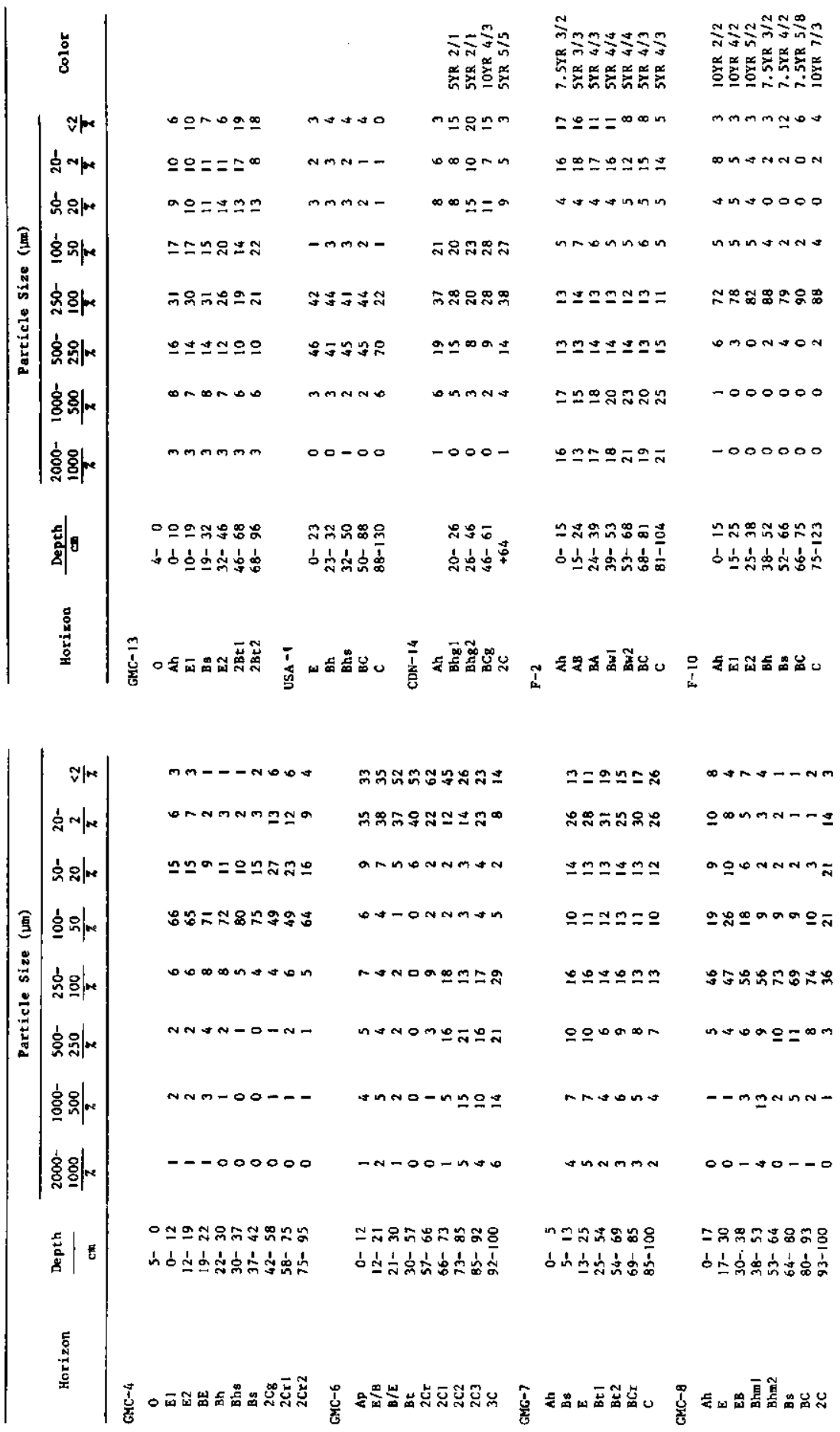


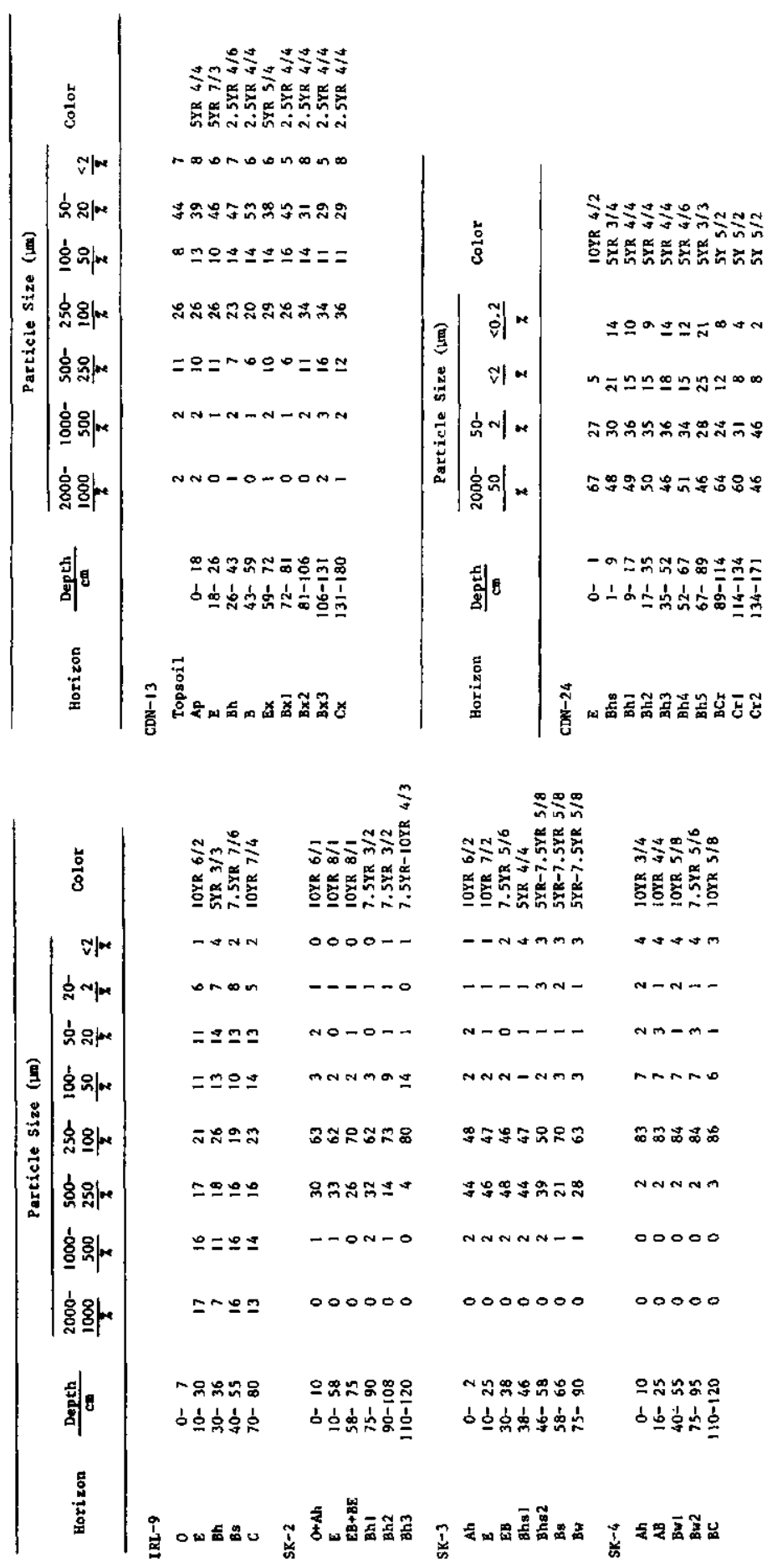




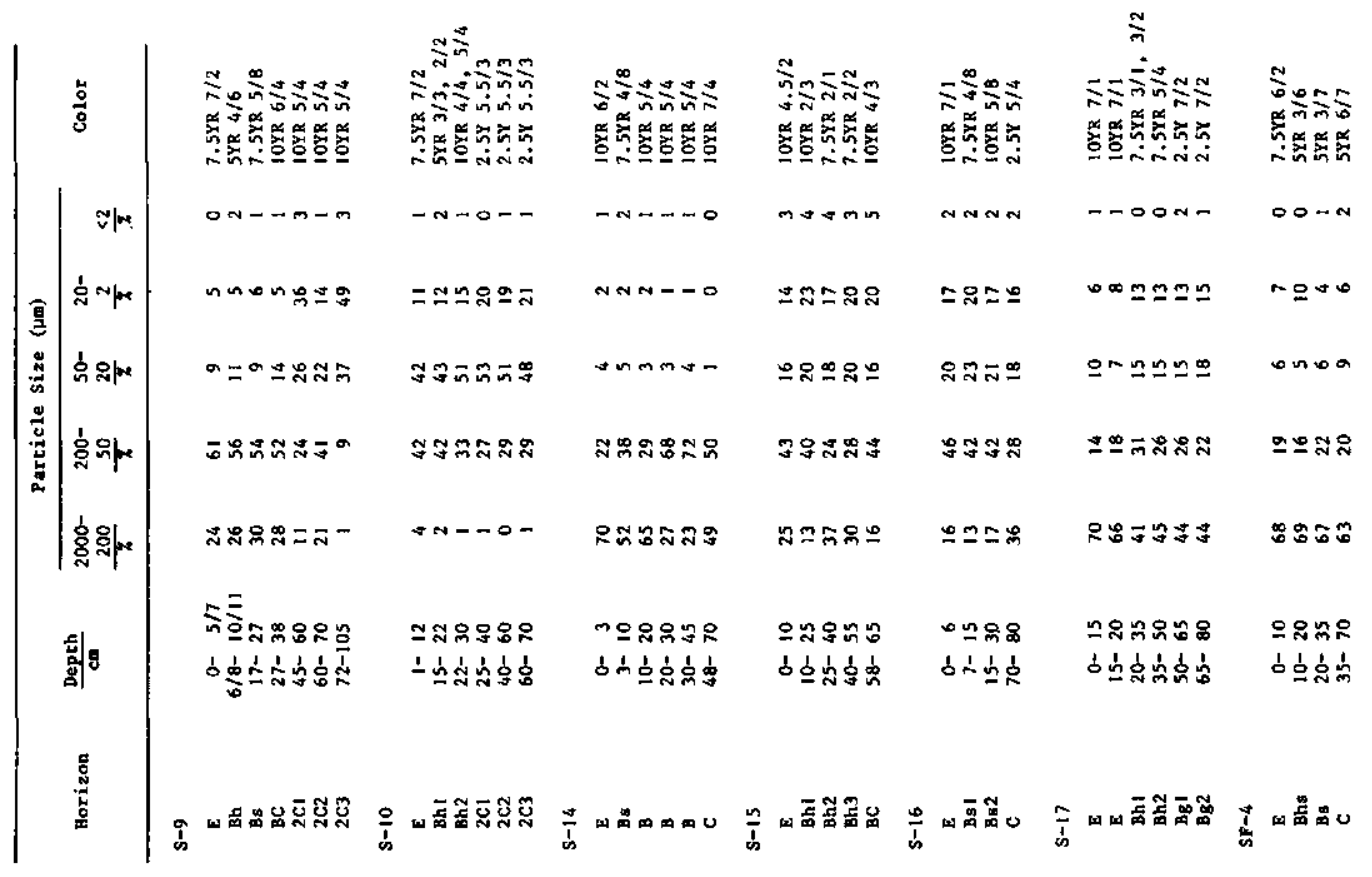

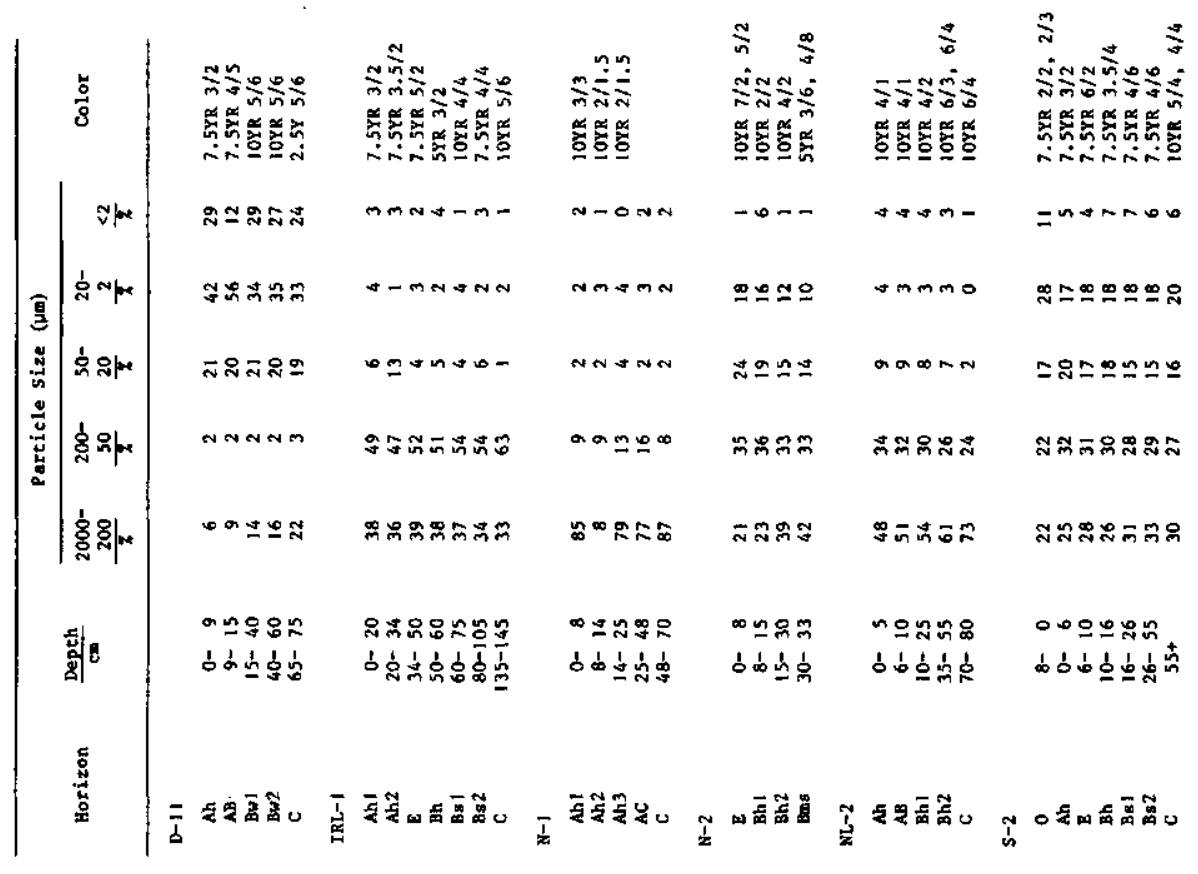




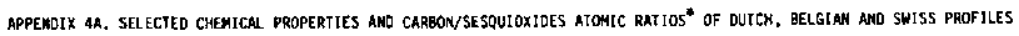

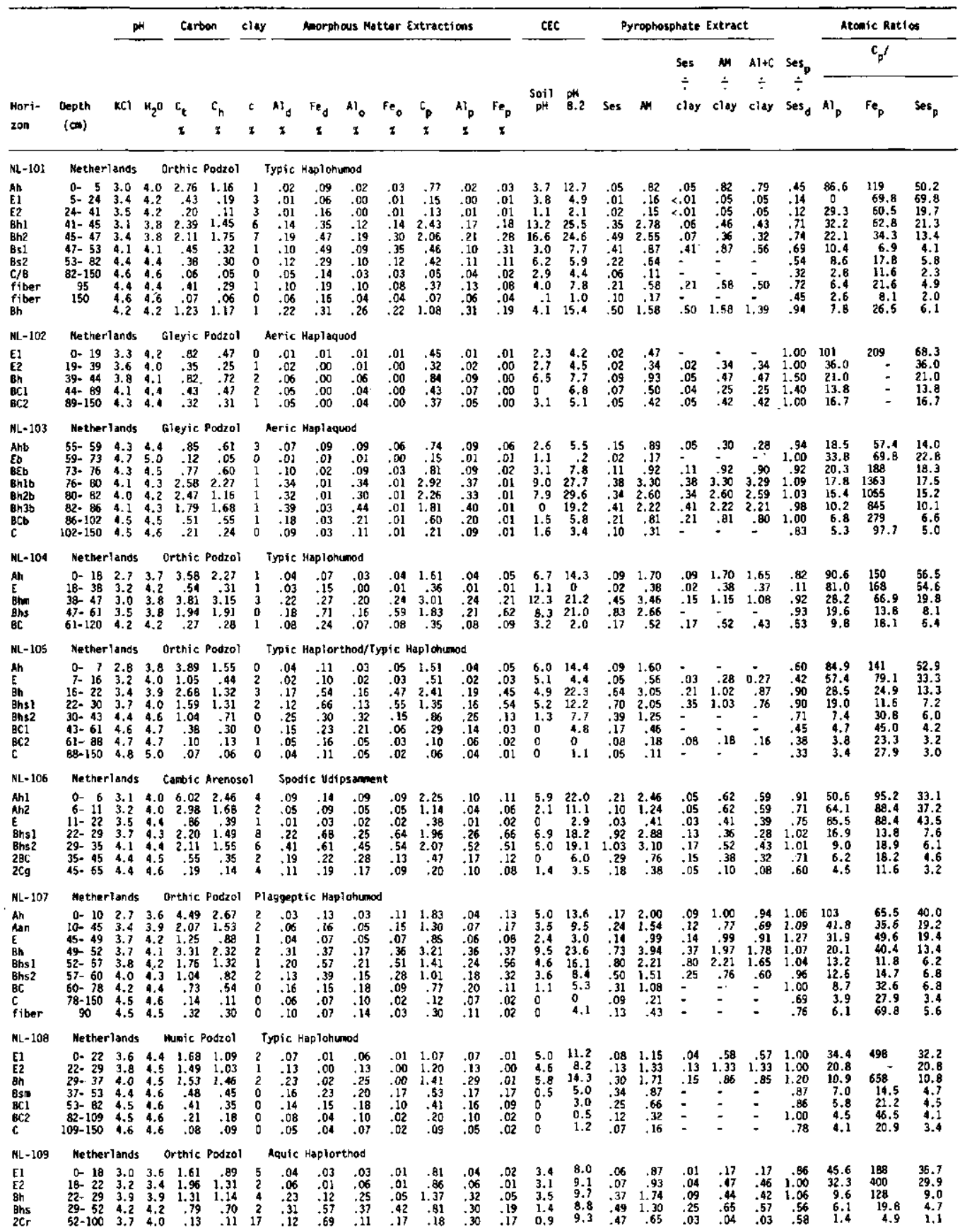




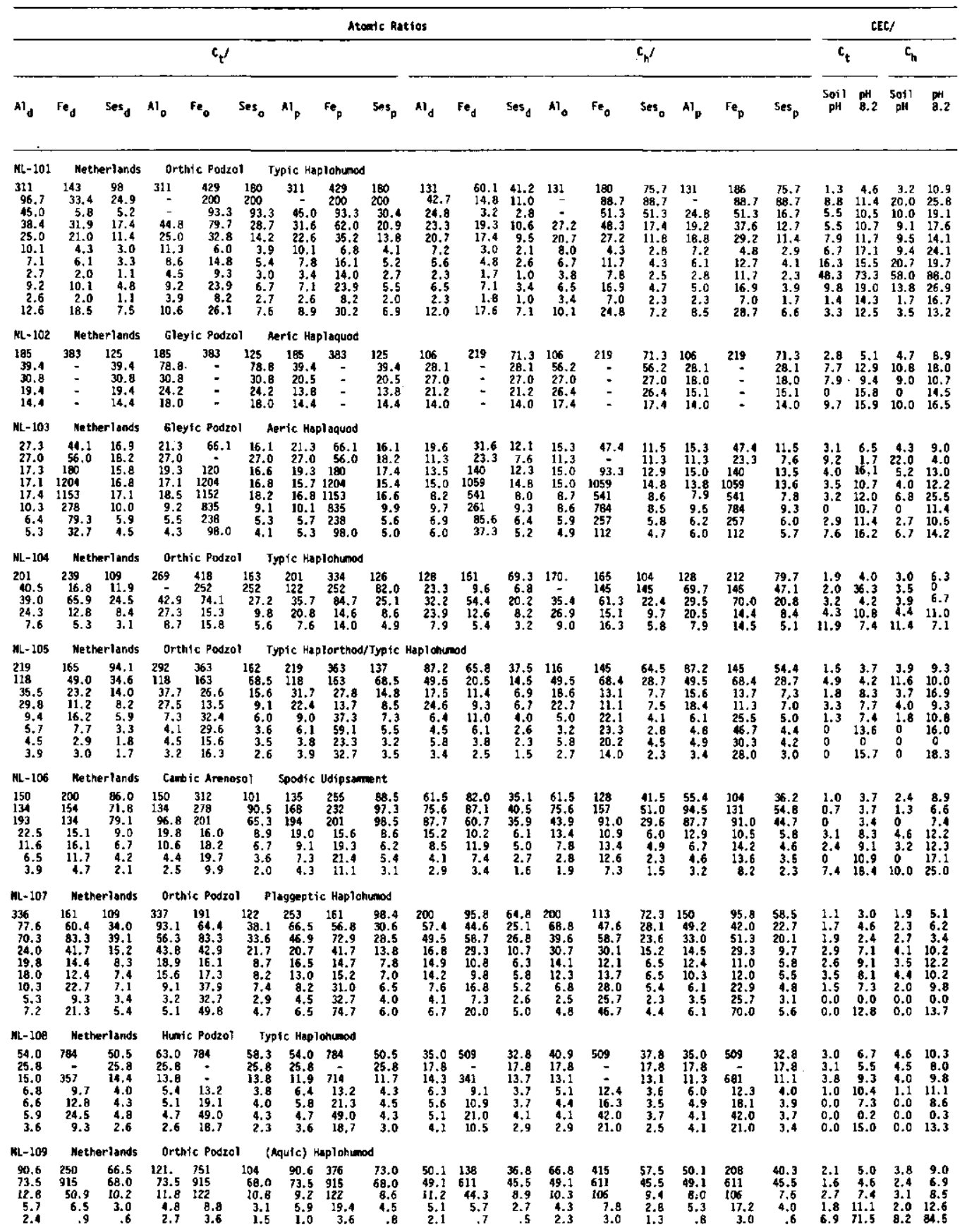


Appendix 4h (ctd). Selected cheaical properties and carbon/sesquioxides atomic ratios" of Dutch. Belgian and Swiss profiles

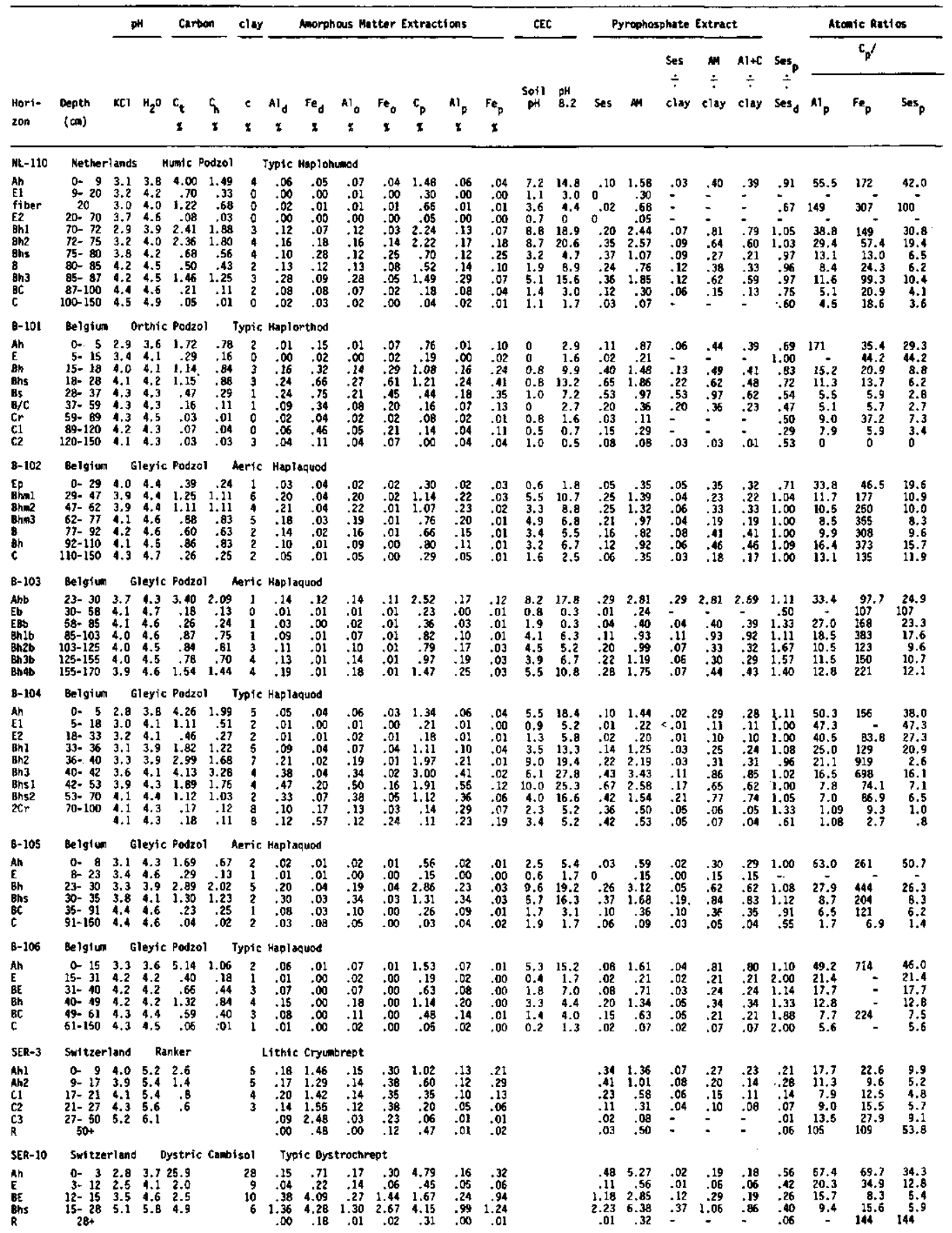




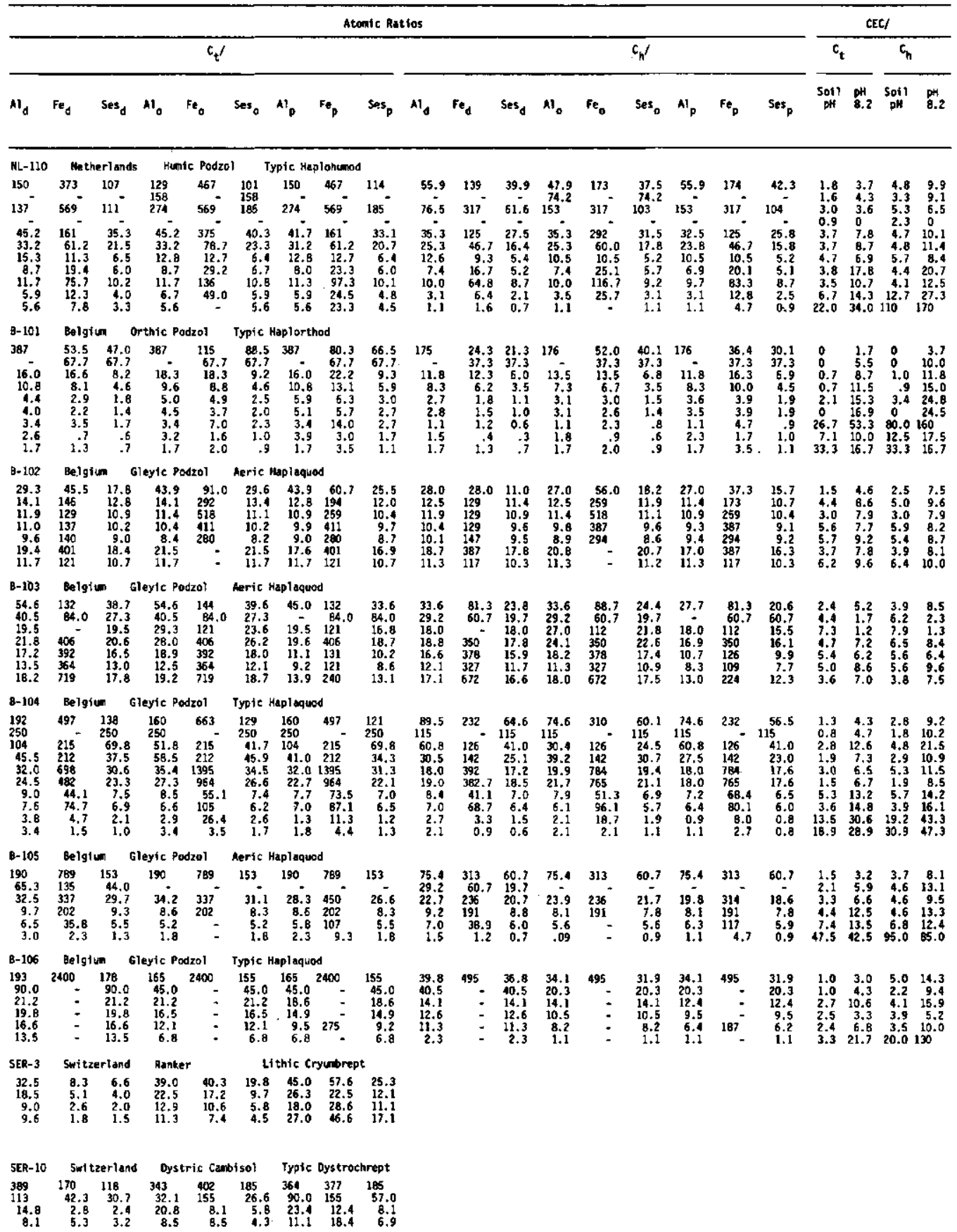


APPEMOIX 4B. SELECTEO CHEMICAL PROPERTIES NO CARBON/SESQUIOXIDES ATOMIC RATIOS" OF PROFILES IM THE ISM COLLECTIOM

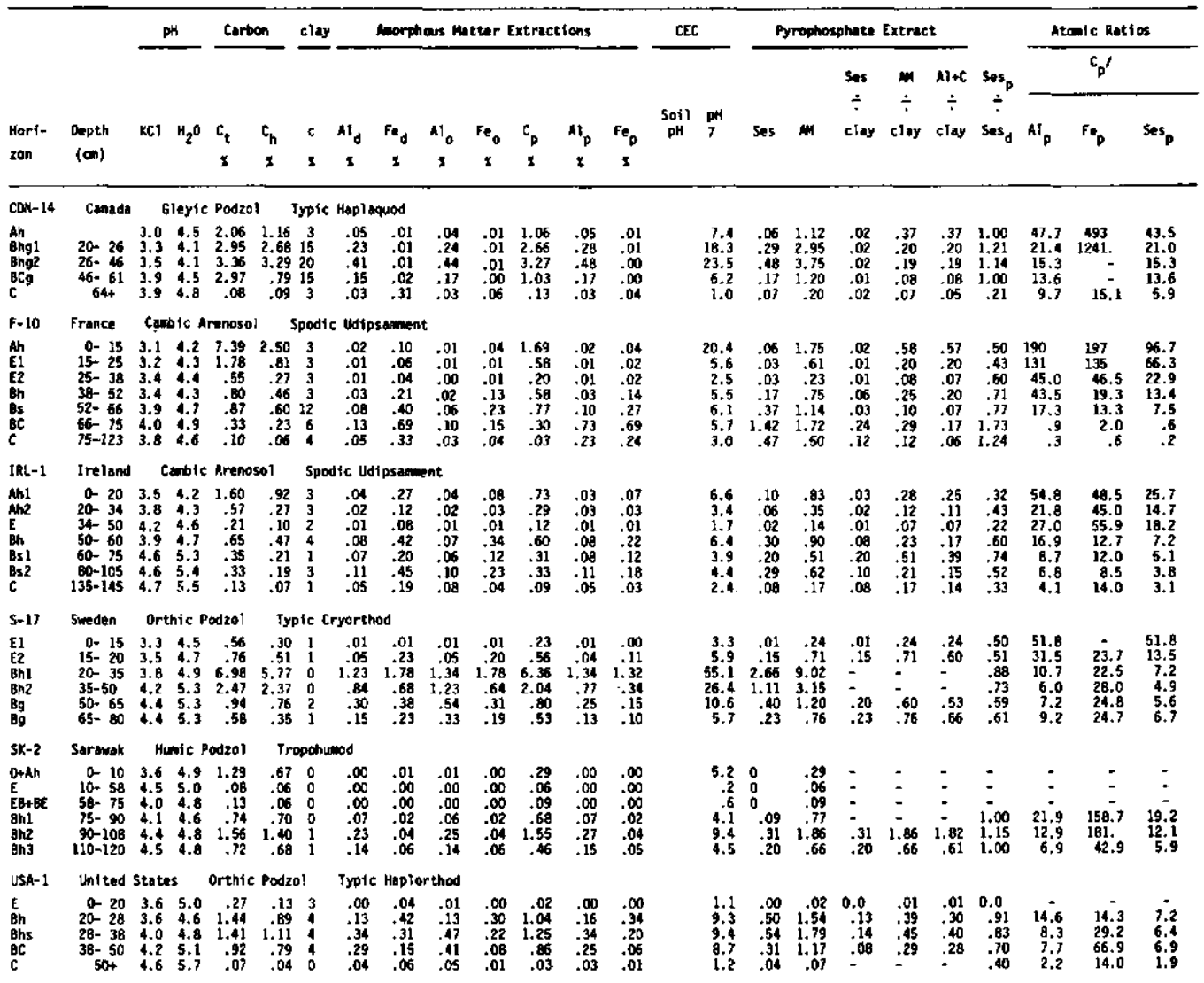




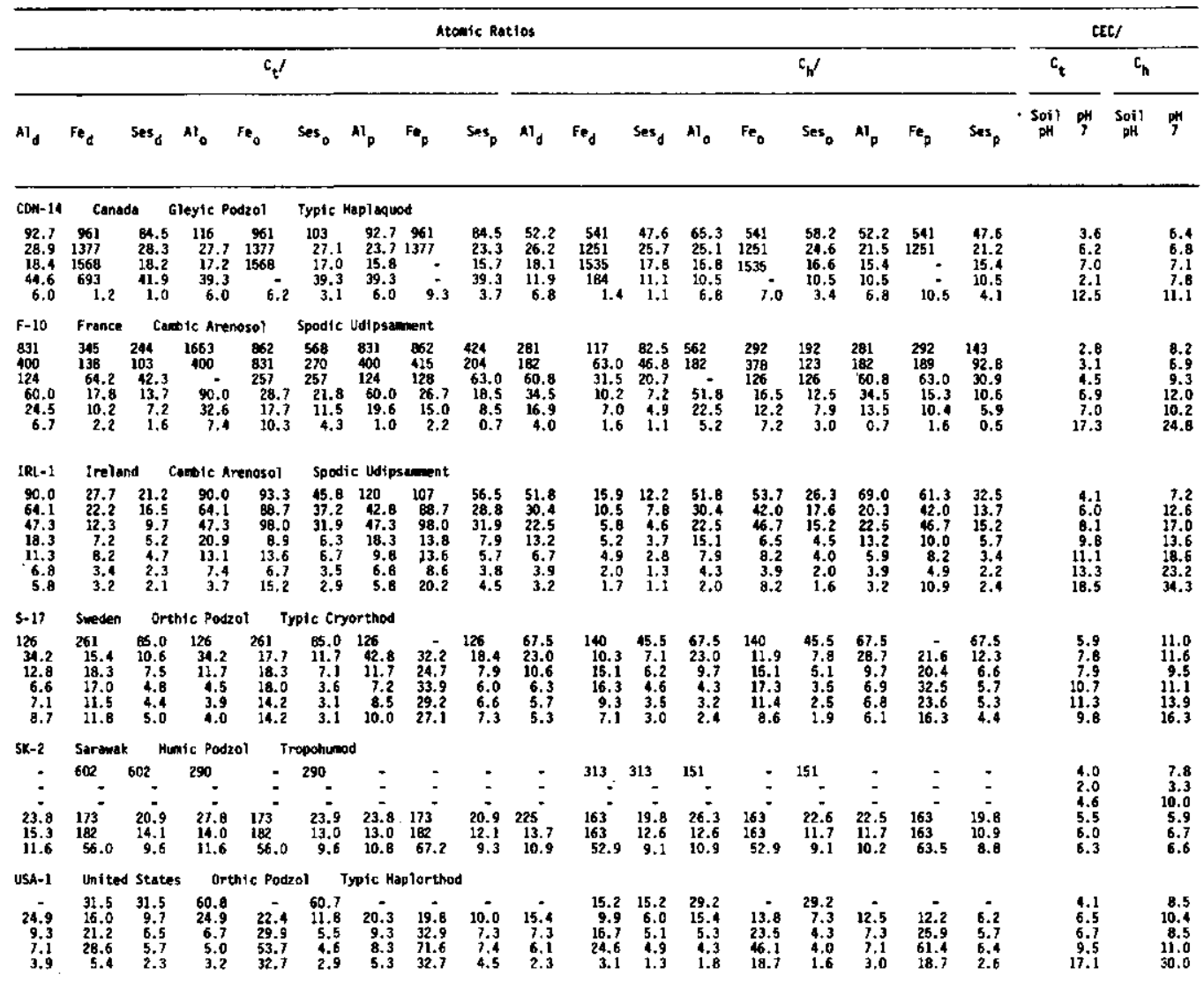


Appendix 48 (ctd). Selected chenical properties and carbon/sesquioxides atomic ratios of profiles in the ISM collection

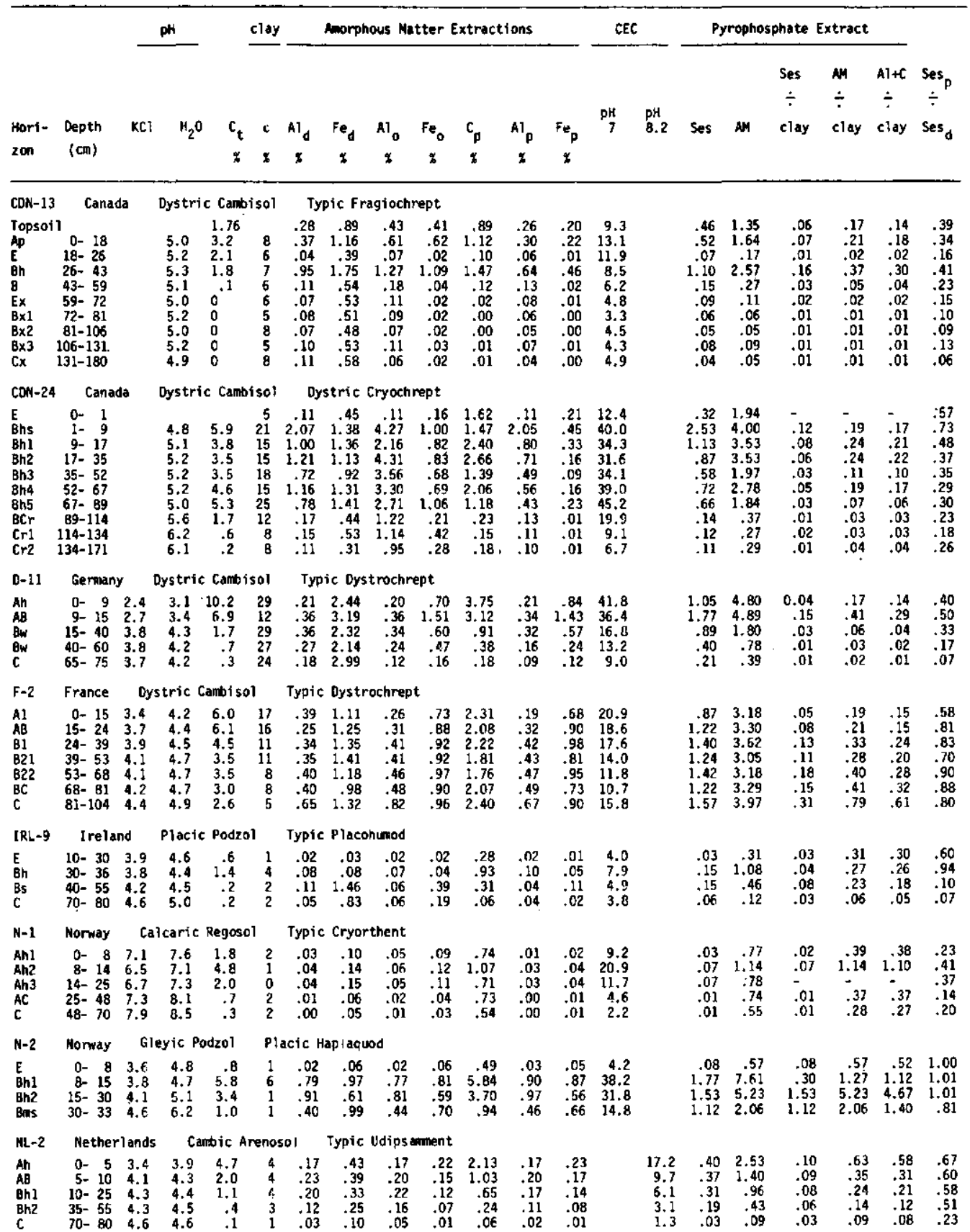




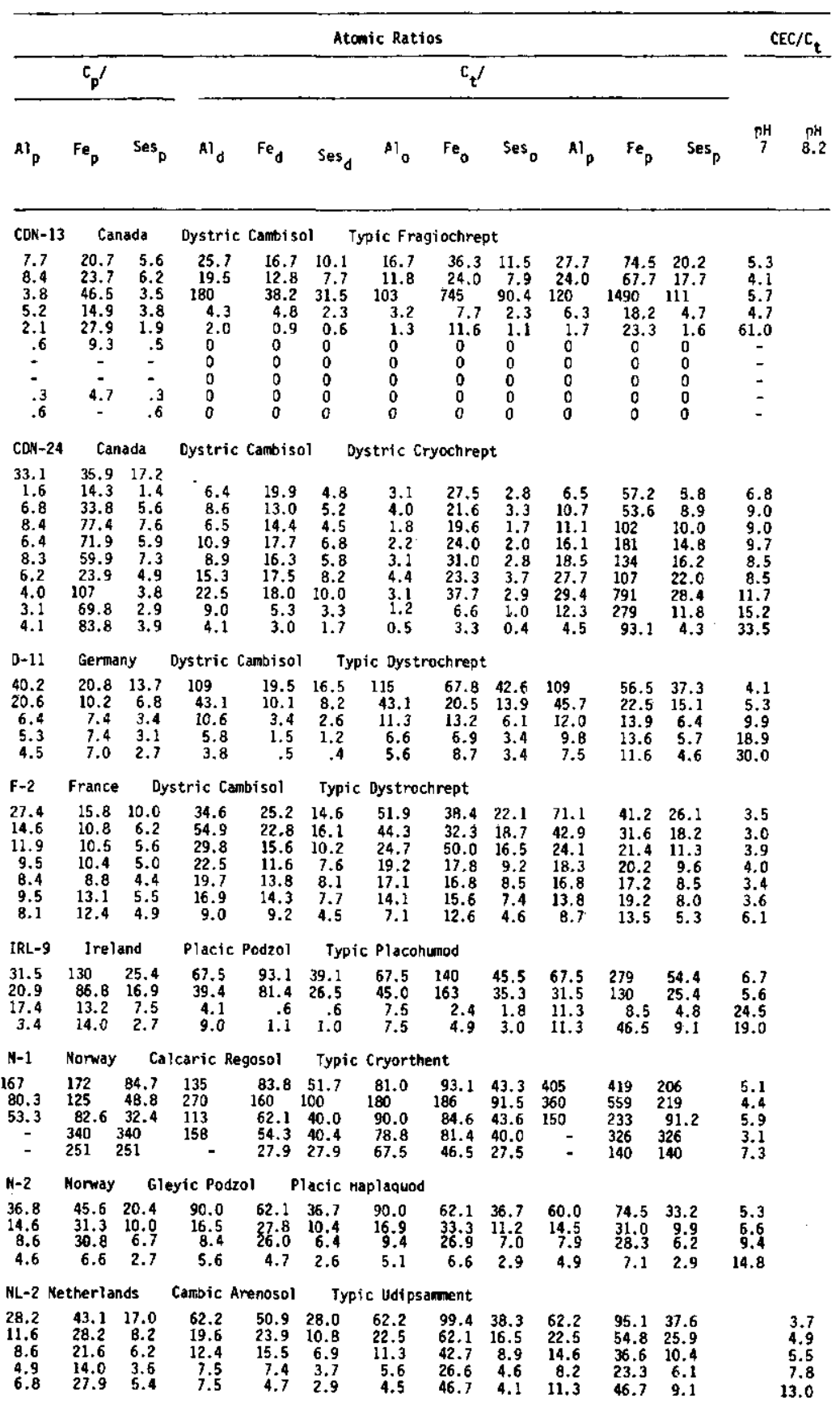


Appendix $4 \mathrm{~B}$ (ctd). Selected chemical properties and carbon/sesquioxides atomic ratios" of profiles in the 1SM collection

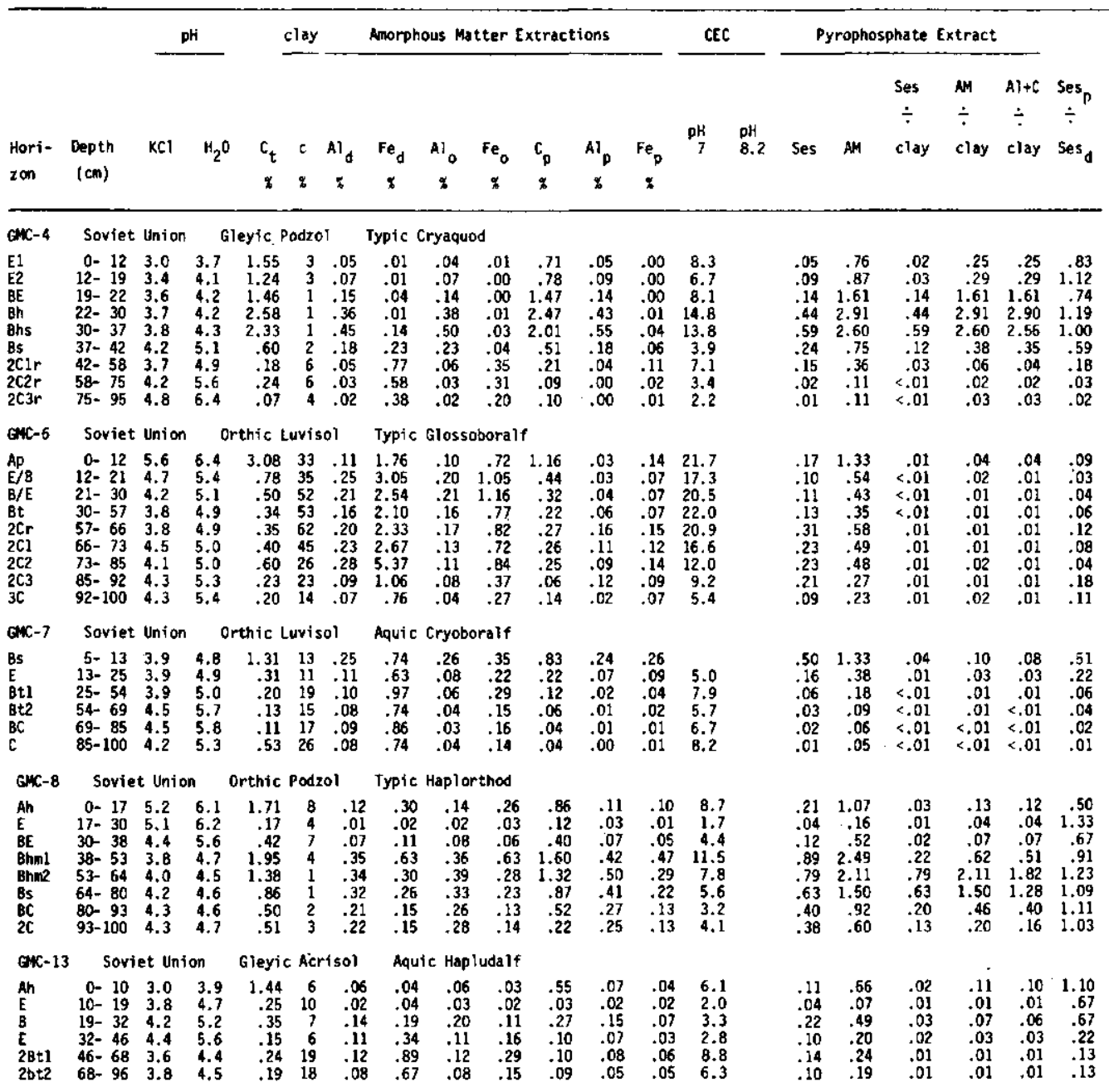




\begin{tabular}{|c|c|c|c|c|c|c|c|c|c|c|c|c|c|}
\hline \multicolumn{12}{|c|}{ Atomic Ratios } & \multicolumn{2}{|c|}{$\mathrm{CEC} / \mathrm{C}_{\mathrm{t}}$} \\
\hline \multicolumn{3}{|c|}{$c_{p^{\prime}}$} & \multicolumn{9}{|c|}{$c_{t^{\prime}}$} & \multirow[b]{2}{*}{$\stackrel{\mathrm{pH}}{7}$} & \multirow[b]{2}{*}{$\begin{array}{l}\mathrm{pH} \\
8.2\end{array}$} \\
\hline$A l_{p}$ & $\mathrm{Fe}_{\mathrm{p}}$ & Ses $_{p}$ & ${ }^{A} l_{d}$ & $\mathrm{Fe}_{\mathrm{d}}$ & Ses $_{d}$ & $A 1_{0}$ & $\mathrm{Fe}_{\mathrm{o}}$ & Ses & $\left.{ }^{A}\right]_{D}$ & $\mathrm{Fe}_{\mathrm{p}}$ & Sesp $_{p}$ & & \\
\hline GMC-4 & \multicolumn{2}{|c|}{ Soviet Union } & \multicolumn{3}{|c|}{ Gleyic Podzol } & Typic C & ryaquod & & & & & & \\
\hline $\begin{array}{r}32.0 \\
19.5 \\
23.6 \\
12.9 \\
8.2 \\
6.4 \\
11.8 \\
- \\
-\end{array}$ & $\begin{array}{r}- \\
1153 \\
234 \\
39.7 \\
8.9 \\
20.9 \\
46.5\end{array}$ & $\begin{array}{r}32.0 \\
19.5 \\
23.6 \\
12.8 \\
7.9 \\
5.5 \\
5.1 \\
20.9 \\
46.5\end{array}$ & $\begin{array}{r}69.8 \\
39.9 \\
21.9 \\
16.1 \\
11.7 \\
7.5 \\
8.1 \\
18.0 \\
7.9\end{array}$ & $\begin{array}{r}723 \\
579 \\
170 \\
1204 \\
77.7 \\
12.2 \\
1.1 \\
1.9 \\
0.9\end{array}$ & $\begin{array}{r}63.6 \\
37.3 \\
19.4 \\
15.9 \\
10.1 \\
4.6 \\
1.0 \\
1.7 \\
0.8\end{array}$ & $\begin{array}{r}87.2 \\
39.9 \\
23.5 \\
15.3 \\
10.5 \\
5.9 \\
6.8 \\
18.0 \\
7.9\end{array}$ & $\begin{array}{r}723 \\
- \\
1204 \\
362 \\
70.0 \\
2.4 \\
3.6 \\
1.6\end{array}$ & $\begin{array}{r}77.8 \\
39.9 \\
23.5 \\
15.1 \\
10.2 \\
5.4 \\
1.8 \\
3.0 \\
1.4\end{array}$ & $\begin{array}{r}69.8 \\
31.0 \\
23.5 \\
13.5 \\
9.5 \\
7.5 \\
10.0 \\
- \\
-\end{array}$ & $\begin{array}{r}: \\
1204 \\
272 \\
46.7 \\
7.6 \\
56.0 \\
32.7\end{array}$ & $\begin{array}{r}69.7 \\
31.0 \\
23.5 \\
13.4 \\
9.2 \\
6.5 \\
4.4 \\
56.0 \\
32.7\end{array}$ & $\begin{array}{r}5.4 \\
5.4 \\
5.5 \\
5.7 \\
5.9 \\
6.5 \\
39.0 \\
14.2 \\
31.4\end{array}$ & \\
\hline GMC -6 & \multicolumn{2}{|c|}{ Soviet Union } & \multicolumn{3}{|c|}{ Orthic Luvisol } & \multicolumn{3}{|c|}{ Typic Glossoboralf } & & & & & \\
\hline $\begin{array}{r}87.0 \\
33.0 \\
18.0 \\
8.2 \\
3.8 \\
5.3 \\
6.3 \\
1.1 \\
15.8\end{array}$ & $\begin{array}{r}38.6 \\
29.3 \\
21.3 \\
14.6 \\
8.4 \\
10.1 \\
8.3 \\
3.1 \\
9.3\end{array}$ & $\begin{array}{r}26.7 \\
15.5 \\
9.8 \\
5.3 \\
2.6 \\
3.5 \\
3.5 \\
.8 \\
5.9\end{array}$ & $\begin{array}{r}63.0 \\
7.0 \\
5.4 \\
4.8 \\
3.9 \\
3.9 \\
4.8 \\
5.8 \\
6.4\end{array}$ & $\begin{array}{l}8.2 \\
1.2 \\
0.9 \\
0.8 \\
0.7 \\
0.7 \\
0.5 \\
1.0 \\
1.2\end{array}$ & $\begin{array}{l}7.2 \\
1.0 \\
0.8 \\
0.7 \\
0.6 \\
0.6 \\
0.5 \\
0.9 \\
1.0\end{array}$ & $\begin{array}{r}69.3 \\
8.8 \\
5.4 \\
4.8 \\
4.6 \\
6.9 \\
12.3 \\
6.5 \\
11.3\end{array}$ & $\begin{array}{r}20.0 \\
3.5 \\
2.0 \\
2.1 \\
2.0 \\
2.6 \\
3.3 \\
2.9 \\
3.5\end{array}$ & $\begin{array}{r}15.5 \\
2.5 \\
1.5 \\
1.4 \\
1.4 \\
1.9 \\
2.6 \\
2.0 \\
2.6\end{array}$ & $\begin{array}{r}231 \\
58.5 \\
28.1 \\
12.8 \\
4.9 \\
8.2 \\
15.0 \\
4.3 \\
22.5\end{array}$ & $\begin{array}{c}103 \\
52.0 \\
33.3 \\
22.7 \\
10.9 \\
15.6 \\
20.0 \\
11.9 \\
13.3\end{array}$ & $\begin{array}{r}71.1 \\
27.5 \\
15.3 \\
8.2 \\
3.4 \\
5.4 \\
8.6 \\
3.2 \\
8.4\end{array}$ & $\begin{array}{r}7.0 \\
22.2 \\
41.0 \\
64.7 \\
59.7 \\
41.5 \\
20.0 \\
40.0 \\
27.0\end{array}$ & \\
\hline GMC-7 & \multicolumn{2}{|c|}{ Soviet Union } & \multicolumn{3}{|c|}{ Orthic Lurisol } & \multicolumn{3}{|c|}{ Aquic Cryoboralf } & & & & & \\
\hline $\begin{array}{r}7.8 \\
7.1 \\
13.5 \\
13.5 \\
9.0 \\
-\end{array}$ & $\begin{array}{l}14.9 \\
11.4 \\
14.0 \\
14.0 \\
18.6 \\
18.6\end{array}$ & $\begin{array}{r}5.1 \\
4.4 \\
6.9 \\
6.9 \\
6.1 \\
18.6\end{array}$ & $\begin{array}{r}11.8 \\
6.3 \\
4.5 \\
3.7 \\
2.8 \\
14.9\end{array}$ & $\begin{array}{l}8.3 \\
2.3 \\
1.0 \\
0.8 \\
0.6 \\
3.3\end{array}$ & $\begin{array}{l}4.9 \\
1.7 \\
0.8 \\
0.7 \\
0.5 \\
2.7\end{array}$ & $\begin{array}{r}11.3 \\
8.7 \\
7.5 \\
7.3 \\
8.3 \\
29.8\end{array}$ & $\begin{array}{r}17.5 \\
6.6 \\
3.2 \\
4.0 \\
3.2 \\
17.7\end{array}$ & $\begin{array}{r}6.9 \\
3.7 \\
2.3 \\
2.6 \\
2.3 \\
11.1\end{array}$ & $\begin{array}{c}12.3 \\
10.0 \\
22.5 \\
29.2 \\
24.8 \\
-\end{array}$ & $\begin{array}{r}23.5 \\
16.1 \\
23.3 \\
30.3 \\
51.3 \\
247\end{array}$ & $\begin{array}{r}8.1 \\
6.2 \\
11.5 \\
14.9 \\
16.7 \\
247\end{array}$ & $\begin{array}{l}16.8 \\
16.1 \\
39.5 \\
43.9 \\
60.9 \\
15.5\end{array}$ & \\
\hline GMC-8 & \multicolumn{2}{|c|}{ Soviet Union } & \multicolumn{3}{|c|}{ Orthic Podzol } & \multicolumn{3}{|c|}{ Typic Haplorthod } & & & & & \\
\hline $\begin{array}{r}17.6 \\
9.0 \\
12.9 \\
8.6 \\
5.9 \\
4.8 \\
4.3 \\
2.0\end{array}$ & $\begin{array}{r}40.0 \\
55.9 \\
37.2 \\
15.8 \\
21.2 \\
18.5 \\
18.6 \\
7.9\end{array}$ & $\begin{array}{r}12.2 \\
7.8 \\
9.6 \\
5.6 \\
4.6 \\
3.8 \\
3.5 \\
1.6\end{array}$ & $\begin{array}{r}32.1 \\
38.3 \\
13.5 \\
12.5 \\
9.1 \\
6.0 \\
5.4 \\
5.2\end{array}$ & $\begin{array}{l}26.6 \\
39.7 \\
17.8 \\
14.4 \\
21.5 \\
15.4 \\
15.6 \\
15.9\end{array}$ & $\begin{array}{r}14.5 \\
19.5 \\
7.7 \\
6.7 \\
6.4 \\
4.3 \\
4.0 \\
3.9\end{array}$ & $\begin{array}{r}27.5 \\
19.1 \\
11.8 \\
12.2 \\
8.0 \\
5.9 \\
4.3 \\
4.1\end{array}$ & $\begin{array}{l}30.7 \\
26.4 \\
32.7 \\
14.4 \\
23.0 \\
17.4 \\
17.9 \\
17.0\end{array}$ & $\begin{array}{r}14.5 \\
11.1 \\
8.7 \\
6.6 \\
5.9 \\
4.4 \\
3.5 \\
3.3\end{array}$ & $\begin{array}{r}35.0 \\
12.8 \\
13.5 \\
10.4 \\
6.2 \\
4.7 \\
4.2 \\
4.6\end{array}$ & $\begin{array}{l}79.8 \\
79.3 \\
39.2 \\
19.4 \\
22.2 \\
18.2 \\
17.9 \\
18.3\end{array}$ & $\begin{array}{r}24.3 \\
11.0 \\
10.0 \\
6.8 \\
4.9 \\
3.7 \\
3.4 \\
3.7\end{array}$ & $\begin{array}{r}5.1 \\
10.0 \\
10.5 \\
5.9 \\
5.7 \\
6.5 \\
6.4 \\
8.0\end{array}$ & \\
\hline GMC- -13 & \multicolumn{2}{|c|}{ Soviet Unior } & \multicolumn{3}{|c|}{ Gleyic Acrisol } & \multicolumn{3}{|c|}{ Aquic Hapludalf } & & & & & \\
\hline $\begin{array}{r}17.7 \\
3.4 \\
4.1 \\
3.2 \\
2.8 \\
4.1\end{array}$ & $\begin{array}{r}64.0 \\
7.0 \\
18.0 \\
15.5 \\
7.8 \\
8.4\end{array}$ & $\begin{array}{r}13.9 \\
2.3 \\
3.3 \\
2.7 \\
2.1 \\
2.7\end{array}$ & $\begin{array}{r}54.0 \\
28.1 \\
5.6 \\
3.1 \\
3.6 \\
5.3\end{array}$ & $\begin{array}{r}168 \\
29.2 \\
8.6 \\
2.1 \\
1.0 \\
1.3\end{array}$ & $\begin{array}{r}40.9 \\
14.3 \\
3.4 \\
1.2 \\
0.8 \\
1.1\end{array}$ & $\begin{array}{r}54.0 \\
18.8 \\
3.9 \\
3.1 \\
3.6 \\
5.3\end{array}$ & $\begin{array}{r}224 \\
58.3 \\
19.8 \\
4.4 \\
3.1 \\
5.9\end{array}$ & $\begin{array}{r}43.5 \\
14.5 \\
3.1 \\
1.8 \\
1.6 \\
2.8\end{array}$ & $\begin{array}{r}46.3 \\
28.1 \\
5.3 \\
4.8 \\
5.3 \\
8.5\end{array}$ & $\begin{array}{l}168 \\
58.3 \\
23.3 \\
23.3 \\
14.8 \\
17.7\end{array}$ & $\begin{array}{r}36.3 \\
19.0 \\
4.3 \\
4.0 \\
3.9 \\
5.8\end{array}$ & $\begin{array}{r}4.2 \\
8.0 \\
9.4 \\
18.7 \\
46.3 \\
33.2\end{array}$ & \\
\hline
\end{tabular}




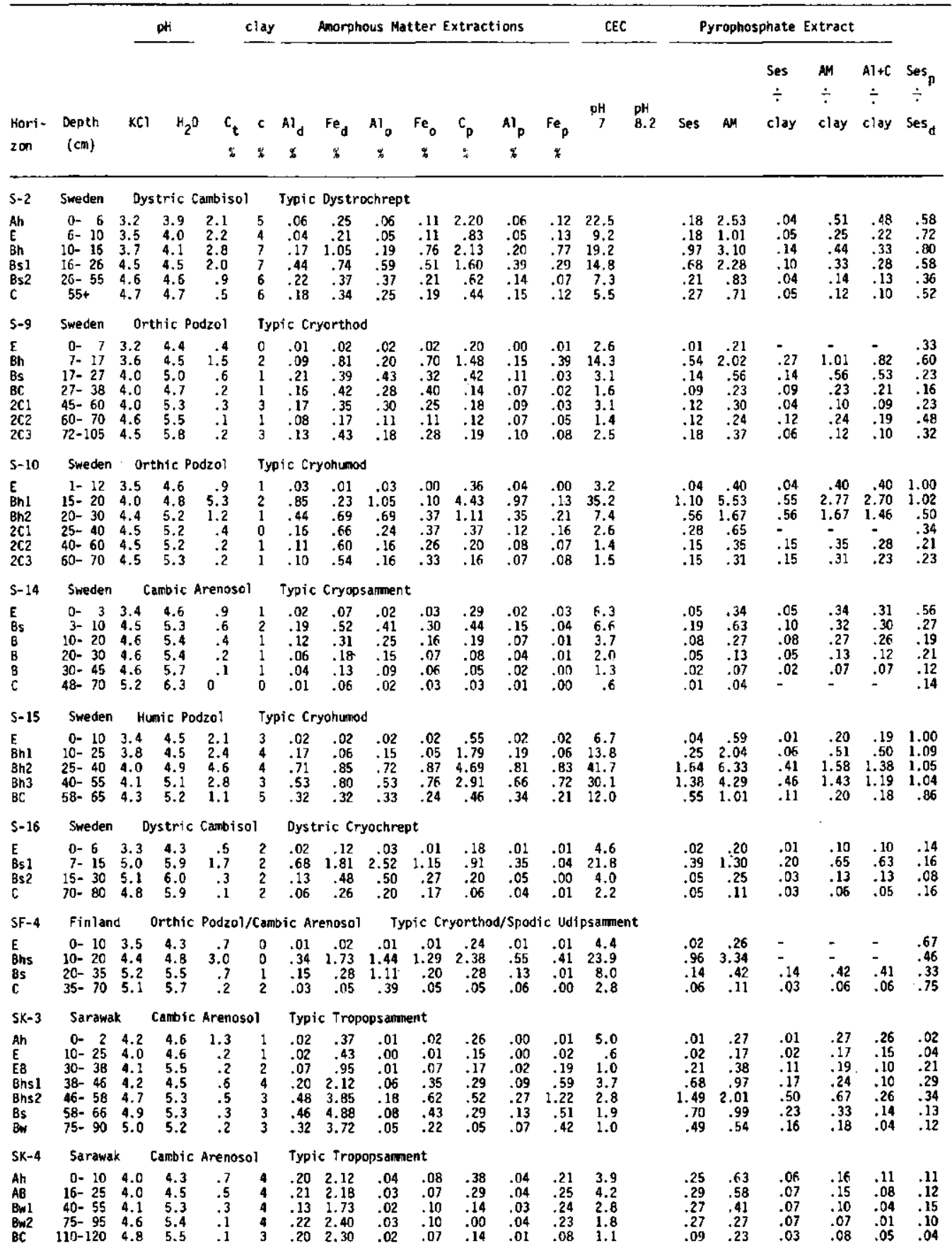




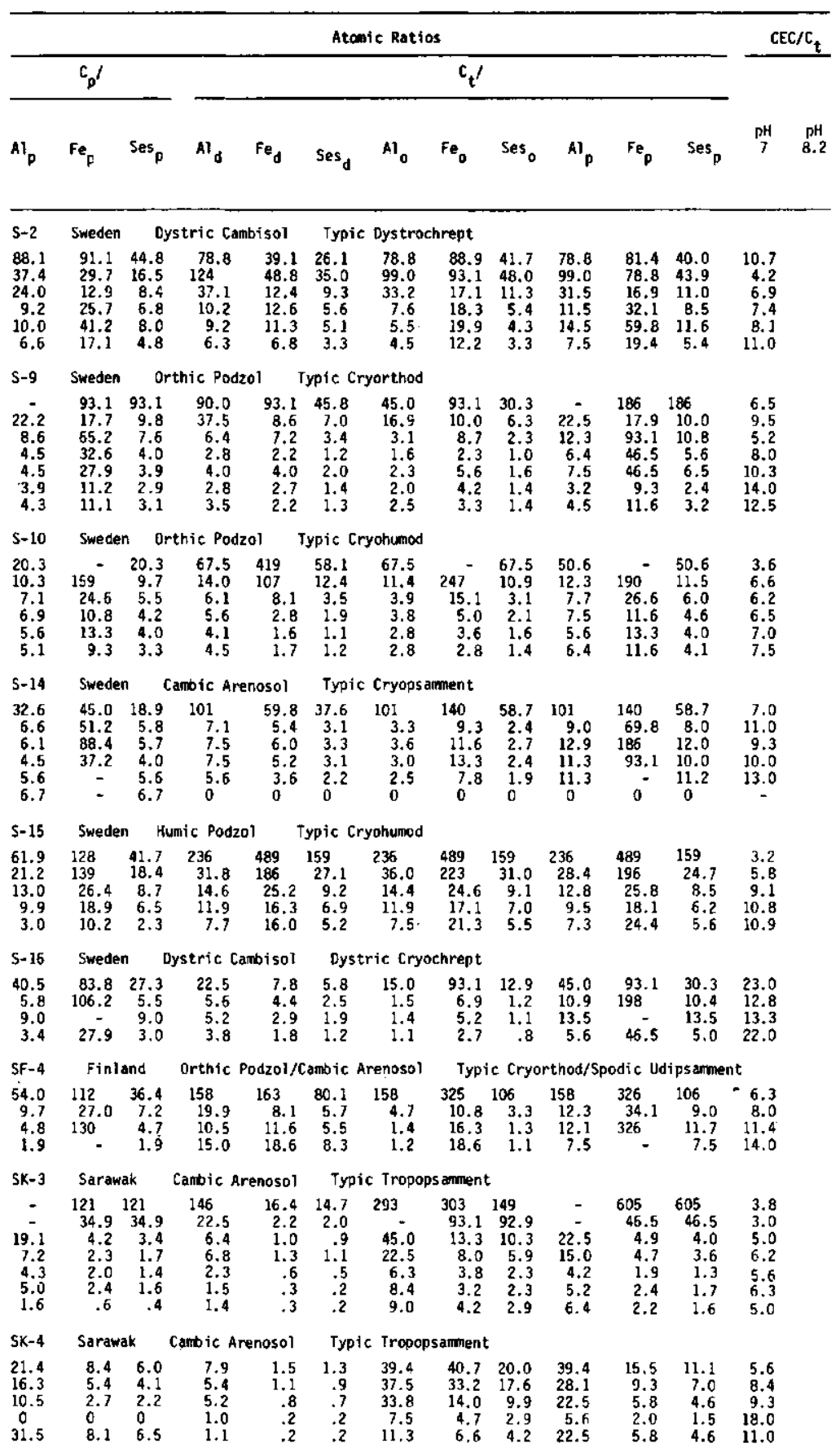




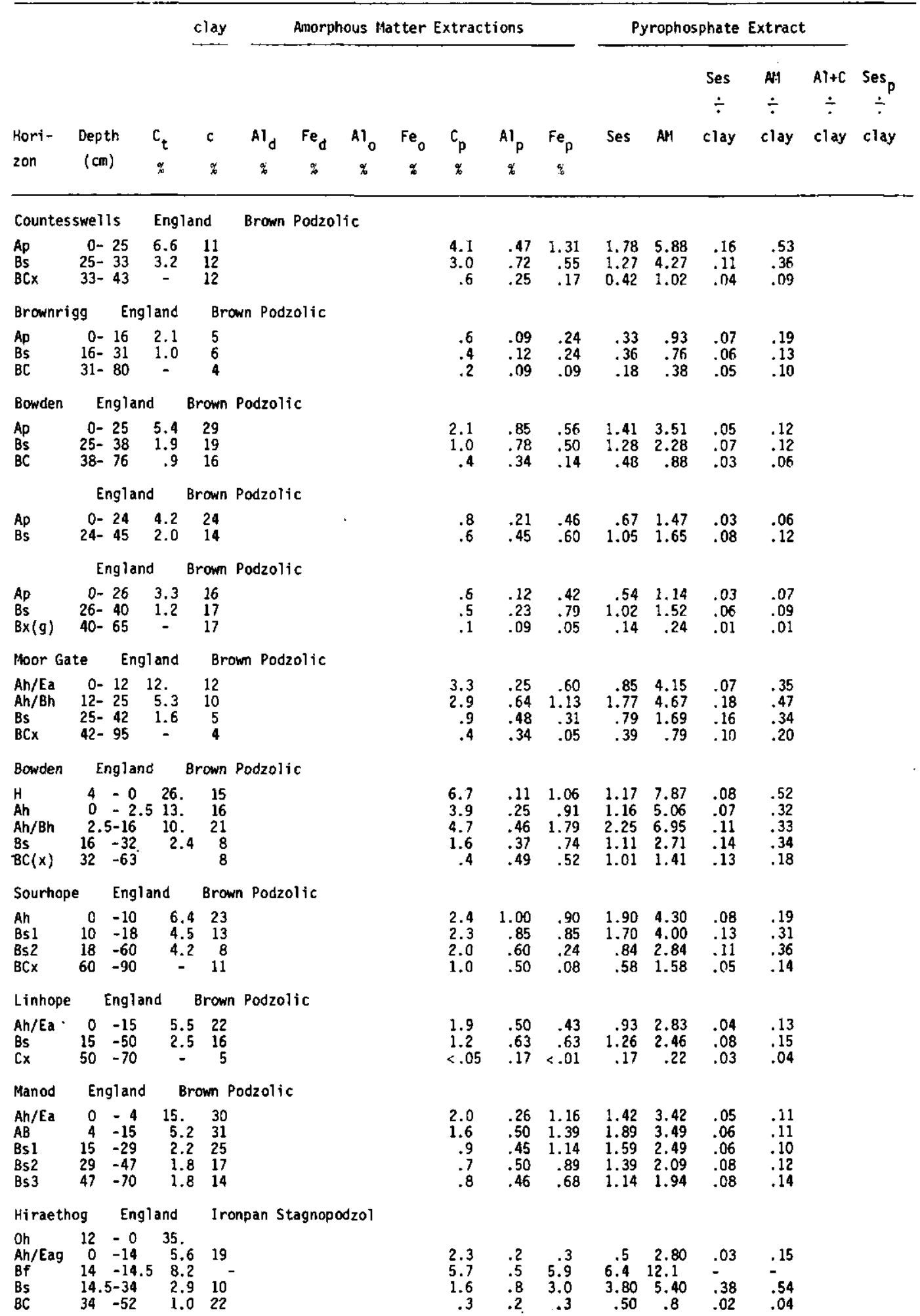




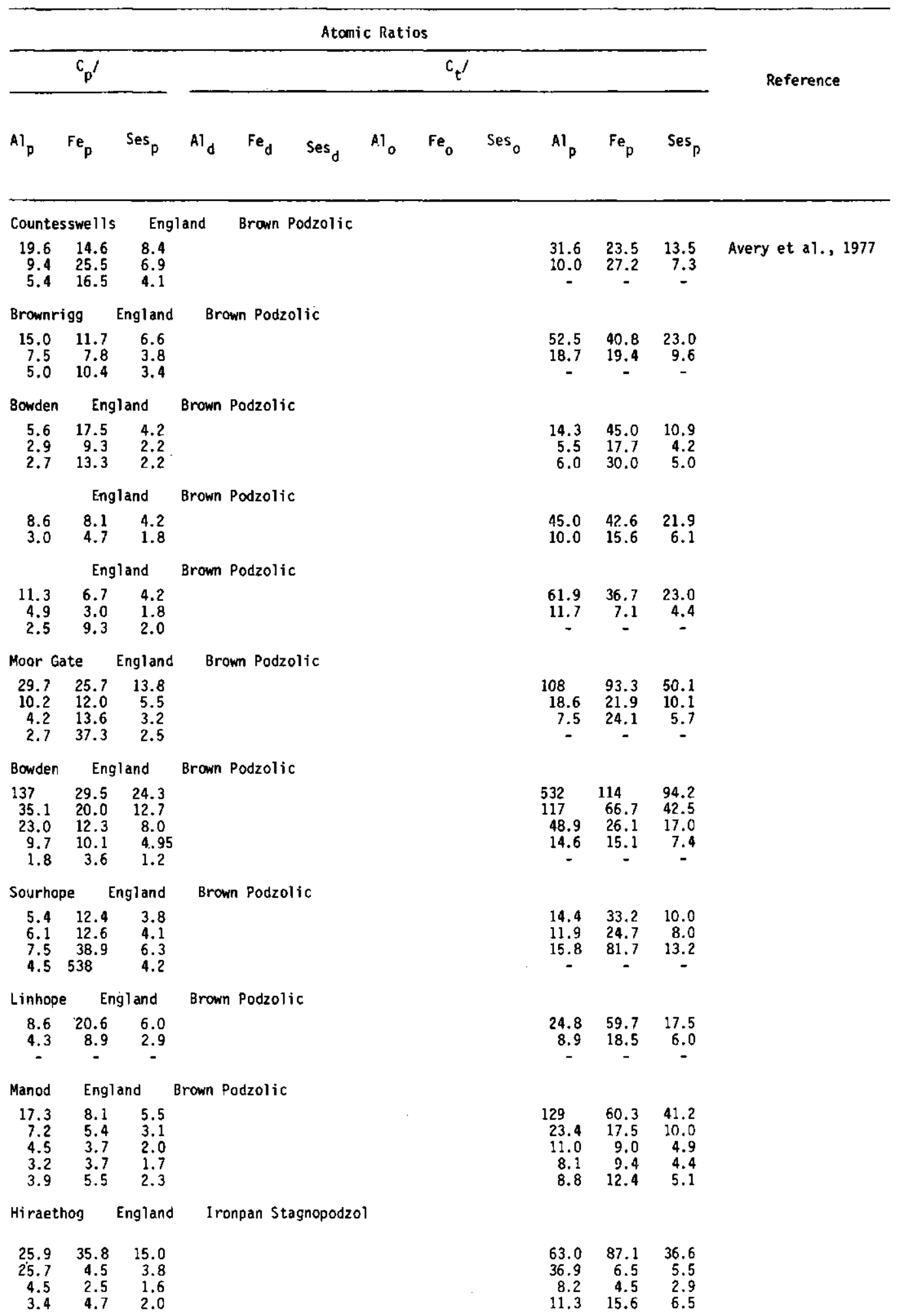


Appendix 5 (ctd). Selected chemical data from literature and carbon/sesquioxide atomic ratios

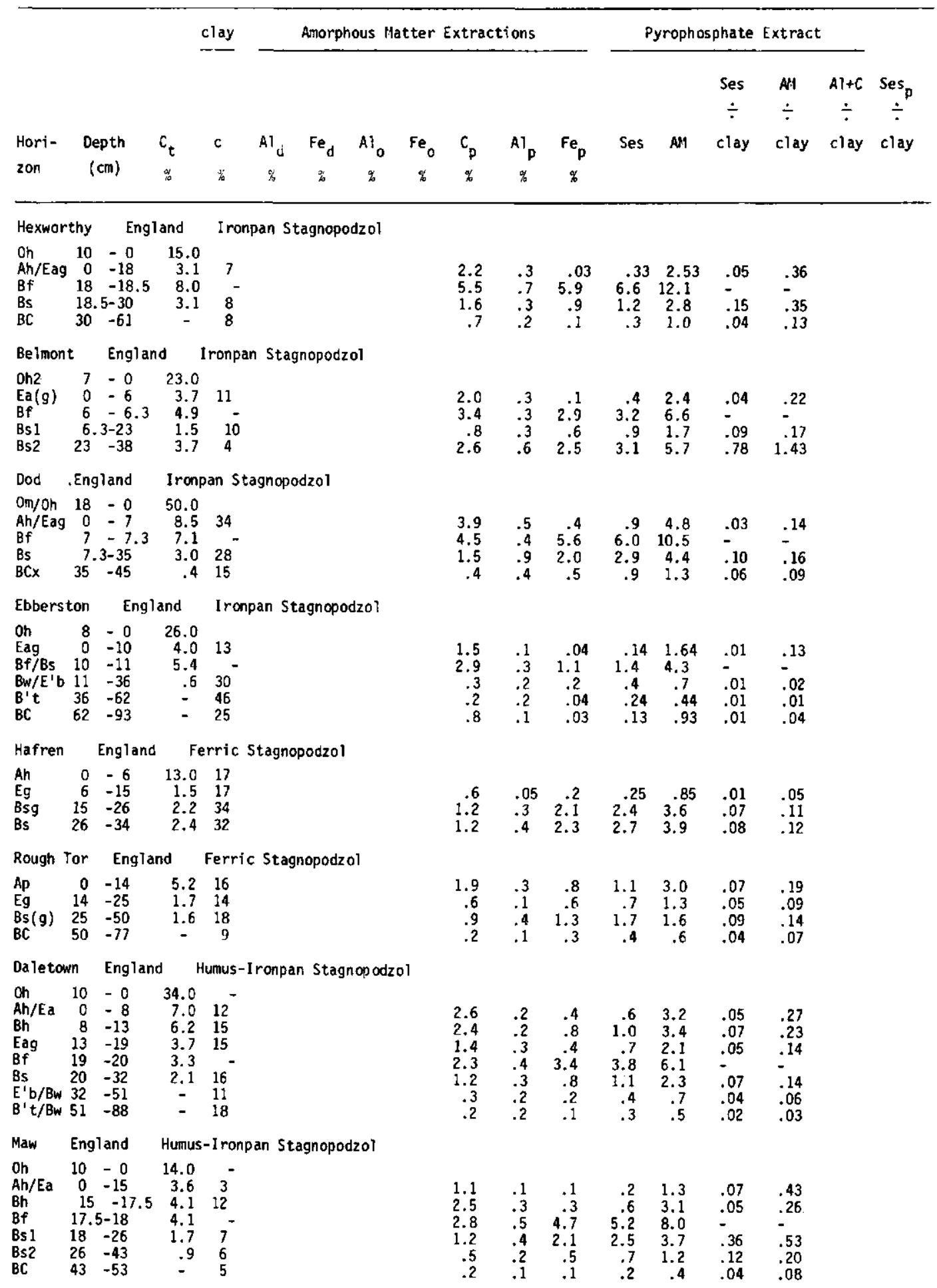




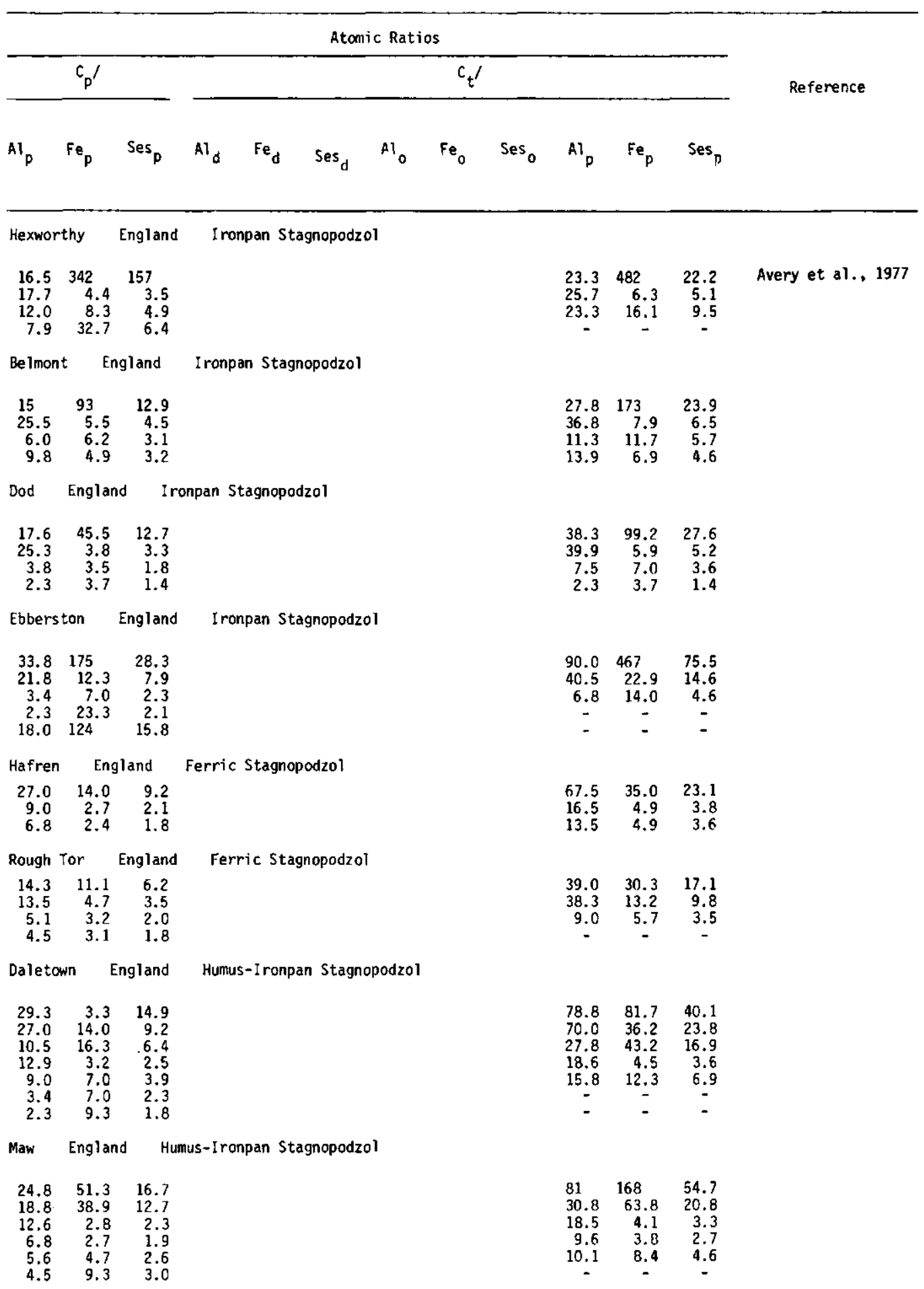


Appendix 5 (ctd). Selected chenical data from literature and carbon/sesquioxide atomic ratios

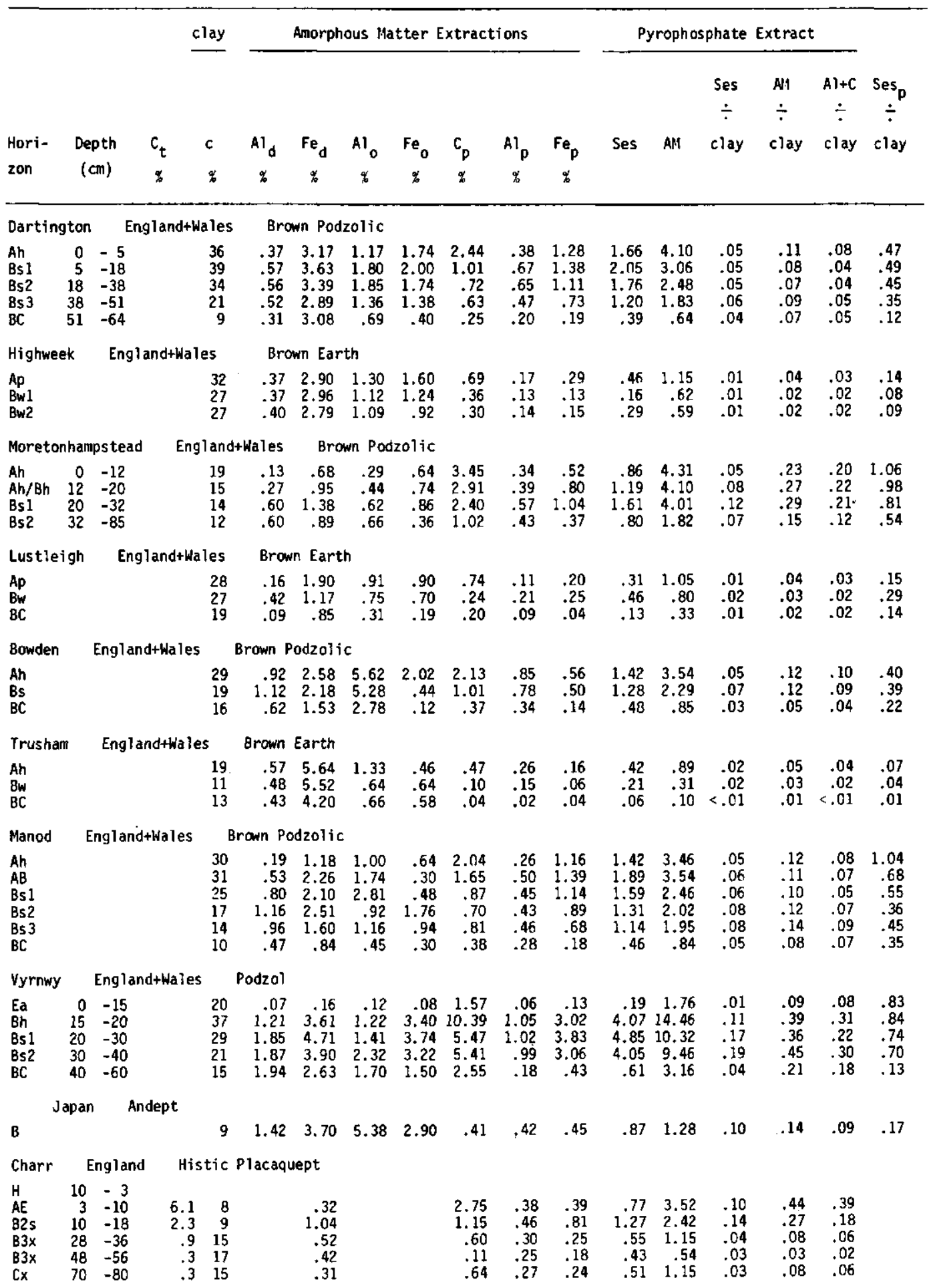




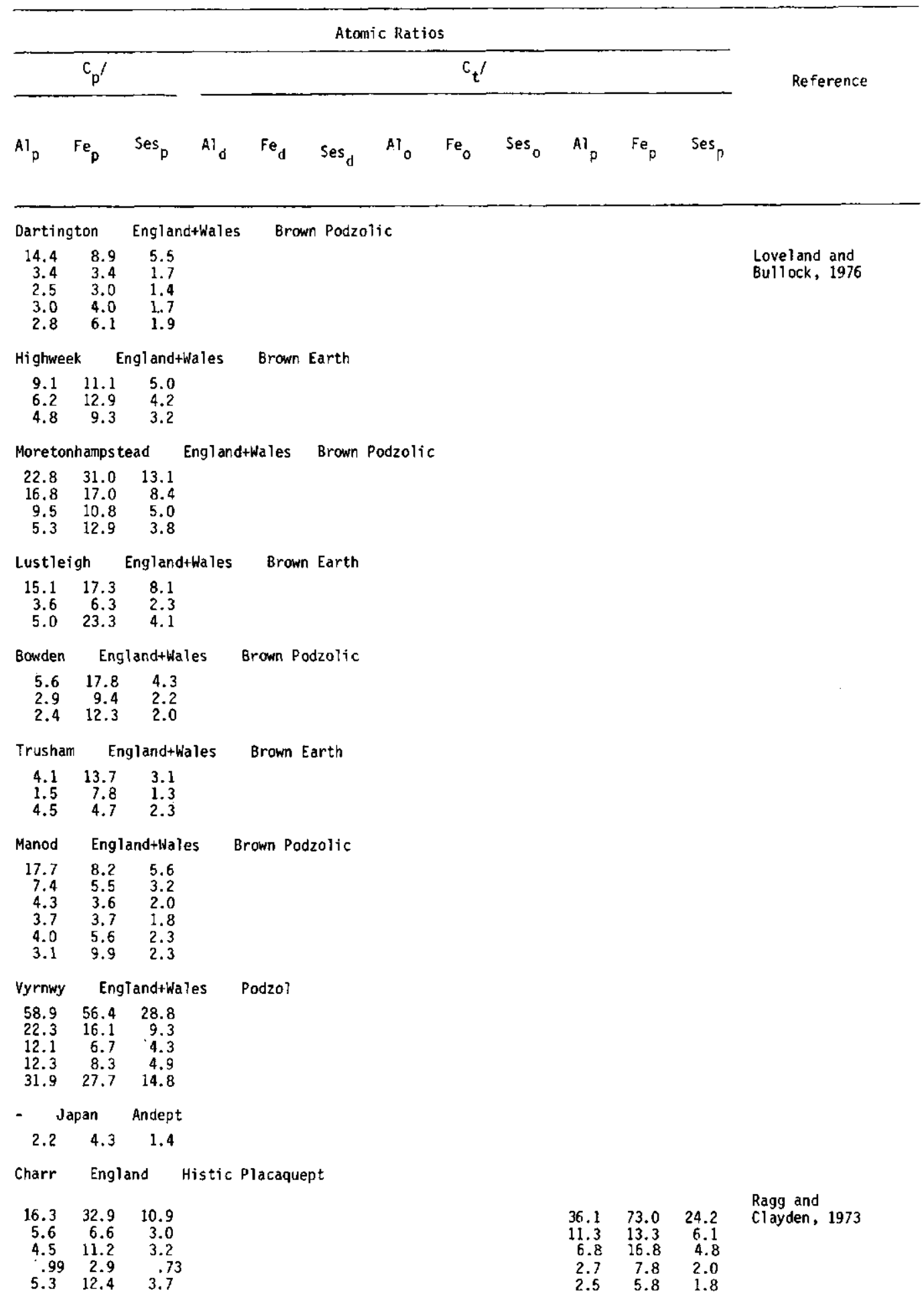


Appendix 5 (ctd). Selected chemical data from literature and carbon/sesquioxide atomic ratios

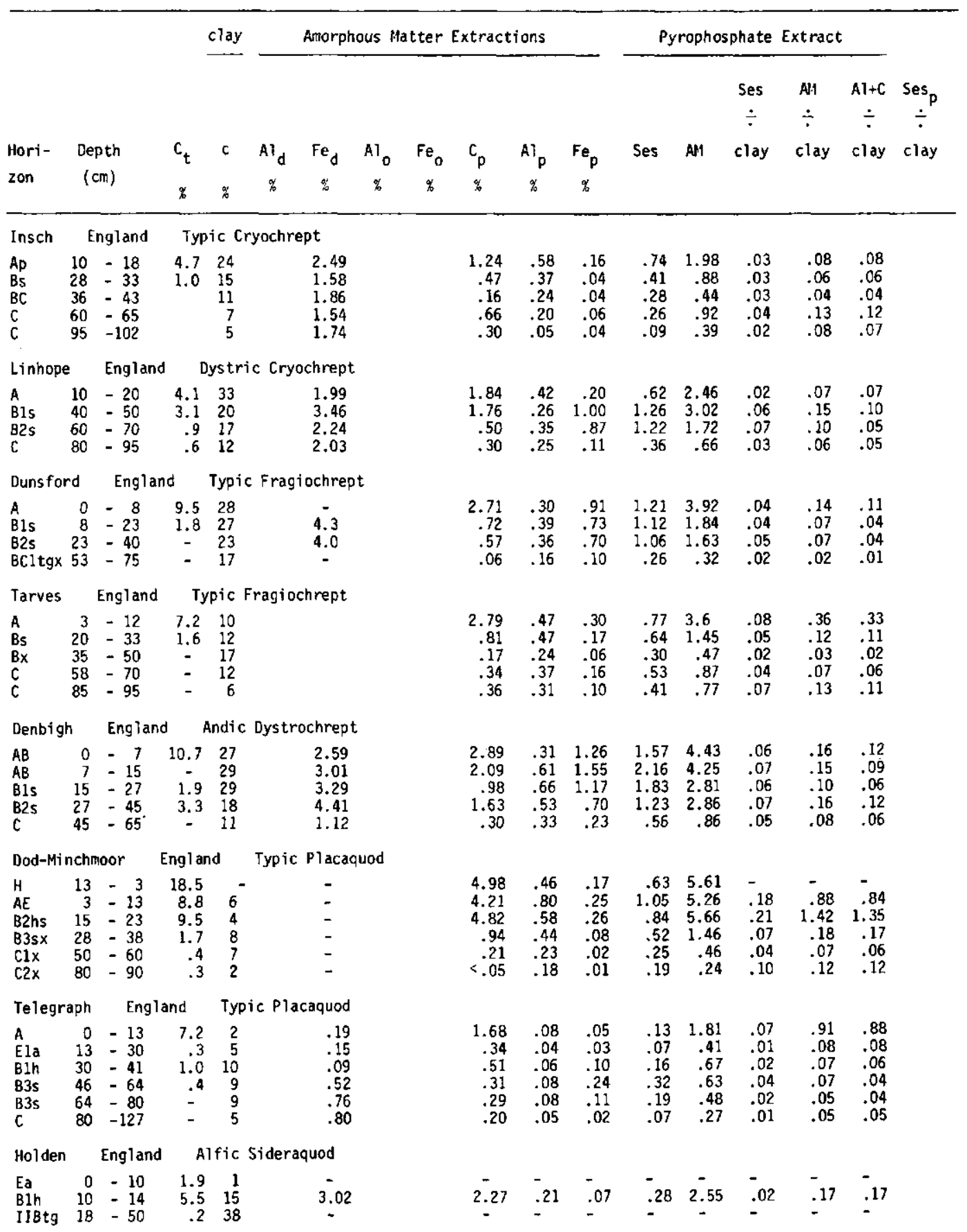




\begin{tabular}{|c|c|c|c|c|c|c|c|c|c|c|c|c|}
\hline & & & & & Aton & c Rat & & & & & & \\
\hline & $C_{p}^{\prime}$ & & & & & & $c_{t} /$ & & & & & Reference \\
\hline $\mathrm{Al}_{\mathrm{P}}$ & $\mathrm{Fe}_{\mathrm{p}}$ & $\operatorname{Ses}_{p}$ & $\mathrm{Al}_{\mathrm{d}}$ & $\mathrm{Fe}_{\mathrm{d}}$ & $\operatorname{Ses}_{\mathrm{d}}$ & $A l_{0}$ & $\mathrm{Fe}_{0}$ & Ses $_{0}$ & $A I_{p}$ & $\mathrm{Fe}_{\mathrm{p}}$ & $\operatorname{Ses}_{p}$ & \\
\hline Insch & Englo & and & Typic & ryochr & & & & & & & & \\
\hline $\begin{array}{r}4.8 \\
2.9 \\
1.5 \\
7.4 \\
13.5\end{array}$ & $\begin{array}{l}36.2 \\
54.9 \\
18.7 \\
51.3 \\
35.0\end{array}$ & $\begin{array}{l}4.3 \\
2.7 \\
1.4 \\
6.5 \\
9.7\end{array}$ & & & & & & & $\begin{array}{c}18.2 \\
6.1 \\
- \\
- \\
-\end{array}$ & $\begin{array}{r}137 \\
116 \\
- \\
- \\
-\end{array}$ & $\begin{array}{c}16.1 \\
5.8 \\
- \\
- \\
-\end{array}$ & Clayden, 1973 \\
\hline Linhope & Ens & $\mathrm{gl}$ and & Dystr & ic Cry & hrept & & & & & & & \\
\hline $\begin{array}{r}9.9 \\
15.2 \\
3.2 \\
2.7\end{array}$ & $\begin{array}{r}42.9 \\
8.2 \\
2.7 \\
12.7\end{array}$ & $\begin{array}{l}8.0 \\
5.3 \\
1.5 \\
2.2\end{array}$ & & & & & & & $\begin{array}{r}22.0 \\
26.8 \\
5.8 \\
5.4\end{array}$ & $\begin{array}{r}95.7 \\
14.5 \\
4.8 \\
25.5\end{array}$ & $\begin{array}{r}17.9 \\
9.4 \\
2.6 \\
4.5\end{array}$ & \\
\hline Dunsfor & En & ngland & Typi & C Frag & chrept & & & & & & & \\
\hline $\begin{array}{r}20.3 \\
4.2 \\
3.6 \\
.8\end{array}$ & $\begin{array}{r}13.9 \\
4.6 \\
3.8 \\
2.8\end{array}$ & $\begin{array}{r}8.3 \\
2.2 \\
1.8 \\
.7\end{array}$ & & & & & & & $\begin{array}{c}71.3 \\
10.4 \\
- \\
-\end{array}$ & $\begin{array}{c}48.7 \\
11.5 \\
- \\
-\end{array}$ & $\begin{array}{c}28.9 \\
5.5 \\
- \\
-\end{array}$ & \\
\hline Tarves & Engl & 1 and & Typic & Fragio & rept & & & & & & & \\
\hline $\begin{array}{r}13.4 \\
3.9 \\
1.6 \\
2.1 \\
2.6\end{array}$ & $\begin{array}{r}43.4 \\
22.2 \\
13.2 \\
9.9 \\
16.8\end{array}$ & $\begin{array}{r}10.2 \\
3.3 \\
1.4 \\
1.7 \\
2.3\end{array}$ & & & & & & & $\begin{array}{c}34.5 \\
7.7 \\
- \\
-\end{array}$ & $\begin{array}{c}112 \\
43.9 \\
= \\
=\end{array}$ & $\begin{array}{c}26.4 \\
6.5 \\
- \\
- \\
-\end{array}$ & \\
\hline Denbigh & Ens & $g l$ and & Andic & Dystr & hrept & & & & & & & \\
\hline $\begin{array}{r}20.7 \\
7.7 \\
3.3 \\
6.9 \\
2.0\end{array}$ & $\begin{array}{r}10.6 \\
6.3 \\
3.9 \\
10.9 \\
6.1\end{array}$ & $\begin{array}{l}7.0 \\
3.5 \\
1.8 \\
4.2 \\
1.5\end{array}$ & & & & & & & $\begin{array}{c}77.7 \\
- \\
6.5 \\
14.0 \\
-\end{array}$ & $\begin{array}{c}39.6 \\
- \\
7.6 \\
22.0 \\
-\end{array}$ & $\begin{array}{c}26.2 \\
- \\
3.5 \\
8.6 \\
-\end{array}$ & \\
\hline Dod-Min & nehmo or & Ens & Igl and & Typi & Placaqu & & & & & & & \\
\hline $\begin{array}{r}24.4 \\
11.8 \\
18.7 \\
4.8 \\
2.1 \\
.6\end{array}$ & $\begin{array}{r}136.7 \\
78.6 \\
86.5 \\
54.8 \\
49.0 \\
23.3\end{array}$ & $\begin{array}{r}20.7 \\
10.3 \\
15.4 \\
4.4 \\
2.0 \\
0.6\end{array}$ & & & & & & & $\begin{array}{r}90.5 \\
24.8 \\
36.9 \\
8.7 \\
3.9 \\
3.8\end{array}$ & $\begin{array}{c}508 \\
164 \\
171 \\
99.2 \\
93.3 \\
140\end{array}$ & $\begin{array}{r}76.8 \\
21.5 \\
30.3 \\
8.0 \\
3.8 \\
3.7\end{array}$ & \\
\hline Telegra & aph & Engl and & $\mathrm{Ty}_{\mathrm{p}}$ & ic $\mathrm{Pla}$ & xquod & & & & & & & \\
\hline $\begin{array}{r}47.3 \\
19.1 \\
19.1 \\
8.7 \\
8.2 \\
9.0\end{array}$ & $\begin{array}{r}157 \\
52.9 \\
23.8 \\
6.0 \\
12.3 \\
46.7\end{array}$ & $\begin{array}{r}36.3 \\
14.0 \\
10.6 \\
3.6 \\
4.9 \\
7.5\end{array}$ & & & & & & & $\begin{array}{c}203 \\
16.9 \\
37.5 \\
11.3 \\
= \\
-\end{array}$ & $\begin{array}{c}672 \\
46.7 \\
46.7 \\
7.8 \\
- \\
-\end{array}$ & $\begin{array}{c}156 \\
12.4 \\
20.8 \\
4.6 \\
- \\
-\end{array}$ & \\
\hline Hoiden & Eng & land & Alfic & Sidera & & & & & & & & \\
\hline 24.3 & $151^{-}$ & 21.0 & & & & & & & 58.9 & $367^{-}$ & 50.8 & \\
\hline
\end{tabular}


Appendix 5 (ctd). Selected chemical data from literature and carbon/sesquioxide atomic ratios

\begin{tabular}{|c|c|c|c|c|c|c|c|c|c|c|c|c|c|c|c|c|}
\hline \multirow{5}{*}{$\begin{array}{l}\text { Hori- } \\
\text { zon }\end{array}$} & \multirow{5}{*}{$\begin{array}{c}\text { Depth } \\
(\mathrm{cm})\end{array}$} & \multirow{5}{*}{$c_{t}$} & \multirow{4}{*}{$\begin{array}{c}\frac{c l a y}{} \\
c\end{array}$} & \multicolumn{7}{|c|}{ Amorphous Hatter Extractions } & \multicolumn{5}{|c|}{ Pyrophosphate Extract } & \multirow{4}{*}{$\begin{array}{c}\operatorname{Ses}_{p} \\
\dot{\div} \\
\text { clay }\end{array}$} \\
\hline & & & & & & & & & & & & & Ses & An & $A l+C$ & \\
\hline & & & & & & & & & & & & & $\div$ & $\div$ & $\dot{\div}$ & \\
\hline & & & & $A i_{d}$ & $\mathrm{Fe}_{d}$ & $A 1_{0}$ & $\mathrm{Fe}_{0}$ & $C_{p}$ & $A)_{p}$ & $\mathrm{Fe}_{\mathrm{p}}$ & Ses & AM & clay & clay & clay & \\
\hline & & & $\%$ & $\%$ & $\stackrel{i}{*}$ & $\%$ & $\%$ & $\%$ & $\%$ & $\approx$ & & & & & & \\
\hline
\end{tabular}

Minchmoor England Haplic Cryohumod

\begin{tabular}{|c|c|c|c|c|c|}
\hline $\begin{array}{l}\mathrm{H} \\
\mathrm{AE} \\
\text { BIh } \\
\text { B2S } \\
\mathrm{C}\end{array}$ & $\begin{array}{r}8 \\
1 \\
10 \\
23 \\
58\end{array}$ & $\begin{array}{l}-0 \\
-\quad 9 \\
-15 \\
-28 \\
-75\end{array}$ & $\begin{array}{r}52.4 \\
5.7 \\
8.7 \\
2.9 \\
.6\end{array}$ & $\begin{array}{l}12^{-} \\
10^{-} \\
14 \\
18\end{array}$ & $\begin{array}{r}- \\
.11 \\
.52 \\
3.11 \\
1.59\end{array}$ \\
\hline
\end{tabular}

Merrick England (Cryic) Fragiohumod

$\begin{array}{lrrrrr}H & 10 & -2 & 13.3 & - & - \\ \text { A } & 5 & -13 & 21.0 & - & .99 \\ \text { Bh } & 13 & -23 & 11.7 & 6 & 1.19 \\ \text { BC } & 43 & -53 & 1.9 & 11 & .53 \\ \text { IICX } & 60 & -70 & .5 & 12 & .56\end{array}$

Shirrel Heath England Ferrudalfic Haplohumod

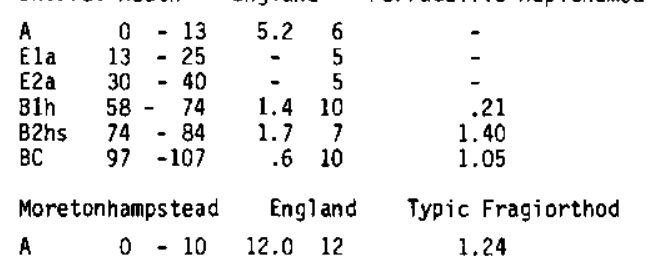

\begin{tabular}{lrrrrc} 
A & 0 & -10 & 12.0 & 12 & 1.24 \\
ABh & 10 & -20 & 5.3 & 10 & 1.47 \\
Bs & 20 & -40 & 1.6 & 5 & 1.35 \\
CX & 40 & -100 & - & 4 & \\
\multicolumn{7}{c}{ Countesswel is } & England & Typic Fragiortho \\
Ap & 5 & -15 & 6.6 & 13 & .87 \\
Bs & 23 & -30 & 3.2 & 14 & 1.26 \\
Bx & 33 & -43 & - & 15 & 1.44 \\
Bx & 53 & -63 & - & 17 & 1.10 \\
C & 70 & -80 & - & 15 & 1.13
\end{tabular}

$$
\text { Foudland England Cryic Fragiorthod }
$$

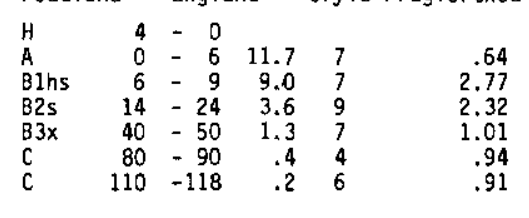

Merrick England Cryic Fragiorthod

$$
\begin{array}{lrrrrr}
H & 5 & -0 & 16.0 & & \\
\mathrm{~A} & 0 & -18 & 7.5 & 7 & 2.6 \\
\mathrm{Bh} & 20 & -30 & 9.9 & 6 & 3.31 \\
\mathrm{IICX} & 50 & -60 & .6 & 14 & .92
\end{array}
$$

Crannymoor England Typic Haplorthod

$\begin{array}{lrlllllllllllll}\text { A } & 0 & -20 & 7.1 & 3 & & & & & & & & & & \\ \text { Ea } & 20 & -33 & .8 & 2 & .34 & .05 & .02 & .07 & .04 & .21 & .20 \\ \text { Bih } & 33 & -40 & 2.5 & 10 & .49 & 1.73 & .28 & .29 & .57 & 2.30 & .06 & .23 & .20 \\ \text { B2hs } & 40 & -65 & 1.6 & 13 & .77 & 1.21 & .31 & .57 & .88 & 2.09 & .07 & .16 & .12 \\ \text { BC } & 65 & -75 & 4 & 5 & .28 & .37 & .18 & .10 & .18 & .65 & .06 & .13 & .11\end{array}$

$\begin{array}{rrrrrrrr}- & - & - & - & - & - & - & - \\ 1.42 & .16 & .03 & .19 & 1.61 & .02 & .13 & .13 \\ 4.13 & .48 & .06 & .54 & 4.67 & .05 & .47 & .46 \\ 1.65 & .97 & .95 & 1.92 & 3.57 & .14 & .26 & .19 \\ .34 & .32 & .12 & .44 & .78 & .02 & .04 & .04\end{array}$

$\begin{array}{rrrrrrrr}- & - & - & - & - & - & - & - \\ 10.72 & .46 & .66 & 1.22 & 11.84 & - & - & - \\ 6.12 & .79 & .81 & 1.60 & 7.72 & .27 & 1.29 & 1.15 \\ .94 & .39 & .11 & .50 & 1.44 & .05 & .13 & .12 \\ .05 & .28 & .01 & .29 & .34 & .02 & .03 & .03\end{array}$

$\begin{array}{llllllll}- & - & - & - & - & - & - & - \\ - & - & - & - & - & - & - & - \\ .31 & .03 & .05 & .08 & .39 & .02 & .08 & .07 \\ .61 & .10 & .08 & .18 & .79 & .02 & .08 & .07 \\ 1.18 & .19 & .68 & .87 & 2.05 & .12 & .29 & .20 \\ .40 & .19 & .35 & .54 & .94 & .05 & .09 & .06\end{array}$

$\begin{array}{rrrrrrrr}2.69 & .25 & .53 & .78 & 3.47 & .07 & .29 & .25 \\ 1.95 & .46 & .75 & 1.21 & 3.16 & .12 & .32 & .24 \\ .92 & .40 & .12 & .52 & 1.44 & .10 & .29 & .26 \\ .33 & .34 & .06 & .40 & .73 & .10 & .18 & .17\end{array}$

$\begin{array}{rrrrrrrr}4.10 & .47 & 1.31 & 1.78 & 5.88 & .14 & .45 & .35 \\ 3.05 & .72 & .55 & 1.27 & 4.32 & .09 & .31 & .27 \\ .60 & .25 & .17 & .42 & 1.02 & .03 & .07 & .06 \\ .39 & .10 & .04 & .14 & .53 & .01 & .03 & .03 \\ .71 & .05 & .04 & .09 & .80 & .01 & .05 & .05\end{array}$

$\begin{array}{lllrrrrr}3.8 & .28 & .10 & .38 & 4.18 & .05 & .60 & .58 \\ 4.69 & .74 & .60 & 1.34 & 6.03 & .19 & .86 & .78 \\ 2.74 & .90 & .59 & 1.49 & 4.23 & .17 & .47 & .40 \\ .75 & .42 & .08 & .50 & 1.25 & .07 & .18 & .17 \\ 1.0 & .19 & .05 & .24 & 1.24 & .06 & .31 & .30 \\ .12 & .13 & .04 & .17 & .29 & .03 & .05 & .04\end{array}$

$\begin{array}{lrrrrrrr}4.0 & .83 & 1.34 & 2.17 & 6.17 & .31 & .88 & .69 \\ 7.39 & .89 & 3.07 & 3.96 & 11.35 & .66 & 1.89 & 1.38 \\ .52 & .23 & .36 & .59 & 1.11 & .04 & .08 & .05\end{array}$

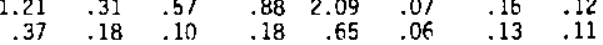




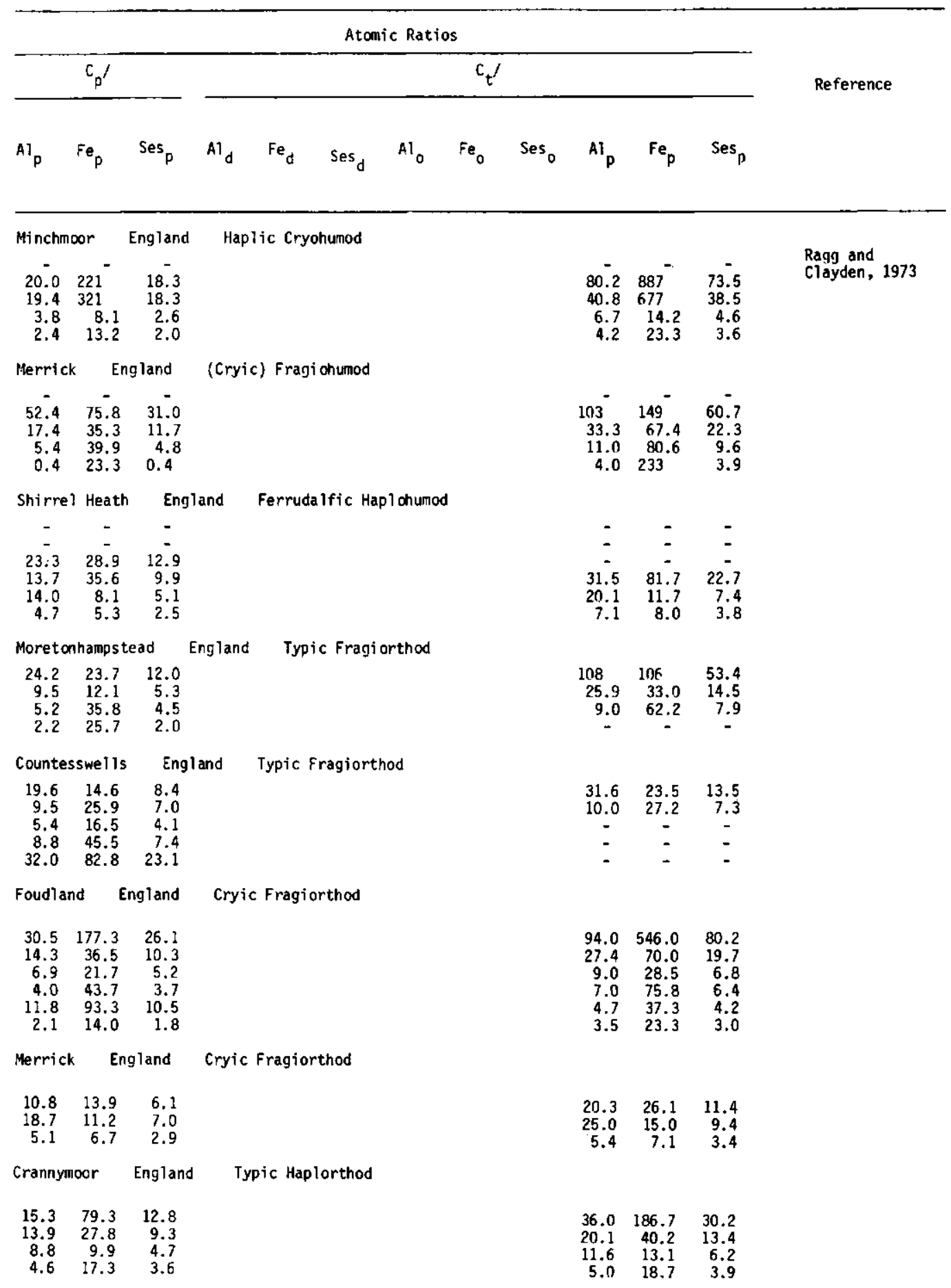


Appendix 5 (ctd). Selected chemical data from literature and carbon/sesquioxide atomic ratios

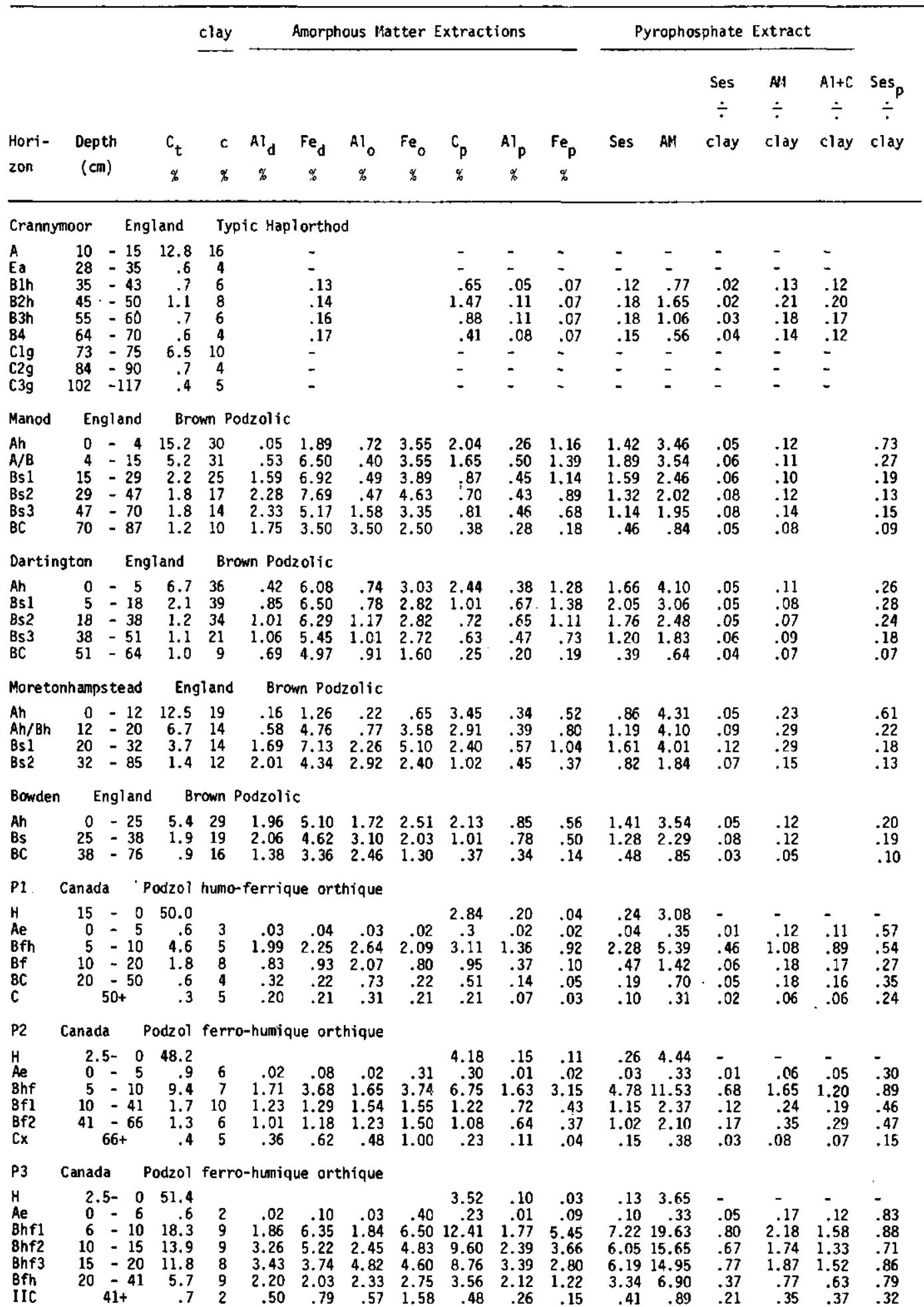




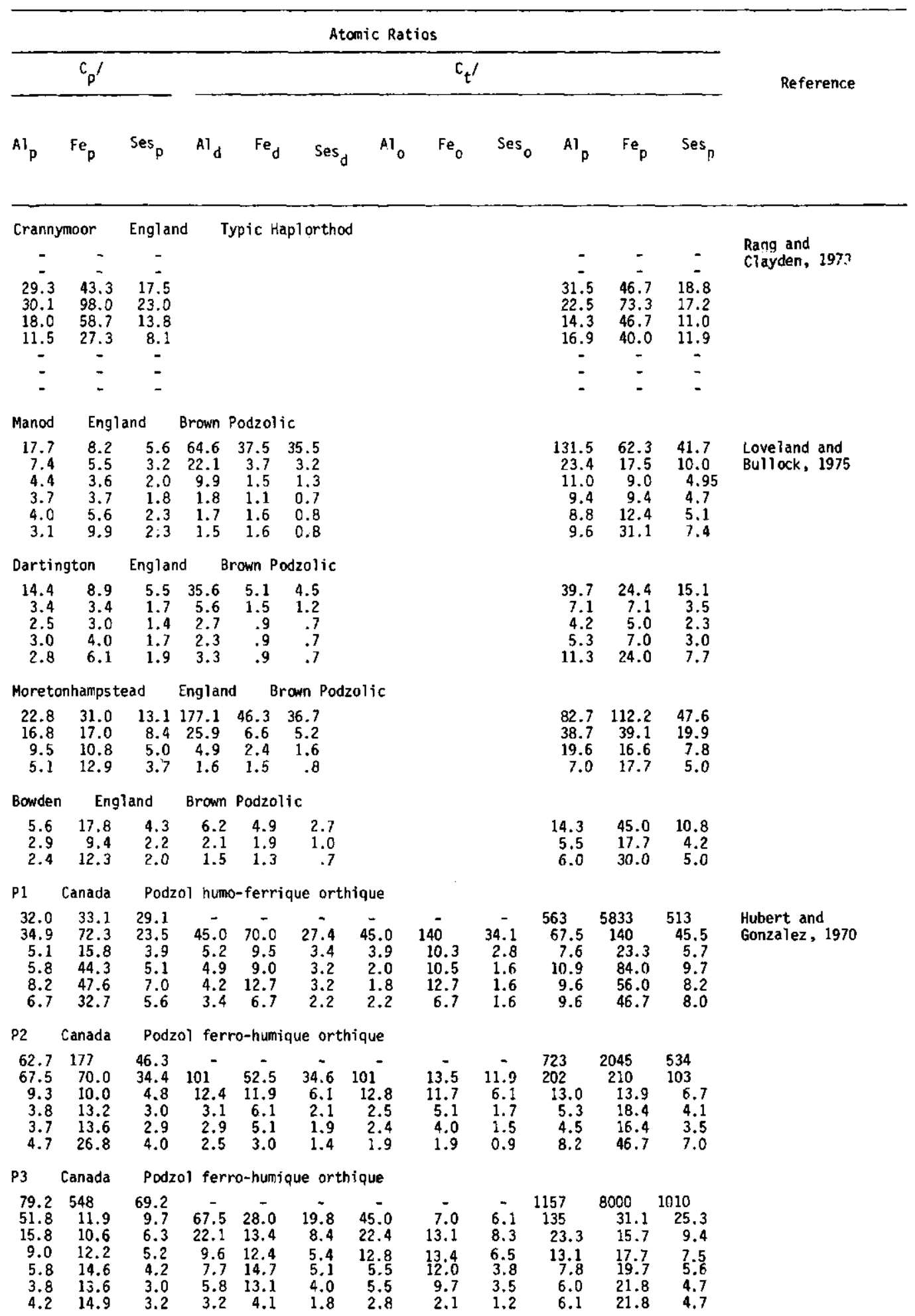


Appendix 5 (ctd). Selected chemical data from literature and carbon/sesquioxide atomic ratios

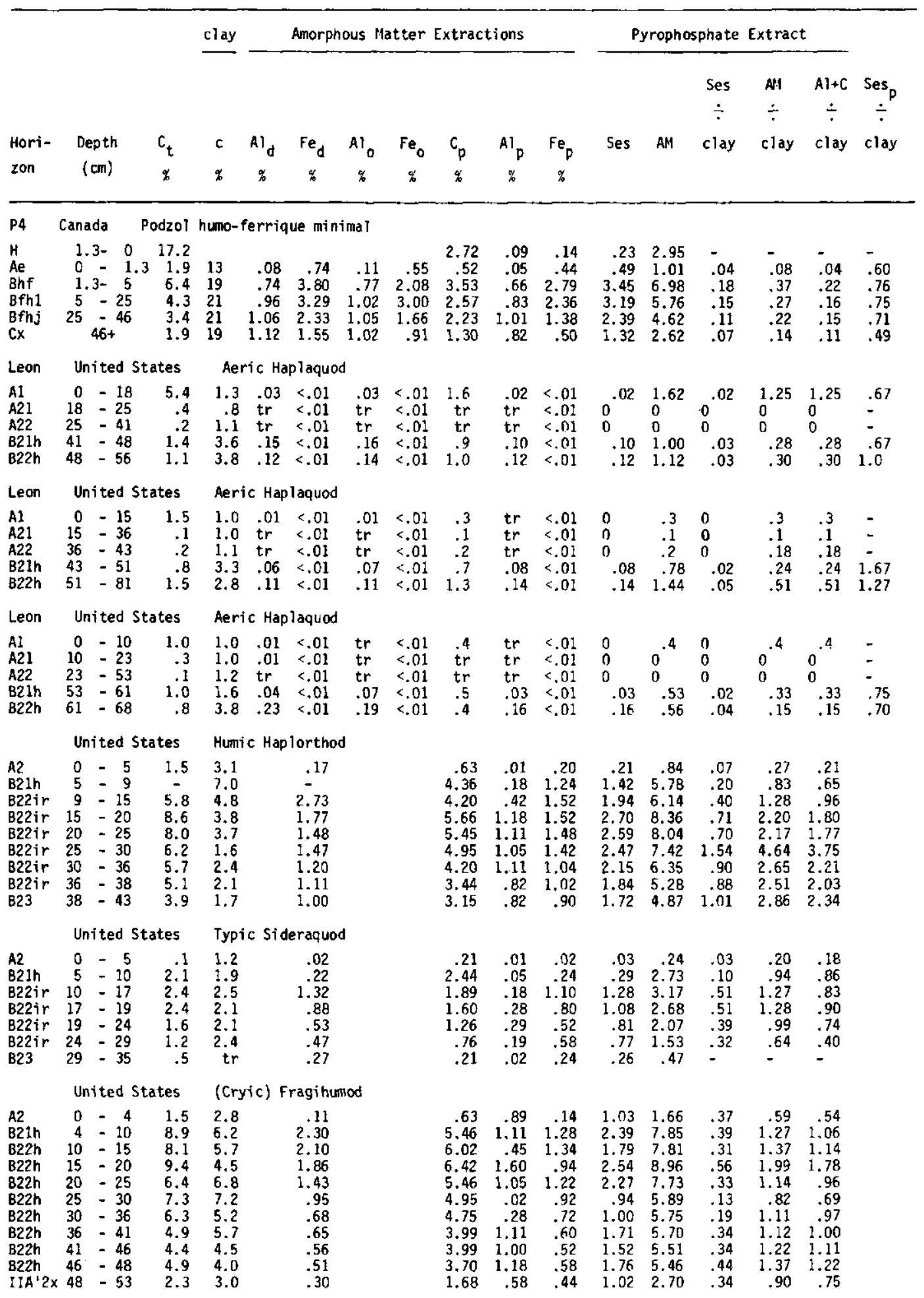




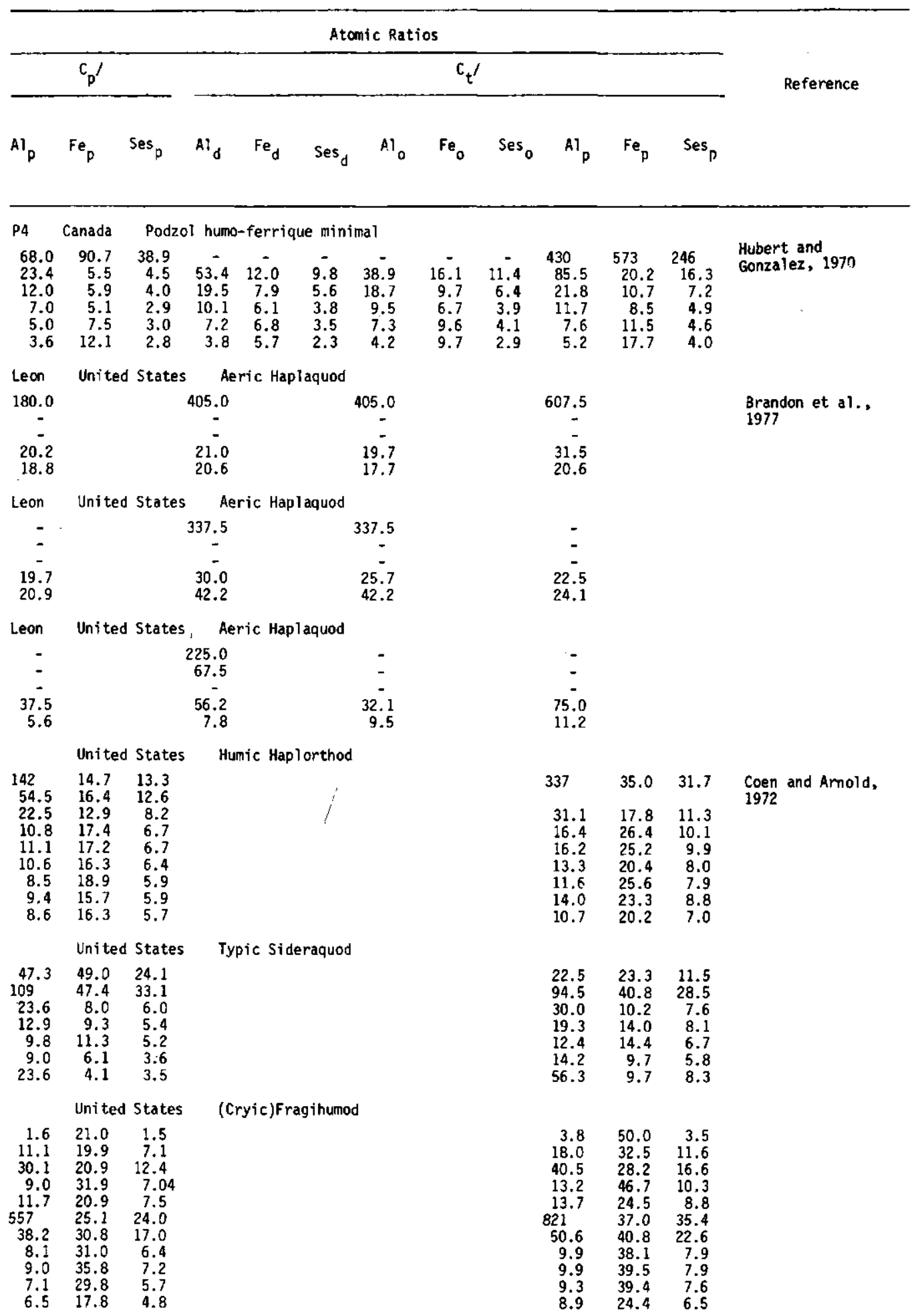


Appendix 5 (ctd). Selected chemical data from literature and carbon/sesquioxide atomic ratios

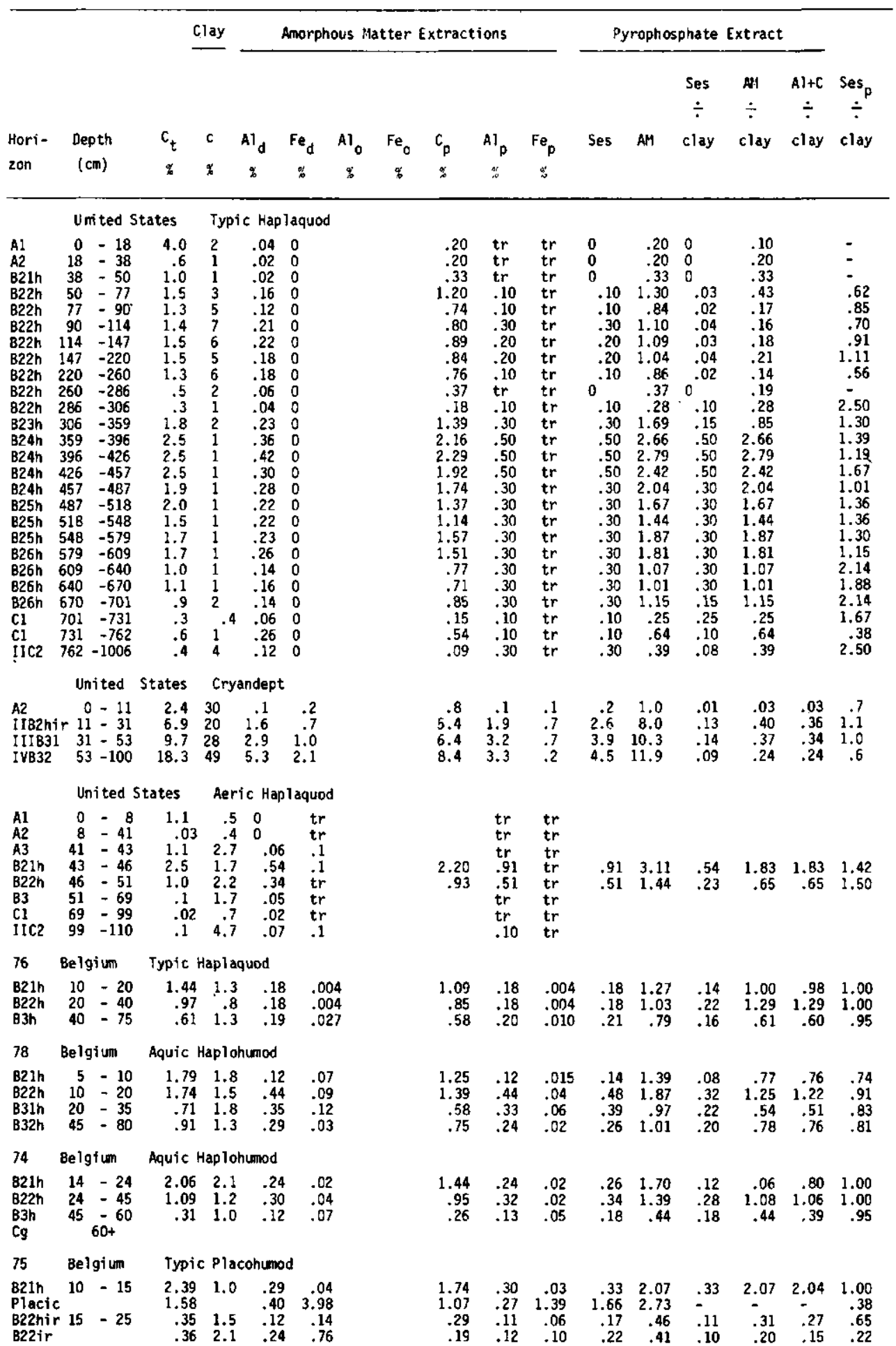




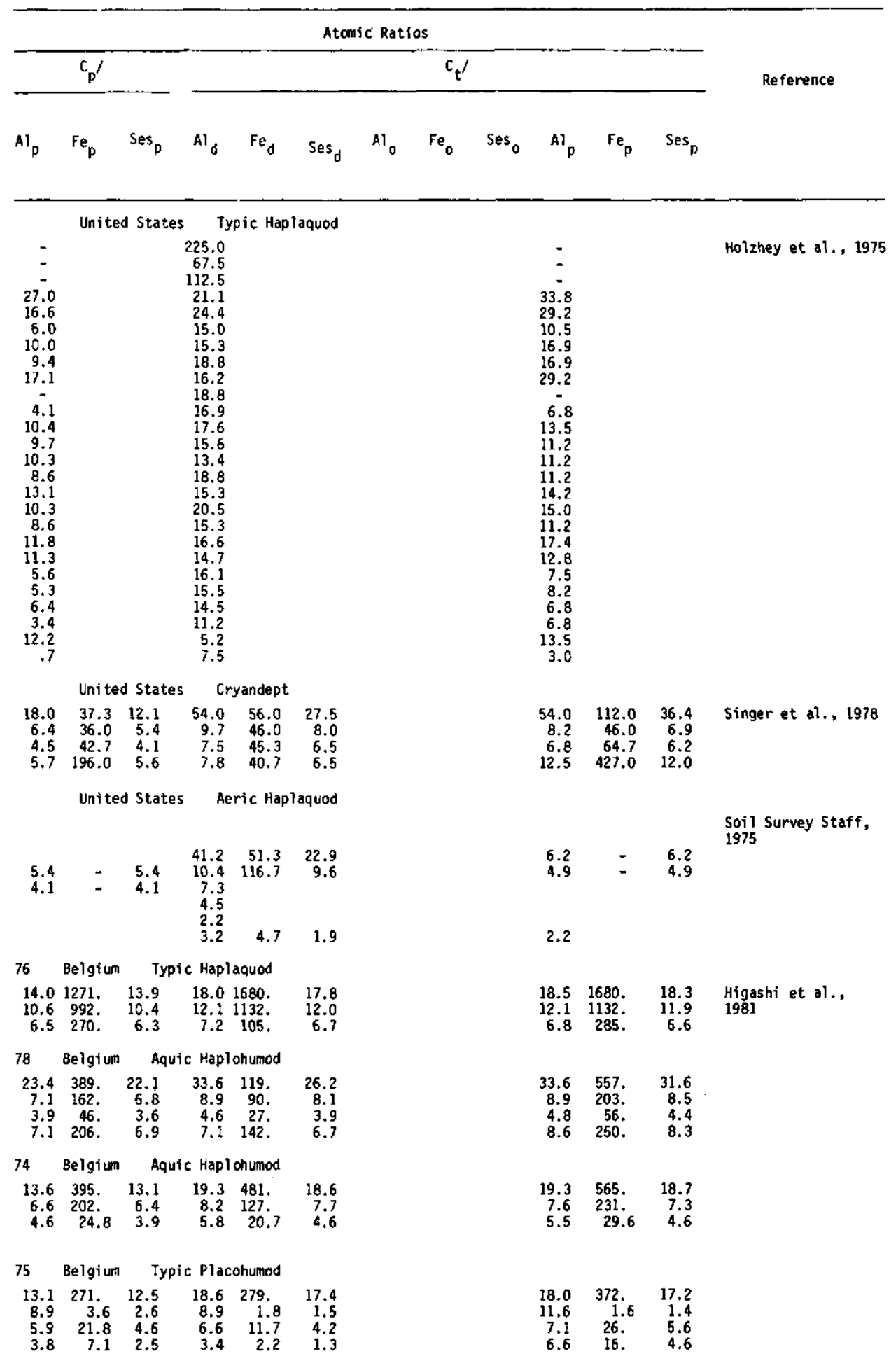


The content of carbon in soils may be determined by either dry or wet combustion. In both methods soil $\mathrm{C}$ is converted to $\mathrm{CO}_{2}$. The amount of evolved $\mathrm{CO}_{2}$ is estimated by direct methods as measuring the volume of $\mathrm{CO}_{2}$ or as weighing the $\mathrm{CO}_{2}$ adsorbed on a solid or by back titration of excess hydroxide after absorption in aqueous or non-aqueous alkaline medium. The dry combustion method has long been regarded as the most accurate method for determining $C$ in soils but the apparatus is expensive.

Different mixtures of $\mathrm{K}_{2} \mathrm{Cr}_{2} \mathrm{O}_{7}$ and $\mathrm{H}_{2} \mathrm{SO}_{4}$ and later with $\mathrm{H}_{3} \mathrm{PO}_{4}$ have been used in wet combustion methods. Rapid methods are mostly based on wet combustion in which excess oxidant is determined for estimation of organic $c$. These methods do not give complete oxidation of all forms of organic matter and therefore require a conversion factor. The use of a factor may introduce an error as organic matter in different soils and in different horizons of the same profile is not always oxidized to the same degree. These methods are also affected by the presence of readily oxidizable substances other than $c$ in the soil.

When directly measuring the evolved $\mathrm{CO}_{2}$, a purifying train is used to remove the co-evolved gases, such as $\mathrm{sO}_{2}$. Allison (1960) used powdered $\mathrm{K}_{2} \mathrm{Cr}_{2} \mathrm{O}_{7}$ and a $3: 2$ mixture of $\mathrm{H}_{2} \mathrm{SO}_{4}$ and $\mathrm{H}_{3} \mathrm{PO}_{4}$ and a simplified purifying train to determine soil $c$, including $C$ from calcareous and saline soils. Later, Anderson and Harris (1967) dissolved the $\mathrm{K}_{2} \mathrm{Cr}_{2} \mathrm{O}_{7}$ in the $\mathrm{H}_{2} \mathrm{SO}_{4}-\mathrm{H}_{3} \mathrm{PO}_{4}$ mixture. Although several researchers have proposed modifications, Allison's method has been generally accepted as being the most reliable.

Evolved $\mathrm{CO}_{2}$ can be absorbed quantitatively according to the reaction $\mathrm{CO}_{2}+2 \mathrm{OH}^{-}+\mathrm{Ba}^{Z+}+\mathrm{BaCO}_{3} \downarrow+\mathrm{H}_{2} \mathrm{O}$. Both the amount of consumed OH and the amount of $\mathrm{BaCO}_{3}$ formed are a measure of the amount of $\mathrm{C}$. The amount of $\mathrm{BaCO}_{3}$ formed was determined by measuring the $\mathrm{pH}$ after dissolving the precipitate with EDTA (Begheijn, 1976). The amount of $\mathrm{OH}^{-}$consumed is determined

1 The appendix 6 is a preliminary account of the work done on the determination of carbon undertaken for the research on podzols, but applicable under non-podzol conditions as well. The finalization of the paper is awaiting the results of further study on one of the three described methods. However, in its present form the paper is considered as a useful complement to the main paper and has therefore been attached.

2 International soil Museum, P.0. Box 353, 6700 AJ Wageningen, Netherlands.

3 Department of Crop and soil Sciences, Michigan state University, East Lansing, MI 48824, U.S.A. 
by back titration of excess hydroxide (Duursma, 1961; Römer, 1975; sixta, 1977). Duursma (1961) and sixta (1977) titrated the solution using a continuous coulometric technique whereas Römer (1975) titrated with NaOH using an automatic titrator reacting on the lowering of the $\mathrm{pH}$ as $\mathrm{CO}_{2}$ is absorbed in the $\mathrm{Ba}(\mathrm{OH})_{2}$, $\mathrm{pH} 10.2$ solution. These titrimetric methods have low detection limits and are easy to perform.

To determine organic $\mathrm{C}$ in calcareous soils the carbonates must be determined separately or destroyed before combustion of the sample. Various acids have been used successfully in the determination of inorganic $c$ in soils and rocks. To determine inorganic C Allison (1960) used $\mathrm{H}_{2} \mathrm{SO}_{4}$ to which FesO 4 had been added to prevent oxidation of organic matter. Nömmik (1971) used hot, meta-phosphoric acid to remove inorganic $c$ from soils before determining organic $C$. Sixta (1977) used hot $\mathrm{H}_{3} \mathrm{PO}_{4}$ to determine carbonates in rocks and found it superior to dilute $\mathrm{H}_{2} \mathrm{SO}_{4}$ in releasing inorganic $\mathrm{C}$ because dilute $\mathrm{H}_{2} \mathrm{SO}_{4}$ has slight oxidizing properties and oxidizes some of the organic $\mathrm{C}$ in samples containing organic matter.

To determine organic $C$ in soil extracts, Allison (1960) recommended the extract be evaporated to drymess and then handled in a similar way as a soil sample. However, evaporation to dryness may cause a loss of $\mathrm{c}$. Shaw (1959) determined organic $c$ in plant extracts without evaporating to dryness. He doubled the quantities of $\mathrm{K}_{2} \mathrm{Cr}_{2} \mathrm{O}_{7}$ and $\mathrm{H}_{2} \mathrm{SO}_{4}-\mathrm{H}_{3} \mathrm{PO}_{4}$ mixture when the volume of extract being analyzed was greater than $6 \mathrm{ml}$. Duursma (1961) used his wet combustion method to determine organic $c$ in sea water.

The objective of this study was to develop simple, accurate and rapid methods to determine organic $\mathrm{C}$ in soils and soil extracts and inorganic $\mathrm{C}$ in soils and rocks. The organic $C$ method is based on the wet combustion method of Allison (1960) while the inorganic $\mathrm{C}$ method is based on the $\mathrm{H}_{3} \mathrm{PO}_{4}$ combustion of sixta (1977). In both methods the evolved $\mathrm{CO}_{2}$ is measured using the sensitive detection method of Römer (1975).

\section{Methods}

\section{Apparatus}

The apparatus is shown in figure 1, the components being as follows: A, flow valve (Rotaflo $T F / 13$ ); B, absorption tower filled with ascarite (sodium hydroxide-coated asbestos), 4-8 mesh; C, 250-ml Drechsel gas washing bottle filled with water, serving as bubble counter; D, 50-ml separating funnel (R.B. Radley FSO/50); E, Liebig condensor, $20 \mathrm{~cm}$ long (Quickfit C1/13) with Drechsel bottle head (joints NS 29), the inflow tube was cut off and a 2-ml graduated pipette, connected with rubber tubing, was added so the bottom of the pipette was $2 \mathrm{~cm}$ above the bottom of the digestion tube; F, digestion tube (Duran 50 glass), $11.5 \mathrm{~cm}$ long and $30 \mathrm{~mm}$ outside diameter, with joint NS 29; G, microscale gas burner, preferably shielded (Monastere); H, threeway 


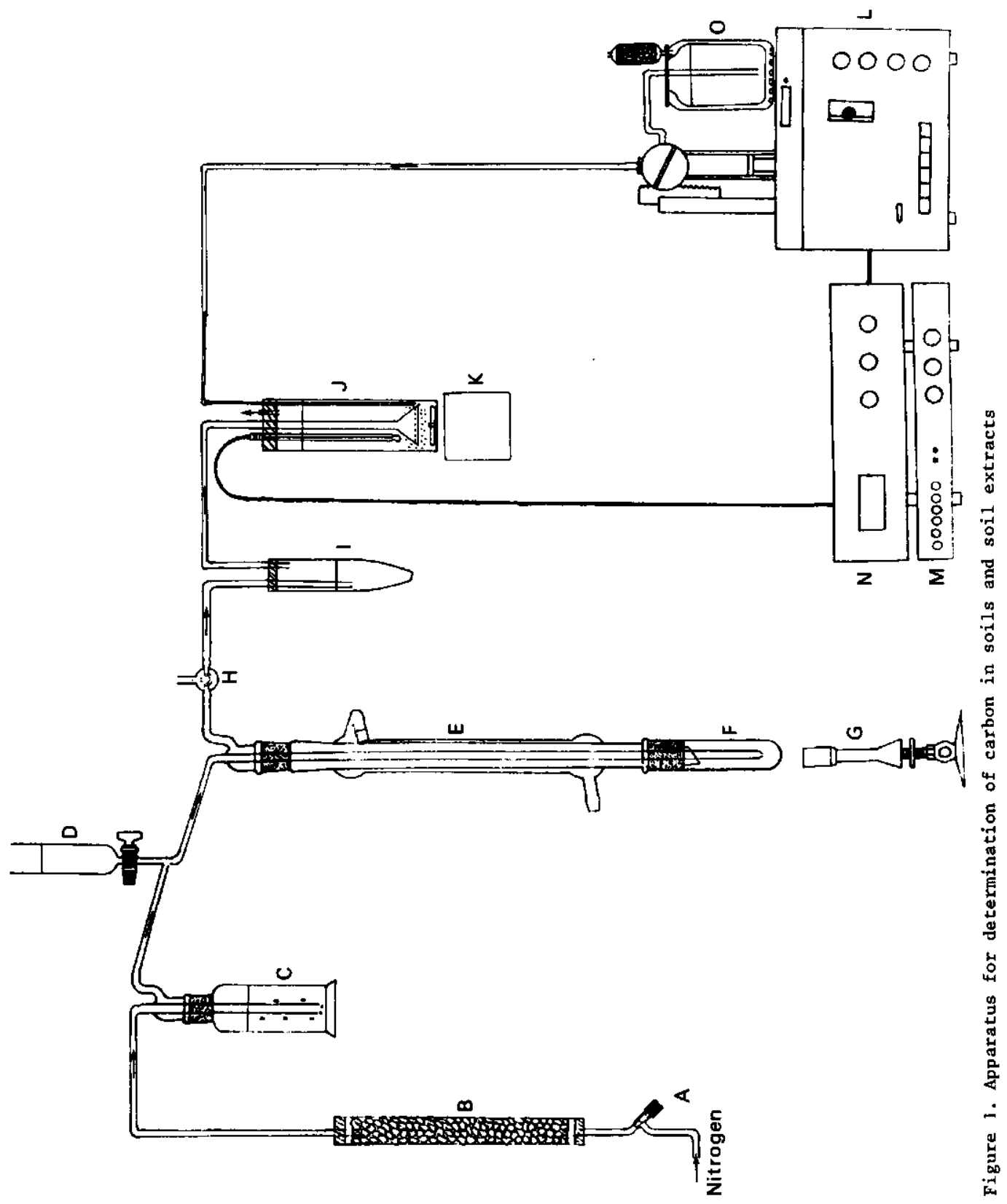


stopcock, plain (Vestale); I, 100-ml test tube filled with about $20 \mathrm{ml}$ of concentrated $\mathrm{H}_{2} \mathrm{SO}_{4}(95-97 \%)$, inflow tube made from a $5 \mathrm{ml}$ pipette extended $1.5 \mathrm{~cm}$ into the acid; $J$, absorption chamber of plexiglass, $16 \mathrm{~cm}$ high and 5 cm inside diameter, closed by rubber stopper with a fritted-glass gas dispersion tube in the center $(35 \mathrm{~mm}$ in dianeter, $20 \mathrm{~cm}$ long, porosity $\mathbf{P 2}$, no lip on rim), a delivery tip (Radiometer D 4346) for the titrant and an electrode; K, magnetic stirrer (TOYO MS-16B) with $35 \mathrm{~mm}$ stirring bar coated with PTFE in the absorption chamber; I, Autoburette (Radiometer ABU 13e) with 2.500-ml burette assembly (Radiometer B 220) with maximum speed set at $0.250 \mathrm{ml} / \mathrm{min}$; M, titrator (Radiometer TTT 60c); N, pH meter (Radiometer PHM 64b, research pH meter) with combined electrode, internal reference electrode systems saturated Ag/AgCl (Radiometer GK 2402C); 0 , titrant reservoir, 500-ml plastic bottle stored in glass botter with a tube filled with ascarite on the air inlet. Connections between glass components should be made with polyethylene tubing and kept to a minimal length. For routine analyses a second set of components A through $\mathrm{H}$ were mounted adjacent to the first set. While one analysis was being made, the $\mathrm{CO}_{2}$ can be flushed from the other half of the system.

\section{Reagents}

Digestion mixture $A$. Dissolve $10.00 \mathrm{~g} \mathrm{~K}_{2} \mathrm{Cr}_{2} \mathrm{O}_{7}$, reagent grade, powdered in a mixture of $120 \mathrm{ml} \mathrm{H}_{2} \mathrm{SO}_{4}(95-97 \%)$ and $80 \mathrm{ml}$ of $\mathrm{H}_{3} \mathrm{PO}_{4}$ (85\%) with heating. Do not allow temperature to exceed $125^{\circ} \mathrm{C}$.

Digestion mixture $B$. Dissolve $10.00 \mathrm{~g} \mathrm{~K}_{2} \mathrm{Cr}_{2} \mathrm{O}_{7}$, reagent grade, powdered in $120 \mathrm{ml} \mathrm{H}_{2} \mathrm{SO}_{4}(95-97 \%)$ with heating. Do not allow temperature to exceed $125^{\circ} \mathrm{C}$.

Absorption solution. Dissolve $122.14 \mathrm{~g} \mathrm{BaCl}_{2} \cdot 2 \mathrm{H}_{2} \mathrm{O}$ in about $800 \mathrm{ml}$ of water, add $100 \mathrm{ml}$ tertiary butyl alcohol (99\%) and dilute to 11.

ritrant. Add an analytical concentrate from an ampoule (Baker) containing $0.4 \mathrm{~mol} \mathrm{NaOH}$ to about $800 \mathrm{ml}$ of $\mathrm{CO}_{2}$-free water according to the directions provided with the ampoule, add $100 \mathrm{ml}$ tertiary butyl alcohol (99\% and dilute to 11 with $\mathrm{CO}_{2}$-free water.

\section{Procedure}

Total $C$ in non-calcareous soil. Weigh 25 to $300 \mathrm{mg}$ of finely ground soil into a digestion tube and record weight to nearest $0.1 \mathrm{mg}$. Add $1.0 \mathrm{ml}$ water. Put tube on distillation column. Begin flow of $\mathrm{N}_{2}$ gas at rate of 6-8 bubbles/ sec to remove $\mathrm{CO}_{2}$ with stopcock (H) open to atmosphere. Add $5 \mathrm{ml}$ of digestion mixture $A$ with 5-m1 graduated cylinder to 50-ml separating funnel (D). When system is free of $\mathrm{CO}_{2}$, stop $\mathrm{H}_{2}$ flow and add digestion mixture $A$ to digestion tube by opening stopcock on separating funnel (D). Begin heating and change stopcock (H) so $\mathrm{CO}_{2}$ will enter absorption chamber. Bring diges- 
tion mixture to boiling in 3 to 4 minutes with a $1-\mathrm{cm}$ flame, $1 \mathrm{~cm}$ below bottom of digestion tube. Begin timing with stopwatch. Adjust $\mathrm{N}_{2}$ flow rate to 2 - 3 bubbles/sec. Heat for $10 \mathrm{~min}$. Remove flame and increase $\mathrm{N}_{2}$ flow to 6 - 8 bubbles/sec. Record the total amount of titrant added after each minute beginning with 11 th minute. When the amount of titrant is $0.001 \mathrm{ml} / \mathrm{min}$ the absorption of $\mathrm{CO}_{2}$ from the digestion of the sample is considered complete. close stopcock $\mathrm{H}$ so air cannot enter the absorption chamber. Wash system including the inside of the lower part of the distillation column with water. place the next soil sample in a digestion tube on the distillation column and begin flushing.

Each day a new precipitate must be formed. This should be done prior to the determination of a soil sample with a small amount of material containing $c$. At the same time the $\mathrm{pH}$ of the absorption solution is raised to pH 10.208 to insure absorption of $\mathrm{CO}_{2}$. To test whether all components of the system were functioning properly, a chemical of known $c$ content was run first each day. A blank was also run each day.

If a large amount of $\mathrm{CO}_{2}$ is produced, the $\mathrm{pH}$ may go below 9.0. Before this happens reduce $\mathrm{N}_{2}$ flow with flow valve (A), it may be necessary to stop the flow. If not much $\mathrm{CO}_{2}$ is being produced the flow may be increased before the end of heating.

Inorganic $c$ in calcareous soil. Weigh 25 to $300 \mathrm{mg}$ of powdered soil in a digestion tube and record weight to nearest $0.1 \mathrm{mg}$. Add $1.0 \mathrm{ml}$ water. Put tube on distillation column. To determine inorganic $\mathrm{C}$ add $2 \mathrm{ml}_{3} \mathrm{PO}_{4}(85 \%)$ with $5 \mathrm{ml}$ graduated cylinder through separating funnel to sample without flushing. Set flow of $\mathrm{N}_{2}$ at 2 - 3 bubbles per second. Heat for 7 minutes with a $1-\mathrm{cm}$ flame $1 \mathrm{~cm}$ below bottom of digestion tube. Remove flame and increase flow of $\mathrm{N}_{2}$ to 6 - 8 bubbles per second. Record the total amount of titrant added after each minute beginning with the 11 th minute. When the amount of titrant added is $0.001 \mathrm{ml} / \mathrm{min}$. the absorption of $\mathrm{CO}_{2}$ from the digestion of the sample is complete.

Total $c$ in soil extracts. Soil samples were extracted with $0.5 \mathrm{~N}$ NaOH (Schnitzer et al., 1958; Schnitzer and skinner, 1968; chen et al., 1978) and $0.1 \mathrm{M} \mathrm{Na}{ }_{4}{ }_{2} \mathrm{O}_{7}$ (USDA, 1972). Add $1.0 \mathrm{ml}$ of extract to digestion tube. No water is added. Repeat procedure for total $C$ in non-calcareous soils. For a blank $1.0 \mathrm{ml}$ of the extractant was used. To test the system $1.0 \mathrm{ml}$ of extractant was added to the chemicals.

\section{resting materials}

To test the procedure ascorbic acid, benzoic acid, potassium hydrogenphthalate, and calcium carbonate were mixed with sand to give $c$ contents similar to those found in soils. The procedure for organic $c$ was then applied to four soils (Table 1). 
Table 1. Classification of soils according to the FAO-Unesco Legend (FAO, 1974) and Soil Taxonomy (Soil survey Staff, 1975)

\begin{tabular}{lll}
\hline Soil Profile & FAO-Unesco & Soil Taxonomy \\
NL-102 & Gleyic Podzol & Aeric Haplaquod \\
NL-106 & Dystric Regosol & Spodic Udipsamment \\
B-103 & Gleyic Podzol & Aeric Haplaquod \\
USA-1 & Orthic Podzol & Typic Haplorthod \\
\hline
\end{tabular}

\section{Results and Discussion}

The reagent-grade chemicals used to test the method were completely oxidized (Table 2 ). Complete oxidation was achieved regardless of sample size, 50 to $150 \mathrm{mg}$. The reproducibility of the method is very good with a standard deviation of $0.02 \%$ for the chemicals and $0.04 \%$ for the soil sample.

The recovery of calcium carbonate in the inorganic carbon determination was also very good. The calculated carbon content was $1.20 \%$. The measured carbon content was $1.20 \%$ with a standard deviation of $0.01 \%$ for five determinations .

The addition of $1 \mathrm{ml}$ of sodium pyrophosphate or sodium hydroxide to the chemicals had no interference in the determination of $c$ in the chemicals (Table 3 ). Neither the mean nor the standard deviations are significantly different.

The methods were used to determine total carbon $\left(c_{t}\right)$ and carbon in sodium pyrophosphate $\left(C_{p}\right)$ and sodium hydroxide $\left(C_{h}\right)$ extracts of samples from four soil profiles (Table 4). $c_{p}$ and $c_{h}$ were lower or not significantly different from $C_{t}$. In the $A h$ and $E$ horizons $C_{h}$ was greater than or not significantly different from $C$. In the $B$ and $C$ horizons $c_{p}$ and $c_{h}$ were similar.

\section{Conclusions}

The methods described for determining organic $c$ in soils and soil extracts and inorganic $c$ in soils and rocks give complete combustion of the $c$ and very accurate measurement of the evolved $\mathrm{CO}_{2}$. The apparatus is built from readily available laboratory equipment or easily constructed parts. The apparatus and procedure are simple to operate and perform. A skilled analyst can complete up to 30 analyses in one day.

The determination of inorganic carbon with $\mathrm{H}_{3} \mathrm{PO}_{4}$ in soil samples needs further study and will be reported upon in a later publication. 
Table 2. Carbon content of organic materials.

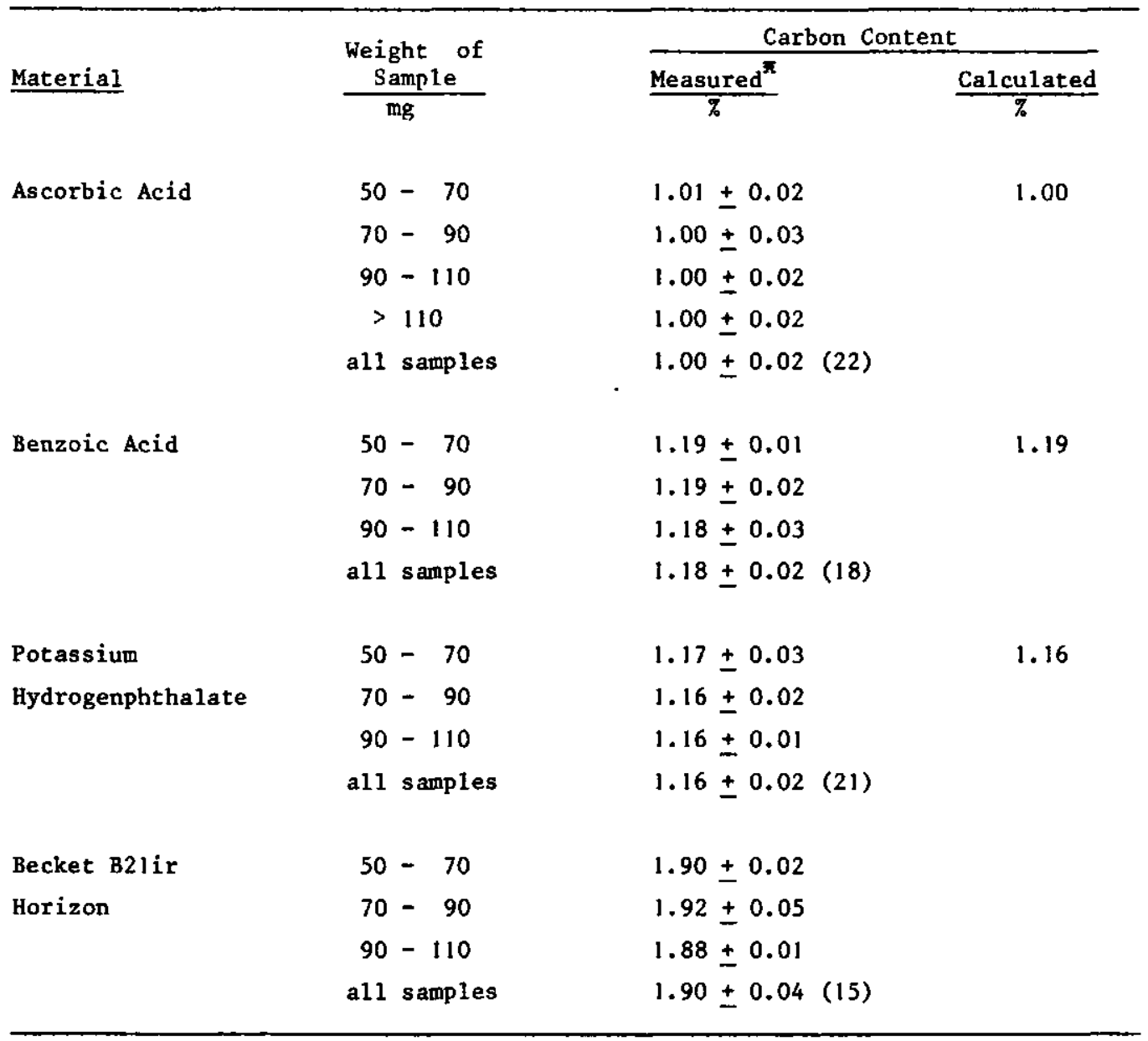

* Mean and standard deviation. Number in parenthesis is number of determinations. 
Table 3. Carbon content of chemicals with $1 \mathrm{ml} \mathrm{H} \mathrm{H}_{2} \mathrm{O}\left(\mathrm{C}_{t}\right), 1 \mathrm{~m} 10.1 \mathrm{M} \mathrm{Na}{ }_{4}{ }_{2}{ }_{2}{ }_{7}$ $\left(\mathrm{C}_{\mathrm{p}}\right)$ and $1 \mathrm{mI} 0.5 \mathrm{~N} \mathrm{NaOH}\left(\mathrm{C}_{\mathrm{h}}\right)$.

\begin{tabular}{|c|c|c|c|}
\hline \multirow[b]{2}{*}{ Material } & \multirow[b]{2}{*}{ Determination } & \multicolumn{2}{|c|}{ Carbon Content } \\
\hline & & $\frac{\text { Measured }}{\%}$ & $\frac{\text { Calculated }}{\%}$ \\
\hline Ascorbic Acid & $\begin{array}{l}c_{t} \\
c_{p} \\
c_{h}\end{array}$ & $\begin{array}{l}1.00 \pm 0.03 \\
1.01 \pm 0.01 \\
1.00 \pm 0.03\end{array}$ & 1.00 \\
\hline Benzoic Acid & $\begin{array}{l}c_{t} \\
c_{p} \\
c_{h}\end{array}$ & $\begin{array}{l}1.19 \pm 0.02 \\
1.18 \pm 0.02 \\
1.19 \pm 0.03\end{array}$ & 1.19 \\
\hline $\begin{array}{l}\text { Potassium } \\
\text { Hydrogenphthalate }\end{array}$ & $\begin{array}{l}c_{t} \\
c_{p} \\
c_{h}\end{array}$ & $\begin{array}{l}1.16 \pm 0.01 \\
1.17 \pm 0.03 \\
1.16 \pm 0.02\end{array}$ & 1.16 \\
\hline $\begin{array}{l}\text { Becket } 821 \text { ir } \\
\text { Horizon }\end{array}$ & $\begin{array}{l}c_{t} \\
c_{p} \\
c_{h}\end{array}$ & $\begin{array}{l}1.90 \pm 0.04 \\
1.22 \pm 0.06 \\
1.39 \pm 0.11\end{array}$ & \\
\hline
\end{tabular}

* Mean and standard deviation. 
Table 4. Total carbon $\left(C_{t}\right)$ and carbon in sodium pyrophosphate $\left(c_{p}\right)$ and sodium hydroxide $\left(C_{h}\right)$ extracts of soils.

\begin{tabular}{|c|c|c|c|c|c|}
\hline \multirow[b]{2}{*}{ Profile } & \multirow[b]{2}{*}{ Horizon } & \multirow[b]{2}{*}{ Depth } & \multicolumn{3}{|c|}{ Carbon Content } \\
\hline & & & $\overline{\mathrm{C}_{\mathrm{t}}}$ & $\mathrm{C}_{\mathrm{p}}$ & $\mathrm{C}_{\mathrm{h}}$ \\
\hline & & $\mathrm{cm}$ & $\%$ & $\%$ & $\%$ \\
\hline \multirow[t]{5}{*}{$N L-102$} & E) & $0-19$ & .82 & .39 & .47 \\
\hline & E2 & $19-39$ & .35 & .23 & .25 \\
\hline & $\mathrm{Bh}$ & $39-44$ & .82 & .62 & .72 \\
\hline & $\mathrm{BCl}$ & $44-89$ & .44 & .43 & .47 \\
\hline & $\mathrm{BC} 2$ & $89-150$ & .32 & .27 & .31 \\
\hline \multirow[t]{7}{*}{ NL-106 } & Ahl & $0-6$ & 6.02 & 1.98 & 2.45 \\
\hline & Ah2 & $6-11$ & 2.98 & .88 & 1.68 \\
\hline & $\mathbf{E}$ & $11-22$ & .86 & .19 & .39 \\
\hline & Bhs 1 & $22-29$ & 2.20 & 1.60 & 1.49 \\
\hline & Bhs 2 & $29-35$ & 2.11 & 1.66 & 1.55 \\
\hline & $2 \mathrm{BC}$ & $35-45$ & .55 & .42 & .35 \\
\hline & $2 \mathrm{Cg}$ & $45-65$ & .19 & .11 & .14 \\
\hline \multirow{7}{*}{$8-103$} & Ahb & $23-30$ & 3.40 & 1.99 & 2.09 \\
\hline & $\mathrm{Eb}$ & $30-58$ & .18 & .19 & .13 \\
\hline & EBb & $58-85$ & .26 & .36 & .24 \\
\hline & Bhlb & $85-103$ & .87 & .82 & .75 \\
\hline & $\mathrm{Bh} 2 \mathrm{~b}$ & $103-125$ & .86 & .79 & .81 \\
\hline & $\mathrm{Bh} 3 \mathrm{~b}$ & $125-155$ & .74 & .76 & .70 \\
\hline & Bhmb & $155-170$ & 1.54 & 1.47 & 1.44 \\
\hline \multirow[t]{5}{*}{ USA-1 } & E & $0-23$ & .27 & .02 & .13 \\
\hline & $\mathrm{Bh}$ & $23-32$ & 1.44 & 1.04 & .89 \\
\hline & Bhs & $32-50$ & 1.41 & 1.25 & 1.10 \\
\hline & BC & $50-88$ & .92 & .86 & .79 \\
\hline & $\mathrm{c}$ & $88-130$ & .07 & .03 & .04 \\
\hline
\end{tabular}




\section{Literature cited}

Allison, L.E. 1960. Wet-combustion apparatus and procedure for organic and inorganic carbon in soil. Soil sci. Soc. Amer. Proc. 24:36-40.

Anderson, J.W. and W. Harris. 1967. Determination of organic carbon and carbonates in soils. Soil sci. Soc. Amer. Proc. 31:341-343.

Begheijn, L.Th. 1976. Determination of organic and inorganic carbon in soil by potentiometry. Analyst 101:710-716.

Chen, Y., N. Senesi and M. Schnitzer. 1978. Chemical and physical characteristics of humic and fulvic acids extracted from soils of the Mediterranean Region. Geoderma 20:87-104.

Duursma, E.K. 1961. Dissolved organic carbon, nitrogen and phosphorus in the sea. Neth. J. Sea Res. 1:1-147.

Food and Agriculture organization. 1974. Soil Map of the World. Volume I. Legend. Unesco, Paris, $59 \mathrm{pp}$.

Nömmik, H. 1971. A modified procedure for determination of organic carbon in soils by wet combustion. Soil sci. 111:330-336.

Schnitzer, M. and S.I.M. Skinner. 1968. Alkali versus acid extraction of soil organic matter. Soil sci. 105:392-396.

Schnitzer, M., J.R. Wright and J.G. Desjardins. 1958. A comparison of the effectiveness of various extractants for organic matter from two horizons of a Podzol profile. Can. J. Soil Sci. 38:49-53.

Shaw, K. 1959. Determination of organic carbon in soil and plant material. J. Soil sci. 10:316-326.

Sixta, v. 1977. Coulometric determination of carbonates in rock samples. Z. Anal Chem. 285:369-372.

Soil survey staff. 1975. Soil Taxonomy. A basic system of soil classification for making and interpreting soil surveys. Agric. Handbk. No. 436. U.S. Gov't. Prtg. Off., Washington, D.C. 20402, 754 pp.

U.S. Department of Agriculture, scs. 1972. Soil survey laboratory methods and procedures for collecting soil samples. Soil survey Investigations Report No. 1. Washington, D.C. $63 \mathrm{pp}$. 
APPENDIX 7. NOTE ON THE PLATE: "PODZOLS AND RELATED SOILS"

A large number of soils used in this study have been selected for representation on a colour plate on podzols and related soils. This plate is published as a seperate sheet. In some cases the classification of the soil profiles on the plate does not correspond with the classification given in this paper. This concerns soils with distinct podzol morphology, which could be classified as podzols on the basis of the presence of cracked coatings or dark pellets- (micro)morphologic criteria for spodic horizon - but they do not meet the chemical criteria. In the context of this publication such soils are not classified as podzols in order to stress the discrepancies between chemical and morphological criteria. However, on the plate they are placed with the podzols, notably the profiles IRL-1, F-10, NL-106, SER-10, $\mathrm{S}-16, \mathrm{SE}-4$ and $\mathrm{SK}-3$. 